

\section{THE}

\section{LEEDS UNIVERSITY LIBRARY}

Classmark:

COOKERY

A LAN

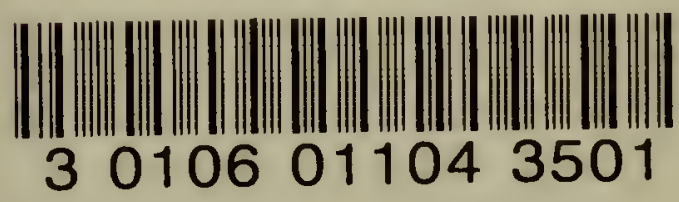





\title{
VEGETABLE SUBSTANCES
}

\author{
USED FOR \\ THE FOOD OF MAN. \\ BY \\ DR. LANKESTER.
}

WITH ILLUSTRATIONS.

LONDON :

11. A NATTALI, 23, BEDFORD STREET,

COVENT GARDEN. 
UMULKSIY

LIERARY

LEEDS

$4 \times 38670$ 


\section{CONTENTS.}

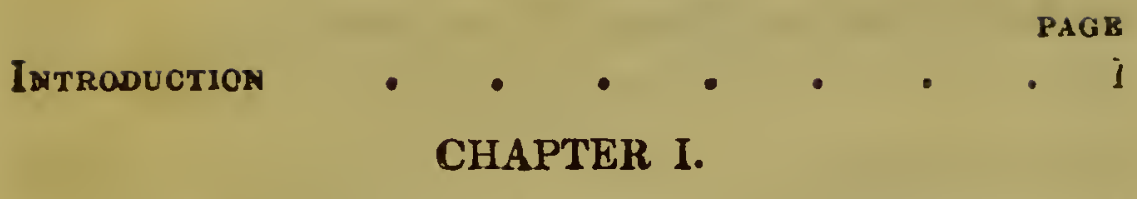

The Cerealia, sr Corn-Plants generally $\quad$. $\quad$ - 9

CHAPTER II.

Wheat

\section{CHAPTER III.}
Rye-Barley-Oats . . . . . . 51
On the use of Corn in England $\quad . \quad$. . 73
CHAPTER IV.

Rice • . . • . . . . 81

CHAPTER V

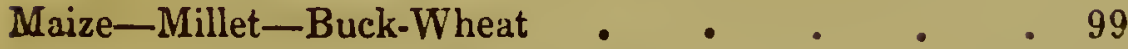

CHAPTER VI.

The Potato • . • • . . . 125

CHAPTER VII.

Other Vegetable Substances used for Substantive Food . 152

CHAPTER VIII.

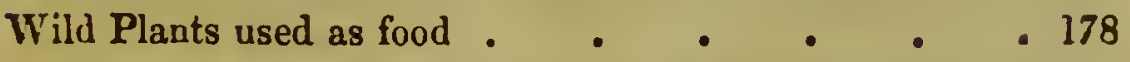

CHAPTER IX.

On Vegetahle Gardening • • • • • 196 
CHAPTER X

Leguminuus Plants

CHAPTER XI

Succulent Roots

CHAPTER XII.

Brassica-Spinaceous Plants-Asparaginous Plants

CHAPTER XIH.

Alliaceous Plants

CHAPTER XIV.

Acetarious Plants, \&c.-Seasoning Herbs • . 299 CHAPTER XV.

Esculent Fungi $\quad \cdot \quad \cdot \quad \cdot$

CHAPTER XVI.

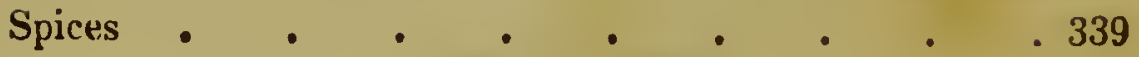

CHAPTER XVII.

Coffee-Caca-Tea-Suga: • . • • . 365

** The following Nole should have been inserted at page 74.

Pierce Plowman was an anonymous writer of satires ayainst the Popish clergy. These productions, which are exceedingly bitter, are attributed to Rohert Langlinde, as secular priest, and fellow of Oriel College, Oxford. 


\section{ILLUSTRATIONS.}

No. Page

1. Grain of Wheat, upper and under sides . . . 28

?. Ear and Plant of Spring Wheat . . . 30

3. Ear and Plant of Winter Wheat • . . 32

4. Ear and Plant of Duck-Bill Wheat . . . 33

5. Ear and Plant of Egyptian or many-spiked Wheat . 34

6. Ear and Piant of Pulish Wheat . . . . 35

7. Ear and Plant of Spelt Wheat . . . . 36

8. Ear and Plant of one-seeded Wheat . . . 37

9: Wheat-fly (Musca pumilionis) in its different stages . 41

10. Corn Mildew (Uredo frumenti) greatly magnified . 48

11. Ear and plant of Rye . . . . . . 51

12. Ear and Plant of Cummon Spring Barley . - 57

13. Premature germination of an Ear of Barley • . 60

14. Ear and Plant of Winter Barley • . • 62

15. Ear and Plant of 'Two-rowed Barley . • . 63

16. Common bearded Oats, and Comınon Oats . . 69

17. Thames Corn-Barge . • . . . . 80

18. Far and Plant of Rice . . . . . 82

19. Rice-birds, male and female . . . . . 95

20. Maize-Zea mays . • . . . . 99

21. Ears of Maize, in different stages . . . . 168

22. Italian Millet-Situria Italica . . . . 116

23. Buck-wheat-Polygonum fagopyrum . . . 122

24. Cassava-Jatropha manihot . . . . 153

25. Indians preparing Cassava . . . . . 156

26. Salep-Orchis mascula . . . . '. 158

27. Indian Arrow-root-Maranta arundinacea . . 162

28. Wake-Robin-Arum maculatum . . . . 164

29. Sweet Potato-Convolvulus batata . . . 165

30. Yam-Dioscorea satıva • . • . . 167

31. Different surts of Yam-rnots . . . . . 168

32. The Ranana. . . . . . 170

33. Stem of the Sago-tree, showing the pith from which the Sago is extracted . . . . . 173

34. Cabbage-Palm-Areca oleracea . . . . 177 
No.

35. Cuuch. grass

36. Flower and Root of the Wild Parsnip .

37. Iceland Moss-Lichen islandicus . . . . 184

38. Pile-wort-Ficaria ranunculoides . . . 186

39. Great Cat's Tall-Typha palustris . . . . 188

40. Rampion-Campanula rapunculus . . . 19l

41. Samphire-Crithumum maritimum . . . . 191

42. Chick-Pea-Cicer arietinum . . . . 223

43. Flowers and Puds of the Turnıp . . . . 228

44. Umbel of the Carrot . . . . 237

45. Flowers and Roots of the Skirret . . . . 249

46. Flower and Root of Scorzonera . . . . 254

47. Colewort-Brassica oleracea . . . . 262

48. Spinach-Spinacia oleracea . . . . 269

49. New Zealand Spinach-Tetragonia expansa . $\quad 273$

50. Cardoon-Cermum cardunculus . . . . 284

51. Tree-Onion-Allium proliferum . . . . 290

52. Garlic-Allium sativum . . . . . 296

53. Rhubarb-Rheum palmatum . . . . . . 309

54. Causicum . • . . . . 313

55. Black and White Truffles . . . . . 329

56. Morelles-Phalli psculenti . . . . 331

57. Common Mushrooms_Agaricus campestris and Agaricus auruntiacus . . . . . . . 332

58. Champignons-Agaricis pratensis - . . 335

59. True Cinnamon-Laurus cinnamomum . . . 342

60. The Clove-Caryophyllata . . . . 348

61. Nutmeg-Myristica moschata . . . . 352

62. Ginger-Zingiber officinale . . . . 356

63. Allspice-Myrius pimenta . . . . . 362

64. Coffee, with the Flower and Berry . . . 365

65. Tea-Thea viridis . . . . . . 375

66. Tea-gathering, from a Chinese drawing . . 377

67. Sugar-Canes • 


\title{
VEGETABLE SUBSTANCES
}

\author{
USED FOR THE FOOD OF MAN.
}

\section{INTRODUCTION.}

The culture of the earth is a pursuit which in itsel offers a sufficient distinction, not only between man and the inferior orders of animate creation, but also between man while in his merely animal state, and after he has become humanized by adopting the arts of civilization. It is this pursuit which must, in fact, precede, and be made the foundation for all other useful and ennobling occupations, - the spring whence must flow, certainly, the greater part of those reciprocal duties and affections which at once form society, and render it the source of enjoyments. That man who first, among a tribe of hunters or fishers, sows a grain or plants a root, and thus brings home the advantages of forethought to the 'business and the bosoms' of his less provident fellows, becomes their benefactor, not merely by pointing out the means for avoiding the horrors of famine, and for lessening that succession of miseries which must attend upon a life of wandering, but also, by relieving their minds from the selfish exigencies that previously attended every moment, affording thereby lei- 
sure and opportunity for cultivating the social and kindly affections. It is not until men have placed themselves beyond that state of merely physical existence wherein the plenty of to-day may be followed by the destitution of to-morrow, that the higher faculties and feelings of our nature can be expandea. It must certainly, therefore, be matter of more than common interest to obtain some knowledge of those vegetable substances through the cultivation of which man has been enabled to localize himself, to reap and to store up harvests; and by thus becoming freed from an incessant call upon his physical energies for the supply of his necessities, to acquire the motives and the means for becoming something higher and better in the scale of being.

Vegetables form the primary source of sustenance to everything that lives. Were the earth without them and bare-and but for cultivation how much of it would be in that state-the effects of heat and cold, of drought and rain, would be so violent, that apart from ali considerations as to food, the whole world would speedily become uninhabitable. Frosts and drought would break, and the returning water would wash away the surface, until the whole would hecome one wide and swampy waste. 'The presence of vegetation prevents this desolating action, and converts what otherwise would be destructive ag'ents, into ministers of abundance. No vegetable productions tend so much to bring about this beneficial result as those which are cultivated for human food. By the shade which they afford to the ground in the hot season, they check that evaporation, and prevent that excessive hardening of the surface, which, in an exposed wild, render the soil impervious and inert; while, on the other hand, the humidity which they imbibe during the rainy season is ggain given out by continual and gradual evaporation, and they minister 
in the refreshment and the productiveness of all around them. In countries which are uncultivated the weather is mostly in extremes. Rain, when it comes, takes the form of an overwhelming flood, not gently entering into and moistening the soil, but rushing along the surface, tearing up one place, strewing another with the debris, and reducing both to a state of indiscriminate ruin; while scarcely has the flood gone by, when the returning heat evaporates the little moisture which is left behind, and burns up the coarse and scanty vegetation which the rains had fostered.

These effects of the unmitigated action of the elements are most strongly marked in those parts of the world where hitherto the seasons have defied the labour of man, and have seemed to wage war upon his agriculture. This is the case in some paris of India, in Southern Africa, and in a great part of what we yet know of Australia, where at one time the earth is parched up, and the beds of rivers become dry channels or unconnected pools, while at another they suddenly pour onward to the sea in a wide spreading inundation, or roll their rapid floods in narrow but deepened channels. That the labours of cultivation exert the most beneficial effect upon climate may be shown, by contrasting the waste and uncultivated parts of our own country with other parts in the same latitude, and at the same elevation above the level of the sea, but which are in a state of high cultivation. In these, while the immediate object of providing a certain and abundant supply of food has been accomplished by the labours of man, an indirect influence has been exerted scarcely less beneficial, by rendering the country in general more healthy and agreeable.

In the central parts of Scotland, where the introduction of agricultural improvements has been much 
more recent than in England, but where, owing to causes whose investigation would be misplaced in these pages, their progress has been much more rapid, the change of climate has fully kept pace with those improvements. It is within the experience of persons still living, to have noticed that the snow, which in that country formerly began to fall in November, was not wholly gone until the month of April; while in the middle of summer the heat was so excessive that agricultural labourers were obliged to suspend their toil during four or five hours in the middle of the day. At that tirne tlee autumnal rains frequently descended with so much violence, that the crops, which had been retarded by the coldness of the spring, were prevented from ripening on the high grounds, were lodged and rotted on lands that were lower, and swept away by the swelling of the streams over the holms and meadows. In the same spots, at the present day, the quantity of snow which usually falls during the winter is comparatively small, appears rarely before Christmas, and is gone in February, or early in March. The summer heat is more uniformly distributed, seldom amounting to a degree oppressive to the labourer, or protracted to a term injurious to the crops; while the rain which follows is neither so violent in degree, nor so long continued, and happening when the grain is far advanced towards ripeness, the injury which it does is comparatively trifling.

This mitigation of the seasons, which is wholly referrible to the progress of cultivation, has had the happiest effect upon the liealth of the inhabitants. Diseases, which formerly paid their periodical visits with distressing regularity, have either been wholly put to flight, or have been deprived of the trrours in which they were clothed; the supply of 
food, which rested upon contingencies beyond control or calculation, has been secured with a comparative certainty; and famines, which commonly recurred at periods oniy a few years apart, are now happily unknown, except in some of the very wildest districts, and then only at very distant intervals.

We propose, as far as can be accomplished within narrow limits, to trace the progress of our own country towards one of the chief objects and indications of civilization, - that of obtaining an abundance and a variety of wholesome and agreeable vegetable food, at the cheapest rate, and with unfailing regu larity, for increasing inhabitants. This great object is principally accomplished by the natural progress of a people in knowledge and industry. It is advanced by good commercial laws; it is retarded by bad. But if the general laws of a country have the effect of rendering industry free and property secure, it will go forward, without the assistance of governments, and in spite of that assistance, too often misdirected-an embarrassment instead of a help. As we trace this advance of civilization, we first find that famines, once the unfailing scourges of a country, occur at longer and longer intervals, till at last they disappear altogether. We next perceive that seasons of scarcity, producing much severe misery, though not to be compared in their desolating effects to famines, become also fewer and fewer. Lastly, we discover that, though the great necessary of life, bread, may be dearer in one year than in another, the fluctuations in price are seldom extreme and never sudden. If we investigate the causes of these remarkable circumstances, which always attend a very advanced state of society, we shall find that they are not to be ascribed to the vigilance of the soundest legislation, or to the provident foresight of the wisest ministers; but to the spirit of commerce, 
pursuing its natural course without interference from the cumbrous aid of a grovernment, or the opposing prejudices of a people. When a nation has become accustomed to the best food, instead of habitually resorting to the lowest, which it can only do by its steady but certain progress in industry and a taste for comforts; - when the intercourse between all parts of a country is certain and rapid;-when large capitals may be safely and profitably employed in storing corn in seasons of abundance to meet the exigencies of a season of scarcity;-when such vegetable productions of other lands, as will endure to be naturalized, can be grown in plenty at every man's door; - -and, lastly, when foreign commerce places the natural productions of every country within our reach in exchange for our own natural productions, then, and not till then, can a nation be said to be so advanced in civilization, as to have secured, as far as possible, a constant supply of the best vegetable food that the earth can furnish, at a price accessible to the great mass of consumers.

The particular circumstances which advance or retard this desirable end, will be (as far as may be done without touching upon disputable points) brought out in the following pages. The general subject will embrace a history of the vegetable food of our people, as dependent upon agriculture, gardening, commerce; and that history will be illustrated by notices of the food of other great bodies of mankind. The subject will necessarily involve a few details of vegetable physiology, and of practical agriculture and horticulture; but it must be evident, that any scientific description of the structure of plants, however interesting, would be as much out of place here, as any minute accounts of farming and gardening processes. Our desire is to excite attention to some of those ordinary circumstances in the 
condition of mankind which have such powerfu! effects upon the advance of the world in knowledge and happiness. In this point of view, a blade of wheat, a potato, or a peppercorn, may each be made a theme to direct the attention to some of the most important causes of the prosperity of nations; and the result of such observation and inquiry must necessarily be a conviction, that all human interests are strictly allied, and that the great mutual necessities which bind mankind together are steadily going forward to break down the barriers which separate classes and nations, and to diffuse knowledge, and plenty the fruit of linowledge, over all the earth.

In the study, then, of this subject, all who are engaged in the culture of the soil, whether the wealthy proprietor who draws from his estates a lordly revenue, the farmer who earns from his fields an independent subsistence, or the peasant whose toil obtains from the little nook which joins his cottage a wholesome meal for his family, may draw from the pursuit the means of mental improvement. Those, too, whose callings or professions shut them out from the conteinplation of rural objects, may derive both pleasure and advantage from knowing by what care a grain of wheat is elaborated into the material of a loaf of bread, and how that loaf is supplied with regularity both at seed-time and at harvest. Lastly, each and all may, with equal profit, acquire some information concerning that almost countless number of foreigu productions, which commerce has brought to form a part of the daily food and comfort of almost the hum, lest of our fellow-citizens. Does it not in fact appear natural, it might almost be said inevitable, that every one should feel an interest in prosecuting inquiries as to things to which he is indebted for so many of his daily comforts and enjoy- 
ments-lrow they are produced, whence they are brought, and by what exertions their appearance at his board has been accomplished?

It is not entirely in relation to their uses that a knowledge of vegetable productions will be attempted to be conveyed in the following pages. Circumstances attend the growth of many even among the plants most familiar to us, which need only to be observed to insure our admiration, and these will be incidentally pointed out. 'The seed of a globe-turnip is exceedingly minute-not larger perhaps than the twentieth part of an inch in diameter; and yet in the course of a few short months this seed will be elaborated by the soil and the atmosphere into a solid bulb of matter containing, in some cases, twenty-seven millions of times the bulk of the seed, and this in addition to a considerable bunch of leaves. We cannot, in any case, indeed, open a page in the great volume of Nature that is not calculated to excite our highest admiration; that, if read aright, must not incite us onward to the study of her works; or which can fail to raise our grateful hearts towards the Supreme Author of every good. 


\section{Chapter I.}

THE CEREALIA, OR CORN-PLANTS, GENERALLY.

AlL vegetable productions which afford food, contain, in some proportion or other, a farinaceous * or non-fibrous and granular substance, which, when dried, may be ground or pounded into flour or meal, and which, if boiled in water, will form with it a pulpy substance. This farinaceous constituent of esculent vegetables, the presence of which in some portion appears necessary to the growth of all plants, and which is in perfection only when the plant, of which it forms a part, has attained maturity, has less of an organized structure than is discernible in the membranous and fibrous portions of vegetable growtl. In regard to its consistency, this farinaceous principle is found to take a wide range, existing sometimes in the form of an almost limpid fluid, and thence through different degrees of acquiring consistency, called inspissation, until, in some cases, its hardness approaches to that of woody fibre.

Those vegetable substances which contain the largest proportion of farinaceous matter, are on that account the best adapted for human food. Of this kind are seeds and tubers $t$, when they are ripe, or have attained their full growth. Many plants yielding these are annuals : others, with the exception of their seeds or tubers, die in the autumn, and leave these

* From farina, meal.

$t$ A tuber is an underground stem, distended by the deposit of farinaceous matter. 
as the suurces of their reproduction in the following year.

Tubers, equally with seeds, may be considered as store-houses of nutriment for the sustenance of the germ in the early stages of its growth, before its roots and leaves are expanded, and it has thence become capable of assimilating other substances for its own nutrition. Such parts of the plants which answer best for adoption as the substantive food of man, are thus living vegetables in a dormant state; and the moment that the germ which they contain has begun to vegetate, they undergo a change both in regard to their taste and nutritive qualities, and become less qualified for affording nourishment to man.

Farinaceous seeds are divided into two classes: the first of these are the seeds of annual plants, which are the true grasses, or plants of similar properties. They are styled the CEREALIA - cornplants, or grain-bearing plants. That one among them upon which any people depends chiefly for its food, is called by that people corn; as wheat in England, octs in the northern lowlands of Scotland, rye in the sandy districts on the southern shores of the Baltic Sea, and maize throughout the United States of America.

The second division of farinaceous seeds is also yielded by plants which for the most part are of annual growth, and these seeds being contained in pods or legumes, such plants are styled leguminous or podded: they are liliewise known by the generic name of pulse.

The corn plants are all annuals, both in their stems and roots, the whole plant dying after the seed has fully formed and ripened, and sometines even before the latter process has been perfectly accomplished.

\footnotetext{
* From Ceres, the godiless of Corn.
} 
They all send up a straw or culm, which is hollow, and divided into lengths by nodes or joints; and at these joints the leaves have their insertion, one at each joint on the alternate sides of the stem; each leaf embraces the stem for some length in the manner of a sheath. It is worthy of remark that these stems always contain a portion of silex, or earth of flint, in a state of very minute division-from which circumstance their ashes are found useful in imparting a polish to articles formed of wood, liorn, ivory, or some of the softer metals; while, on the other hand, the presence of this material, and the great difficulty attending its separation from the purely vegetable matter, have always offered obstacles to the employment of straw for the manufacture of paper.

The last leaf of the season performs the office of a sheath to the newly-formed flower, embracing it for a time so firmly, that the sheath cannot be opened without difficulty. With the growth of the flower it bursts open its protecting spatha or sheath, rises above it, and the leaf then turns backward.

The liead or ear consists of an uncertain number of flowers, followed by seeds. These are sometimes placed upon a single rib or rachis, as in wheat and barley, and they then form a spike. In the variety called Egyptian wheat this spike is compound, there being more than one rachis; if this consists of branches that are nakerl at their points of junction, and have spikelets at their extremities, they form what is called a panicle: this is the case, for example, with oats.

The chief corm-plants, or cerealia, are wheat, rye, barley, oats, millet, rice, and maize. The tribe of cereal grasses is not restricted to these seven varieties, but includes numerous others, which, if they are not equally employed as food, are neglected only on account of the smallness of their seeds. "None are 
unwholesome in their natural state, with the singrle exception of Lolium temulentum (darnel), a common weed in many parts of England, the effects of which are undoubtedly deleterious, although perhaps much exagrerated. In this respect an' approach seems to be naturally made to the properties of half-putrid wheat, which are known to be dangerous*."

'The presence of the corn-plants in any region of the earth attests that man is there, in an advanced stage of civilization. In the sepulchres of the Egyptian kings, which were opened by the naturalists and other scientific persons who accompanied the French army to Egypt, was found the common wheat, in vessels which were so perfectly closed, that the grains retained both their form and their colour $t$. The wheat, buried there for several thousand years, was a proof of the ancient civilization of igypt, as convincing as the ruins of temples and the inscriptions of obelislis. The corn-plants, such as they are found under cultivation, do not grow wild in any part of the earth. Wheat has been traced, indeed, in Persia, springing up in spots very remote from human habitation, and out of the line of the traffic of the natives; but this circumstance is far from proving that it is a production natural and indigenous to Persia. In Sicily there is a wild grass called Egilops ovata, which is found in particular districts. It has been held that the seeds of this plant may be changed into corn by cultivation; and that the ancient worship of C'eres, which consideled the fields of Enna and of Trinacria as the cradles of agriculture, had its origin in this transformation of the native grass. Professor Latapie, of Bourdeaux, affirms,

* Lindley's 'Introduction to the Natural System of Botanys' p. 302 .

† See Lyell's Geo!ngy; rol ii. p. 3 !. 
that having cultivated the seed of the Escilops, the plant has changed its generic character, and has made approacles to that of wheat*. Sir Joseph Banks, in a paper addressed by him to the Horticultural Society, in the year 1805 , stated that having received from a lady some packets of seeds, and among them one labelled " Hill Wheat," the grains of which were hardly larger than those of our wild grasses, but which, when viewed through a magnifying lens, were found exactly to resemble wheat, he sowed these grains in his garden, and was much surprised on obtaining, as their produce, a good crop of spring wheat, the grains of which were of the ordinary size. Every inquiry that was made to ascertain the history of these seeds proved fruitless. All that could be established, with regard to the place of their production, was, that they came from India ; but as to the particular locality, or the amount of cultivation they had received, or whether the grain was indeed in that instance a spontaneous offering of nature, could not be ascertained. Experiments such as those we have mentioned, may naturally lead us to think, that in the corn-plants, as in other vegetables, great modifications have been produced by cultivation; but they do not at all interfere with the belief that the cereal grains are spread through the earth by the agency of man alone, and that they are bequests from past ages of civilization too remote to afford any materials for the authentic history of their introduction, even into countries possessing the most ancient records. Other seeds are dispersed throughout the earth by winds and currents, in the hairy coats of quadrupeds, and in the maws of birds. But the corn-plants, in common with many other important vegretable productions, follow the course of man alone. This is a blessing, which even hostile armies

- Dict. Classique d'Histoire Nat., Art. OEgilops. 
are instruments in diffusing. Cortez, the conqueror of Mexico, inhuman as he was in many parts of his conduct, thus writes from Mexico to the King of Spain:- All the plants of Spain thrive admirably in this land. We shall not proceed here as we have done in the isles, where we have neglected cultivation, and destroyed the inhabitants. A sad experience ought to render us more prudent. I beseech your Majesty to give orders that 110 vessel set sail for this country without a certain quantity of plants and grain." The diffusion of plants useful to man is an accident diminishing the evils of hostile invasion; -it is a necessary attendant of commercial intercourse. The Indians of New Engrland called the plantain, "English-man's foot;" and in the same way, in the infancy of ancient society, wheat might have been similarly regarded as springing from the footsteps of the Persians or the Egyptians. In times approaching nearer to our own, we know that wheat followed the march of the Romans, as the vine was in the train of the Greeks; and, to come still nearer, we find cotton remaining in countries which had otherwise suffered from the incursions of the Arabs. " The migration of these plants," observes Humboldt, " is evident; but their first country is as little known as that of the different races of men which, from the earliest traditions, have been found in all parts of the globe*."

The manner in which the most important gifts of Providence to mankind have been diffused by the influences of conquest or commerce, has some striking instances in the history of America. In the New World such facts are too recent to admit of any doubt. The same class of facts, ton, are exhibited in several cases in the history of our empire in Hindostan. We shall give a few examples.

* Géographie des Plantes, p. 35. 
None of the cereal grasses, properly so called, were found in cultivation among the Mexicans when their country was first visited by Europeans. The founda tion of the wheat harvests at Mexico is said to have been three or four grains which a slave of Cortez discovered in 1530 accidentally mixed with a quantity of rice. The careful negro who preserved and made so advantageous a use of the few grains which a happy chance had thrown in his way, and which, in the hands of a careless or thoughtless person, would, with their future inestimable advantages, have been lost to his country, has not been thought worthydoubtless because he was a negro- of having his name preserved. The Spanish lady, Maria d'Escobar, wife of Diego de Chaves, who first imparted the same blessing to Peru, by conveying a few grains of wheat to Lima, has been more fortunate. Her name, together with the means which she took for effecting her object, by carefully distributing the produce of successive harvests as seed among the farmers, have been gratefully preserved in the records of history. The exact period when this cultivation was commenced in Peru is not, indeed, known ; but it appears reasonable to believe that this event did not occur until after the date assigned for the introduction of wheat into Mexico, as, in the year 1547, wheaten bread was hardly known in the important city of Cuzco. The first grains of wheat which reached Quito were conveyed thither by Father Josse Rixi, a Fleming, who sowed them near the monastery of St. Francis, where the monks still preserve and show, as a precious relic, the rude earthen pot wherein the seeds first reached their establishment. 'The rice of Carolina is now the principal produce of that portion of North America. Mr. Ashby, an English merchant, at the close of the seventeenth rentury, sent a hundred weight from China to this 
colony; and from this source all the subsequent rice harves's of that division of the New World, and the large exportations of the same valuable grain to Europe, have sprung. 'The wheat now cultivated in Ruhilcund, in India, "was propagated by seed brought from England, since the corquest, by $\mathrm{Mr}$. Hawkins* ;" and the potato, within a very few years, has beell extensively spread by us through the Indian peninsula, and there, by preventing the exclu. sive use of rice, is greatly ameliorating the condition of the native population. Facts such as these are highly interesting; because they exhibit the moral as well as natural causes which influence the distribution of vegetable food throughout the earth. In the following pages we shall endeavour to collect whatever is satisfactorily known as to this branch of our subject. Before we proceed, however, to a particular history of species or varieties of vegetable substances used for the sustenance of man, we shall take a rapid, though necessarily imperfect view, of the distribution of the corn-plants throughout the globe at the present day.

Agriculture can be pursued but very partially within the northern polar circles, where, for the most part, the intenseness of the frosts during a protracted winter binds up the soil,- - not otherwise sterile,-and condemns it to perpetual unfruitfuluess.

The utmost iimit of the culcure of grain in Siberia reaches only to the sixtieth degree of latitude, and in the more eastern parts of the province these important products are scarcely to be met with higher than fifty-five degrees. In the more southern parts of Siberia, and in districts adjoining the Wolga, the land is extraordinarily fertile, so that crops of grain are obtained with a very trifling amount

* Heber's Journey, vol. ii. I. 13l. 
of labour. Buck-wheat is very commonly cultivated in this district; and it is found that one sowing of the seed will produce five or six crops in as many successive years, each harvest yielding from twelve to fifteen times the quantity first sown. The seed which is shed during the reaping is sufficient to insure the growth of plants for the following year, without any manuring, and with no more labour on the part of the farmer than that of harrowing the land in the spring. This system is continued without intermission until the diminished fertility of the soil compels its abandonınent; but, as already mentioned, this state of things rarely occurs until six years have been thus occupied.

It might be thought that in a country thus fertile, the proprietors or cultivators of the soil would speedily become enriched; this, however, is by no means the case. Facilities for transporting their surplus produce are wretchedly deficient, so that the market is extremely circumscribed; and the inhabitants of the country being grenerally so poor as to be unable to purchase food produced from grain, the farmers limit their cultivation in a great degree to the quantity needed for the supply of their own families. The small amount of labour called for by this cultivation is usually performed by the farmer himself, assisted by the nnembers of his own family; the employment of any other farm.labourers is consequently rare.

All temptation to extend the breadth of culture must be wanting, in a situation where the surplus produce cannot be exchanged, and its value invested in some permanent mode, whereby a larger quantum of human labour may be commanded at any future period.

Europe is indebted to Siberia for a particular description of oats, which are "considered excellent; 
and at Yakoutch barley is sometimes seen to arrive at maturity.

In some districts of Lapland, situated to the westward, the inhabitants are, by dint of careful tillage, enabled to produce plentiful crops of rye. In some spots, nearer even than this to the pole, potatoes are made to supply the place of grain; but for the most part the inhabitants are constrained to subsist upon dried fish.

In Kamtchatka, which is considerably to the south of Siberia, extending from $62^{\circ}$ to $51^{\circ}$ of north latitude, but united with that province at its eastern extremity, no attempts to cultivate the cereal grasses have ever proved successful, the produce not having in any case been sufficient to repay the labour of the tillage. 'These failures may, however, be attributable more to the generally ungrateful nature of the soil than to the effects of an unkindly climate, since in some spots where the land is of better quality, other esculent vegetables are produced in tolerable perfection; cabbages, carrots, turnips, radishes, beet-root, and even cucumbers, are raised constantly and without difficulty. Dried fish and caviare form the principal food of the inhabitants of Kamtchatks and the islands of the Aleoutian A rchipelago.

Barley and oats are the kinds of grain the culture of which extends farthest to the north in Europe. The meal which they yield, and which is seldom or never used by the inhabitants of South Britain for human food, forms, on the contrary, the principal sustenance of the inhabitants of Norway and Sweden, of a part of Siberia, and even of Scotland.

Rye follows next in order, being associated with oats and barley in the more northern division of the temperate zone. In the southern parts of Norway and Sweden, in Denmark, in districts bordering on the Baltic Sea, and in the north of Germany, rye 
forms the principal object of cultivation; barley being raised in those countries, as with us, only for the purpose of brewing, and the use of oats being limited principally to the feeding of horses. In all these last-mentioned places, wheat is also grown; but its consumption is limited, and the principal part is made an object of external trade.

The winters of Norway are intensely cold, but their summers are, on the contrary, excessively warm, particularly in the vallies, upon which the rays of the sun are reverberated during the day from the mountains, while the atmosphere has no time for becoining cool during the few hours when the sun is below the horizon. In such situations barley is generally sown and reaped within the short space of sixty days; sometimes even six weeks are found to suffice for fulfilling the hopes of the husbandman. 'The Norwegian agriculturist is, however, occasionally visited by seasons, throughout which the sun appears to lose its genial power, and vegetation is stunted; blossoms, indeed, appear, but are unsucceeded by fruits, and the straw yields nothing but empty ears. This calamity is happily of rare occurrence; and, unless when checked by a premature frost, the harvests of Norway are for the most part abundant and excellent.

Agriculture is pursued systematically and even scientifically in Sweden, by which means the prevailing barrenness of the soil is partially remedied. The province of Gothland is made to produce barley, oats, rye, and wheat, as well as pease and beans. In these climates, the transition of the seasons is always abrupt. Vegetation, when it has once commenced, proceeds with a rapidity unknown in these more temperate regions; and the interval which elapses between committing the seed to the soil and gathering 
the ripened harvest, is scarcely greater in Sweden than is experienced in Norway.

Somewhat farther to the south, rye in a great measure disappears, and wheat becomes the principal material used for human food. France, England, the southern part of Scotland, part of Germany and Hungary, and the lands of Western and Middle A sia, fall within this description. In most of these countries the vine is also successfully cultivated; and wine forming a substitute for beer, the raising of barley is consequently much neglected.

Still farther southward, wheat is found in abundance, but maize and rice are also produced, and enter largely among the constituents of human food. Portugal and Spain, that part of France which borders on the Mediterranean Sea, Italy, and Greece, are thus circumstanced.

Still farther to the east, in Persia and Northern India, Arabia, Nubia, Egypt, and Barbary, wheat is indeed found; but maize, rice, and millet form the principal materials for human sustenance. On the plains near the Caspian Sea, in the province of Georgia, rice, wheat, barley, and millet are raised abundantly, and with very little culture. In the more elevated parts of those districts rye is sometimes cultivated, but oats entirely disappear, the mules and horses being fed on barley.

The mode of culture followed at the present day in Egypt is exceedingly simple, and calls but for a small amount of labour. All that is required for raising barley and wheat, is, when the inundations of the Nile have subsided, to throw the seed upon the mud; if this should be thought too hard and stiff, the grain is lightly ploughed in, and no farther care or culture is then required until the ripening of the produce, which usually happens from the beginning to the end of April. 
In Nubia, and particularly above the Great Cataract, the banks of the river are so high as seldom to admit of the overflowing of the waters, and the Nubian cultivators are consequently obliged to employ sakies, or water-wheels, for the purpose of irrigating the fields during the summer: this practice prevails as far as Sennaar. Each of these sakies is capable of irrigating as much land as is calculated to yield from twelve to fifteen hundred English bushels of grain, and employs the alternate labour of eight or ten cows. The water thus dispensed over the land is thrown up either from the Nile, or from pits dug to the depth of fifteen or twenty feet, in which an abundant supply is soon collected. The principal vegetable productions of Nubia are barley and dhourra (Sorghum, or Indian millet). The use of wheat is confined to the more wealthy inhabitants.

The grains which form the principal objects of cultivation in our division of the globe are rarely seen in China and Japan, where rice greatly pred.ominates. The reason for this is not to be sought in the influence of climate, but rather in the peculiar manners and tastes of the people; since, throughout the isles of Japan, and in a very considerable part of the Chinese empire, every one of those grains might be successfully reared. The denseness of population in China furnishes a sufficient reason why the pursuit of agriculture should be so much encouraged as it is by the government. The annals of that singular people acquaint us, that one of their emperors who enjoyed the highest reputation for wisdom was taken from the plough to sit upon the throne. Another has been celebrated for having discovered the art of draining low lands, of collecting the water in canals, and of converting it from a noxious impediment to the useful purpose of irrigation. Their emperor, Ven-ti, who reigned 179 years before Christ, is said 
to have incited his subjects to the more zealous cultivation of their lands, by ploughing with his own hands the land surrounding his palace, which example being followed by his ministers and courtiers, influenced in turn those who moved in a less exalted sphere*.

Of the countries which lie between the tropics, those of Asia adopt principally the use of rice, while maize is made the common food of the Americans. There exists a natural reason for this distribution, Asia being undoubtedly the native region of rice, while maize is as certainly the production of America. In Africa, except as already particularized, and in the British settlements of that continent, the two grains are used indifferently and in nearly equal proportions.

Wheat is found in some situations within the tropics; but its high price, as compared with that of other grains, occasions its use to be confined to the more wealthy classes. In many parts of British India, and particularly in the upper provinces, the quality of the wheat is represented as being excellent, although the grain is smaller than with us. Barley is likewise grown in some of the more northern districts, but the grain does not attain to the same size or plumpness as in Europe. The variety cultivated in India is that known by us under the name of Bigg: its cheapness causes it, however, to be extensively used by the native population, who eat it in the form of cakes.

The agriculture of the Hindu Ryots is of the very ruclest description: their plouglis are scarcely deserving of the name, having no contrivance for turning over the soil; the instrument employed as a harrow is nothing more than the branch of a

- Du Halde, Nouvelle relation de la Chine, tome i. pp. 274-5. 
tree, or, at best, is only a wooden frame sixteen or eighteen feet long, in the form of a ladder, which is drawn by four oxen, and driven by two men, who add to its effectiveness by standing upon the instrument. Dr. Buchanan, in the account of his 'Journey through Mysore, Canara, and Malabar,' closes a very disparaging account of Indian husbandry with the following remarks:-

"I am afraid, however, that the reader, in perusing the foregoing accounts, will have formed an opinion of the native agriculture still mole favourable than it deserves. I have been obliged to use the English words plouglings, weedings, and hoeings, to express operations somewhat similar that are performed by the natives; and the frequent repetitions of these, mentioned in the accounts taken from the cultivators, might induce the reader to imagine that the ground was well wrought, and kept remarkably clean. Quite the reverse, however, is the truth. Owing to the extreme imperfection of their implements, and want of strength in their cattle, a field, after six or eight ploughings, has numerous small bushes remaining as upright in it as before the labour, while the plough has not penetrated above three inches deep. The plough has neither coulter nor mould-board to divide and to turn over the soil, and the handle gives the ploughman very little power to command its direction. The other instruments are equally imperfect, and are more rudely formed than it was possible for my draughtsman to represent."

The only circumstance which is stated favourable to the agricultural skill of the Hindus, is the existence of contrivances for irrigating the lands in seasons of drought. 'Ihis process is effected by means of tanks, which are maintained under the compulsory

$$
\text { * Vol. i. p. } 126 .
$$


regulations of the governments, whose revenueg depend upon the produce of the soil.

It remains to trace the distribution of the Cerealia throughout America. The highest limit for the cultivation of these plants on that vast continent is in the more southern portion of the Russian possessions, situated between $57^{\circ}$ and $58^{\circ}$ of north latitude, where barley and rye are brought to maturity. On the more easteru coast of America, the same cultivation rarely succeeds higher than $50^{\circ}$ or $51^{\circ}$.

In the United States, wheat and rye grow as in the more temperate regions in Europe; and it is perhaps owing to faulty methods of tiilage, occasioned by the great abundance of land and the dearness of labour, that the produce bears a small propurtion when compared with that obtained from cultivating the same extent of land in Europe. Great improvements in this respect have already been introduced; and when population shall be found, as in older settled countries, pressing against the means of subsistence, there is no reason why the lands should not be made as productive generally, as they are in the carefullycultivated districts of this country. Maize is very extensively raised in the United States, and in the southern parts of the Union rice is also very largely cultivated.

Callada produces wheat in sufficient abundance to supply its own population, and to make large occasional shipments to the mother-country, where this produce is received upon more advantageous terms as regards the duty payable on importation, than wheat the produce of any part of the continent of Europe. In proportion as the lands of Canada are cieared of their timber, we may expect that a larger amount of grain will be spared by that province for consumption in Europe; unless the tide of emigration 
should continue to set more and more strongly towards that quarter, so as to call for a proportionately iilcreased quantity of grain for the sustenance of the settlers.

Humboldt, in his account of New Spain, has given a very interesting view of the agriculture of South America. In the lower latitudes of the Mexican repunlic, the cereal grains of Europe, comprehending under this dellomination wheat, barley, oats, and rye, are never cultivated at a lower elevation than from 2500 to 3000 feet above the level of the sea. It is well known that the habitation of plants is determined, in a very decided manner, by the elevation of different regions. On this subject De Candolle calculates, that in France every five hundred and forty feet of vertical elevation is equivalent to a receding of one degree from the equator ; while Humboldt estimates every rise of three hundred and ninety-six feet to be equal to the same advance to the north, in tropical countries. We know that the summits of the towering Andes-some of which are placed almost directly under the equatorial line-are yet covered with perpetual snow; and that in many mountainous countries within the tropics, the seeds and fruits of temperate regions are seen to flourish.

On the declivity of the Cordilleras, between Vera Cruz and Acapulco, wheat cultivation does not in general commence at a lower level than 4000 feet. Sometimes, as in the immediate vicinity of the city of Xalana, wheat is sown, not for the sake of the grain, which indeed it there never produces, but because the straw and succulent leaves furnish excellent fodder for cattle.

It does not appear, however, that the degree of latitude and the arnount of elevation are the only circumstances that determine the fructification of wheat, since in Guatemala, which is nearer to the equator, 
and at a much lower level than Xalapa, that grain comes to full perfection. Humboldt offers, as reasons for this variance from the usual rule, the exposed situation of the district, and the prevalence of cool winds, which serve to modify the otherwise unfavourable influence of the climate. "I have seen," says this observant traveller, "in the province of Caraccas, the finest harvests of wheat near Victoria, (latitude $10^{\circ} 13^{\prime}$ ) at 500 or 600 metres (1640 or 1968 feet) of absolute elevation; and it appears that the wheaten fields which surround the Quatro Villas, in the island of Cuba (latitude $21^{\circ} 58^{\prime}$ ), have still a smaller elevation. At the Isle of France (latitude $20^{\circ} 10^{\prime}$ ) wheat is cultivated on a soil almost level with the ocean *."

Circumstances altogether unconnected with climate must be taken into account in determining the relative agricultural capabilities of Mexico, where the absolute absence of rain, throughout a large portion of the time when the plant is on the ground, must be, in a high degree, detrimental to wheat husbandry, unless artificial means were resorted to, as in Nubia, for supplying the natural deficiency of moisture. Throughout a great part of the temperate regions of $\mathrm{New}$ Spain the farmers are compelled to adopt the system of artificial irrigation. This is effected by the agency of canals and reservoirs, which are supplied from the rivers, and which are so constructed that the water may be dispensed at pleasure over any and every part of the farms.

In districts where the system of artificial watering is fully adopted, the fertility of the Mexican farms is extraordinary, - far beyond anything experienced in the richest soils of Eurnpe, the wheat harvest being commonly thirty-five and forty for one, and some considerable estates yielding even fifty and sixty * Humboldt's New Spain, p. 454. 
measures for one measure of seed. In similar localities, and with land of equal quality, but where no opportunity has beell provided for watering the fields, the annual return does not exceed more than fifteen or twenty for one.

Maize is also very extensively cultivated in Mexico ; and, from the genial nature of the climate, and the general fertility of the soil, the returns which it yields to the farmer are most abundant. Humboldt informs us that in the valley of Mexico the maize harvest yields two hundred for one. The Indians and Mestizoes, who form a large proportion of the inhabitants of the republic, feed on maize and manihot (cassava), the consumption of wheat being principally confined to the white inhabitants of the towns.

In the temperate and polar districts of the southern hemisphere, the order of cultivation is very similar to that pursued in similar latitudes and elevations north of the tropics. In America wheat is commonly found in the southern provinces of Brazil, in Buenos Ayres, and in Chili. The same grain predominates at the Cape of Good Hope, the flour which it yields being of beautiful quality, and accompanied by less than the usual proportion of bran. In Australia wheat also forms the principal object of cultivation on the part of the settlers; but, in the southernmost portions of that vast island-which, perhaps, it were more correct to call a continent-and in Van Dienien's Land, barley and rye are likewise to be found. 


\section{Chapter II.}

\section{WHEAT.}

By common consent, and in every climate where it can be cultivated, WHEAT-Triticum-is held in the highest estimation of all the cereal grains. The cost of its production, compared with that of some other substantive articles of aliment, does, indeed, occasion it to be but little consumed in countries where the bulk of the inhabitants are constrained by poverty to subsist upon the cheapest description of food that will sustain life. Where, however, the people are in a situation which enables them to indulge their choice in respect of food, wheaten bread, with scarcely an exception, constitutes the chief material for consumption.

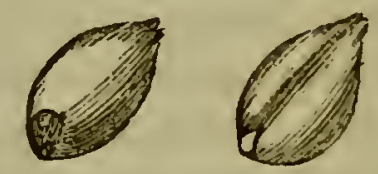

Grain of Wheat, upper and noder sides.

A full-grown and perfect grain of wheat will, on examination, be found to resemble the above figures. In form, it is a compressed oval, and is inclosed firstly in certain chaffy scales, which are readily to be separated from it, and secondly in a membranous tunic, which invests the seed much more closely. Along that side of the grain which, while the plant was growing, was turned towards the rachis, a groove may be observed. At the base, on the op- 
posite or convex side, is to be seen a small protuberant oval space, which indicates the germ or embryo of the future plant, and which is at this time covered by the tunics. The vessels whereby the grain was attached to the plant, and through which it drew nourishment until its maturity, had their point of attachment at the basal termination of this protuberance. When the seed is perfectly ripe, the umbilical vessels separate; the point of separation speedily heals in the same manner as a portion of a deciduous tree from which a matured leaf has detached itself, and the grain may then be easily threshed out from the chaff in which it had lain buried; sometimes, indeed, it sheds itself spontaneously.

Several species, and a still greater number of varieties, of wheat are to be found. Many of these differences are doubtless to be referred to influences of climate and modes of culture. There are but two sorts generally and extensively cultivated in this lingdom, and these have distinguishing names given to them, in agreement with the seasons in which they are sown, one being called Spring or Summer Wheat, the other Winter or Lammas Wheat.

Spring, or Sumare Wheat-Triticum astivu $m$ -is supposed to be a native of Siberia, in the land of the Beschkirs. It is less hardy than the wintersown kind, and the whole plant has a weaker appearance; the stem is thin and delicate, the ear more slender and less erect, and it is provided with much longer beards or awns. This description of grain, which, in our uncertain climate, cannot be safely or productively cultivated throughout the kingdom, is yet domesticated in the more southerly and the midland districts. As its grain is smaller than that of the commoner sort, and as its produce is less abundant, the farmer would not be led to its culti

D 3 
vation, could he be certain of success with earlier sown seed, or if, in the progress of his agricultural operations, the land could always be got ready for the autumnal sowing.

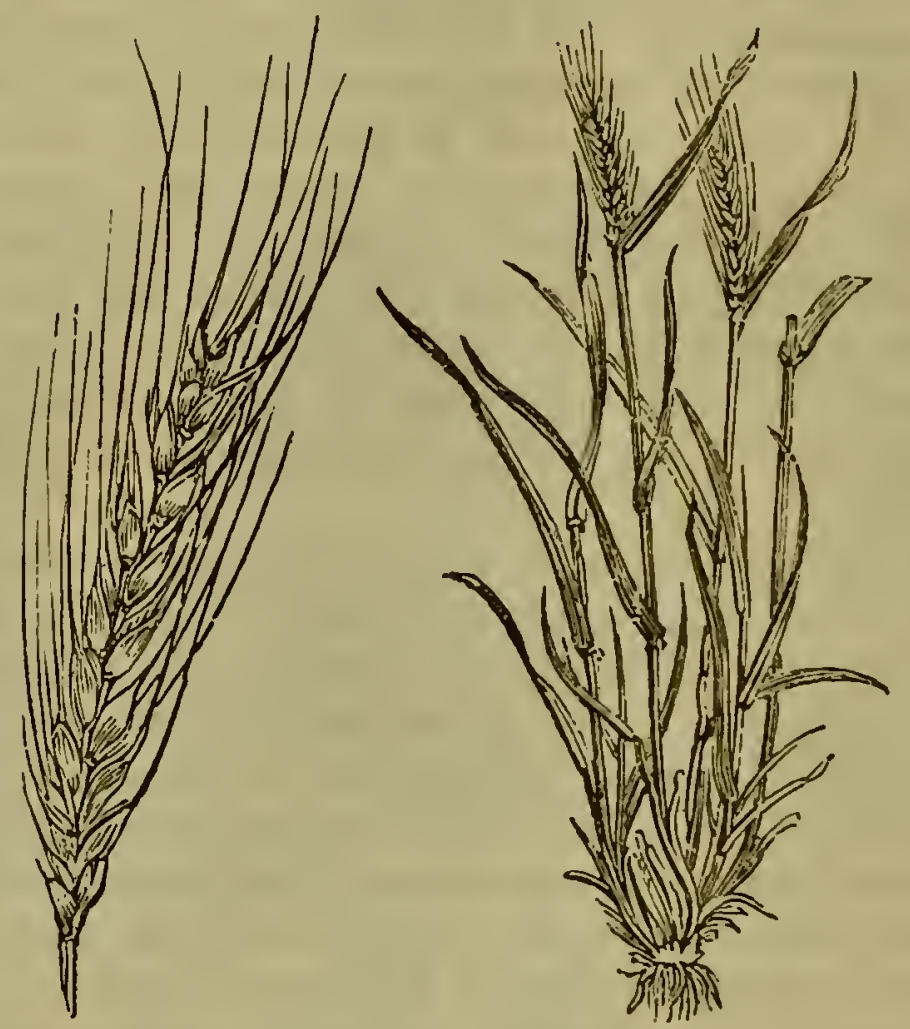

Ear and Plant of Spring Whezt.

The principal advantage to be derived from the adoption of summer wheat consists in the security which it offers against the injurions effects of a cold and rainy spring; so that in situations and seasons where winter-sown wheat is so far injured as to destroy all prospect of a harvest, this delicate but more rapidly growing species may be more confidently depended on for yielding its increase. Some farmers, when they perceive that the seed they have sown in autumn fails and goes off in patches from any untoward causes, are accustomed to rake spring 
wheat into the vacant spaces, and wherever the plants appear weak and thin. By this means the uniformity of the crop is restored; and if the operation las not been delayed beyond the begimning of April, the spring wheat will be matured and ready for the sickle at the same time with the earlier sown plants. This mixture of grain is of no consequence to the miller, but it would be manifestly improper to employ the produce as seed. When spring wheat is sown by itself, the season for this operation is in April, or the early part of May, from which time onward the farmer has but little to dread from any severity of weather in the above-mentioned districts. It is said that this species of wheat is not subject to blight. According to the analysis of Sir Humphrey Davy, the nutritive quality of this lind is not quite equal to that of winter wheat, the proportions being $95 \frac{1}{2}$ per cent. in the latter, and only 94 per cent. in the former, of the entire bulk of the grains. The gluten contained in the two linds varies in a greater degree, that of winter wheat being 24 , while that of spring-sown corn is only 19 , so that the winter variety is most eligible for the purpose of the baker.

Winter, or Lammas Wheat-Triticum hybernum-may easily be distinguished by its appearance, being much more vigorous in the stem, more erect and thick in the ear, and, in comparison with the other, destitute of beard or awn, for which reason its bloom is more conspicuous. The same cause may be cited to account for the fact, that its pollen is both more easily diffused and more liable to be destroyed.

This plant is sown in autumn, stands through the winter, and ripens its seed in the following summer. Slight varieties of this species are exceedingly common in different localities, and are propably attribut- 


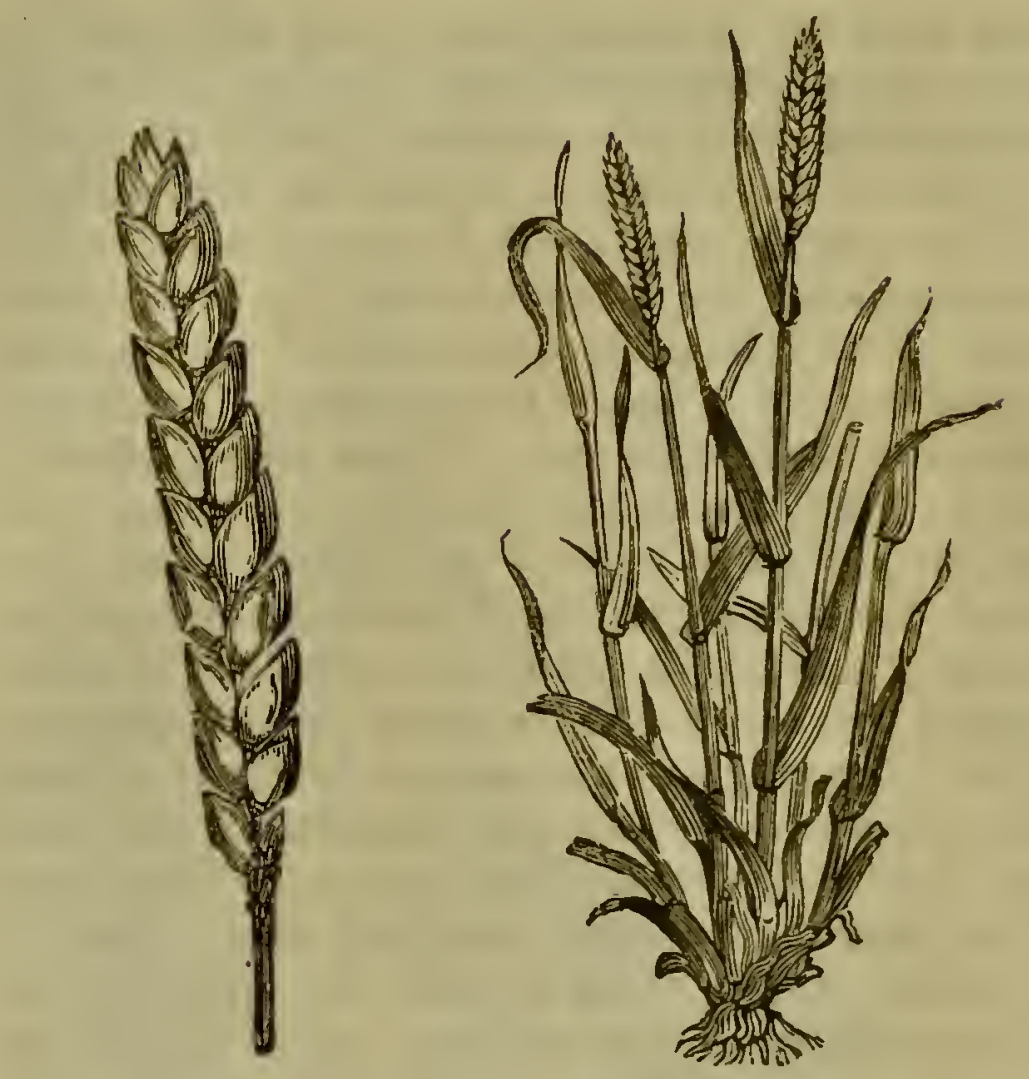

Far and Plant of Winter IVheat.

able to some peculiarities in the mode of culture. The common varieties of winter wheat are distinguished from each other according to the colour of the tunic enveloping the grain, and the difference observable in their chaff. The colours are usually divided into white and red, the latter of these including many different shades of brown. Red wheat is commonly said to be more hardy than white; it is therefore thought better suited for cultivation in bleak and upland districts. The plant is, however, not so productive as the white, and the flour which it yields is seldom of so desirable a quality.

The cultivation of another description of wheat, called, from the form of the ear, the Duck-BILL, or 

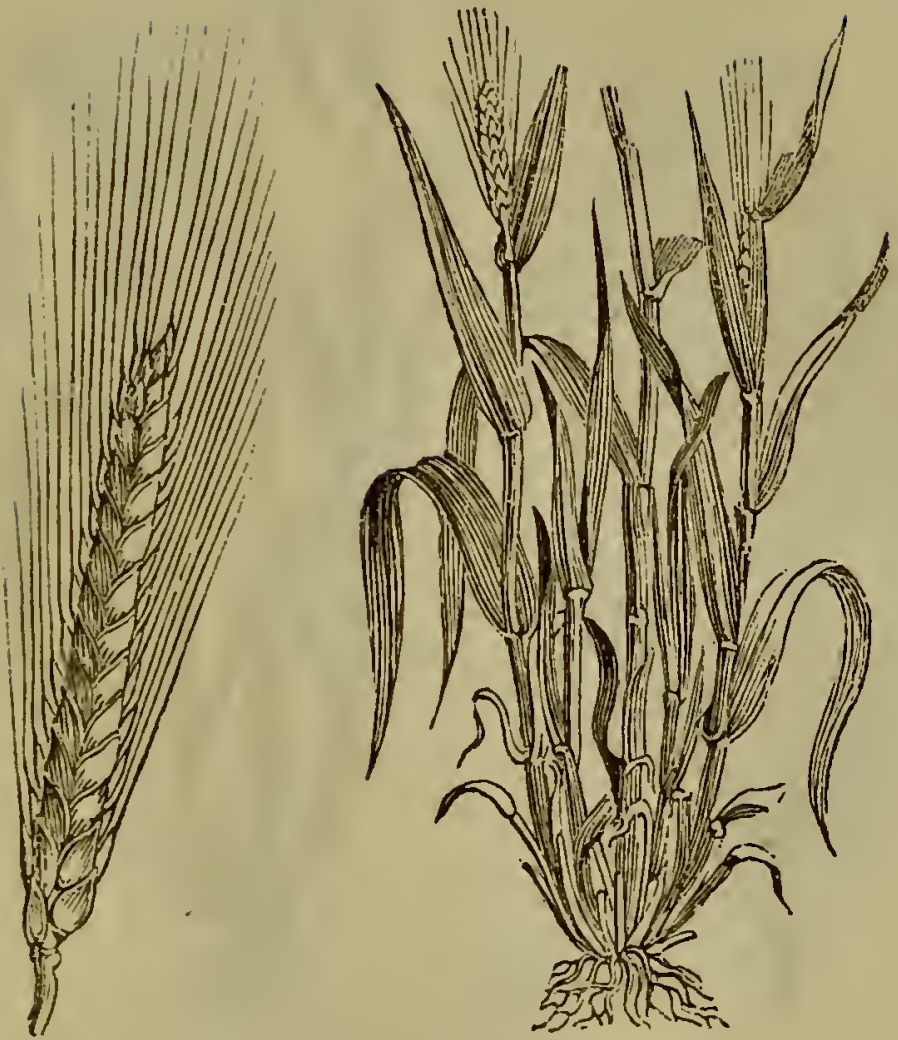

Ear and Plant of Duck-bill Wheat.

Conical Wheat-Triticum turgidum, -has been attempted in Engiand, but without any profitable result, having no qualities that recommend it to the notice of the agriculturist.

Some other varieties exist, which, although they do not appear to be well adapted to the climate of England, are yet cultivated extensively elsewhere; they are therefore deserving of description.

Egyptian, or many-spiked Wheat-Triticum compositum, - called also the Corn of Abundance. This species is principally cultivated in the country whose name it bears, and in Italy. It is probably a native of the north of Africa, and resembles spring wheat, in its habits, more than any other description, 


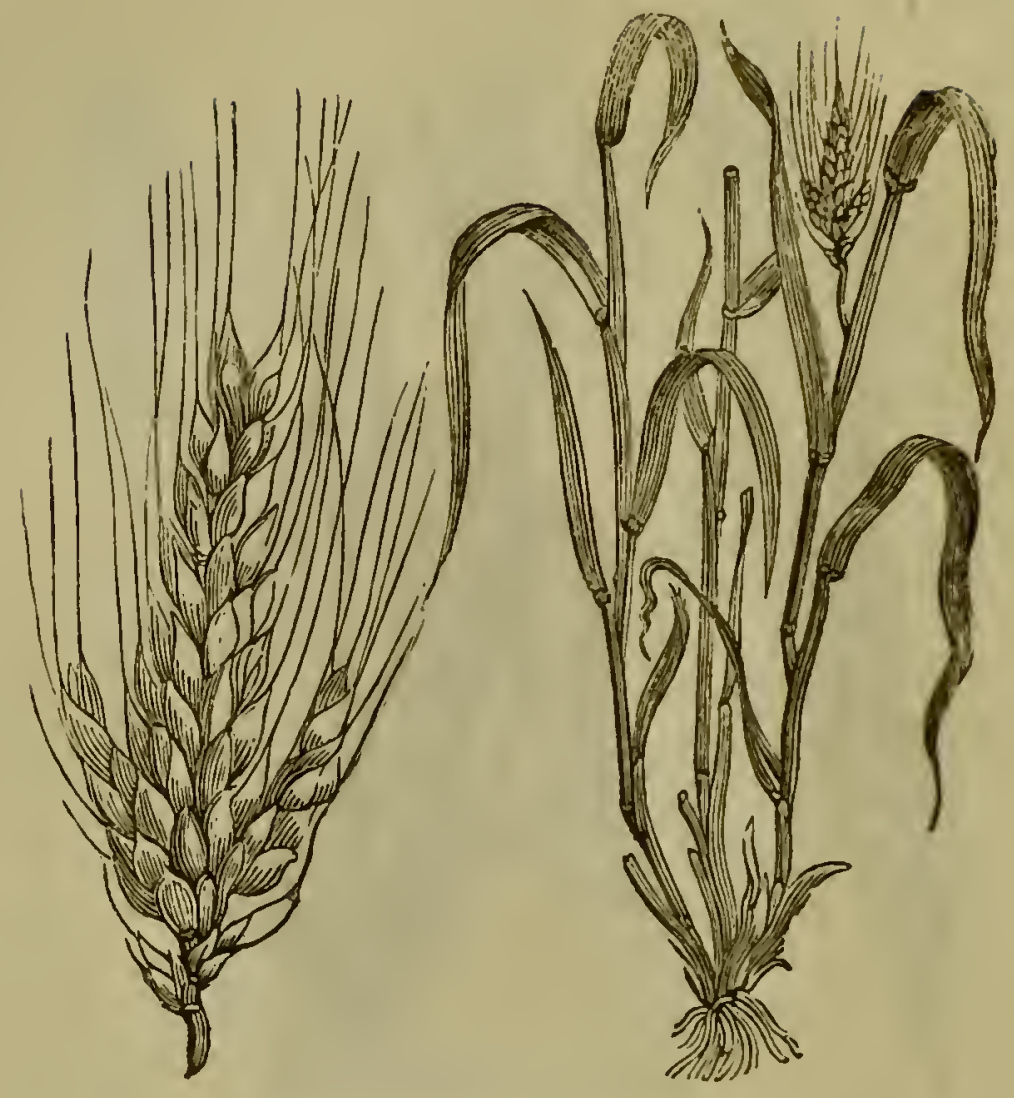

Ear and Plaut of Egyptian, or many-spiked Wheat.

The ear is bearded, and the grains are thinner than those of winter wheat. It is the distinctive peculiarity of this plant that its rachis is branched, so that the ear is made up of several spikelets. Egyptian wheat will bear great degrees of heat and drought without injury, so that it is found to yield abundantly in situations where other kinds would be greatly injured, if not destroyed - a circumstance which points it out as admirably adapted to the arid lands whereon it is chiefly cultivated.

Polish Wheat-Triticum polonicum.-This variety was partially cultivated in England $\mathrm{n}$ the latter part of the seventeent! century, but is now to be found here only in botanic gardens. 


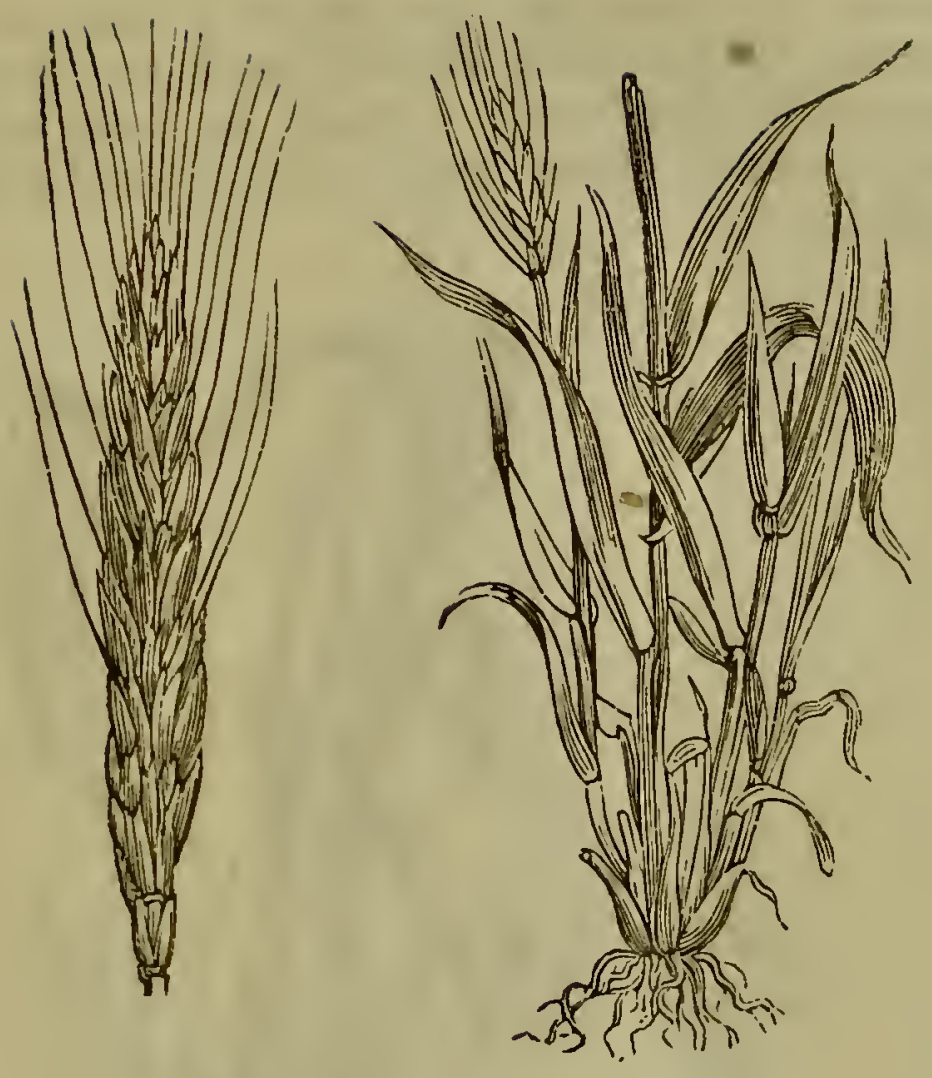

Ear and Plant of Polish Wheat.

Spelt Wheat-Triticum spelta-is imagined to have been the Triticum of the Romans, and the Zea of the Greeks, although this latter name has now been given to Maize, a grain unknown to the ancients. This variety is still very abundantly cultivated in many parts of the Continent, and particularly in the south of Europe. It may be raised upun much coarser soil than is required for the better kinds of wheat in England, and calls for much less culture. In many parts of Germany, in Switzerland, in the south of France, in the north of Africa, and at the Cape of Good Hope, spelt is grown abundantly. This is likewise the case in Spain, where, on occasions when barley is scarce, this grain is given to 
horses. It is said that spelt wheat is better adapted than any of the more delicate kinds for culture in Australia, and probably it would be found the prefitrable sort in all the more southern wheat-growing countries.

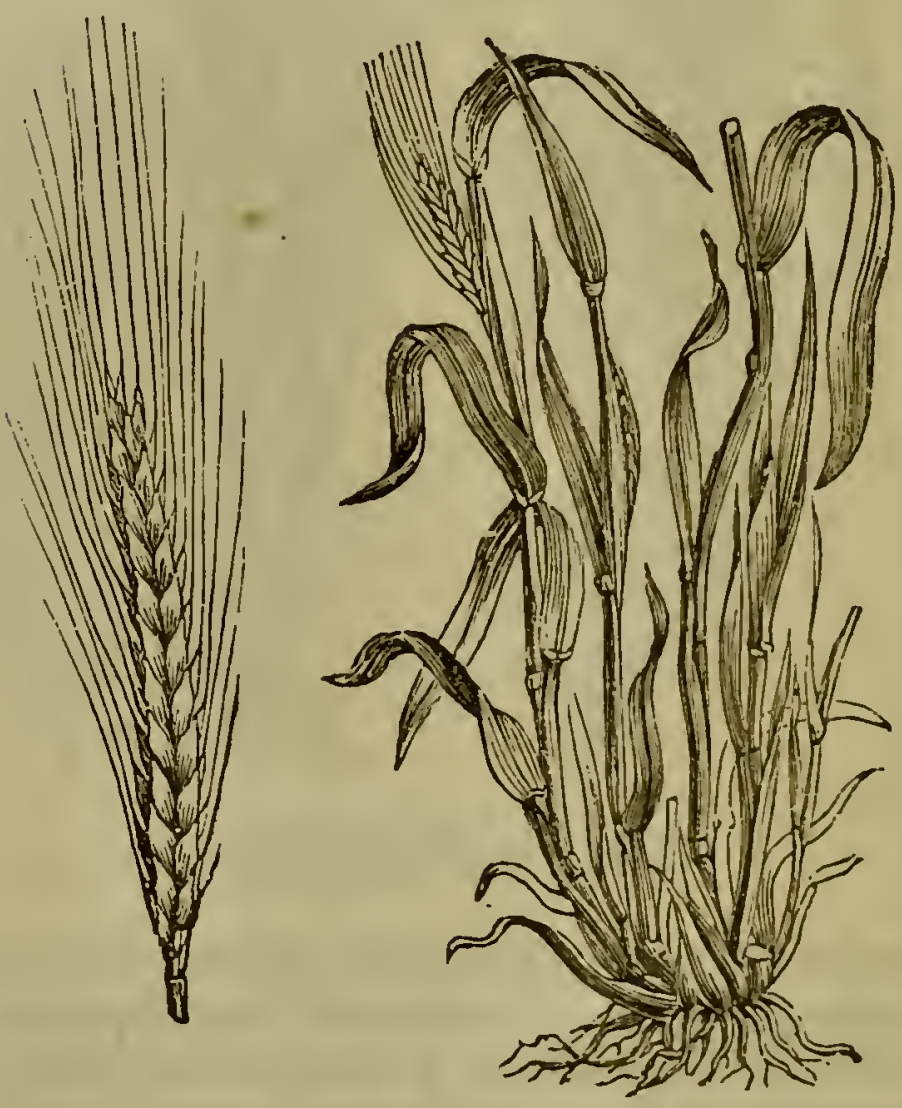

Ear and Plant of Spelt theat.

There are two distinct varieties of spelt, distinguished as the awned and the awnless; the latter is perhaps the most naked of all the cerealia. The grains of this are large, but the ear contains only a small number of them, as a portion of the flowers prove barren. It is generally, if not always, a springsown crop; grows strongly, and its stalks are nearly solid. Bread made of its flour is said to be of a dry quality. 

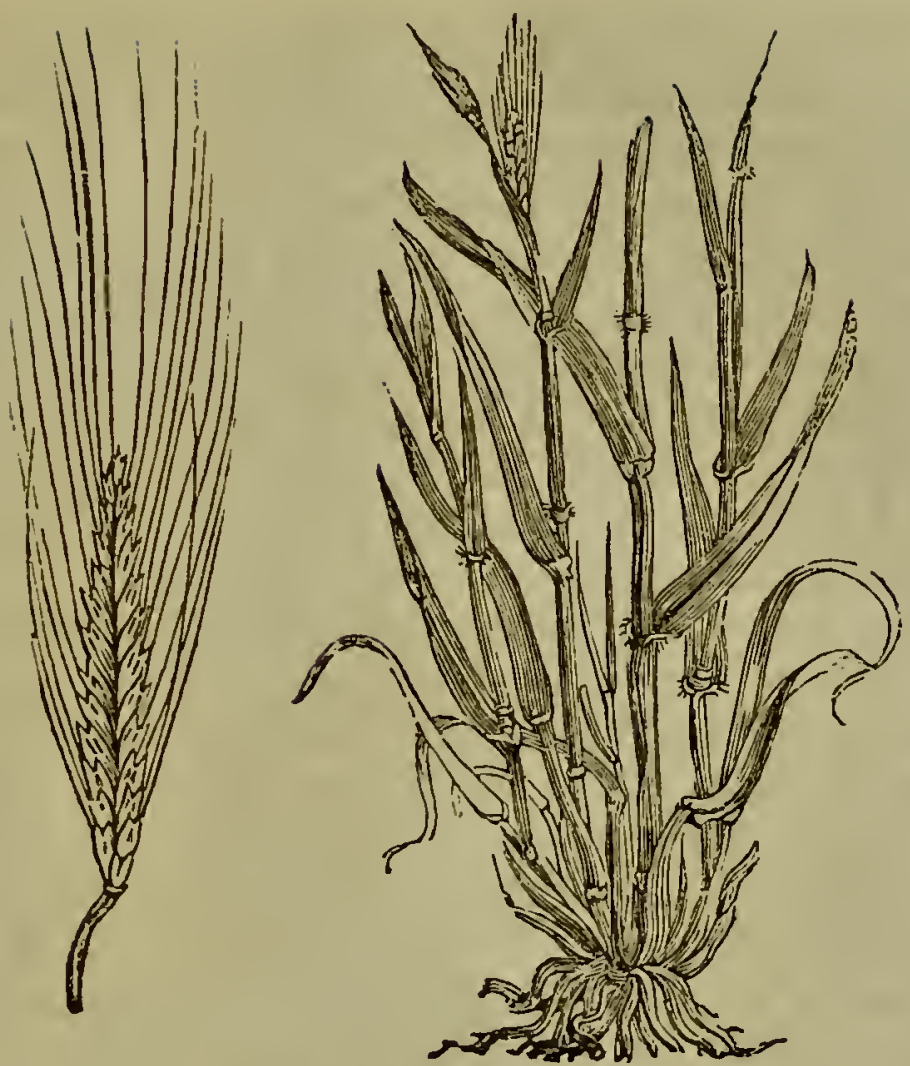

Far and Plant of One-seeded Wheat.

One-segded Wheat, or St. Peter's corn, - Triticum monococcum. 'This is another variety; the stem and leaves of which are among the most diminutive of the species, and the spike contains only a single row of grains. This kind is chiefly used in the mountainous parts of Switzerland, and containing less of gluten than common sorts, it answers better for being boiled into gruel, than for being baked into bread. The four-sided form of the ripe ear is so extremely regular, that it has the appearance of being carved in ivory. 'The straw, which is both hard and firm, is excellent for thatching.

The well-known method of propagating wheat is by sowing the grain in land previonsly prepared for 
its reception by ploughing. It has been held that this important preliminary of pulverizing the soil can laardly be carried to excess, the expense attending it forming almost the only limit to its prosecution. Cato the censor, who, in addition to his accomplishments as a warrior and a statesman, showed an intimate acquaintance with rural economy, has recorded his opinion on the necessity of thoroughly turning up the soil. In his treatise, 'De re rustica,' he has laid it down as the first rule in husbandry to plough well, and the second rule-to plough *

Two distinct practices are followed in committing the seed to the earth. The most ancient and most commonly used of these is that of scattering the seed from the hand of the sower over the whole surface; and this is characteristically called sowing broad-cast. The other method, which is comparatively of modern introduction, is that of depositing the seed in holes formed in straight furrows, and at regular intervals, which is called drilling, or dibbling; while the processes which accompany it, and which are impracticable with the broad-cast method, are distinguished as the horse-hoeing or drill system of husbandry.

Lord Bacon says, that, in his time (the beginning of the seventeenth century), attempts had been made to plant wheat, but that the plan was abandoned, although undoubtedly advantageous, as involving too much labour + . In 1669, Evelyn furnished to the Royal Society a description of a sowing machine invented by Locatelli, an Italian, who had obtained a patent for its use in Spain, having proved its utility by public experiment + . The drill plough was, however, not used in England, and was, perhaps, quite unknown to a body of men who are proverbially

- Cap. Ixi.

+ Sylva Sylvarum. 1817.

See Beckmann's 'History of Inventions,' vol. iv. p. 45 , eld 
slow all over the world to adopt any improvement till public attention was awakened to it, in the early part of the last century, by the celebrated Jethro Tull, who, after practically following for some years his own improved plan of husbandry, and thereby proving its advantages, published a particular account of his process in the year 1733. This work, which he entitled 'An Essay on Horsehoeing Husbandry,' became highly popular, compelling the attention of English agriculturists to the subject, and engaging no less the consideration of scientific foreigners. The system of Mr. Tull con.. sisted in discarding the old method of scattering seed upon the land broad-cast, and in substituting a mode of sowing the grain in straight rows or furrorvs by means of an implement more perfect than Locatelli's machine, which delivered the seed at proper intervals, and in the exact quantity that was found most beneficial. Spaces of fifty inches breadth were left between the furrows, so that the land could be ploughed or horse-hoed in these intervals at various periods during the growth of the crop, the object of these hoeings being to bring fresh portions of the soil into contact with the fibrous roots of the plants, and thus to render every part in turn available for their nutrition. One material advantage that results from the new method of husbandry is the saving which it occasions in seed-corn, and which is said to amount to five-eighths of the quantity usually expended in the old method. The comparative merits of the two plans have for so long a time been submitted to the surest of all tests, that of experience, and have been so well examined by cornpetent persons, who have given the result of their inquiries to the world, that it cannot be necessary to do more in this place than refer the reader to those authors for farther information 
The manner in which plants are produced through the germination of seeds is so well known, that in any community where the human mind has been advanced in that degree which incites to the cultivation of the earth, it would perhaps be difficult to find a man so insensible to the workings of nature by which he is surrounded, as not to have noticed with admiration the phenomena accompanying the developement of vegetable fecundity. It is true we know not how this standing miracle is brought about; and, in all human probability, we never shall be able to pierce the veil wherein the inciting energy is shrouded to which that fecundity is owing; but is it possible for us, while conscious that it exists, not to be grateful for the benevolence whereby that energy is ceaselessly called into action? At one end of the groove, in a grain of wheat, is a small protuberance, as we have already mentioned, which is the germ or embryo of the future plant. This organ has been appropriately called corculum (little-heart). It contains within itself a principle, which, if rightly managed, is capable of evolving not only a plant of wheat, with its abundant spike, but also plant after plant, and spike after spike, until, in the course of a few harvests, the progeny of this little germ would become capable of feeding a nation. 'Thus it is, that in the lapse of ages, amidst the desolations of rude conquerors, and the alternations which the finest portions of the earth have endured from civilization to semibarbarism, the vital principle of vegetable life destined for the chief support of the human race has not been lost; and it has remained to man, like fire. which he alone of all animals has subjected to his use, to be called forth at his bidding to administer to his support, his comfort, and his advance in every art of social existence.

The number of stalks thrown up by one grain of 
wheat is indefinite, and depends upon local causes. This power of multiplication, as possessed by the grain-bearing plants, is called tillering. In its progress, the stalks do not rise immediately from the germ, but are thrown out from different points of the infant sprouts while yet they remain in contact with the moist soil. An increase of the cereal plants, by this means, is sometimes produced beyond anything conceivable by those persons who have not attended to the fact. But for it, the casualties to which these important plants are liable during the earlier stages of vegetation, would in many cases operate fatally to the hopes of the farmer. One or two circumstances may be mentioned in which this power of multiplying themselves at the roots is of the highest advantage in the cultivation of the cereal grains. An insect-musca pumilionis-is accustomed to deposit its eggs in the very core of the plumule or primary shoot of wheat, so that it is completely destroyed by the larvæ.

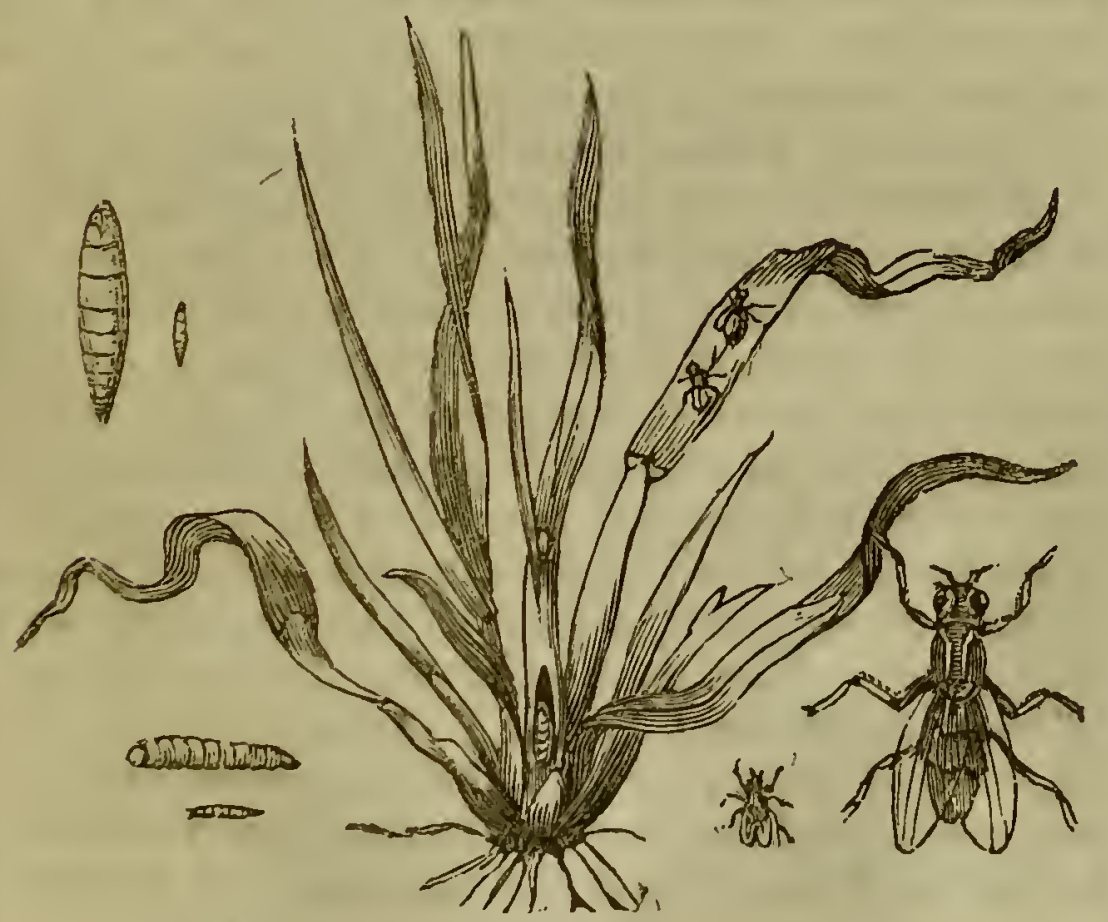

Wheat-Ay. (Musca pumilionis), in its different stages.

E. 3 
Did the plant possess within itself no means of repairing this injury, the whole previous labour of the husbandman would in this case have been in vain. But this destruction occurring in the spring of the year, when the vegetative power of the plant is in the greatest activity, an effect is produced somewhat analogous to that of heading down a fruit-tree; shoots immediately spring up from the nodes (knots), the plant becomes more firmly rooted, and produces, probably, a dozen stems and ears where, but for the temporary mischief, it might have sent forth only one.

Several extraordinary facts have been recorded in connexion with the inherent power of multiplication possessed by these vegetables. Among others, Sir Kenelm Digby asserted, in 1660, that " there was in the possession of the Fathers of the Christian doctrine at Paris, a plant of barley which they at that time kept as a curiosity, and which consisted of two hundred and forty-nine stalks springing from one root or graill, and in which they counted above eighteen thousand grains or seeds of barley." In the Philosophical Transactions* it is recorded, that Mr. C. Miller of Cambridge, the son of the eminent horticulturist, sowed, on the 2nd of June, a few grains of common red wheat, one of the plants from which had tillered so much, that on the Sth of August he was enabled to divide it into eighteen plants, all of which were placed separately in the ground. In the course of September and October so many of these plants had again multiplied their stalks, that the riumber of plants which were separately set out to stand the winter was sixty-seven. With the first growth of the spring the tillering again went forward, so that at the end of Marcin and beginning of April a farther division was made, and the number of plants now amounted to five hundred. Mr. Miller expressed his opinion, * Vol. lviii. 
that before the season had ton far arlvanced one other division might have been effected, when the number might have been at least quadrupled. The five hundred plants proved extremely vigorous, much more so than wheat under ordinary culture, so that the number of ears submitted to the sickle was 2],109, or more than forty to each of the divided plants: in some instances there were one hundred ears upon one plant. The ears were remarkably fine, some being six or seven inches long, and containing from sixty to seventy grains. The wheat, when separated from the straw, weighed forty-seven pounds and seven ounces, and measured three pecks and three quarters, the estimated number of grains being $5 \boldsymbol{7} 6,840$.

Such an enormous increase is not of course attainable on any great scale, or by the common modes of culture; but the experiment is of use as showing. the vast power of increase with which the most valuable of vegetables is endowed, and which, by judiciously varying the mode of tillage, may possibly in time be brought into beneficial action.

The ordinary produce of wheat varies exceedingly, depending much upon the quality of the soil, the nature of the season, and the mode of culture. The average produce of the soil of a country depends, as does every other species of production, upon the advance of its inhabitants in knowledge and in the possession of capital. It has been conjectured, that in the 13th century, an acre of good land in England would produce twelve bushels of wheat*. In two centuries this rate of produce appears to have greatly increased. Harrison, writing in 1574, says, "The yield of our corne-ground is much after this rate following :- Throughout the land (if you please to

* Sir J. Cullum's 'History of Hawksted,' quoted in Eden's 'History of the Poor,' vol, i. p. 18. 
make an estimate thereof by the acre), in meane and indifferent years, wherein each acre of rie or wheat, well tilled and dressed, will yield commonlie sixteene or twentie bushels; an acre of barley, six-and-thirtie bushels; of otes, and suclı like, four or five quarters ; which proportion is notwithstanding oft abated toward the north, as it is oftentimes surmounted in the sonth*." The mean produce in Great Britain, according to the estimate of Mr. Arthur Young, did not, at the time when he wrote (about 50 years ago), exceed twenty-two and a half busheis per acre. Other and later writers have calculated the average at from twenty-four to twenty-eight bushels; while the author of the Reports on Agriculture for Middlesex has asserted, that the medium quancity in that county is forty bushels, the highest produce he has known being sixty-eight, and the lowest twelve bushels per acre. The land in the county which was the subject of these Reports, owing to its proximity to the metropolis, may be considered as in a state of high condition, and much beyond the ordinary rate of fertility. At all times, and in every country, some situations will be found more prolific than others, and some individuals will be more successful in their agricultural labours. Pliny has related a case which occurred among the Romans; where this success was seen in so marked a degree, that the able agriculturist who, by excelling his countrymen, had rendered himself the object of envy, was cited before the Curule Edlile and an assembly of the people, to answer to a charge of sorcery, founded on his reaping much larger crops from his very sinall spot of ground than his ueighibours did from their extensive fields. "In answer to this charge Cresinus produced his efficient implements of liusJandry, his well-fed oxen, and a hale young woman

* 'Description of Britain, ${ }^{3}$ prefixed to Holiingsthed. 
his daughter, and pointing to them, exclaimed,- These, Romans, are my instruments of witchcraft, hut I cannot here show you my labours, sweats, and anxious cares.'

It will easily be conccived that the quantity of straw must vary considerably from year to year, according to the seasons, and that this produce will likewise be generally influenced by the nature of the soil. It is therefore impossible to give any certain information upon this point, but it will perhaps amount to a near approximation to the truth if we consider that for every twelve bushels of wheat, onc load, containing thirty-six trusses of straw, will be obtained, the weight of which is $11 \mathrm{cwt}$. 2 qrs. $8 \mathrm{lbs}$. The straw of summer wheat is more agreeable to cattle than that produced from winter sowing.

This most important vegetable is not wholly free from casualties apart from climate. The principal of these are, blight, mildew, and smut. The examination and treatment of these diseases have proved fruitful topics with writers on agricultural subjects. It does not, however, appear that the public has hitherto benefited much by their speculations, and an author of considerable eminence is so far of a contrary opinion as to have asserted, that " in proportion as words have been multiplied upon the subject, the difficulties attending its elucidation have increased t."

Blight is a disor wer to which the cereal grains are known to have been liable from the earliest times. Annong the ancient Greeks it was regarded as a sigu of wrath on the part of their offended deities; and whenever it occurred they consequently gave themselves up to the infliction, without any thonght of providing a remedy. The same superstitious notion was entertained by the Romans, who believed that

* Nit. Hist., book xviii. chap. 6.

† Loudon's Encyclopedia of Gardening, p. 236. 
the evil, which they called rubigo, was under the control of a particular deity named Rubigus, to propitiate whom in favour of their crops sacrifices were continually offered.

Blight and mildew have been very much confounded together by different writers on agricultural subjects, so as to render it doubtful to which class of appearances each name should in strictness be applied, or whether indeed both are not applicable to one and the same disorder occurring at different periods of the growth of the plant. Wishing to avoid entering upon debateable ground in noticing a subject which remains intricate and obscure, notwithstanding all the laborious treatises to which it has given rise, the forms which the disorders assume, and the bad effects by which they are followed will be plainly but briefly described, leaving the question of their classification to more professional hands.

Three distinct and dissimilar causes are assigned for the production of these disorders-cold and frosty winds-sultry and pestilential vapours-and the propagation of a parasitical fungus. The first of these causes acts by stopping the current of the juices; the leaves, being then deprived of a necessary portion of nutriment, speedily wither and die, when the juices, which are impeded in their passage, swell and burst the vessels, becoming then the food of myriads of little insects. These make their appearance so suddenly as to have been considered the cause rather than one of the effects of the disease. The second canse of blight occurs after the grain has attained its full growth. It has been observed to happen mostly after heavy showers of rain, which, occurring about noontidc, have been succeerled by clear sunshine. The plants are most commonly attacked thus about the middle or end of July. Mr. Loudon informs us that " in the summer of 1509 , a 
field of wheat on rather a light and sandy soil came up with every appearance of health, and also into ear, with a fair prospect of ripening well. About the begimning of July it was considered as exceeding anything expected from such a soil. A week afterwards, a portion of the crop on the east side of the field, to the extent of several acres, was totally destroyed, being shrunk and shrivelled up to less than one half the size of what it had formerly been, and so withered and blasted as not to appear to belong. to the same field. The rest of the field produced a fair crop*." This disorder attacks either the leaves or stem of the plant, which appear to be covered by broken lines, of a black or deep brown colour. This disease has been ascertained to result from the presence of a very minute species of fungus, the roots of which are inserted into the stem, and absorb the nourishment intended for the grain, which when the plant is thus attacked proves little else than husk. The minute seeds of the parasitical plant which occasion this mischief are so exceedingly light that they are borne along by the air to considerable distances. They are like wise of extraordinary quick growth, occupying in warm weather, according to the opinion of Sir Joseph Banks, not longer than one week from the time of their insertion in the plant to the production of their seed. Every pore in the straw whereon they fix will present from twenty to forty plants, so that the extent to which this mischief spreads is difficult to be imagined. Fungus thrives best in damp and shady situations, a circumstance which seems to point out naturally the propriety of providing means for the free ventilation of the fields, keeping low the hedges and fences by which they are surrounded. For the same reason it is found that thin crops, and

* Encyclop. of Gard. p. 237. 
such as are sown by drilling or dibbling, are i... most likely to escape.

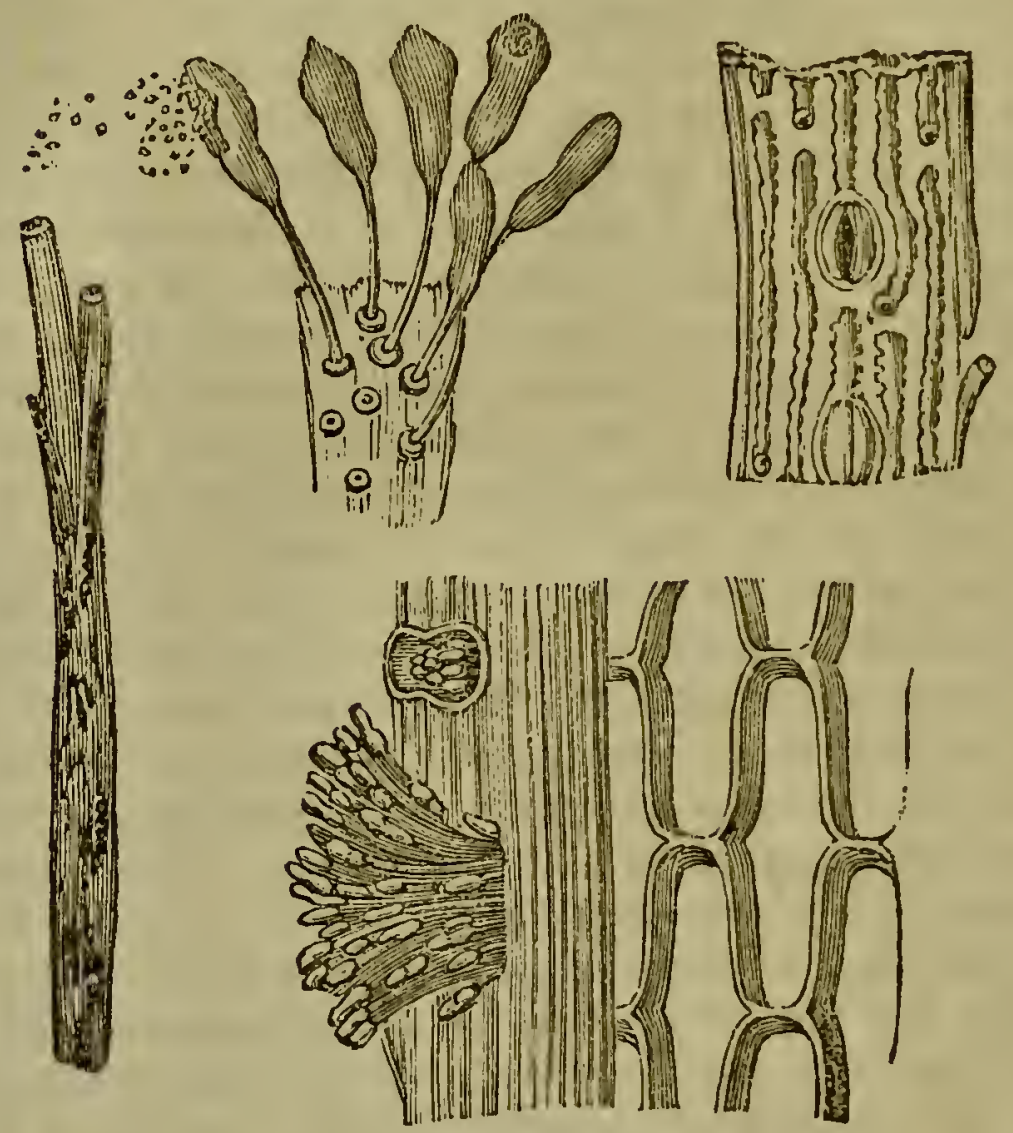

Corn Mildew-Uredo frumenti-greatly magnifiel.

It has been often asserted, and was for a long time believed, that the neighbourhond of barberry bushes was hurtful by attracting the noxious fungus, but this idea is now classed among unfounded prejudices.

The grain of mildewed plants is found to be perfectly good for seed, and being smaller than sound grain, a less measure is required for the purpose.

Another formidable disease to which corn is liable is known under the characteristic name of smut. This injury consists in the conversion of the farina of the grain into a sooty powder, which is more or 
less black and offensive to the smell. Some authors have divided this evil under two different names, retairing that of smut for one of its modifications, while that of burnt-grain has been given to the other. Mills, in his 'Systen of Practical Hushandry,' has drawn the line of distinction between the two in the following terms. "Smut, properly so called, occasions a total loss of the infected ears, but as the black powder which it produces is very fine, and the grains of that powder do not adhere together, wind and rain carry them away, so that the husbandman houses little more than the straw, which does not infect the sound grains and scarcely damages their flour. The burnt or carious grains are, on the contrary, often housed with the sound grain, which they infect with a contagious distemper, at the same time that they render its flour brown, and give it a bad smell*" The name under which this disease was known by the Romans was ustilago: by the French farmers it is called charbon.

If a portion of the black powder be first wetted with water, and then put under the microscope, it will be found to consist of myriads of minute globules, transparent, and apparently encompassed by a thin membrane. The cause of this disease has been held by some investigators to originate in the soil wherein the grain is sown; others have attributed it to the growth of a fungus within the ear; while others again have affirmed that it is owing to a diseased state of the seed whence the plant is produced. The resılt of various experiments conducted with different seeds sown in the same spot, and subjected to the same culture, appear to confirm the correctness of the last hypothesis.

The average weight of a bushel of wheat is about sixty pounds. Inferior samples seldom weigh less

* Vol. ii. p. 392. 
than fifty-six pounds, and the best as seldom exceed sixty-two pounds.

A bushel of wheat of the average weight win yield, on being ground,

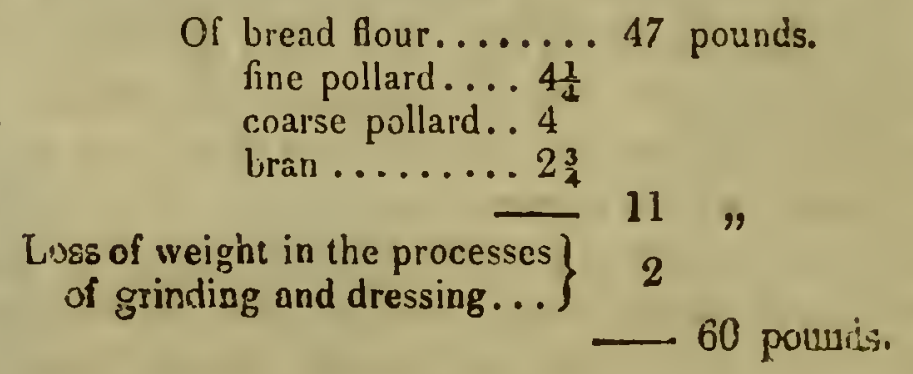




\section{Chapter III.}

RYE-BARLEY-OATS.

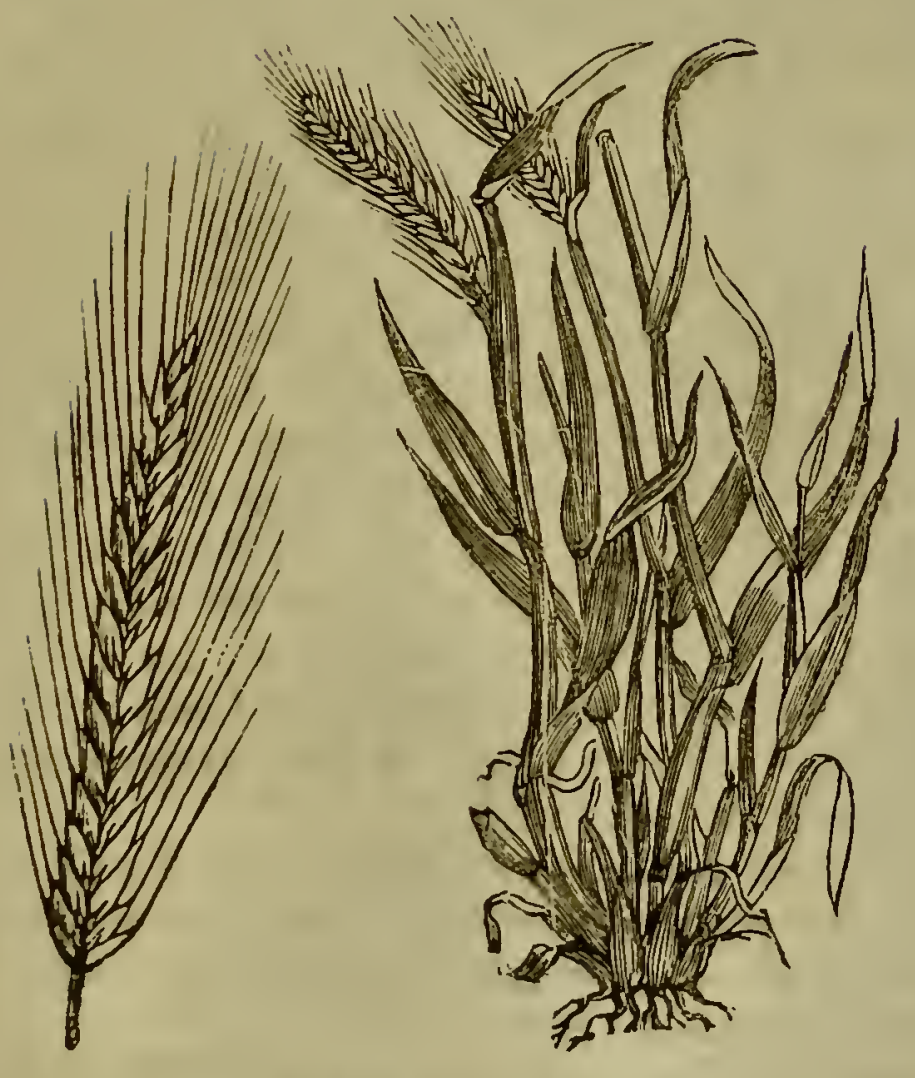

Ear and Plant of Rye.

RYE-Secale cereale. In former times this grain was much more extensively cultivated among us, than it has been of late years. Not two centuries have passed since rye flour, either by itself, or mixed with wheat, furnished nearly all the bread consumea by the labouring classes in England. 
At present rye is cultivated by our farmers prin. cipally that they may draw from it a supply of green iod for their flocks. For this purpose the plants, which are sown in November, are eaten early in the spring, before they begin to spindle, which they will do towards the end of March. After this stage of the growth has taken place, the succulent quality of the blade is impaired; it becomes coarse and harsh ; and is no longer agreeable to animals. When rye is left to ripen its seeds, these are, for the most part, applied in this country to purposes distinct from human food; the principal use to which the grain is put being the preparation of a vegetable acid, to be employed by tanners in an operation which they call ruising, and whereby the pores of the hides are clistended, so as to dispose them the more readily to imbibe the tamning principle of the oak-bark, which is afterwards applied. Rye, when parched and ground, has been recently used as a substitute for coffee. It would be difficult, however, to convince any one accustomed to the use of this grateful beverage, that the grain of home production is ever likely to take place, at least to any extent, of the fragrant Mocha bean.

Rye straw is useless as fodder, but forms an excellent material for thatching, and is so suitable for stuffing horse-collars, that saddlers will usually pay for it a very good price.

Botanists distinguish four species of this plant :-

\author{
Secalc villosum, \\ Secale orientale, \\ Secale crelicum, and \\ Secale sereale;
}

the last only of which is cultivated in Britain. This, which is said to be a native of Candia, was intro- 
duced into England many agges ago. There are two varieties of this species, occasioned more probably by difference of culture than by any inherent variance in the plants: one is lnown as winter and the other as spring rye.

It was formerly usual to sow rye together with an early kind of wheat. 'The harvested grain, thus necessarily intermixed, was termed meslin, from miscellanea: it also obtained the name of mungcorn, corruptly from monk-corn, because bread made with it was commonly eaten in monasteries.

With the exception of wheat, rye contains a greater proportion of gluten than any other of the cereal grains. to which fact is owing its capability of being converted into a spongy bread. It contains, likewise, nearly five parts in every hundred of ready. formed saccharine matter, and is in consequence easily convertible into inalt, and thence into beer or ardent spirit; but the produce of this last is so small, in comparison with that of malted barley, as to offer no inducement for its employment to that purpose. Rye has a strong tendency to pass rapidly from the vinous to the acetous state of fermentation, and whenever that circumstance has intervened, it would be vain to attempt either to brew or to distil it. Unmalted rye meal is mixed in Holland with barley malt, in the proportion of two parts by weight of the former, with one part of the latter, and the whole being fermented together forms the wash whence is distilled all the grain spirit produced in that country, and known throughout Europe as Hollands Geneva. 'There must, however, be soine circumstances of a peculiar nature commected with the process, as conlucted by the Dutch distillers, since no attempts made elsewhere have ever been successful in obtaining. a spirit having the same good qualities.

lige is the common hread-corn in all the sandy 
districts to the south of the Baltic Sea and the Gulf of Finland, furnishing abundance of food for the numerous inhabitants of places which, without it, must have been little better than sandy and uninhabitable deserts. In these districts it not only forms the chief article of consumption, but furnishes a material of some consequence to the export trade of the Prussian ports.

The peasantry in Sweden subsist very generally upon rye-cakes, which they bake only twice in the course of the year, and which, during most part of the time, are consequently as hard as a board.Linnæus observed a curious practice in Lapland. One part of rye and two parts of barley being mixed together, the seed is committed to the ground as soon as the earth is capable of tillage in the spring. 'The barley shoots up vigorously, ripens its ears and is reaped; while the rye merely goes into leaf without shooting up any stem, its growth being retarded by the barley, which may be said to smother it. After the barley is reaped, the rye advances in growth, and, without any farther care of the cultivator, yields an abundant crop in the following year.

'This grain, to which so many human beings are thins indebted for aliment, is subject to a disease which, when it occurs, not only deprives it of all its useful properties as food, but renders it absolutely noxious, and, it may even be said, poisonous to man. When thus diseased it is called by English farmers horned rye, and by the French ergot, from the fancied resemblance to a cock's spur of an excrescence which the grain then bears. Whenever this disease has been witnessed, it has usually happened that a wet spring has been succeeded by a summer more than ordinarily hot. 'Tissot, a French physician, bestowed much attention on this subject, and upon its melancholy consequences. It is fiom him we learn that the 
excrescence just mentioned is an irregular vegetation, which springs from the middle substance, between the grain and the leaf, growing to the length of an inch and a half, and being two tenths of an inch broad: it is of a browrish coloul.

Bread which is made of rye thus diseased has an acrid and nauseous taste, and its use is followed by spasmodic symptoms and gangrenous disorders. These effects cannot by any means be classed among imaginary evils. In 1596 an epidemic prevailed in Hesse, which was wholly ascribed to the use of horned rye. Some of the persons who had unfortunately partaken of this food were seized with epilepsy, the attacks of which, for the most part, ended fatally; of others, who became insane, few ever fully recovered the proper use of their senses; while some, who were apparently restored, were liable through life to periodical returns of their disorder.

Similar calamities were experienced in different parts of the Continent at various times, between 1648 and 1736, and these visitations have been recorded by Burghart, Hoffman, and others. In 1.709, this diseased condition of the rye occurred in a part of France to such a degree, that in consequence of it no fewer than five hundred patients were at one time under care of the surtyeons at the public hospital at Orleans. The symptoms first caine on with all the apparent characteristics of drunkenness, after which the toes became diseased, mortified, and fell off. The disorder thence extended itself up the leg, and frequently attacked the trunk, and this sometimes occurred even after amputation of the diseased limbs had been performed, with the vain hope of stopping the progress of the disorder.

'The poisonous quality of hormed rye is not exerted upon human beings alone, both insects and larger 
animals having been fatally affected by it; even thies, that merely settled casually upon the grain, have been killed by that means; and deer, swine, and different linds of poultry, upon which experiments were tried, all died miserable deaths; some in strong convulsions, and others with mortified ulcers. These circumstances must have been truly appalling by their severity and the frequency of their recurrence. Few evils, however, are wholly of an unmixed character, and this one is not of the number. Ergot of rye, which was formerly productive of so much misery, has since found admission as a medicine into our pharmacopæias, and is now, in the hands of skilful and honest practitioners, rendered subservient to the interests of society. Horned rye is of very rare occurrence in Great Britain.

Barlex-Hordeum-is, next to wheat, the most important of all the cereal grains which are now cultivated in Great Britain. Its use as bread-corn has very much diminished of late years in this country, while its employment for the production of stimulant liquids, has, on the contrary, materially increased.

The Egyptians have a tradition, from which they believe that of all the grains barley is that one which was first used for the sustenance of man. Their histories assert that a knowledge of the art of cultivating this grain was imparted to their ancestors by the groddess Isis, who, having discovered the plant growing wild in the woods, instructed men how to cultivate it, so as at once to increase the quantity and improve the quality of its produce.

Uninstructed people are generally prone to refer to stipernatural agency, the origin of all events for which they are otherwise unable to account. Dr Franklin has related, as coming from the lips of a chief of the Susquehannah Indians, a tradition very 


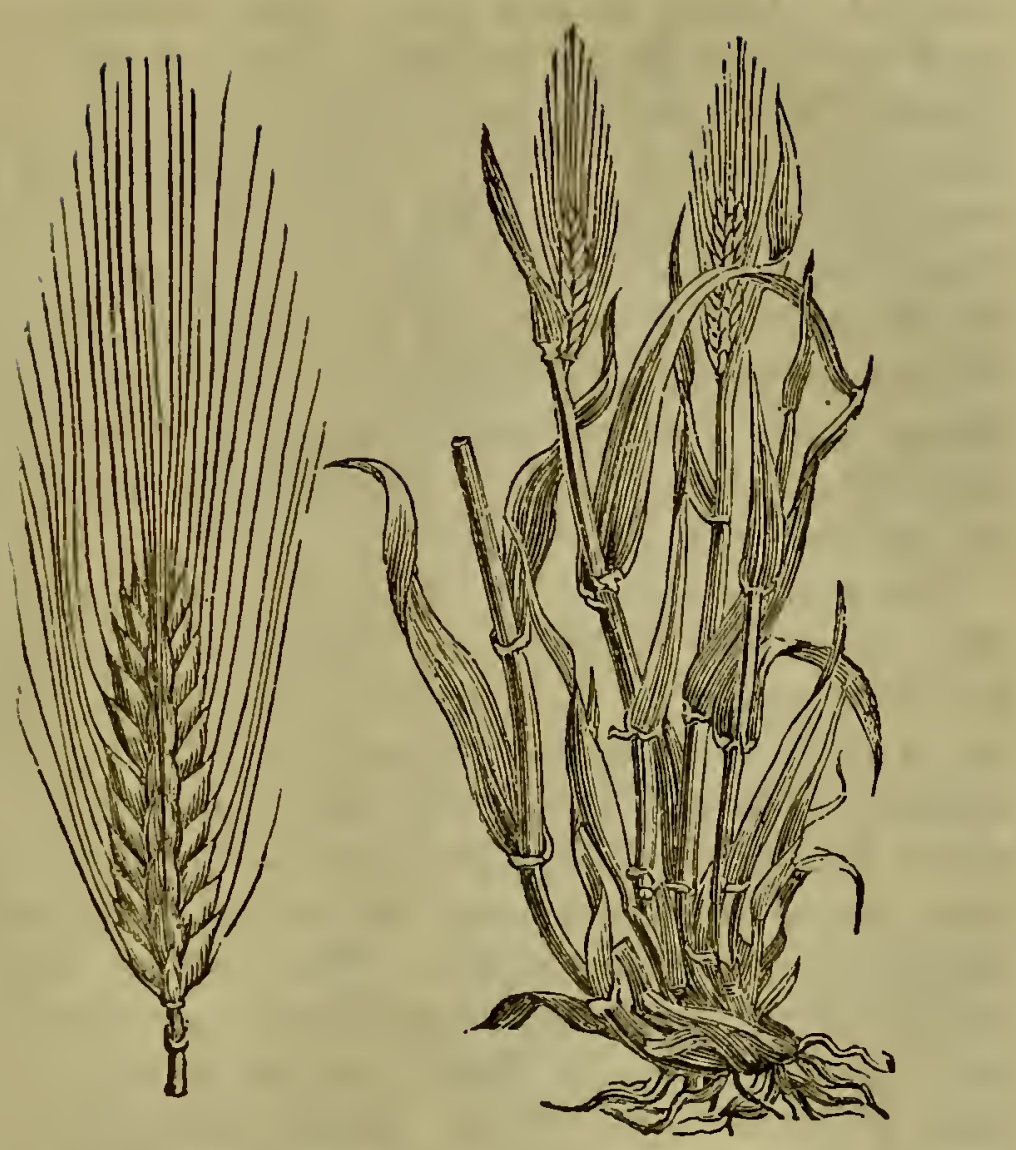

Ear and Plant of Common Spring Barley.

similar lo that of the Egyptians. "In the beginning," suid this child of nature, " our fathers had only the flesh of animals to subsist on; and if their hunting was unsuccessful they were starving. Two of our young hunters having killed a deer, made a fire in the woods to broil some part of it. When they were about to satisfy their hunger, they beheld a beautiful young woman descend from the clouds, and seat herself on that hill which you see yonder among the blue mountains. They said to each other, It is a spirit that perhaps has sinelt our broiling venison, and wishes to eat of it; let us offer some to her. They presented her with the tongue; she was pleased with the taste of it, and said, Your kindness shall be re- 
warded. Come to this place after thirteen moous, and you shall find something that will be of great benefit in nourishing you and your children to the latest generations. They did so, and to their great surprise found plants they had never seen before, but which from that ancient time have been constantly cultivated among us to our great advantage. Where her right.-hand had touched the ground, they found maize; where her left-hand had touched it, they found kidney-beans; and where she had seated herself they found tobacco."

The native country of barley is as little lnown as that of wheat. Some travellers have mentioned it as being produced in a wild state in distant parts of the world; but there is reason for believing that all statements to this effect have been founded in error, since the hardiest varieties of the cultivated grain have never yet been seen to propagate themselves during two following years. The seed of cultivated barley, when chance-sown, will indeed produce plants; but the grains which these bear are rarely, if ever, seen to germinate. Some grasses which have been placed by botanists in the same genus with barley, bear to it a strong outward resemblance, yet none of them can, by any degree of culture, be brought into use as human food, nor indeed be made to exhibit any marked improvement. One of these grasses, the hordeum murinum of Linnæus, known commonly as wall-barley, bears the nearest resemblance of any to the cultivated plant.

In one respect barley is of more importance to mankind than wheat. It may be propagated over a wider range of climate, bearing heat and drought better, growing upon lighter soils, and coming so quickly to maturity, that the short northern summers which do not admit of the ripening of wheat, are 
yet of long enough duration for the perfection of barley. It is the latest sown, and the earliest reaped of all the summer grains. In warm countries, such as Spain, the farmers can gather two harvests of barley within the year, one in the spring from wintersown grain, and the other in autumn from that sown in summer. Barley sown in $\mathbf{J}$ une is commonly ready for the sickle in three months from the time of the seed being committed to the ground; and in very northern climates the period necessary for its growth and perfection is said to be of still shorter duration. Linnæus relates, in his tour in Lulean Lapland, that on the 2Sth of July he observed the commencement of the barley harvest, and although the seed was sown only a few days before Midsummer, that the grain was perfectly ripe, the whole process having thus occupied certainly not longer than six weeks.

The property of not requiring moisture admirably fits barley for propagation in those northern countries where the duration of summer is limited to a very few months in the year, and where wet is of very rare occurrence from the time when the spring rains are over, at the end of May or the beginning of June -after which period the seed-time commencesuntil the autumnal equinox, previous to which the harvest is reaped.

So hurtful is excessive moisture to the plants, that even heavy dews, if of frequent occurrence, are found injurious. Wet is detrimental at all periods; but the mischief is exhibited in a very different manner, according as it occurs before or after the formation of the ear. If cluring the former stage, the leaves, as already mentioned, will become yellow and sickly, and the ears will probably not make their appearance; whereas if these should already have been formed and completely filled when visited by rain, the grain 


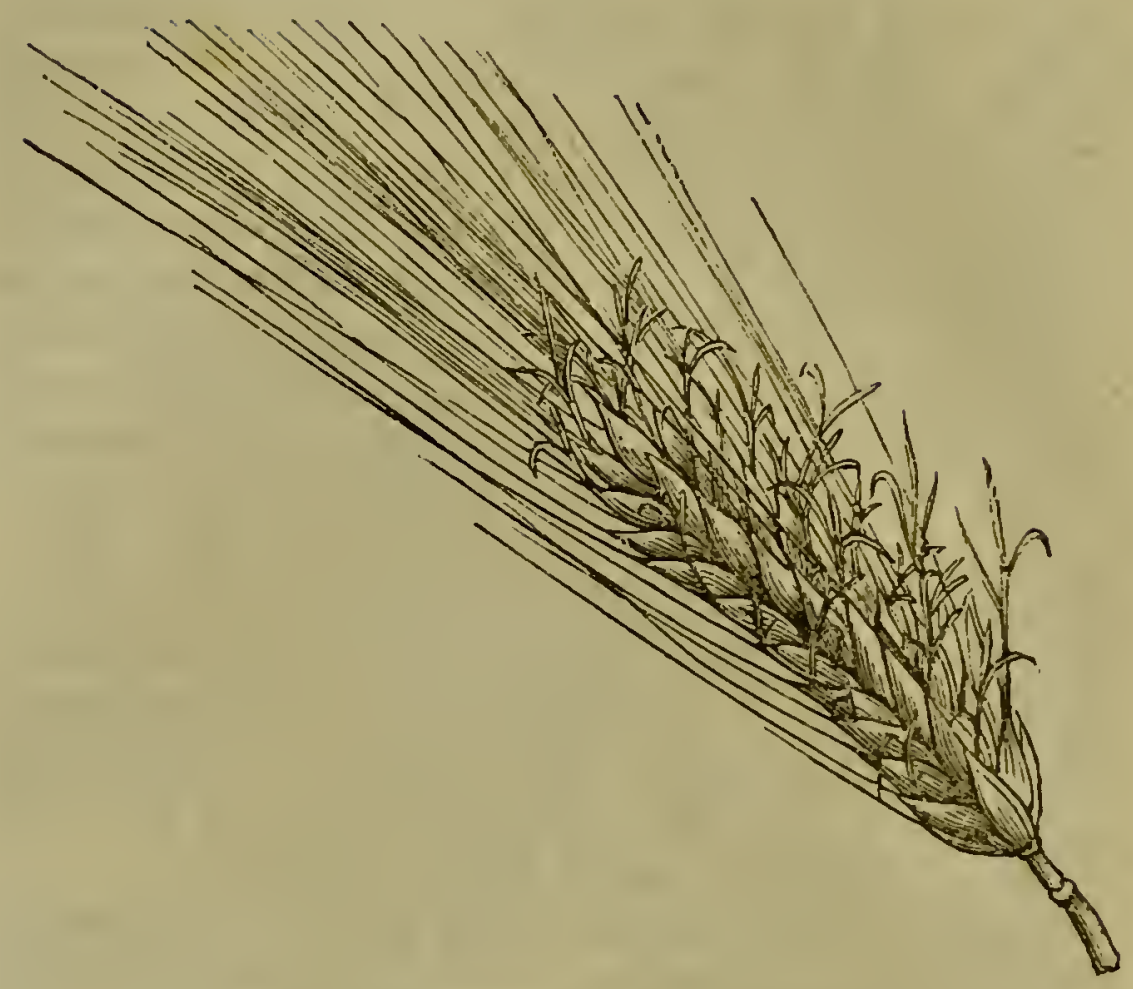

Premature germination of an ear of Barlej.

vill spront in the ear, and should the weather which follows be warm and genial, this growth will be so rapid that the ears will put on the appearance of tufts of grass. Barley is besides very liable to be beaten down by rain and to lodge; and should this occur after the filling of the ear, germination of the grains will take place to such a degree that the first growth will be coinpletely rotted and destroyed by the second. Gentle showers, however, if of short continuance, and if they do not happen either very early after the plant is above the ground, or during the time of blooming, or when the ear is full, are rather beneficial than hurtful. It is worthy of remark that the very quality which renders burley so precarious a crop in unsettled climates, imparts to it likewise its chief value. The facility with which 
the grain is made to germinate is favourable to the operation of converting it into malt, which is, in fict, simply the process of germination induced and carried forward up to and not beyond the point when the maximum quantity of saccharine matter is developed in the grain.

In its composition barley differs materially from wheat: it contains more starch, far less gluten, and about seven parts in a hundred of saccharine matter ready formed, which latter constituent wheat does not possess previous to germination.

Botanical writers enumerate four distinct species of barley: of these there are many varieties produced by differences of soil, climate and culture.

SPRING BarLeY-Hordeum vulgare-is the kind most commonly cultivated in England. Of this species farmers distinguish two sorts; one the common, and the other the rath-ripe barley. These, in fact, are the same plant, the latter being a variety occasioned by long culture upon warm gravelly soils. If seeds of this kind are sown in cold or strong land, the plants will ripen nearly a fortnight earlier than seeds taken from other strong land; but this holds good only during the first year. This variety is said in extraurdinary seasons to have been returned to the barn within two months in this country. Siberian barley, another variety, was brought into culture in the year 1765, by Mr. Halliday, who received a very small portion out of about a pint of seed which had been presented by a foreign nobleman to the London Society for the Encouragement of Arts. This variety exhibits, on first coming up, a broader blade, and is of a deeper green than common barley. The ears are shorter, containing only from five to nine grains in length, while the common sort has from nine to thirteen grains. Siberian barley arrives at maturity about a fortnight earlier than other kinds. 


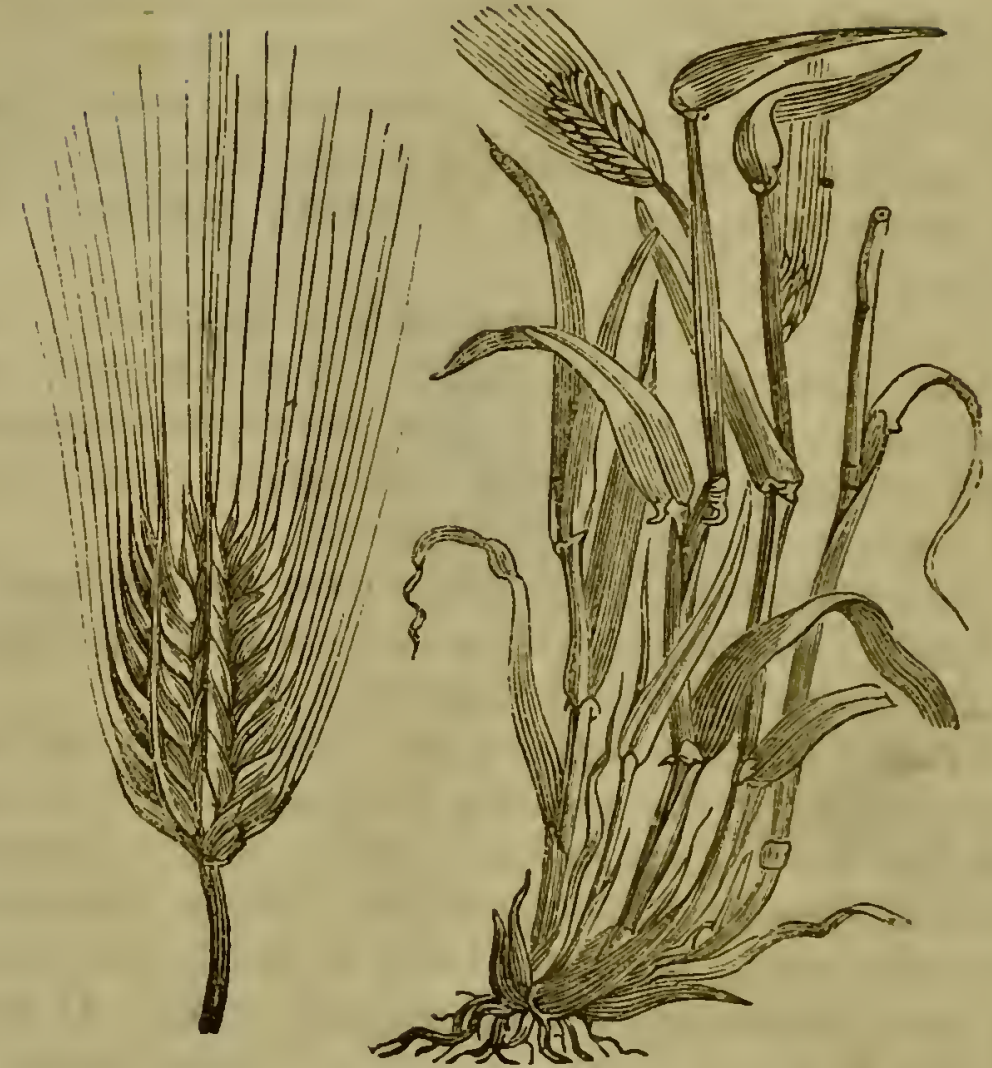

Ear and Plunt of Winter Barley.

Winter or Square Barley, called also Bear, or Big-Hordeum hexastichon-is the second species, $(\beta)$. This is rarely cultivated in the southern parts of England; but in the northern counties and in Scotland is very generally sown, being a much more hardy plant than spring barley. The grains are large and plump, and the spike is thicker and shorter than the last-described species, being seldom longer than two inches, and square. Maltsters in the sonthern division of the kingdom are of opinion that this barley does not answer their purpose so well as that more usually cultivated ainong them, while in scotland this idea is considered to be an unfoundas prejudice.

The number of grains in each ear is greater than 
are found on spring barley in the proportion of three to two, one ear frequently yielding forty or more grains. These are disposed in six rows, two of these being on each of two sides, and one row on each of the other sides.
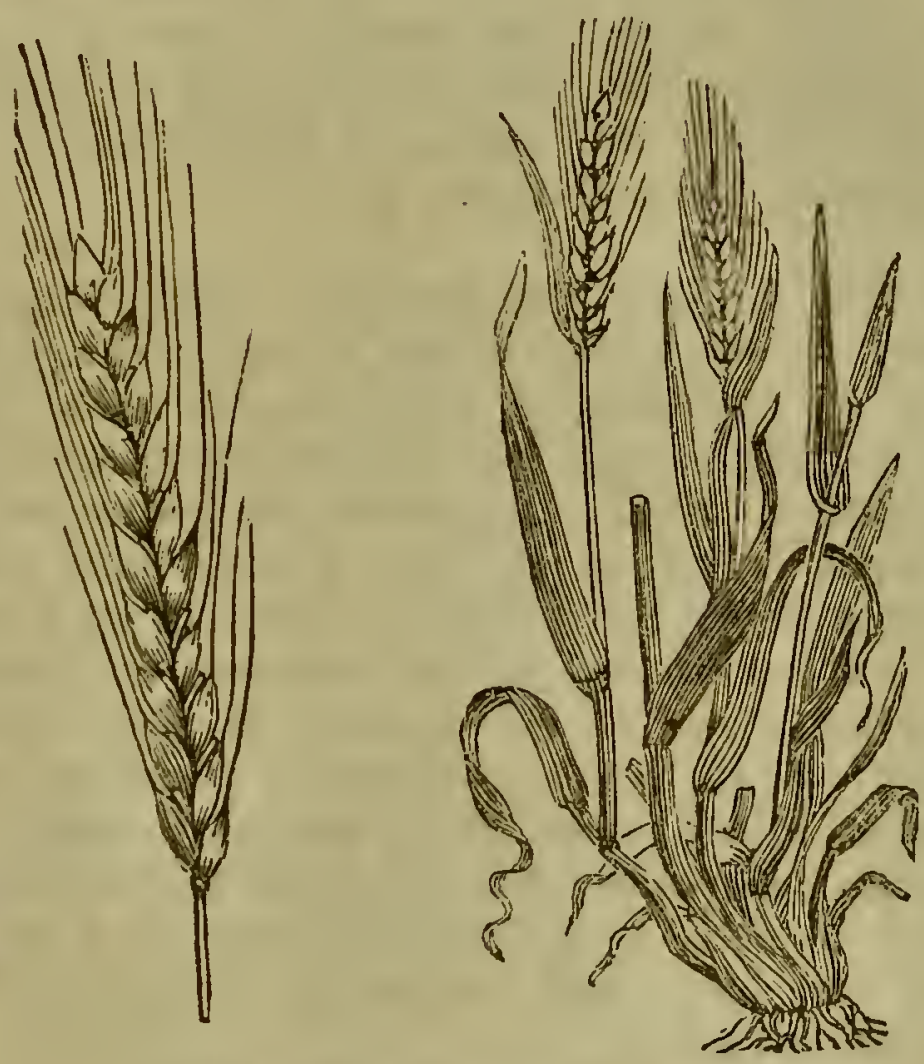

Ear and Plant of Two-rowed Barley.

Long-eared Barley, sometimes called TwoROWED BARLEY-Hordeum distichon-is partially cultivated in every part of England, and is a very good sort. Some persons object to it, that the ears being long and heavy, it is more apt to lodge than other kinds. The grains are regularly disposed in a doible row, lying over each other like tiles on a roof, or like the scales of fishes. The ear is somewhat flatted, being transversely greater in breadth than in thickness. The husk of the grain is thin, and its malting qualities are excellent. 
Sprat or Battledore Barley-Hordeum zeocriton-has shorter and broader ears than either of the sorts already described; its awns or beards are longer, so that birds cannot so easily get. out the grains, which also lie closer together than those of other kinds. Sprat barley seldom, if ever, grows so tall as either of the other species, and its straw is not only shorter, but coarser, so as to render it not desirable for use as fodder.

It was formerly the universal practice in this country to sow barley in the spring. The end of March or beginning of April was the more usual time, but the sowing was sometimes deferred to the beginning of May. The practice in this respect has somewhat varied of late, and a more early season has been chosen for sowing, so that it is not uncommon for the process to be performed in January, under the idea that the produce in such cases is greater. In the county of Norfolk, where the cultivation of barley is carried forward very extensively, anl with the greatest skill, the farmers were formerly gruided in their choice of seed time by a maxim which had long been handed down to them from father to son :-

"When the oak puts on his gosling grey,

"l'is time to sow barley night and day;"

neaning, that when the oak exhibits the grey appearance which accompanies the bursting of its buds, a few days preceding the expansion of the leaves, it is then improper to lose any time in getting their seed-barley into the ground. The budding and leafing of the birch trees is, in Siveden, considered an indication of the proper time for barley-sowing. In different countries there are, of course, different natural guides in the operations of husbandry; but un intelligent and observing farmer, in every country, 
wiil not fail to regard those which have been sanc tioncd by experience; while the agriculturist, who is bound by a servile adherence to particular months and even weeks for his operations, will unwisely treat as old saws such relics of the practical skill of our forefathers as the lines we have quoted. Linnæus, the great Swedish naturalist, constantly exhorted his countrymen to observe at what time each tree unfolds its buds and expands its leaves. In our own country, Mr. Stillingfleet, an eminent naturalist, made a series of very accurate observations upon this interesting appearance of the spring. A farmer who would keep a calenclar of Nature in the same manner for a few years, and at the same time register his days of sowing and the issue of his harvest, would secule, no doubt, a valuable collection of rules for his guidance, peculiarly applicable to the exact circumstances of situation and soil amidst which he pursues his calling *

The produce of barley, according to the quality of the soil, is from three to four quarters to the acre. A larger produce is not unfrequent; and even so much as seven quarter's have been reaped in very favourable seasons and situations.

'The average weight of a Winchester bushel of' barley is between fifty and fifty-one pounds, and the same measure of bigg weighs but little more than forty-six pounds. It is very seldom that the former is found to weigh beyond fifty-two, or the latter beyond forty-eight pounds to the bushel. The average length of a grain of barley, taking the mean of many thousand measurements, is 0.345 inch, while that of a grain of bigg is 0.3245 inch. The medium length of these two species gives, therefore, as nearly asi

* See Howitt's Book of the Seasons, p. 99. 
possible one-third of an inch, which agrees with the lowest denomination or basis - the barleycorn of our linear measure *.

The purposes to which barley is principally applied in this kingdom are those of brewing and distilling. Some portion is still brought nore directly into consumption as human food; but this portion, for the most part, now undergoes the previons process of decortication (removal of the bark), whereby it is converted into what is called Scotch or pearl barley. This grain, in its raw state, is also used to some extent for feeding poultry and fattening swine, for which latter purpose it is commonly converted into meal. The ancients were accustomed to feed their horses upon barley, as is the case among the Spaniards to the present day; and Pliny relates (Book xviii. c. 7,) that the Roman gladiators were called Hordearii, from their use of this grain as food.

The use of barley in the preparation of a fermented liquor dates from the very remotest times. The invention of this preparation is ascribed to the Egyptians by ancient Greek writers, one of whom, Dioscorides, attributes the first cultivation of barley to the same people, under the guidance of Osiris; while Herodotus informs us that the people of Egypt, being without vines, made their wine from barleyt. Pliny, in his Natural History, gives the Egyptian name of this liquid as Zythum $\ddagger$. An intoxicating liquor is still made from this grain, both in Egypt and Nubia, to which the name of bouzah is given. This is of very general consumption among the lower rank of people. Burckhardt observed another use to which barley is applied in the latter

* Supp. Encjc. Brit., Ar!. Brewing.

+ Lib. ii. cap. 78 . \pm Nat. Hist. lit xaii. c. 25. 
country. The green ears are boiled in water, and served up to be eaten with milk. Among the Greeks beer was distinguished as barley wine, a name which sufficiently identifies the intoxicating property of the liquid, and the material whence this was drawn. From a passacre in Tacitus we learn that the German people were, in his day, acquainited with the process of preparing beer from malted grain; and Pliny describes a similar liquid under the name of Cerevisia, an appellation which it retained in Latin books of more recent date. It farther appears that malt liquor has formed an article of manufacture and consumption in this country for a pericd at least coeval with the time of Tacitus; but we do not know whether any one kind of grain was exclusively employed in its preparation, or whether wheat and barley were not used for the purpose, either indiscriminately or in conjunction.

The general drinks of the Anglo-Saxons were ale and mead: wine was a luxury for the great. In the Saxon Dialogues preserved in the Cotton Library in the British Museum, a boy, who is questioned upon his habits and the uses of things, says, in answer to the inquiry what he drank- "Ale if I have it, or water if I have it not." He adds, that wine is the drink " of the elders and the wise." A le was sold to the people, as at this day, in houses of entertainment; "for a priest was forbidden by a law to eat or drink at ceapealethetum, literally, places where ale was sold*." After the Norman conquest, wine became more commonly used; and the vine was extensively cultivated in England. 'The people, however, held to the beverage of their forefathers with great pertinacity; and neither the juice of the grape nor of the apple were ever general favourites. 'The 
wassail song of the fifteenth century, whose burden was-

"Bring us home good ale,"

has been quoted in another volume of this work ${ }^{*}$. "The old ale knights of England," as Camden calls the sturdy yeomen of this period, knew not, however, the ale to which hops in the next century gave both flavour and preservation. Hops appear to have been used in the breweries of the Netherlands in the beginning of the fourteenth century. In England they were not used in the composition of beer till nearly two centuries afterwards. It has been affirmed that the planting of hops was forbidden in the reign of Henry VI.; and it is certain that Henry VIII. forbade brewers to put hops and sulphur into ale + . In the fifth year of Edward VI., the royal and national taste appears to have changed; for privileges were then granted to hop-grounds. Tusser, in his five hundred points of good husbandry, printed in 155\%, thus sings the praises of this plant:-

"The hop for his profit I thus do exalt,

It strengtheneth drink and it flavoureth malt;

And being well-brewed long kept it will last,

And drawing abide, if ye draw not too fast."

In the reign of James $\mathbf{I}$. the plant was not sufciently cultivated in England for the consumption; as there is a statute of $160 \mathrm{~S}$ against the importation of spoilt hops. In 1830, there weit 46,727 acres occupied in the cultivation of hops in Great Britain.

Of barley, there are above thirty million bushels annually converted into malt in Great Britain; and more than eight million barrels of beer, of which four-fifths are strong beer, are brewed yearly. 'This is a consumption, by the great body of the

* 'Timber Trees and Fruits,' p. 255.

†'Archeologia,' rol. iii. 
people, of a favourite beverage which indicates a distribution of the national wealth, satisfactory by comparison with the general poverty of less advanced jeriods of civilization in our own country, and with that of less industrious nations in our own day.

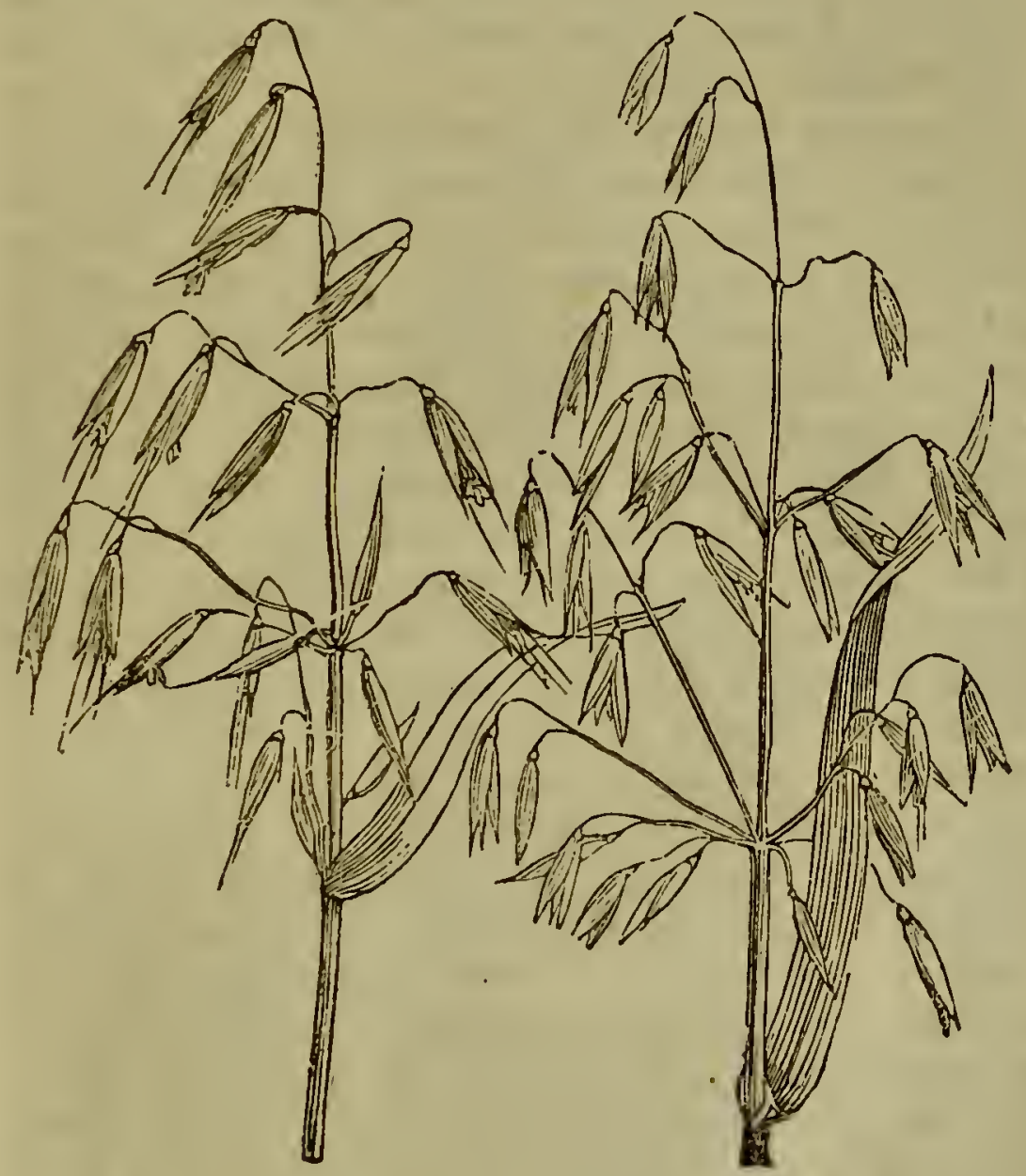

Common bearied Oats.

Common Oats.

OAts-Avena.-This grain is held to have had its origin in a more northern climate than any other of the cereal plants, since it cannot be cultivated with advantage in the lower latitudes of the temperate zone. In the south of England, even at high elevations, the produce is inferior in quality to that which is obtained in more northern districts. 
The time and mode of the introduction of oats into England are equally unlinown, and some writers have expressed their opinion that this grain is indigenous with us. One thing appears sufficiently clear - the varieties cultivated here, at this time, have all been originally imported from different parts of the continent of Europe, the names of which countries they are made to bear.

This grain is extremely serviceable to man, possessing the advantage of growing upon soils and in situations where neither barley nor wheat can be raised. It is the hardiest of all the cereal grains that are cultivated in Great Britain. In its outward structure the oat plant differs from wheat and barley in the form of the ear. This in oats is not a spike with a single rachis, but a panicle, resembling in some degree the stem and branches of a pine. While young and light, these branches arrange themselves round the centre of the stem, but as they advance towards maturity and acquire weight, they generally bend over on one side. By this arrangement the air and light are enabled to visit, and the rain to wash, each individual grain, so that any lodgment of the larvæ of insects or the seeds of parasitical plants is prevented. The grains being pendent, and having the open extremities of their chaff towards the earth, are effectually defended from the lodgment of rain within, an advantage which does not attend the growth of wheat or barley; and those grains are consequently liable to diseases from which oats are exempted. Drought and heat are unfavourable to this grain, which under such circumstances becomes husky and tasteless, containing but little farinaceous matter, and that little being of if ferior quality.

The Avena sutiva, which species is commonly cultivated, has several varieties. The most remarkable 
of these are the black or long-bearded oat; the white oat; red oat; and the naked oat, or pilcorn.

The best variety of oats produced in Great Britain is unquestionably the potato oat. Of this kind the first plants were discovered growing accidentally on a heap of manure in company with several potato plants, the growth of which was equally accidental; and it is to this circumstance that the distinctive name of this variety is owing. To an occurrence thus purely accidental, and which might well have passed unnoticed, we are indebted for decidedly the best and most profitable variety we possess of this useful grain. It requires to be sown on land in a good state of cultivation, when the grains on ripening will be found large, plump, and firm, often double, and of a quality which ensures for the corn a higher price in the market than is given for any other variety. It also yields an abundant produce of straw. Potato oats form almost the only kind now cultivated in the north of England and the lowland districts of Scotland.

The seed-time of oats is almost universally in March and April. The grain is scattered broad-cast in the large proportion of from four to six bushels to the acre, the medium produce of which is from forty to fifty bushels.

The nutritive quality of oats is smaller in a given weight than that of any other cereal grains. In oats of the best quality it does not exceed 75 per cent., while that of wheat is $95 \frac{1}{2}$ per cent. The very small proportion of saccharine matter ready formed in oats renders it very difficult and unprofitable to, convert this grain into malt. Brewers at the present day do not employ cats in the preparation of any kind of beer; in former times, when the public taste was different from what it is at present, a drink called mum was manufactured for sale, and in the 
preparation of this liquid, oatmeal was employed. The principal use now made of oats in the southern division of the kingdom is the feeding of horses, for which purpose the grain is admirably adapted; a large quantity of this grain is farther consumed in the fattening of poultry. 'The deer of Henry VIII. were fed with oats. In the Privy Purse Expenses of this king (published by Mr. Nicolas), is the following entry:- " Paied to the keper of Grenewiche parke for xiiij lode of hey And for vi lode of Oots, for the relief of the dere there, And for the carriage thereof, vjli. ijs. viiid." Oatmeal, prepared by various processes of cooking, composes at this day a large proportion of the food of the inhabitants of Scotland, and particularly of the better-fed portion of the labouring classes. Oaten cakes, too, are much used in Lancashire.

The wild oat, which is certainly indigenous to this country, is found to be a very troublesome weed. It is said that the seed will remain buried under the soil during a century or more without losing its vegetating power, and that ground which has been broken up after remaining in grass from time immemorial, has produced the wild oat abundantly.

It is a curious fact that the vital principle of some vegetables will lie dormant, under certain circumstances, for long and indefinite periods without being extinguished. Seeds have been made to grow in this country which were brought fiom Herculaneum, after having been buried for more than seventeen centuries, but which, having during all that period been deprived of air, had been prevented from vegetating. The necessity that exists for the access of air in some degree, in order to promote or set in action vegetable life, has been shown by the experiments of several ingenious men, who, having placed seeds under circumstances otherwise favomable to their 
growil, in the exhausted receiver of an air-punıp, ascertained that they were thereby prevented fiom exhibiting any sign of vitality.

'THe Anglo-Saxon monks of the abbey of St. Edmund, ill the eighth century, ate barley bread, because the income of the establishment would not admit of their feerling twice or thrice a day on wheaten bread*. 'The Engiish labourers of the southern and mid!and connties, in the latter part of the eighteenth century, refiused to eat bread made of one-third wheat, onethird rye, and one-third barley, saying, that " they had lost their rye-teetl $\uparrow . "$ It would be a curious and not unprofitable inquiry, to trace the progress of the national taste in this particular. It would show that whatever privations the English labourer may now endure, and whatever he has endured for many generations, he has succeeded in rendering the dearest kind of vegetable food the general food of the country; this single circumstance is a security to him against those suffering's from actual famine which were familiar to his fore-elders, and which are still the objects of continual apprehension in those countries where the labourers live upon the cheapest substances. Warges cannot be depressed in such a manner as to deprive the labourer, for any leugth of time, of the power of maintaining himself upon the kind of food which habit lias made necessary to him; and as the ordinary food of the English labourer is not the very cheapest that can be got, it is in his power to have recourse for a while to less expensive

* Dugdale's Monasticon, quoted in Turner's History of the Anglo-Saxons, vol. iii. p. 25 .

$f$ Annals of Agriculiture, quoted in Eden's History of the Poor vol. i. p. 520. 
articles of subsistence should any temporary scarcity of food or want of employment deprive him of his usual fare, -an advantage not possessed by his Irish fellow-subjects, to whom the failure of a rice or potato crop is a matter not of discomfort merely, but of absolute starvation. But the materials for such an inquiry are very imperfect; - and although the assiduous devotion of an antiquary might collect many valuable illustrations from neglected records, it is evident that in the present instance we can do little more than put togrether a few scattered facts, which the diligence of previous inquirers has already collected.

Pierce Plowman, a writer of the time of Edward III. says, that when the new corn began to be sold,

- Woulde no beggar eat bread that in it heanes were, But of coket, and clemantyne, or else clene wheate*."

This taste, however, was only to be indulged "when the new corn began to be sold ;" for then a short season of plenty succeeded to a long period of fasting; the supply of corn was not equalized throughout the year by the provident effects of commercial speculation. The fluctuations in the price of grain, experienced during this period, and which were partly owing to insufficient agricultural skill, were su.lden and excessive. On the securing of an abundant harvest in 1317, wheat, the price of which had been so highl as $80 s$., fell immediately to $6 s .8 d$. per quartert. The people of those days seem always to have looked for a great abatement in the price of grain on the successful gathering of every harvest; and the inordinate joy of our ancestors at their harvest-home -a joy which is faintly reflected in our own timesproceeded, there is little doubt, from the change which the grathering of the crops produced, from

* See the Athenæum, a weekly literary parer, leb. 3, 1832. t Stow. 
want to abundance, from fannine to fulness. That useful class of men who employ themselves in purshasing from the producers that they may sell agais to the consumers, was then unknown in England. Immediately after the harvest, the people bought their corn directly from the farmers at a cheap rate, and, as is usual under such circumstances, were improvident in the use of it, so that the supply fell short before the arrival of the following harvest, and prices arvanced out of all proportion.

In a valuation of Colchester, in 1296, almost every family was provided with a sinall store of barley and oats, usually about a quarter or two of each. Scarcely any wheat is noticed in the inventory, and very little rye*. The corn was usually ground at home in a handmill, or quern; although wind and water mills were not uncommon. The general use of the latter machines was probably prevented by the compulsory laws by which the tenant was under an obligation to grind his corn at the lord's mill; and, therefore, to evade the tax, called multure, the labour of the handmill was endured. In Wicliff's translation of the Bible we find a passage in the $24 \mathrm{th}$ chapter of St. Matthew thus rendered:- "Two wymmell schulen (shall) be gryndynge in one querne." Harrison, the historian, two centuries later, says, that his wife ground her malt at home upon her quern. In the present authorized version of the Bible, published more than half a century after Harrison, the word "quern" yields to "mill." By that time, probably, the trades of a miller and a baker were freely exercised; and the lord's mill and the corporation oven had been superseded by the competition growing out of increasing capital and population.

'The Reformation, and the discovery of $\Lambda$ merica,

* For some particulars of another valuation of this town. nee Rights of Industry-Capital and Labour, p. 101. 
were events that had a considerable influence upon the condition of the great body of the people in England. The one drove away the inmates of the mo nusteries, from whence the poor were accustomed to receive donations of food; the other, by pouring the precious metals into Europe, raised the price of provisions. In the latter half of the sixteenth century, wheat was three times as dear, both in England and France, as in the former half. The price of wheat, upon an average of years, varied very little for four centuries before the metallic riches of the New World were brought into Europe; upon an average of years it has varied very little since** The people of the days of Hewry VIII. felt the change in the inoney-value of provisions, although the real value remained the saine; and they ascribed the circumstance to the dissolution of the monasteries. - There is an old song of that day in the Somersetshire dialect, which indicates the nature of the populas error :-

"I'll tell thee what, good vellowe, Before the vriars went hence,

A bushel of the best wheate

Was zold for vourteen pence;

And vorty eggs a penny

That were both good and newe;

And this, I say, myself have scen,

And yet I am no Jewe t.'

When wheat was fourteen-pence a bushel, it was probably consumed by the people, in seasons of plenty, and soon after harvest. During a portion of the year there is little doulst that the English labourers had better food than the French, who, in the fifteenth century, were described by Fortescue thus:- "Thay drynke water, thay eate apples, with

- Sce Storch, Cours d’Economie Politique, tome i. p. 177. + Reliques of Antient Poetry. 
bred right brown, made of rye." Locke, travelling in France, in 1678, says of the peasantry in his journal, "Their ordinary food, rye bread and water*." 'The English always disliked what they emphatically termed, " changing the white loaf for the brown." They would have paid little respect to the example of Masinissa, the African general, who is described by Polybius as eating brown bread with a relish at the door of his tent. Their dislike to brown bread in some degree prevented the change which they proverbially dreaded. In the latter part of the sixteenth century, however, this change was pretty general, whatever was the previous condition of the people. Harrison says, speaking of the agricultural population, "As for wheaten bread, they eat it when they can reach unto the price of it, contenting themselves, in the mean time, with bread made of oates or barlie, a poore estate, God wot!" In another place, he says, "The bread throughout the land is made of such graine as the soil yieldeth; nevertheless, the gentilitio commonlie provide themselves sufficiently of wheate for their own tables, whilst their household and poore neighbours, in some shires, are inforced to content themselves with rie or barlie." Harrison then goes on to describe the several sorts of bread made in England at his day, viz. manchet, cheat, or wheaten bread; another inferior sort of bread, called ravelled, and lastly, brown breadt. Of the latter there were two sorts: "One baked up as it cometh from the mill, so that neither the bran nor the floure are any whit diminished. The other hath no floure left therein at all; and it is not only the worst and weakest of all the other sorts, but also

* Lord King's Life of Locke.

+ See Percy's Preface to the Northumberland Flonsehols Pronk, Nicolas's edit. p. xiv. 
appointed in old time for servants, slaves, and the inferior kind of people to feed upon. Here. unto, likewise, because it is drie and brickle in the working, some add a portion of rie-meale in our time, whereby the rough drinesse thereof is somewhat qualified, and then it is named mescelin, that is, bread made of mingled corne." In the household book of Sir Edward Coke, in 1596, we find constant entries of oatmeal for the use of the house, besides "otmell to make the poore folkes porage," and "rie-meall, to make breade for the poore." The household wheaten bread was partly baked in the house and partly taken of the baker. In that year it appears, from the historian Stow, that there was a great fluctuation in the price of corn; and he particularly mentions the price of oatmeal, which would indicate that it was an article of general consumption, as well in a liquid form, as in that of the oat-cakes of the north of England.

In l'626, Charles I., upon an occasion of subjecting the brewers and maltsters to a royal license, declared that the measure was "for the relief of the poorer sort of his people, whose usual bread was barley; and for the restraining of innkeepers and victuallers, who made their ale and beer too strong and heady." The grain to be saved by the weakness of the beer was for the benefit of the consumers of barley-bread.

At the period of the Revolution (1689) wheaten bread formed, in comparison with its present consumption, a sinall proportion of the food of the people of England. The following estimate of the then produce of the arable land in the kingdom tends to prove this position. 'This estimate was made by Gregory King, whose statistical calculations have generally becu considered entitled to credit. 
Bushels.

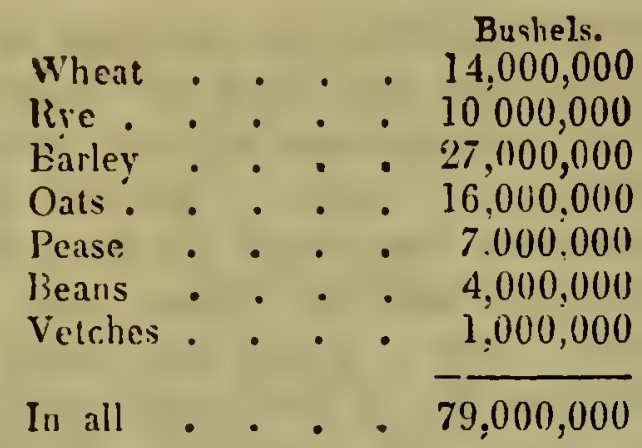

At the commencement of the last century wheaten bread became much more grenerally used by the labouring classes, a proof that their condition was improved. In 1725, it was even used in poorhouses, in the southern counties*. The author of "Three Tracts on the Corn 'Trade," published at the beginning of the reign of George III., says, "It is certain that bread made of wheat is become much more grenerally the food of the common people since 1689. than it was before that time; but it is still very far from being the food of the people in general." He then enters into a very curious calculation, the results of which are as follow: "The whole number of people is $6,000,000$, and of those who eat

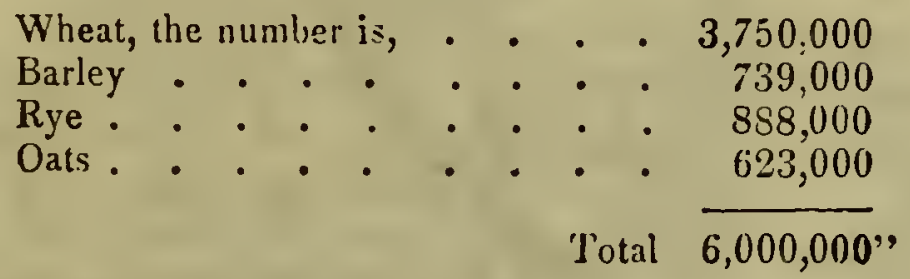

This calculation applies only to England and Wales. Of the number consuming wheat, the proportion assigned to the northern counties of York, Westmoreland, Durham, Cumberland, and Northumberland, is only 30,000. Eden, in his History of the Poor, says, "About fifty years ago (this was written in 1797), so small was the quantity of wheat used in the county of Cumberland, that it was only

- Eden, vol. i. p. 562. 
a rich family that used a peck of wheat in the course of the year, and that was used at Christmas. The usual treat for a stranger was a thick oat-cake (called haver-bannock) and butter. An old labourer of eighty-five remarks that when he was a boy he was at Carlisle market with his father, and wishing to indulge himself with a penny loaf made of wheat flour, he searched for it for somne time, but could not procure a piece of wheaten bread at any shop in the town."

At the time of the Revolution, according to the estimate of Gregory King, 14,000,000 bushels of wheat were grown in England. In 18:28, according to the estimate of $\mathrm{Mr}$. Jacob, in his Tracts on the Corn Trade, 12,500,000 quarters, or 100,000,000 bushels, were grown. 'The population of England at the Revolution was under five millions, so that each person consumed about three bushels annually. The population, at the present time, is under fifieen millions, so that each person consumes about seven bushels annually.

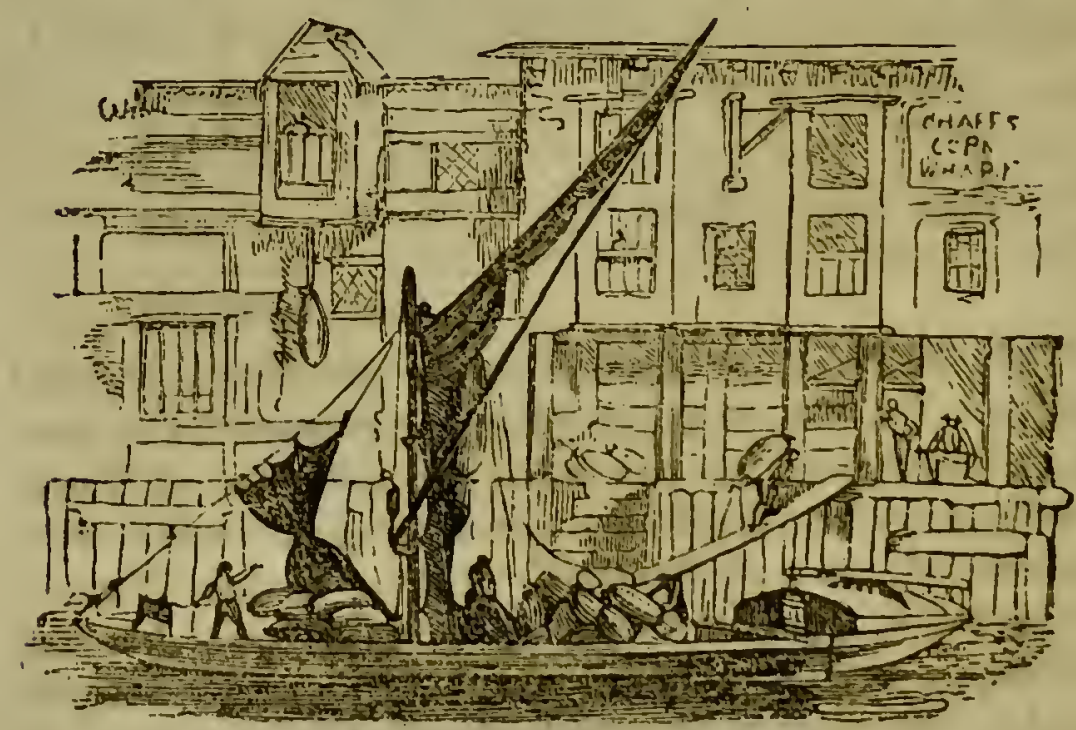

Thames Corn-Barge. 


\section{Chapter. IV.}

The principal cereal plants which cannot be profitabiy cultivated in Great Britain, but upon which the inhabitarts of other countries depend for subsistence in even a greater degree than the English peasantry depend npon the supply of wheat, are rice, maize, and millet. The seeds of these plants are less palatable than wheat, and less nutritious than that or any other of the cerealia already described: the chief cause of this last mentioned inferiority appears to be the absolute absence of gluten from their composition.

The three grains just mentioned will be treaten of in the order wherein they are here set down, which is likewise the order of their importance, considered with reference to the number of hunan beings who draw from them their sustenance.

RICE-Oryza sativa. This is a panicled grass, bearing, when in ear, a nearer resemblance to barley than to any other of the corn-plants grown in England. The seed grows on separate pedicles springing from the main stalk; each grain is terminated with an awn or beard, and is inclosed in a rough yellow husk, the whole forming a spiked panicle. The stalk is not unlike that of wheat, but the joints are more numerous. The farina of rice is almost entirely composed of starch, having little or no gluten, and being without any ready formed saccharine matter. The outer husk clings with great tenacity to the grain, and is only to be retached from it by passing the rice 
between a pair of mill-stones, placed at such a dislance from each other as shall serve to remove the husk by friction, without crushing the grain. 'This is besides enveloped by a thin pellicle, which for the most part is rubbed off by trituration in large mortars, with pestles weighing from two to three hundred pounds.
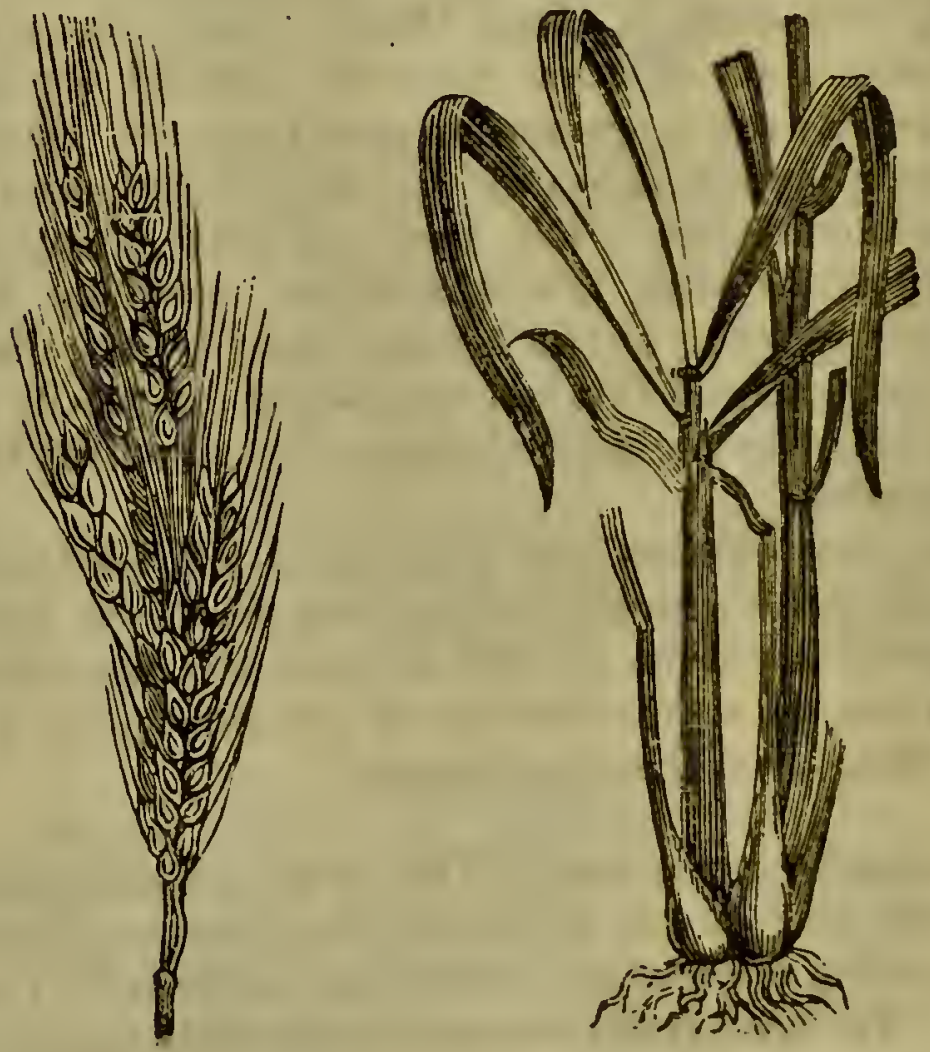

Ear and Plant of Rice.

There is little reason for doubting that this grain is of A siatic origin. From the earliest records it lats formed the principal, if not the only food of the great mass of the population on the continent and islands of India and throughout the Chinese smpire.

The introduction of rice as an object of cultivation 
in America is of very modern occurrence. The author of a work ' On the importance of the British Plantations in America,' which was published in London during the year 1701, has recorded, as a circumstance then recent, that "a brigantine from the island of Madagascar happened to put in at Carolina, having a little seed-rice left, which the captain gave to a gentleman of the name of Wood. ward. From part of this he had a very good crop, but was ignorant for some years how to clean it. It was soon dispersed over the province, and by frequent experiments and observations, they found out ways of producing and manufacturing it to so great perfection, that it is thought to exceed any other in value. The writer of this hath seen the said captain in Carolina, where he received a handsome gratuity from the gentlemen of that country, in acknowledgment of the service he had done the province. It is likewise reported, that Mr. Dubois, then Treasurer of the East India Company, did send to that country a small bag of seed-rice some short time after, from whence it is reasonable enough to suppose might come those two sorts of that commodity; the one called red rice, in contradistinction to the white, from the redness of the inner husk or rind of this sort, although they both clean and become white alike."

There is a trifling discrepancy between the latter part of this account, and the statement respecting Mr. Ashley alrearly mentioned in a former chapter; but the main fact and the time of its occurrence are the same, and it is probable that the latter gentleman may have acted in the matter under the instruction of Mr. Dubois.

The swamps of South Carolina, both those which are occasioned by the periodical visits of the tides. and those which are caused by the inland floodings 
of the rivers, are well suited for the production of rice; and not only is the cultivation accomplished with trifling labour, but the grain proves of a remarkably fine quality, being decidedly larger and nanusomer than that of the countries whence the seed was originally derived.

It cloes not appear that this naturalizing of rice in Carolina and Georgia was ever productive of much effect in regard to the diet of the inhabitants of those provinces. Their consumption of rice was doubtless increased by it, because the abundance and cheapness of an article always influence persons to its use. But wheat and inaize continued, as before, to be the bread-corn of the country, and the newly introduced grain was cultivated principally becanse it furnished an article in constant demand which might be transmitted to the mother-country in return for British manufactured goods.

Had a contrary effect followed upon the introduction of rice into the then British colonies of Americal, and this grain had become, as in India, the universal food of the inhabitants, it is not probable that their condition would have been in any way ameliorated by the change. In countries where rice forms the chief article of food, dearths are not by any means of uncommon occurrence. A failure of the usual supply of rain, which is followed by cril consequences where other descriptions of grain are raised, is productive of tenfold misery where the chief dependance is its due degree of moisture proves wholly unproductive. In such cases there can be found few sources of relief, other objects of cultivation being pursued to only a linited extent, and the means of the people not eilabing them to compass the purchase of these scarcer articles of food, even when, through the general abundance, they may be pro- 
cured at their natural price. Happily for the interests of humanity, dearths are becoming less and less frequent of occurrence, through the better understanding of subjects connected with the production and distribution of commodities. In England the people are especially guarded against this calamity by the diversity of the crops which are raised, and by the opportunity they thence enjoy of falling back upon articles of consumption less costly than those to which they are ordinarily accustomed. It is this circumstance which constitutes the advantage of the general use of wheaten bread-a taste which has beeu slowly but steadily acquired amongst us. In no way, perhaps, is the progress of a nation in civilization more unequivocally shown than in the improvement which it realizes in the food of the community. In the infancy of societies, the people are necessarily satisfied with the enjoyment of such indigenous productions as fall most naturally withis their reach. But in the more advanced stinges of society, when articles of food, which at one time have been introduced as luxuries, are so far naturalized as to form a part at least of the sustenance of the common people, they, in the event of an unkindly season, have something upon which they can still fall back, so that what would otherwise be famine is at worst changed into privation. "In those countries," it has been judiciously observed by the late David Ricardo, "where the labomingr classes have the fewest wants, and are contented with the cheapest food, the people are exposed to the greatest vicissitudes and miseries. They have no place of refuge from calamity; they cannot seek refuge in a lower station; they are already so low, that they can fall no lower. On any deficiency of the chief article of their subsistence, there are few substitutes of which they can 
avail themselves, and dearth to them is attended with almost all the evils of famine."

If a scarcity of food should be experienced in this country, the great bulk of the common people, nay even the very poorest anong them, have, generally speaking, still some articles, that in foreign countries would be considered luxuries, which they can forego, some property which they can sacrifice, in order to satisfy the cravings of hunger. In India, on the contrary, and in most of the countries where rice forms the principal article of human food, the labouring classes are poor in the extremest sense of the word. Having few artificial wants, they are without those habitual incentives to exertion which actuate so powerfully and so beneficially people of the same rank in countries like our own. If they can acquire a ineal for themselves and their families they have little thought about higher comforts; the price of labour in such countries is, in fact, equal to very little beyoud the purchase of the lowest description of food; - the Indian labourer is contented with the ruclest hut as a place of shelter; - he is without what we are accustomed to consider the most indispensable articles of household furniture, and his clothing consists of a few yards of the commonest cotton cloth. When the price of his ordinary food advances beyond the usual rate, he is sunk into immediate wretchedness; he has no fund whereon lie call draw for assistance, and the wages of his labour are so far from advancing under these circumstances, that the contrary tendency is uniformly experienced; and the competition for employment is increased while the means of paying for labour are diminished.

Some botanical writers enumerate four varieties of rice which they consider as being originally distinct from each other; while ochers have been of opinion 
tiat the unimportant varieties which these preseni, and which do not in any way affect the chemical or alimentary properties of the grain, are simply the effects of difference of soil, culture, and climate. The four varieties are common rice, early rice, mountain rice, and clammy rice.

Common rice is a marsh plant. If the ground on which it is sown should become dry before the plants arrive at maturity, they wither. It is this variety which grows most strongly; and on lands peculiarly adapted for it the culture is probably as advantageous as can well be pursued.

Early rice, like the other, is a marsh plant, but it does not grow to the same size. It comes much sooner to maturity; for while common rice is never ripe in less than six months from the time of ploughing, this variety, if placed in favourable situations, requires only four months for arriving at perfection.

Mountain rice thrives on the slopes of hills and in other situations where it can receive humidity only occasionally. Dr. Wallich, the able successor of $\mathrm{Dr}$ Roxburgh as superintendent of the botanical garden at Calcutta, sent to London a few years ago some specimens of rice grown on the cold mountains of Nepal. These seeds were furnished to him by the resident of the East India Company in that district, and were recognised by the Doctor as mountain rice. The degree of cold which this plant is qualified to bear is very great. According to the information collected on the subject by Dr. Wallich, the cultivators consider their crop quite safe if the growth of the plants is advanced five or six inches above the surface at the time the winter snows cover the ground. It is probable that the slow melting of the snow is beneficial to the growth of the plant, 
which advances with great vigour on the return of spring.

A knowledge of these circumstances might have led to the opinion that this variety of rice could be naturalized in England, if the attempt had not already been fairly made by one well qualified for conducting the experiment. Samples of six different sorts of mountain rice which had been procured by Sir John Murray from the neighbourhood of Serinagur at the foot of Mount Imaus, werc, on the occasion alluded to, presented by the Board of Agriculture to Sir Joseph Banks, who planted each kind in a separate bed, in a sheltered spot with a south aspect, in his garden at Spring Grove. 'I'he grains, which were sown very thin on the 21 st of May, speedily sprang up, and the plants tillered so much that the beds put on the appearance of compact, dense masses of vegetation; each plant having from ten to twenty off-sets. Although the blades grew vigorously, attaining in a short time to the length of two feet, there was never any symptom of a rising stem, and if the ground was not watered, either by rain or artificially every three or four days, the plants began to assume a sickly hue. In this manner vegetation proceeded, without the smallest symptom of their perfecting themselves by fructification, when the plants were suddenly destroyed by an early night frost in September. Some of the plants, which had been transferred to pots and placed in the hot-house at an early period of their growth, soon died; while otlers, which were sown originally in a hot-house, produced ears and flowered, but the blossoms dropped without perfecting any seed.

'The conclusion to which Sir Joseph Banks arrived from these experiments was unfavourable to the cultivation of rice in this country as a grain-bearing 
plant; but he was led to consider, from the greast quantily of its blades, that it would afford excellent green-meat for cattle.

Clammy rice appears to be endowed with the peculiar property of growing both on wet and on dry lands: the period occupied by its growth is inter mediate between those of the common and early varieties.

Rice seed is sown in Carolina in rows, in the bottom of trenches, which are about eighteen inches apart, reckoning from the centres of the trenches. The sowing is generally performed by negro women, who do not scatter the seed, but put it carefully into the ground with the hand, so as to preserve the perfect straightness of the line. The sowing is for the most part completed by the middle of March. 'The water, which until then has been kept back by means of flood-gates, is at this time permitted to overflow the ground to the depth of several inches, and things remain in this state for some days, - genenally about a week. The gernination of the seed is promoted by this flooding, and the water being then draivn from the surface of the land, the plants sprout, rising in ahout four weeks to the height of three or four inches. At this time the flood-gates are agrain opened, the fields are once more over flowed, and remain in that state during about sixteen days; one goorl effect of this second flooding being the destruction of the grass and weeds which may have sprouted at the same time with the rice. Thie land is allowed after this to remain without further irrigation until the middle of July, being repeatedly hoed during the interval, as well to remove any weeds at the moment of their appearance, as to loosen the soil about the roots of the rice, adopting thus in all its principal parts the drill system of husbandry. At the time last mentioned, water is 
agrain admitted, and remains covering the surface until the grain is actually ripened.

The rice harvest in the United States usually commences at the end of August, and extends through the entire montl of September, or even sumewliat later. The reaping is performed with a sickle by male negroes, and these are followed by females, who collect the rice into bundles.

This cultivation is found to be extremely unhealthy to the negroes employed in its prosecution. The alternate flooding and drying of the land in so hot a climate, where natural evaporation proceeds with great rapidity, must necessarily be prejudicial to health. To avoid exposure to this unwholesome atmosphere, the whole white population abandon the low grounds to the care of negro cultivators. The mortality thus occasioned among the labourers in rice districts is so great, that while the general increase of population in the States exceeds by far that realized in the older settled countries of Europe, fresh supplies of negro slaves must continually be brought, to repair the waste of life, from the more northern slave states of the Union.

The cultivation of rice is very extensively and successfully carried on in the rich meadows of Lombardy, which can be irrigated by the waters of the Po. The meadows chosen for the purpose are perfectly flat. After the seed is sown, the water is turned on and allowed to cover the surface to the depth of several inclies during the whole course of its growth, and until the rice is ripe. Three crops are taken successively from the gromnd in this manner without manuring; but the soil is then so far exhausted, that it must be manured and planted for a time with other crops, before another succession of rice harvests cau be drawn from it.

This system of agriculture proves the most profit. 
able to the cultivator, of any that is carried on in Lombardy; but the same unwholesome effect is experienced there as in Carolina; and the government at Milan finds it expedient to restrict the cultivation within a certain limit, beyond which the production of rice is not allowed. The quantity of seed usually sown is three bushels to the acre, and the average produce, firom the same measure of land, is commonly about six quarters

In the province of Valencia in Spain, the method of rice cultivation is very similar to that pursued in Lombardy. The water remains on the grround even during the operations of harvest, and the reapers are obliged to wade up to their knees in order to cut the grain, other persons following to receive the sheaves as they are cut, and to convey them to some dry place, where the grain is detached from the ear by the treading of mules.

The hollows between Columbo and Candy, in the island of Ceylon, are devoted to the production of rice. The fields on which it is sown are artificially formed into a regular succession of terraces, one above another, so that the water of irrigation may be made to flow from a higher to a lower level, the plants being in different stages of their growth. In some cases the water is led for a mile, or even two miles along the side of a mountain, and is then discharged over the highest terrace, and thence downward in succession to the lowest, according as moisture may be required by each. Bishop Heber, for whom the charms of nature, whether in a wild or culiivated state, were never displayed in vain, remarks, on visiting this district, that " the verdure of the young rice is particularly fine, and the fields are really a heautiful sight, when surrounded by and contrasted with the magnificent mountain scenery*."

* Heber's Journey, val. iii. p. 169. 
M. Duhamel, in his admirable work on Husbaiddry, has detailed the varions processes followed by Chinese sultivators in raising rice. 'The great and careful abour bestowed upon this object is no doubt called for in that vast empire by the state of its population, which renders it a matter of necessity to draw continually from the soil all the assistance which it can be wade to impart.

"To hasten the germination of the seed-rice it is placed in baskets and immersed during some days in standing water.

"When the ground is so thoroughlly soaked that the surface is like soft mud, it is ploughed with a buffalo, yoked to a very simple plough, without wheels, and having only one handle. The clods are after this broken down by means of a rude kind of hurdle, drawn also by a buffilo, the driver sitting upon the lumdle to increase the weight. The gromid is cleared very carefully of ali stomes, and whatever weeds may be found are diligently removed with their roots. 'The land is then partly covered with water, and smoothed by a harrow which has several rows of great iron teeth.

"The seed-rice, when it has once sprouted, is known to he good; grains not in this sitnation are rejected, and the remainder is sown by hand very. thickly and as equally as possible upon a part only of the land, which is thus used as a sort of nursery for the remainder. 'The land having at this time upon it just as much water as will barely cover it, the points of the plants appear above the surface onc day after the seed has been sown.

"In a short time, when the plants have acquired a little strength, they are sprinkled over with limewater, the object of this being the destruction of insects. For this purpose a small basket with a longr handle is used, and this being filled by immersion 
in the hme-water, the fluid runs through in divided portions over the plants. This practice is found to be so efficacious, that the Chinese are said to hold its first inventor in the highest vemeration.

"Towards April, when the plants cover thickly the ground that has been sown, the greatest part of them are pulled up with their roots and planted in tufts, pretty far asunder in a quincunx form, in fields prepared for their reception. A serene day is chosen for this operation, which must be performed quickly, so that the plants are as short a time as possible out of the ground.

"After this, water is admitted to overflow the rice, the grounds being, for this purpose, always situated near a rivulet, pond, or great pool of water, from which they are separated only by a bank which may readily be cut. It sometimes happens, however, that the water is below the level of the fields, in which case the necessary quantity is conveyed in buckets, which are worked chiefly by the aid of ropes,-a most laborious occupation.

" Though a man cannot step in these rice-grounds without sinking up to his knees, the Chinese weed thein three times during the summer, and that so carefully, that every weed they can find is pulled up. by the roots.

"When the rice is ripe, which is known in the same manner as wheat, by its turning yellow, it is cut down with a sickle, marle into sheaves, and conveyed into a barı, where it is threshed with flails very similar to those used among ourselves *." The husk and inner pellicle are removed by beating and trituration, pretty much in the same manner as has already been described.

It is worthy of remark, that with the view of obtaining from the soil the largest produce it will yield,

* Cillure de Terres, tom. ii. p. 180. 
the Chinese are careful not to place the plants at all close together lest they should rob one another of their needful portion of nourishment. This and the farther practice of frequent weeding, which from their manner of performing the operation is equivalent to hoeing among us, brings their method completely into agreement with Tull's system of horsehoeing husbandry, which was not proposed for adoption in Europe until its prosecution had been thus practised commonly, and for ages, in the Chinese empire.

In all its principal features the method of culture is the same in Hindostan as it is in China. In some parts of Bengal the farmer suffers much from the depredations committed by wild hogs during the night. In order to guard as much as possible against this evil, a sort of shed is erected upon bamboos in the field, wherein a servant is stationed to scare away these intruders, - a precaution that is accompanied by much trouble and expense, and which yet is not always completely efficacious in preserving their property. These erections, which are very numerous in some districts towards the period of harvest, present a very curious appearance to the traveller.

'The cultivators of rice in America sometimes suffer severely from the depredations of the rice-bird of Catesby (Emberiza oryzivora), known familiarly in the country by the name of Bob Lincoln. This bird is about six or seven inches long; its head and the under part of its body are black, the upper part is a mixture of black, white, and yellow, and the legs are red. Immense flocks of these birds are seen in the island of Cuba, where the rice crop precedes that of Carolina; but when from the hardening. of the grain the rice in that quarter is no longer agrecable to them, they migrate towards the north, and pass over the sea in such numerous parties, as 


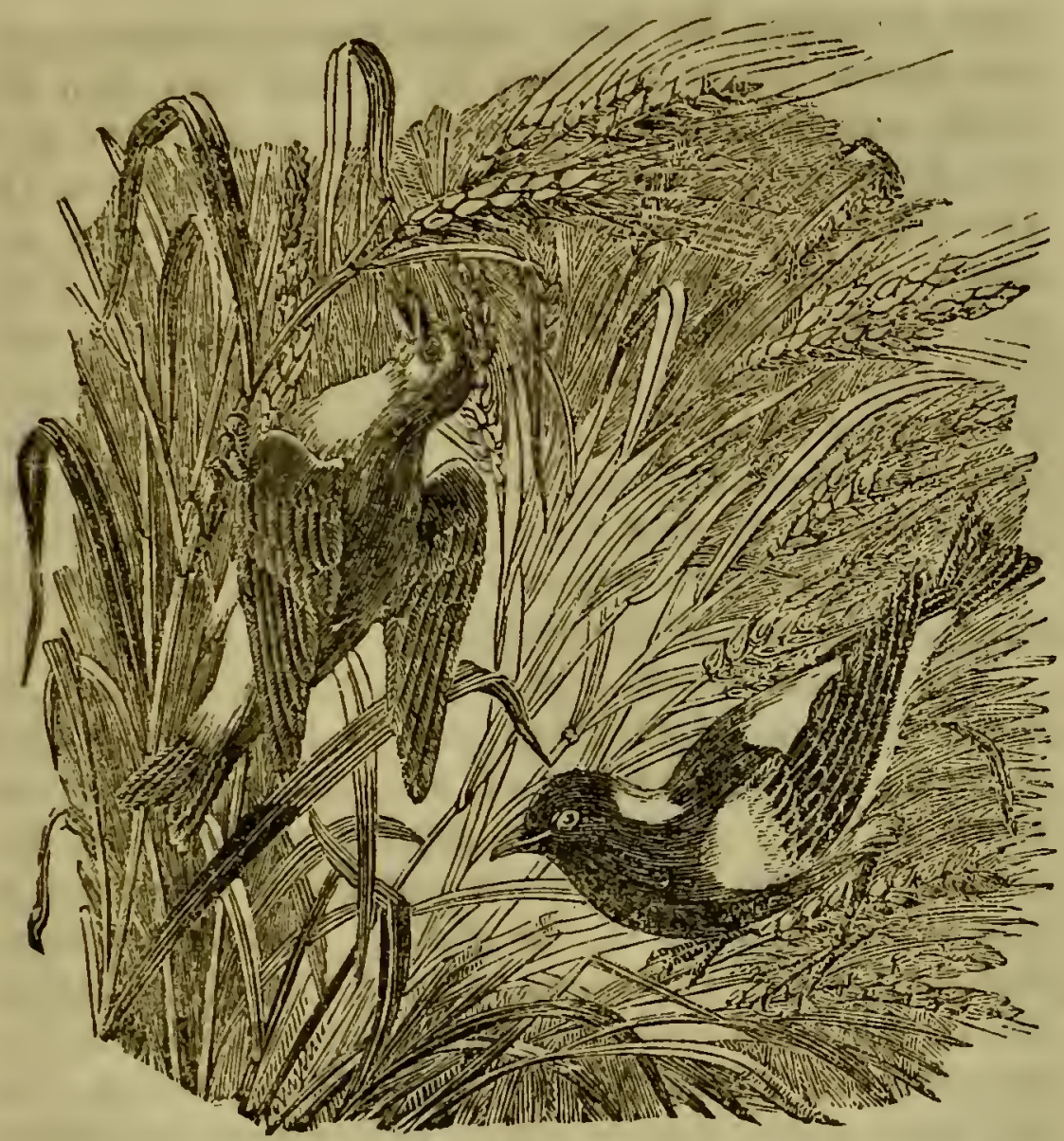

Riceburds, Male and Female.

to be sometimes heard in their flights by sailors frequenting that course. These birds appear in Carolina while the rice is yet milky. Their attacks upon the grain while in this state are so destructive as to bring' considerable loss upon the farmers. 'The birds arrive in the United States very lean, but thrive so well upon their favourite diet, that during the three weeks to which their visit is usually limited, they become excessively fat, so as to fly with difficulty, and when shot to be burst with the fall. So soon as the rice begins to harden here, they retire to other parts, remaining in nue place only so long as the rice continues green. When this food entirely fails, they 
have recourse for their subsistence to insects, until the maize begins to form its grains, and then the milky substance which these contain is devoured with the same avidity that marks their attacks upon the rice-plant. Extensive flocks of the oryzivora are found during the spring and summer in New York and Rhode Island; there they breed, quitting witk their young for the southward, in time for the tender rice-grains of Cuba. It is remarkable that the males and females do not migrate in company, the females being alway's the first to perform their voyages. 'These birds are eaten as a great delicacy, and the song of the male is said to be melodious.

The uses to which rice is actually applied may be easily defined. In a great part of India and China it forms the subsistence of the native population, more exclusively and to a greater extent than can perhaps be said of any other vegetable substance in any known region of the globe. In the countries just mentioned, as well as in those districts of Africa where it is used indiscriminately with maize, rice undergoes but little culinary preparation, being, for the inost part, simply boiled with water, and eaten either by itself, or accompanied by some stimulating or oily substance. In countries, on the other hand, where it is employed only as an auxiliary article of food, rice is subjected to a greater degree of preparation for the table, and except when used to thicken broths, is seldom presented, unless after concoction with eggs, and milk, and sugar, which cover the natural insipidity of the grain.

In years when the harvest is deficient in this country, it is usual to hear a great deal about the practicability and advantage of mixing rice with wheaten or rye flour for making bread, and this may, without doubt, be done in a certain moderate proportion; such brad, howerer speedily becomes 
harsh and dry. A writer in the Journal des Sciences, des Leitres, et des Arts; has, indeed, given directions, by following which, it is said, fermented bread may be made of rice without admixture with the flour of any other grain*.

We are told that the Chinese make a kind of wine of rice, which resembles, both in colour and flavour, the white wine of Xeres; but it is not known by what process they are enabled to succeed in this manufacture. In the East, considerable quantities of ardent spirit are extracted from this grain by fermentation and distillation.

It has been declared impracticable to manufacture beer from rice, in consequence of the difficulty which attends its previous conversion into malt. M. Dubrunfaut has stated that this necessary process may be readily and completely accomplished in the mash tub, by mixing one part, by weight, of malted barley, with four parts of crushed rice, which has previously been mixed with its own weight of water. The

* The method herc referred to is as follows.-First reduce the rice to powder in a mill, or throw the whole grains into water at nearly a boiling heat, and allow them to soak during some hours. Then drain off the water, and when the rice shall have becoms sufficiently dry, beat it in a mortar, and pass the powder through a fine sieve. This flour must next be placed in a kneading-trough, and moistened in the necessary degree with water rendered glutinous by boiling whole rice in it for some time; add salt, and the proper quantity of leaven or yeast, and knead the whole intimately together. The dough must then be covered with warm cloths and left to rise. During this fermentative process, the dough, which was of a pretty firm consistence, will become so soft as not to be capable of being formed into loaves. It is, therefore, placed in the requisite quantities in iin forms, and these being covered with large leaves, or with sheets of paper, are introduced into the oven, the heat of which speedily sets the dough sufficiently, so that the tins being reversed, their contents are turned out upon the leaves or paper. The bread, when perfectly baked, will be of a fino yellow colour, similar to that imparted to flour by the yolks of eggs, and when new is said to be sufficiently agreeable. 
ready formed saccharine matter of the barley inalt appears to have the singular property of speedily converting the fecula of unmalted corn into a kind of soluble matter which has the fermentative properties of sugar. If inalt and rice flour, diluted so as to have a pasty consistence, he mixed and mashed together, and then left during three or four hours, the mixture will present the appearance of a liquid which is slightly saccharine to the taste, and having a sediment at the bottom of the vessel, which is found, on examination, to be composed of only the husks of barley and rice. M. Dubrunfaut used for the purpose rice from which the husk had not been removed previous to its being crushed, and which in this state is known by the name of paddy, or more properly paddee.

The practice has obtained very much, during the last few years, of importing this paddee, in preference to shelled rice, its cost being lower in foreign markets, and the importers avoiding a very large proportion of the customs' duty chargeable on that already prepared for use. Some very effective machinery has been set up for the purpose of removing the husk and cuticle, and these operations are performed full as perfectly, and with less breaking of the grains than follows the employment of the ruder methods usually pursued in the countries of production ; the loss, by waste, is also found to be less on the transport of paddlee than of shelled rice 


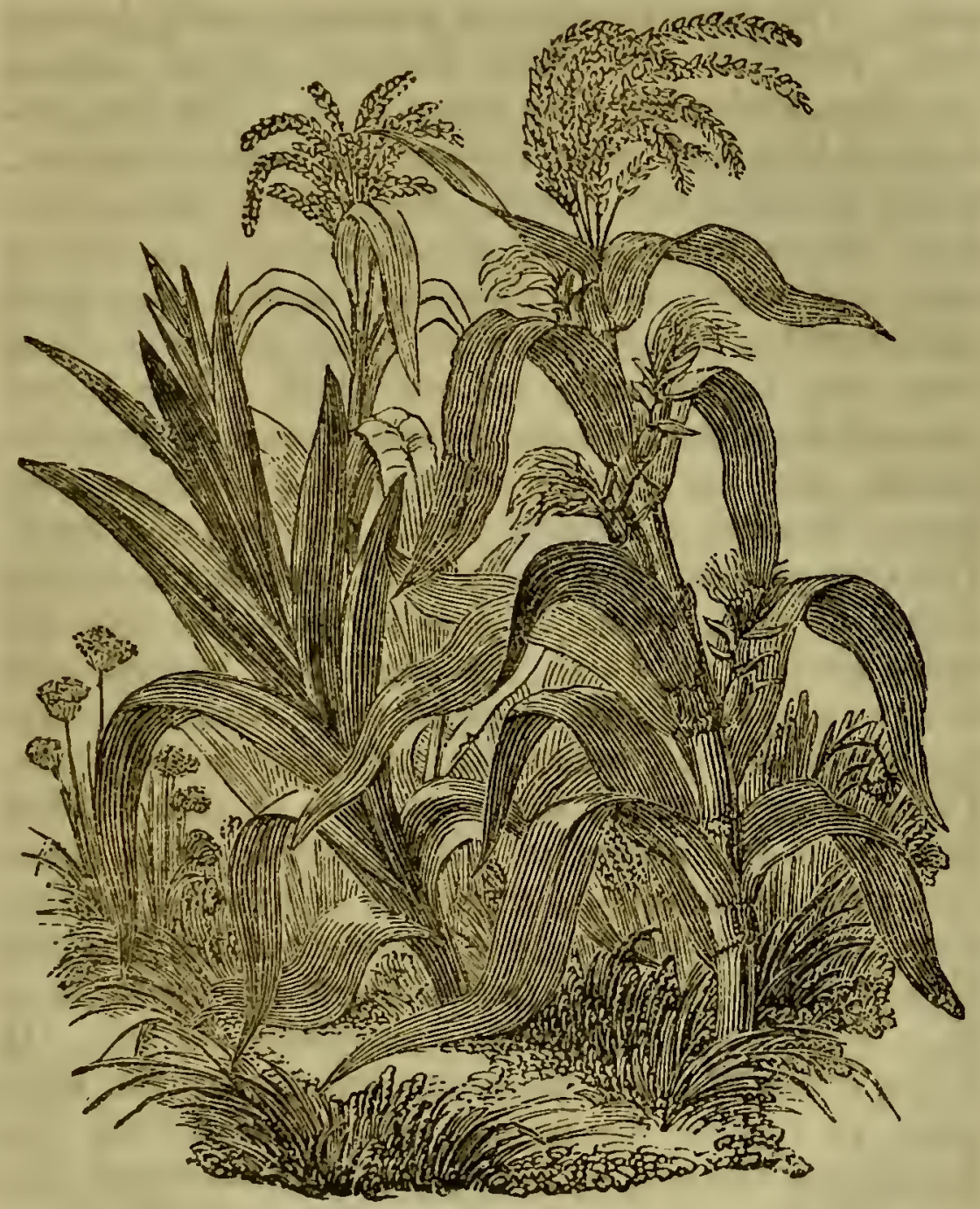

diaze-Zea liriys.

Chapter V.

MIIZE-MILLET-BUCK-WHEAT.

Maiz: or Indian Corn-Zea Mays.-Of this plant only one species is known, but there are severai varieties which are thought to owe their distinctive character to the accidental modifications of climate, soil, and culture. rather than to any original vari- 
ance. The plant consists of a strong, reedy, jointed stalk, provided with large alternate leaves, almost like flags, springing from every joint. The top produces a bunch of male flowers, of various colours, which is called the tassel. Each plant bears, likewise, one or more spikes or ears, seldom so few as one, and rarely more than four or five, the inost usual number being three: as many as seven have been seen occasionally on one stalk. These ears proceed from the stalk at various distances from the ground, and are closely enveloped by several thin leaves, forming a sheath, which is called the husk. The ears consist of a cylindrical substance, of the nature of pith, which is called the $c o b b$, over the entire surface of which the seeds are ranged, and fixed in eight or more straight rows, each row having generally as many as thirty or more seeds. The eyes or germs of the seeds are in nearly radial lines from the centre of the cylinder; from these eyes proceed individual filaments of a silky appearance, and of a bright green colour; the aggregate of these hang out from the point of the husk, in a thick cluster, and in this state are called the silk. It is the office of these filaments, which are the stigmata, to receive the farina, which drops from the flowers on the top, or tassel, and without which the ears would produce no seed, - a fact which has been established by cutting off the top previous to the developement of its Howers, when the ears proved wholly barren. So soon as their office has been thus performed, both the tassel and the silk dry up, and put on a withered appearance.

The grains of maize are of different colours, the prevailing hue being yellow, of various shades, sometimes approaching to white, and at other times deepening to red. Some are of a deep chocolute colour, others greenish or olive-coloured, and even 
the same cars will sometimes contain grains of different colours.

Unlike the cereal grains which have been already described. naturalists are at no loss in determining the native region of maize, which is confidently held to be America, the Indians throughout that continent having been found engaged in its cultivation at the period when the New World was first discovered.

This grain is of scarcely less importance than rice, for the sustenance of man. It forms a principal food of the rapidly increasing inhabitants of the United States of America; it constitutes almost the entire support of the Mexicans; and is consumed in Africa to an extent nearly, if not quite, equal to the consumption of rice in the same quarter.

The merits of Indian corn have been very differently estimated; and while some persons have invested it with a value equal, if not superior, to that possessed by the rest of the cerealia, other persons have, on the contrary, placed it at the lowest station among the family, scarcely, indeed, allowing it worthy to take its place in the group. Without meaning in any way to involve the reader in this controversy, it is yet necessary to set fairly before him the facts connected with the question, and he may then be enabled to form a correct judgment on the matter.

Maize is said to contain no gluten, and little, if any, ready-formed saccharine matter, whence it has been asserted to have but a very small nutritive power; on the other hand, it is seen that domestic animals which are fed with it very speedily become fat, their flesh being at the same time remarkably firm. Horses which consume this corn are enabled to perform their fill portion of labour, are exceedingay hardy, and require but little care; and the common people of countries where Indian corn forms the

K 3 
ordinary food, are for the most part strong and hardy races. The produce of maize, on a given extent of cultivation, is greater than that of any other grain; and the proportional return for the quantity of seed committed to the ground is equally advantageous.

No argument can be founded either way upon the liking or disliking of individuals. Man is in this, as well as in most other respects, very much the creature of habit; and preferences, both national and individual, are often shown by him, in regard to articles of food, which would be wholly incomprehensible upon any other ground. We need not go beyond the bounds of Europe for abundant proofs of this fact, if indeed such are not offered by our own personal observation. It falls within the knowledge of the writer, that a gentleman who in his boyish days had been nurtured in a village on the coast, in a remote part of Scotland, acquired such a fondness for some weed throivn up by the sea, and which through the poverty of the inhabitants was made to form part of their sustenance, that in after-life, and when he had returned from a protracted residence abroad, he procured a supply of his favourite weed to be regularly sent to him in London, and ate as the greatest delicacy that upon which the members of his family could only look with disgust.

Of all the cerealia, maize is the least subject to disease. Blight, mildew, or rust, are unknown to it. It is never liable to be beaten down by rain, or by the most violent storms of wind; and in climates and seasons which are favourable to its growth and maturity, the only enemies which the maize farmer has to dread are insects in the early stages, and birds in the later periods of its cultivation.

Americhn Indian Corn is the largest known variety of maize. It is found growing wild in inany of the West-Indian islands, as well as in 
the central parts of America; and there can be no doubt of its being a native of those regions. In favourable situations it has a very considerable growth, attaining to the height of from seven to ten feet; in some cases it has acquired the gigantic height of fourteen feet, without in any way impairing its productive power. Its spike, or ear, is eight or ten inches in length, and five or six inches in circumference. The plant generally sends out one, two, or more suckers from the bottom of the stalk, but these it is advisable to remove, not only as they draw away part of the nourishment which should go to support the main stalk, but because the ears which the suckers bear ripen at later periods than the others, and the harvest could not all be simultane ously secured in the properest state of maturity.

'This variety will rarely come to maturity in north ern climates, and could never be securely relied on for a crop in any part of Europe. In the Mexican states, where this grain is known by the name of Tlaouili, there are few parts of either the lower districts-tierra caliente-or of the table-land, whereon it is not successfully cultivated. In the former districts its growth is naturally more luxuriant than in the latter; but even at an elevation of six or seven thousand feet above the level of the sea, its productiveness is calculated to excite wonder, if not to provoke incredulity on the part of European agriculturists. Some particularly favoured spots have been known to yield an increase of eight hundred for one; and it is perfectly common in situations where artificial irrigation is practised, to gather from three hundred and fifty to four hundred measures of grain for every one measure that has been sown. In other places, where reliance is placed only on the natural supply of moisture to the soil from the periodical rains such an abundant return is not expected. 
but even then, and in the least fertile spots, it is rare for the cultivator to realize less than from forty to sixty bushels for each one sown.

The system of husbandry employed is closely analogous to that so often alleady referred to as Tull's Horse-hoeing Plan. 'The seed is sown, froin three to five grains together, at regular intervals of three feet, in rows sufficiently far apart to admit of the passage of a small plough between them, for the purposes of loosening the soil around the roots, and of removing the weeds. The use of manure is altogether unknown in Mexican maize husbandry.

Humboldt states that in some warm and humid regions of Mexico three harvests of maize may be annually gathered, but that it is not usual to take more than one. The seed-time is from the middle of June to near the end of August. A great part of the internal commerce of Mexico consists in the transmission of this grain, the price of which varies considerably in not very distant stations, owing to the imperfect state of the roads, and the insufficient means of transport. As an instance of this, Humboldt mentions the fact, that during his stay in the intendancy of Guanaxuato, the fanega (five bushels) of maize cost at Salamanca nine, at Queretaro twelve, and San Luiz Potosi twenty-two, livres. For want of a proper diffusion of commercial capital, the Mexican public is withont the advantage of magazines for storing corn, and for preventing, by that means, great fluctuations in price. It is a fortunate circumstance, and one which shouli be mentioned as adding yery materially to the uatural value of maize in warm climates, that it will remain in store uninjured for periods varying from three to fice years, according to the mean temperature of the district.

This kind of corn is grenerally planted in the 
United States of America about the middle of May, no as to avoid the mischance of its experiencing frost after it is once out of the ground. The Indians who inhabited the country previously to the formation of any settlement upon its shores by Europeans, having no calendar or other means of calculating the efflux of time, were guided by certain natural indications in their choice of periods for agricultural operations. The time for their sowing of maize was governed by the budding of some particular tree, and by the visits of a certain fish to their waters, both which events observation had proved to be such regular indicators of the season, as fully to warrant the faith which was placed on their recurrence. These simple and untaught people discovered and practised a method of preserving their grain after harvest, which afforded a certain protection against the ravages of insects, and which might be advantageously adopted in other siturations, and in climates where this evil is very prevalent. Their method was to separate the corn from the cobb as soon as the harvest was finished ; to dry it thoroughly by exposure to the sun, and to a current of air; and then to deposit it in holes dug out of the earth in dry situations, lining these holes with mats of dried grass, and covering them with earth, so as completely to prevent the access of air.

With the exception of artificial irrigation, to which recourse is not had in the United States, the method of sowing and managing maize is there singularly analogous to that pursued in Mexico. The proportionate produce, from a given quantity of seed or a certain breadth of land, is smaller, however, than that realized in Mexico, although the practice of manuring is universally followed. As compared with the yielding of other kinds of grain, maize cultivation is, nevertheless, highly productive in the United 
States. In Pennsylvania, where the average crop of wheat does not exceed from fourteen to seventeen bushels, that of maize amounts to from twenty tc thirty bushels to the acre. A writer in the "Montlı!y American Journal of Geology and Natural Science' considers that maize produces the heaviest crops near the northern limits of its range. The American farmers find this advantage to attend the partial culture of maize upon their farms, that the time of harvesting is some weeks later than that of wheat, and that, consequently, the general operations of the harvest may be conducted without great bustle and temporary advance of wages, to be followed by a season of inaction and consequently of idleness to the labourer,-evils which are commonly expeisenced in England.

The second variety of maize has white grains. This kind, which is cultivated in Spain, Portugal, and Lombardy, is altogether a smaller plant than the variety just described, seldom exceeding six or seven feet in height: the leaves are narrower, and the tops hang downwards. The ears or spikes are not more than six or seven inches long. The French, among. whom this grain is partially cultivated, have given to it the name of Blé de Turqnie, doubtless because their seed was originally obtained from that country.

Except in unusually favourable seasons, the two varieties hitherto described will not come to maturity in England, although they are sometimes sown as a curiosity in warm spots in gardens.

The third variety has both yellow and white seeds. It is even smaller than the last-mentioned, seldom rising to a greater height than four feet: the ears do not often exceed four or five inches in length. In ordinary seasons, it will ripen its grains perfectly in England; and one reason why it has been presumed that it:s cultivation would prove 
advantageous to this country, is the shortness of time required for its growth, whereby the late frosts to which we are sometimes liable in spring, and the early frosts of autumn, would be alike avoided. This particular variety is cultivated in some of the middle regions of the European continent, as well as in some parts of North America, from which latter country it is understood to have its origin. It is also partialiy cultivated in Germany, not as a bread. corn, but that it may he malted and used in the prebaration of a kind of beer, or made to yield an ardent spirit. The use chiefly made of it, however, is that of fattening swine and poultry.

In the cultivation of Indian corn in northern climates, it is proper to make choice of warm spots, and particularly to avoid shady situations. In order to admit the sun as much as possible to the plants, and probably also with the view of affording more nutriment to the grain, it is usual to remove the blades, together with the top and tassel, as soon as its office of dropping its fecundating farina upon the ears has been fully accomplished. This process is very easy of performance: when the blades and tops are perfectly dry they are stacked and thatched, and form an excellent substitute for hay and chaff in the spring, both for cattle and horses, as well as for sheep, all these animals being attracted by its sweetness.

It may generally be known when the corn is ripened by the dry and white appearance put on by the husk: a more intimate inspection is, however, accomplished without difficulty. The ears must then be plucked off, together with the husks, and conveyed at once in carts to the barn. In America, the stalks are usually left standing for some time longer. Being then 'cut near to the ground, tied up into bundles, and stacked in a dry place, they will prove 
useful as food tor horned cattle, which, from the saccharine quality of the plants, will thrive upon them.

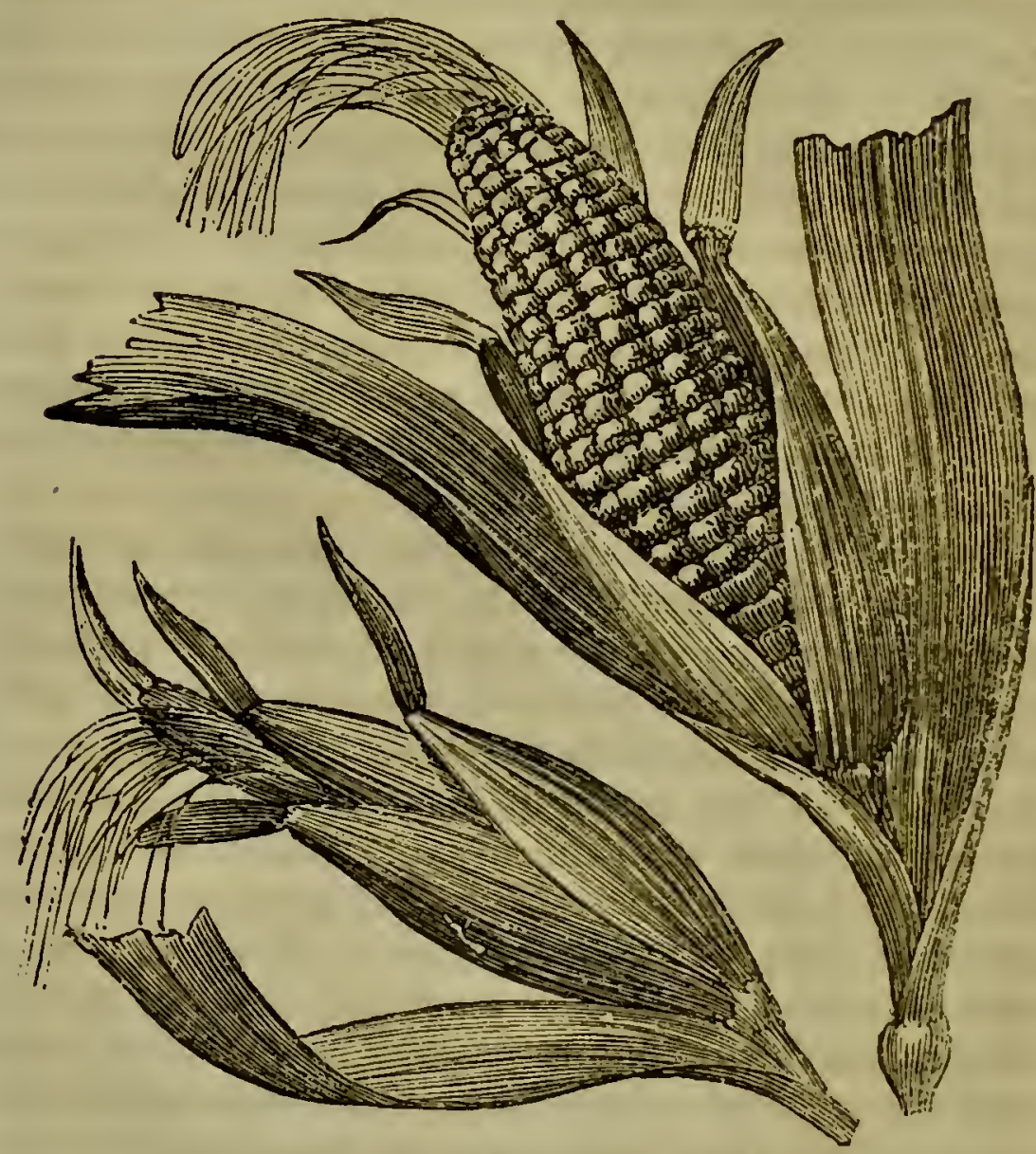

Fars of Maize in difforent stages.

The ears are preserved in bins or cages which are called corn-cribs, sometimes with the husk and at other times without it, and it is not considered good farming to shell the corn before it is required to be sent to market. This operation of shelling is very easily performed. The only implement required for the purpose is a piece of iron in shape like a sword-blade, the edge of which is not slarp, and this iron being fixed across the top of $a^{\circ}$ tub in which the shelled grains are to be collected, the ear is taken 
in both hands and scraped lengthwise smartly across the edge of the iron until all the grains are removed. In this manner, it is said, an industrious man will shell from twenty to twenty-five bushels of corn in the course of the day. 'The cobb which remains makes a very tolerable quick-burning fuel, and thus no part of the plant proves altogether without use.

The grain forms one-half the measure of the ear, that is to say, two bushels of ears will yield one bushel of shelled corn. So correct is this estimate found to be, that in the markets of the United States, where Indian corn is sold both shelled and with the cobb, two bushels of the latter are taken without question by the purchaser, as being equal to one bushel of shelled grain.

An amusing, and in many respects an instructive book, was published a few years since upon the merits of Indian corn, by one whose sanguine wishes upon the subject of its introduction as a corn-plant into England, led him farther than most people have been inclined to accompany him. There is to be seen in the work here referred to a very minute and interesting account of all the various processes which must be attended to by the maize-grower before his grain is ready for sale, as well as very minute directions for turning the produce to the best and most agreeable account in family economy*. Although the public mind seems at present to be differently impressed upon the matter, it does not appear very improhable that some hardy variety of this plant may at no very distant day be regularly cultivated in some parts, at least, of England, and in Ireland. Sir Richard Bulkely, who obtained some seed from Brandenburgh, sowed it in the last-mentioned island, and it is recorded that his produce was exceedingly great, fully equal indeed to anything asserted of * A Treatise on Cobbett's Corn, by W. Cobbett. 
Mexican fecundity. Might not this grain be gradually introduced, to the advantage of that portion of the kingdom, affording to the peasantry a more nourishing food than that upon which the bulk of them are now constrained to subsist? That Indian corn is well qualified to form the entire food-if that were necessary-of a people, is amply exemplified by the Mexicans, the great bulk of whom seldom partake of any other description.

Captain Lyon, in the narrative of his travels in Mexico, has given an amusing account of the mode of preparing tortillas, a species of cake made with the crushed grains of maize, which is eaten hot at the ineals of all classes of people, the more wealthy using the cakes in the way we are accustomed to use wheaten bread,- - as an auxiliary to more nourishing aliments - and the peasants being fain to enjoy them as a substantive food, seasoning them, when they have the opportunity, by the addition of chilies stewed into a kind of sauce, wherein the tortillas are dipped. Simple as the art may appear of thus making an unleavened cake with moistened flour, some persons are found to acquire a greater degree of expertness in it than others; and so great is the necessity for their preparation, and the desire of having them well concocted, that according to Captain Lyon, "in the houses of respectable people, a woman, called from her office Tortillera, is kept for the express purpose; and it sounds very oddly to the ear of a stranger during meal-times, to hear the rapid patting and clapping which goes forward in the cooking-place, until all clemands are satisfied.*"

The various uses to which the maize plant and grain may be applied cannot perhaps be better enuinerated than in the words of Dr. Franklin, a man accustomed to make a sober estimate upon every

* Lyon's Mexico, vol. ii. p. 136. 
subject that fell under his observation; and who, however enthusiastic he might be in the cause of virtue and rational freedom, never suffered himself to be betrayed into exaggeration, or to be carried away by a too sanguine imagination in affairs connected with the business of life.

"It is remarked in North America, that the English farmers, when they first arrive there, finding a soil and climate proper for the husbandry they have been accustomed to, and particularly suitable for raising wheat, they despise and neglect the culture of maize or Indian corn ; but observing the advantage it affords their neighbours, the older inhabitants, they by degrees get more and more into the practice of raising it; and the face of the country shows from time to time that the culture of that grain goes on visibly augmenting.

"The inducements are the many different ways in which it may be prepared so as to afford a wholesome and pleasing nourishment to men and other animals. First, the family can begin to make use of it before the time of full harvest; for the tender green ears, stripped of their leaves, and roasted by a quick fire till the grain is brown, and eaten with a little salt or butter, are a delicacy. Secondly, when the grain is riper and harder, the ears, boiled in their leaves and eaten with butter, are also good and agreeable food. The tender green grains dried may be kept all the year, and, mixed with green haricots (kidney beans), also dried, make at any time a pleasing dish, being first soaked some hours in water, and then boiled. When the grain is ripe and hard there are also several ways of using it. One is to soak it all night in a lessive or lye, and then pound it in a large wooden mortar with a wooden pestle; the skin of each grain is by that means skinned off. arid the farinaceous part left whole, which being 
toiled swells into a white soft pulp, and eaten with milk, or with butter and sugar, is delicious. The dry grain is also sometimes ground loosely, so as to be broken into pieces of the size of rice, and being winnowed to separate the bran, it is then boiled and eaten with turkies or otlier fowls, as rice. Ground into a finer meal, they make of it by boiling a hasty pudding or bouilli, to be eaten with milk, or with butter and sugar; this resembles what the Italians call polenta. They make of the same meal, with water and salt, a hasty cake, which being stuck against a hoe or other flat iron, is placed erect before the fire, and so baked to be used as bread. Broth is also agreeably thickened with the same meal. 'They also parch it in this manner. An iron pot is filled with sand, and set on the fire till the sand is very hot. Two or three pounds of the grain are then thrown in, and well mixed with the sand by stirring. Each grain bursts and throws out a white substance of twice its bigness. The sand is separated by a wire sieve, and returned into the pot to be again heated and repeat the operation with fresh grain. Tliat which is parched is pounded to a powder in mortars. This being sifted will keep long for use. An Indian will travel far and subsist long on a small bag of it, taking only six or eightht ounces of it per day mixed with water. The flour of maize, mixed with that of wheat, makes excellent bread, sweeter and more agreeable than that of wheat alone. To feed horses, it is good to soak the grain twelve hours, they mash it easier with their teeth, and it yields them more nourishment. The leaves stripped off the stalks after the grain is ripe, tied up in bundles when dry, are excellent forage for horses, cows, \&c. The stalks, pressed like sugar-cane, yield a sweet juice, which being fermented and distilled yields an excellent spirit; boiled without fermentation, it 
affords a pleasant syrup. In Mexico, fields are sown with it thick, that muititudes of small stalks may arise, which being cut from time to time, like asparagus, are served in desserts, and thin sweet juice extracted in the mouth by chewing them. The meal wetted is excellent food for young chickens, and the old grain for grown fowls *."

In addition to the many uses enumerated by Franklin in the foregoing account, Humboldt acquaints us that the Mexican Indians, previous to the conquest of their country, were accustomed not only to express the sweet juice from maize-stalks for the purpose of fermenting it into an intoxicating liquor, but that they boiled down this juice to the consistence of syrup ; giving it likewise as his opinion that they were able even to make sugar from this irspissated juice. In confirmation of this opinion, he recites a letter written by Cortez, who in describing to the Emperor Charles V. the various productions in both a natural and manufactured state which he found in the new country, asserts, that among these were seen "honey of bees and wax, honey from the stalks of maize, which are as sweet as sugar-cane, and honey from a shrub which the people call maguey. The natives make sugar from these plants, and this sugar they also sell." There is no question that the productions here enumerated will yield saccharine matter; but crystallized sugar, properly so called, is a different preparation, and, from our present knowledge, it is difficult to believe that any such substance could have been so prepared.

The Indians, at the period above alluded to, evinced considerable skill in the preparation of fermented liquors, which is by no means lost by the Mexicans of the present day. "A chemist," says Humboldt, "would have some difficulty in preparing

* Franklin's Works, vol. ii. pp. 276-8, 4to edition, 1818. 
the innumerable variety of spirituous, acid, or saccharine beverages which the Indiaus display a peculiar address in making, by infusing the grain of maize, in which the saccharine matter begins to develope itself by germination. These beverages, generally known by the name of chicha, have some of them a resemblance to beer and others to cyder." The spirituous liquor called pulque de mahis or tlaouili, which is prepared from juice expressed from the stalk of the maize, forms, in some parts of the republic, a very important article of commerce.

It has been said that Indian corn is free from all liability to disease. In contradiction of this, M. Roulin has asserted that a diseased state of this grain, similar in its nature to that described as inci. dent to rye under certain circumstances, is not unfrequently met with in Columbia. The ill effects attributed to the ergot of maize, although serious, are however by no means of so fatal a character. Among the effects, all animals, including the human race, who partake of it, are subject to the shedding of their teeth and hair, and quadrupeds to the additional loss of their hoofs; fowls that have fed upon it lay their eggs without shells. Its action, when administered medicinally, is said to be even more powerful than that of the ergot of rye. It must be remarked that in the narrative of no other traveller have we met with a similar statement, and that in other countries, where maize is quite as familiarly known as in Colombia, the disease has never been observed.

Millet-Species of Sorghum and Sitaria. These are true grasses, and naturally allied to one of the most numerous tribes. In light sandy soils, under the scorching rays of the sun, and in situations where sufficient moisture cannot be obtained for the 
production of rice, millet is successfully cultivated Sorghum forms a chief dependance of the peopie in some parts of India-through the arid districts of Arabia-in Syria, where it has been produced from the earliest periods-and in Nubia, whose inhabitants cultivate this almost to the exclusion of every other grain.

The seeds of Panicum millet are by much the smallest of any of the cereal plants, but the number borne upon each stalk is so exceedingly great as to counterbalance that disadvantage, and to render this equally productive with other of the culmiferous plants : it is to this circumstance that its name, from mille, a thousand, has been ascribed.

Of this sort there are two modifications, distinguished by the form of their spike, one being composed of a single rachis, while the other is very much branched. The difference of form thus exhibited is of so marked a character that it can scarcely be viewed as a modification brought about by difference of culture.

Of each of these there are to be found some species which chiefly exhibit themselves as such by the varying colour of their grains, and by the circumstance of these being either naked or encrusted.

One kind of millet, the spike of which is compact, has beer supposed to be a native of the north of Europe, and is commonly known-at least in this quarter of the globe-as German MiLLET, Sitaria germanica. It is thought, however that this variety was originally imported from India and acclimatized in Germany. Nor does it afford any direct evidence against this opinion, that seeds apparently of the same kind, brought from India, and subjected at once to the same culture, do not perfect their seeds; since it is well known that the habits of plants may be changed by slow degrees 
to an extent quite sufficient to account for this variance. The stalk of this, and indeed of all the varieties of millet, resembles a jointed reed, having at every joint a long broad leaf embracing the stulk with its base. This variety rises to the height of three or four feet, and terminates in a compact spike about eight or nine inches long, somewhat thicker at the base than at the top, beset with small round grains, which adhere but slightly to the husk, and therefore are very liable to be shaken out when ripe. The use principally made of this grain is the feeding of poultry.

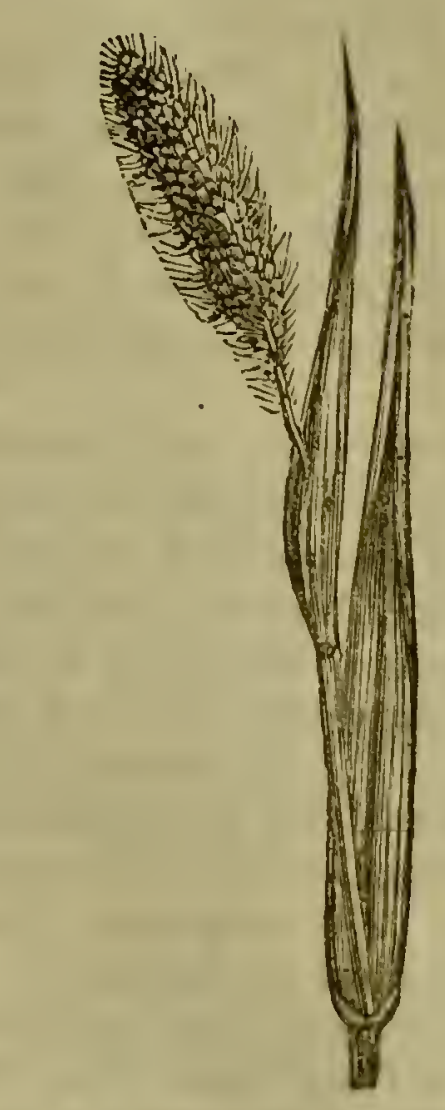

Italian Millet-Sitaria,talica.

ITalian Millet-Sitaria italica-bears a considerable resemblance to the variety just described. 
This variety is decidedly a native of India, where in bears the name of congue. The plant is stronger. the spike and the seed are larger, and to bring it to maturity requires a warmer climate than suffices for German millet. The use to which this grain is brought in Tuscany, is that of feeding domestic fowls and animals, including horses. The larger species of animals are also fed upon the leaves and culms, of which last-mentioned portion brushes are like:vise made. The Italians also make from the flour a kind of bread, which is dark coloured and coarse. Like those of maize, the seeds of both these varieties are of various colours.

Panicled Miliet is the species most usually cultivated. The commonest variety, which botanists call Sorghum vulgare, is known by various names in the different districts where it is grown. In India it is called jovaree; in Egypt and Nubia dhourra; while in our West-Indian colonies it has received the name of Guinea corn, either because the seed was first conveyed thither from the western coast of Africa, or as some persons have affirmed, because of its extensive use in feeding the African negroes throughout those colonies. The height to which this plant attains varies according to the soil and culture. In Egypt its growth seldom exceeds five or six feet, while Burckhardt* speaks of the stalks of dhourra as being sixteen or twenty feet long. The leaves are thirty inches long, and two inches wide in the broadest part. The flowers, when they first come out in large panicles at the top of the stalk, resemble the male spikes of the maize plant. These flowers are succeeded by roundish seeds, the colour of which is, in some cases, a milky white, with a black umbilica: dot; in others the seeds are red, but in both cases they are wrapped round with the chatf, and are

* Travels in Nubia, p. 280. 
beiter protected from feathered depredators than other kinds of millet.

This grain was introduced into cultivation in Switzerland about the middle of the last century by M. Tschiffeli, who received about a spoonful of the seed from Dr. Schreber. M. Tschiffeli published an account of his method of cultivation in the Transactions of the Berne Society; some extracts from which paper will suffice to show the capabilities of this grain when cultivated in northern latitudes. Among the advantages which it offers are stated, its adaptation to all sorts of soils, the small quantity of manure which it requires, the trifling amount of labour for which it ealls, and the small degree of exhaustion which it occasions to the soil, in comparison with the largeness of the return which it yields.

M. Tschiffeli sowed his first seed in the month of May, on a gravelly soil exposed to the north wind, and which the year before had borne a very indifferent crop of bigg. 'The seed was spread very thin, and to this circumstance he attributed the fact that the stalks rose to the height of eight feet and upwards. The ears were above ten inches long, and but for an iniopportune shower of hail which destroyed half the seed, the spoonful would probably have been multiplied into a peck of grains. In May of the following year, about a quart of seed was sown upon a piece o ground twenty paces long and half as broad, whic's space, it was soon apparent, was far too circumscriben for the quantity of seed. The stalls came up very close, and were interwoven with each other, reaching scarcely to the lieight of five feet; and the ears were nuch smaller than those of the preceding year. The produce, however, was seven pecks, or equivalent to fifty-six for one. In the next year, thirty square rods of land were sowed with half a peck of the seed. 
Here, again, the millet came up far too thick, being almost as much crowded from its greater tillering, as it was in the preceding year; notwithstanding which, the produce was so great, that twenty bushels were harvested, being a return of one hundred and sixty for one, and at the rate of more than one hundred bushels to the acre. M. Tschiffeli was of opinion that ten pounds of seed would prove an ample allowance for an acre of ground, and that greater space being thus allowed for the individual plants, the proportion between the quantities sown and harvested would be still more favourable. It does not appear that millet has ever been subjected to the system of drill husbandry, althongh the results here given seem to point out that system as being peculiarly applicable to its cultivation

Sorghum is cultivated largely in some parts of China and in Cochin China. In England the autumn is rarely sufficiently dry and warm for ripening its seeds, otherwise the plant inight prove useful in some poor and light soils, the produce of which is ordinarily insufficient to repay the greater expense attendant upon the cultivation of other grain. Sorghum was raised in this country as a rare plant, in the garden of John Gerarde, as early as 1596.

The golden-coloured millet seeds seen in our grocers' shops are the produce of the sorghum saccharatum, or yellow-seeded millet. Use is made of these in a similar manner with rice, for the preparation of puddings.

This variety is likewise a native of India; it is cultivated largely in China and Cochin China; and has been introduced into the island of Jamaica. Philip Miller reared it in his garden in 1759.

In warı climates millet is usually sown in May and June, and perfects its seeds within four months. The plant is not subject to blight, nor is it easily 
injured by either drought or rain. The only care required in its cultivation is to allow sufficient space for the tillering of the plants, and to weed and hoe the intervals during the early part of the growth; after which it will overtop and smother all weeds.

When millet is ripe, the panicles are cut off near to the top of the stalk, and collected in sacks or baskets. They are then laid up in heaps, and carefully covered during five or six days; after which they are spread on the barn floor, and the grain is threshed out in the ordinary manner with a flail. The more primitive method of treading out the grain by means of oxen is resorted to in some parts of India

If millet is not perfectly dry when deposited in the granary, it will soon be spoiled; but, on the other hand, if this precaution be properly taken, there is no grain that will keep longer or better. The weevil will not touch it, and although it is doubtless the better for being turned over occasionally, that process, so indispensable with other grain, may be omitted here without producing any serious injury. In addition to the use made of the stalks as fodder, the Nubians employ them in the construction of temporary huts.

In the barren districts of Bornou, a species of millet is produced, which is called by the inhabitants gussub, and upon which both men and animals are almost exclusively fed. By the poorer class it is frequently eaten, simply parched, or even without any culinary preparation. Other persons crush and then steep the seeds in water previous to eating them, and some few, who are the epicures of the land, clear the grain from the husk, pound it, and make it up into a light paste with melted fat: this favourite dish is called kaddel.

Travellers who have visited the central parts of 
A frica complain much of a grievous annoyance to which they were there subjected from the prickles of a grass which grows wild and in great abundance, particularly in the neighbourhood of water. "These prickles are of the finest and most penetrating sharpness that can be imagined, they attach themselves to every part of the dress, and so small are the points that it is impossible to extract them without breaking and leaving a part behind*" The seed from this grass, which is called kaschia, is parched, broken, cleared from the husk, and, when boiled, is eaten in the manner of rice. When previously made into flour, kaschia is considered to be a great luxury.

The Nubians are accustomed to prepare a fermented liquor from dhourra; this, which they call bouzah, is considered by them as a very wholesome and nutritious beverage.

There is one plant, the name of which seems to point it out as proper for receiving some notice in this place, although it has no natural affinity with the cerealia, and the seeds, which are rarely used as human food in any country, are never so employed in England. 'This plant is Buck-wheat-Polygonum fagopyrum,-also frequently called brank. 'The name given to this plant in Germany, where it is most cultivated, is beech-wheal, from the resemblance which the grains bear in shape to the mast or nuts of the beech tree.

Buck-wheat is an annual plant, growing rather handsome, with branched herbaceous stems, having leaves which at first are roundish, but afterwards become arrow-shaped, resembling somewhat those of ivy, but being longer-pointed and much softer. The stalk is round and hollow; its general colour is green, but it sometimes has a reddish tinge - it com-

$$
\text { * Denham. }
$$




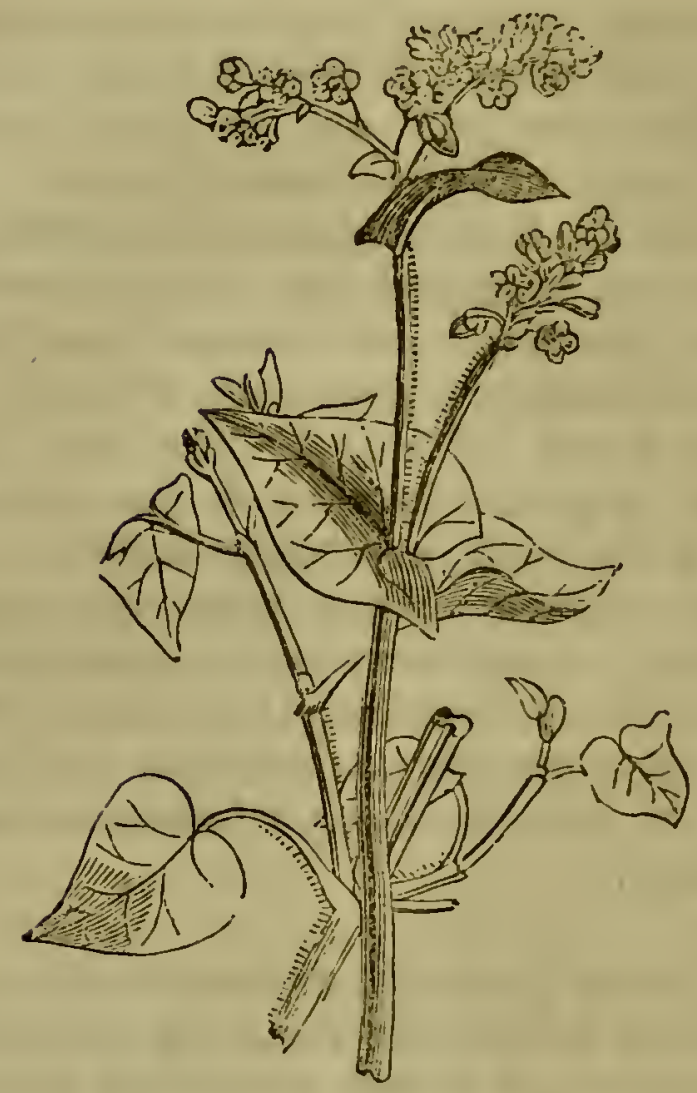

Buck-wheat-Polyyonum fagopyrum.

monly grows to the height of about thirty mches. At almost every joint of the stalk, lateral branches shoot out, which are terminated by purplish flowers, and these are succeeded by small triangular-shaped seeds, which are of a brownish-black colour on the outside, and white within. This grain is usually sown in May or June, and is of such rapid growth that it generally ripens its seeds within about one hundre? days from the time of sowing. It will thrive in any soil, even in those which contain little else than sand. The largest increase is, however, obtained froun dry ground, which has been thoroughly ploughed and pulverized; and in such circumstances as much as fifty or sixty bushels have been reaped from an 
acre on which only one bushel of seed has been bestowed.

This plant is more generally cultivated for the sake of its green fodder, and then the seed is strewn much thicker, as much as three or four bushels being allotted to the acre. If the season is forward, and the weather continues warm, buck-wheat may be sown for this purpose in A pril, and will bear cutting twice during the summer; but the slightest degree of frost will destroy it entirely. When it is thus intended to apply the plant as green meat, a sufficient quantity should be cut one day for the consumption of the next. The state most proper for cutting is when the blossoms are making their appearance.

All animals are fond of this food, and will thrive upon it. When given to cows it causes them to yield an abundance of excellent milk, which makes good butter and cheese. The stalk and leaves will continue green during the driest weather, even when all the grasses in the meadows are burnt up. The straw or haulm is sometimes given in a dry state to cattle, but is not then so useful as when green.

Buck-wheat is also sometimes sown in order that the plants may be ploughed into the ground, and serve as manure in the process of bringing lands into proper order for other crops. The time most proper for this ploughing is when the blossoms are full upon the plants, as they are then in their most succulent state. The land is then left at rest for some months, during which time the vegetable matter of the buckwheat becomes fermented and decomposed. The variety known as Tartarian buck-wheat-Polygonum tataricum,-being of more luxuriant growth than the common sort, fagopyrum, has been preferably recommended for this object.

Birds are exceedingly fond of the seeds, and one of the principal uses made of them in this country is 
to feed pheasants during the winter, in spots set apart for the preservation of that species of game. With this object, the grain is sometimes sown in these preserves, and left standing to afford both cover and food to the birds; at other times, the straw is taken unthreshed, and left in heaps at intervals throughout the places where the birds resort. Such an abundance of their favourite food will not only prevent pheasants from rambling, but frequently allures others from spots where an equally comfortable provision is not made.

Horses are fond of the seeds, which are sometimes given to them in conjunction with oats; it is proper, however, in such case, to subject the buckwheat to the previous operation of crushing. Pigs are often fattened upon buck-wheat, and it is said that if this food be given to them in great quantity at first, it will occasion the animals to exhibit symptoms of intoxication, so that they run squeaking and tumbling about in a grotesque manner. As they become habituated to the use of the grain, such an effect ceases. It is necessary to crush the seeds for this purpose also.

Buck-wheat is sometimes used by distillers, it being capable of yielding a considerable quantity of good spirit. This use is made of it to a great extent at Dantzig, where an extensive manufacture of cordial waters is continually carried on.

The poor of some countries mix the meal of buckwheat with a small proportion of wheat-flour, and make a kind of bread of the compound, which is black and bitter, and deficient in a due degree of nourishment. In Brabant it is not unusual for persons who derive a profit from keeping bees to sow this grain near to their divellings, they being of opinion that no plant is equal to it for affording to those insects a proper supply of materials whelice their sweet store is elaborated. 


\section{Chapter VI.}

\section{The Potato-Solanum tuberosum.}

Potatoes now form so valuable an article of frod in many countries, as to be classed almost among the necessaries of life, and to be ranked next in importance to the cerealia.

The common and very general culture of the potato in this kingdom at the present day renders it difficult of belief, that so comparatively short a period should have elapsed since its introduction, and that the time when this vegetable was served up in small quantities as a rarity should be in the present recollection of aged persons.

There is strong evidence for believing that this plant was first introduced into England by the colorists adventuring to North America under the auspices of Sir Walter Raleigh, who had obtained a patent in 1584 from Queen Elizabeth "for discovering and planting new countries not possessed by Christians." Thomas Heriot, afterwards known as a mathematician, was among these voluntary exiles; who, however, all returned within two years after they had first gone forth for the purpose of founding a colony. These voyagers most probably brought home the potato, since in Heriot's report of the country, which is printed in De Bry's collection of Voyages, he describes (vol. i. p. 17), under the article Roots, a plant called openawk, which there is little doubt is identical with the potato. "The roots of this plant," says he, "are 
round, some as large as a walnut, others much larger-they grow in damp soils, many hanging together as if fixed on ropes. 'They are good food either boiled or roasted." 'The introduction of this plant into Ireland by Sir Walter Raleigh, on his return froin Virginia, is indeed well authenticated by corroborative testimony. In the manuscript minutes of the Royal Society we find that Sir R. Southwell distinctly stated to the fellows, that his grandfather was the first who cultivated the potato in Ireland, and that for this valuable root he was indebted to Sir Walter Raleigh. Among the anecdotes told of this enterprising voyager, it is said that when his gardener at Youghall, in the county of Cork, had reared to the full maturity of "apples" the potatoes which he had received from the knight, as a tine fruit from America, the man brought to his master one of the apples and aslied if that were the fine fruit. Sir Walter having examined it, was, or feigned to be, so dissatisfied, that he ordered the "weed" to be rooted out. The gardener obeyed, and in rooting out the weeds found a bushel of po. tatoes.

In contradiction to the above account, Dr. Campbell, in his Political Survey, states that this plant was not introduced into Ireland until the year 1610; while some writers affirm that the people of that country were in possession of tle potato at a period prior to the one just assigned. One supposition is, that this root was brought from Santa Fe into Ireland in the year 1565; and another, that it is of so very ancient a date in that island as to make it equally probable that it is a native vegretable of the country. It is found, however, that the plant carried to Ireland by Captain Hawkins, in 1565, was the Spanish batata, or sweet potato. The claim to its greater antiquity in that country was made by Sir Lucius O'Brien, 
who stated to Mr. Artliur Young that the venerable Bede mentioned this plant as being in Ireland about the year 700. Sir Lucius did not, however, point out the passage containing any proof of his assertion; and the potato. largely as it is cultivated in that country, has not yet made out its title to a place in the indigenous flora of Ireland.

Gerarde mentions in his Herbal, published 1597 , that he cultivated this plant in his garden, where it succeeded as well as in its native country. He gives a drawing, which he distinguishes by the name of Virginian potato, having, as he states, received the roots from Virginia, otherwise called Nozembega. It was, however, considered by him as a rarity, for he recommends that the root should be eaten as a clelicate dish, and not as common food.

From the authority of more than one writer, it would appear that the potato was brought into southern Europe through a different channel, and at all earlier perod than the introduction of the root from Virginia into this country. Clusius relates that he obtained this root at Vienna in 1599, from the governor of Mons in Hainault, who had procured it in the preceding year from Italy, where, in common with the truffle, it had received the name of taratoufli. Peter Cieca, in his Chronicle, printed in 1553 , chap. xl. p. 49 , relates that the inhabitants of Quito and its vicinity, besides producing maize, cultivated a tuberous root which was used as food under the name of papas: this, it is affirmed, is the same plant which had been transplanted to the south of Europe, and which Clusius received from Hainault.

Humboldt rather doubts if sufficient proof can be produced of this root having been indigenous to South America Upon the interesting subjert of 
the native country of the potato, we gladly quote the following account by Mr. Cruickshanks* :

"Mr. Lambert, in the tenth volume of Brande's Journal, and in the appendix to his splendid work on the genus Pinus, has collected many valuable facts which prove that the potato is found wild in several parts of America, and among others in Chili and Peru. Don José Pavon, in a letter to Mr. Lambert, suys, "The Solanum tuberosum grows wild in the environs of Lima, and fourteen leagues from Lima on the coast; and I myself have found it in the kingdom of Chili,'-and Mr. Lambert adds, 'I have lately received from Mr. Pavon very fine wild specimens of Solanum tuberosum, collected by himself in Peru.' There is also a note from Mr. Lambert on the same subject, in the third volume of the New Edin. Phil. Journ., with an extract from a letter of Mr. Caldcleugh, who sent tubers of the wild plant, some years ago, from Chili to the Horticultural Society. But it is frequently objected, that in some of those countries where the potato is found wild, it may, like many other species met with in that state in America, be an introduced, not an indigcnous plant. There are, however, many reasons for believing that it is really indigenous in Chili, and that wild specimens found there have not been accidentally propagated from any cultivated variety. In that country it is generally found in steep, rocky places, where it could never have been cultivated, and where its accidental introduction is almost impossible. It is very common about Valparaiso, and I have noticed it along the coast for fifteen leagues to the northward of that port; how nucle farther

* Oricinally published in Dr. Hooker's ' Botanical Miscellany; and quoted in she 'Jourual of the Royal Institution,' for December, 1831. 
it may extend north or sonth, I know not. It chiefly inhahits the cliffs and hills near the sea, and I do not, recollect to have seen it at more than two or three leagues from the coast. But there is one peculiarity in the wild plant that I have never seen noticed in print, that its flowers are always pure white, free from the purple tint so common in the cultivated varieties, and this, $I$ think, is a strong evidence of its native origin. Another proof may be drawn from the fact, that while it is often met with in mountainous places, remote from cultivated ground, it is not seen in the immediate neighbourhood of the fields and gardens where it is planted, unless $a$ stream of water run through the ground, which may carry tubers to uncultivated spots. Having observed the distribution of this and other plants through the agency of the streams employed for irrigating the land, I am led to think, that the wild specimens found near Lima may have had similar origin. If they occurred in the valley, this is more than probable, as almost the whole of the land is either cultivated by irrigation, or the uncultivated spots are overflowed when the river is swelled by the rains in the interior. Upon the whole, it may be safely concluded that this important vegetable is really indigenous to Chili; but with respect to Peru, some further evidence appears necessary to remove all doubt on the subject. The question can only be decided by ascertaining the exact situations in which the plants present themselves at Lima and Chancay, especially with respect to land that is or has been cultivated. It would be interesting, too, to know the colour of the flowers."

Though now so extensively used, the value of this root as an esculent was not perfectly appreciated for a great length of time in this country, during which period it was indeed only cultivated in gardens, ard 
that as a curious exotic. 'The potato was considered as a great delicacy in the reign of James the First. At that period, though it formed one of the articles provided for the household of the Queen, the quantity used was extremely small and exorbitantly dear, being at the price of two shillings per pound*. This esculent remained equally scarce throughout the turbulent times of the succeeding reign, and during the Commonwealth. Its cultivation very gradually spread in different parts of Ireland, and also into Lancashire, but not till nearly a hundred years after the discovery of Virginia by Raleigh. Mr. Buckland, of Somersetshire, in the year 1663, drew the attention of the Royal Society to its value, earnestly recommending the general cultivation of the potato throughout the kingdom to guard against a famine. This appeal was not made in vain. A committee was appointed to inquire into its merits, and all those Fellows of the Society who had lands adapted for the growth of the potato, were entreated to plant them with that vegetable;while Mr. Evelyn was requested to notice the subject at the close of his 'Sylva.' This celebrated man appears, however, not to have been aware of the importance of the potato as an article of food, for he did not mention it until more than thirty years after that period, and then in rather slighting terms. In his 'Kalendarium Plantarum,' the first gardener's calendar published in Britain, he thus writes :- ' Plant potatoes in your worst ground. Take them up in November for winter spending, there will enough remain for a stock, though ever so exactly gathered.' In another of his works, - 'Acetarius,' he remarks that the small green fruit or apples of the potato make an excellent salad. This assertion has not, however, been verified by experience.

$$
\text { * Viden on the State of the Poor. }
$$


The zeal of the Royal Society to promote the growth of his vegetable failec for a long time to exercise much influence upon the habits of the nation; and, if we may judge from the opinions which were published respecting the plant, we must conclude that the necessities of the poor of Ireland, who have ever been left too entirely to their own resources, did more to promote the culture of potatoes than all the labours of the learned, and the philanthropy of the patriotic. At the end of the seventeenth century one writer on gardening, indeed, admits that " potatoes are much used in Ireland and America as bread, and may be propagated with advantage to poor people." Woolridge, who wrote in 1687, twenty-four years after the appeal of $\mathrm{Mr}$. Buckland, describes potatoes as being very useful in 'forcing fruits,' stating that they are planted in several places in this country to good advantage; he adds, "I do not hear that it has been yet essayed whether they may not be propagated in great quantities for the use of swine and other cattle." The celebrated Ray, who began to publish his 'Historia Plantarum' in 1656 , takes no farther notice of this vegetable than by saying that it is dressed in the same manner as Spanish batatas. Merritt, who wrote in the following year, records that potatoes were then cultivated in many fields in Wales, but in what part of the principality he does not mention.

On the other hand, Lisle, who made observations on husbandry from the year 1694 to 17222 , is wholly silent about the potato. In Mortimer's Gardener's Kaleudar for 1708 , this plant is directed to be sown in February; and, as if its character had not been generally known, it is added-that " the root is very near the nature of the Jerusalem artichoke, although not so good and wholesoine, but that it may prove good for swine." In the Complete Gardener, by the 
eminent nurserymen, Loudon and Wise, the seventh edition of which was published in 1719 , no mention is Inade of this root; and Bradley, who wrote about the same time, and whose very extensive works on horticultural subjects treated expressly on new improvements in the art, notices it as if by compulsion. "They (potatoes) are," says he, "of less note than horse-radish, radish, scorzonera, beets, and skirret; but as they are not without their admirers, I will not pass them by in silence."

'These facts and extracts are curious, as they serve to show that this most valuable article of food was not brought into g'eneral use by the skill and labour of professional men, but in defiance of their prejudices, and the bad methods of culture which they promulgated. There can indeed be little doubt that the imperfect modes of both cultivating and preparing the potato as an esculent were in a great measure the causes which prevented its more speedy adoption as a wholesome and substantive article of food; while this very ignorance of its nature and management produced the low estimation in which it was held by writers about the beginning of the eighteenth century.

To those who know anything practically of the cultivation of this plant, it must be evident how much the early sowingr, the late taking up, and the leaving in the ground during winter of the roots intended for propagation, tended to deteriorate the quality of the potatoes. These circumstances, together with the little culinary skill exercised in its preparation, caused it to appear under no very tempting form. A person who had been invited to taste the first potatoes which were planted in the county of Forfar, in or about the year 1730, related that the roots had been merely heated, and that they adhered to the teeth like glue, while their flavour 
was far from agreeable. The food was abont to be condernned through the ignorance of the cook, when the accidental arrival of a gentleman who had tasted a potato in Lancashire, caused the rejected roots to be remanded back to the hot turf ashes, till they became as dainty as they had before been nauseous.

We have no records of the early practice and progress of potato-husbandry in Ireland. The more tardy progress and the less favourable results, attendant on this culture in England, might induce a belief that it had been better conducted in the former country; though no doubt the more genial climate of Ireland, its humidity, and the absence of those chilling winds from the east, which are so often fatal to the tender spring crops of England, gave to it a natural advantage, and might perhaps sufficiently account for the superiority of this branch of husbandry in Ireland over England.

The early practice in this country of planting potatoes in February was, in itself, an effectual bar to their goodness as field culture, since the young plants betray their origin to have been from a warmer climate, by their inability to bear the slightest degree of frost with impunity; so that if they put forth their tender heads to the nipping frosts of spring, a great part of the crop is certain to fall a sacrifice. The better quality of the potato grown in Ireland, and its excellence as a substantive article of food among a population sunk to the lowest state of poverty, caused it to be brought into general use in that country, finding its way even to the tables of the rich, at a period when it was scarcely known in the sister island.

The introduction of this plant into Scotland was probably earlier than into any part of England, with the exception, perhaps, of Lancashire. The people 
living in that county were then distinguished by a marked difference of habits, manners, and characier, from their neighbours. A remnant of these peculiarities is even still to be found, notwithstanding the singularities of the inhabitants, and local circumstances, combined to render this a favourable situation for the introduction and improvement of the potato.

The land in Lancashire is rather poor, and the climate rainy, so that wheat, with even the present improved system of husbandry, cannot be raised to very great advantagee. Oats were consequently there, as in Ireland and the Lowlands of Scotland, the staple production. The mechanics, who worked chiefly in iron and brass, were all cottagers, who followed their respective employments in the winter, and raised food for themselves upon their little patches of land in the summer. The population of Lancashire then bore a great resemblance to the cotters of Ireland. They were, however, more ingenious in handicraft works, and still more resem. bled the manufacturing peasantry in the centre and south of Scotland, who grow the whole or the greater part of their food upon their cottage lands. Even the education of their children was formerly often obtained out of the produce of their little field; the school-master went " thigging," that is, collecting a portion of produce from every cottager, in proportion to the wealth of the individual, and to the number of pupils he might have contributed to the school-room. The poor likewise were relieved by a voluntary contribution of produce, and it is probable that this system worked as well as that of a compulsory rate. Even in the smaller burghts of Scotland, and in the villages where the lands are held on feu or perpetual lease, the same system was, and in many places still is, followed. The portioners, as they are called, are allowed a house in the village, 
and land for their subsistence, in the surrounding fields.

In such a state of the peasantry the cultivation of the potato would offer peculiar advantages, as no other substantive article of food could be raised by the inexperienced rustic in equal quantities, with so little risk and trouble, and without any but his own and his family's labour being required for its culture and after-preparation. Accordingly, when once this plant was introduced into cottage cultivation in Scotland, its importance was quickly recognized.

It is understood, however, that this valuable root was not, until the year 1728, made the object of useful culture annong the Scotch, and they were then indebted to a cottager for first attempting its culture. 'This man's name was Thomas Prentice; he was a day-lahourer living near Kilsyth, in Stirlingshire, and drawing his subsistence partly from the produce of his little plot of ground. This crop proved extremely valuable, and was almost instantly in demand for propagating other crops, first among the cottagers, and then among the farmers. Prentice continued to cultivate this root very carefully, and to supply his neighbours with the produce of his crop. He was, moreover, frugal and industrious, so that in a few years he found himself in possession of two hundred pounds, no small fortune at that time and in that place. When he had " made his fortune," he sank his capital in an annuity, at a good interest, upon which he lived independently to an old age. The last years of his life were spent in Edinburgh, where he died in the year 1792, at the advanced age of eighty-six, havirog thus been, for sixty-four years, a witness to the happy effects of the blessing which lie had been instrumental in conferring on his country. 
But notwithstanding the success that attended the culture of the potato among the cottagers, its progress among the higher classes in Scotland was retarded by the opinions of the writers formerly alluded to ; while, what is not a little singular, a mistaken zeal in religious matters made some of the Scotch folks hostile to the innovation. "Potatoes," said they, "are not mentioned in the bible," and thus the same anathema was pronounced against them as against the "spinning-wheel," and the " corn farmers.

The name of this plant was indeed inserted in the - Hortus Medicus Edinburgensis,' published by Sutherland in 1683. It is therefore probable that the potato had been introduced as a curiosity into some of the gardens about Edinburgh some time before it was brought into fuli culture by Prentice. But if its management was the same as that recommended by so great an authority as Evelyn, the produce was, most probably, of little value.

The year 1742, which was long remembered in Scotland as "the dear year," gave an impulse to the cultivation of the potato. Old people who were still living at the beginning of the present century, represented the state of things in the simmmer of 1743 as being dreadful. Many of the destitute wandered in the fields seeking to prolong the misery of existence by devouring the leaves of pease and beans, of sorrel and other wild plants, while not a few perished from absolute want, and still more were carried off by those diseases which always follow and aggravate the devastations of famine. This state of distress naturally called the general attention to the cultivation of the potato, and indeed to the whole agriculture of the country. So that, during the latter half of the eighteenth century, the practice and science of husbandry made much more rapid progress 
in Scotland than in England. Previously to this general scarcity in 1743 , some potatoes which were growing in the county of Roxburgh were so uncommon as to have been considered objects of curiosity. But the state of things soon altered, and immediately after " the dear year" the farmers of Lothian began to make this a branch of field husbandry.

In England, with the exception of Lancashire, the progress of the cultivation of the potato continued at an extremely slow pace. It was known in Yorkshire only as garden produce down to 1760 ; and in Somersetshire it was rare indeed to meet with a whole acre under this culture so late as 1770 .

So little attention had been bestowed on this subject even by the most intelligent land-owners, that Miller, in the quarto edition of his Gardener's Dictionary, published in 1771 , names only two varieties, and founds the distinction of these not upon quality, or time of coming to maturity, but on the trifling accident of a red and of a white colour, which is found to be productive of no other difference. At present, however, the varieties are so numerous, without any reference to colour, that it would be equally vain to attempt their description within any limited compass, as it is unnecessary to point out their uses or enumerate their properties.

Not many years after the appearance of Miller's valuable work, the potato began to form an important article of English husbandry; and in the year 1796 it was found that in the county of Essex alone seventeen hundred acres were planted with this root for the supply of the London market *

The culture of the potato is now so extensive in this country, that an abundant supply can be ob tained in all places throughout the year, and such have been the improvements in the culture, and the 
varieties to which these improvements have led, that a succession is furnished fresh out of the earth for nearly six months in the year. The early sorts have been the reward of horticultural skill now so success. fully exerted in this country; under the shelter of frames, with careful management, the tender young plants are made to struggle through ungenial weather, and to produce tubers at the earliest approach of sumimer.

The culture of the potato in the rest of Europe appears to have attained to no great extent until during the last century. In the latter half of this period it was made in more than one country a subject of interest and inquiry. Several works published about that time, treating on its culture, are to be found in both the French and (ierman languages. From one of these* we learn that the potato was introduced from England into the Netherlands; and was thence transplanted into some parts of Germany. It was first cultivated in Sweden in 1720, but, notwithstanding the exertions and recommendations of Linnæus, it did not come into general cultivation until 1764, when a royal edict was published for the encouragement of this branch of husbaudry.

The potato was still unknown to the agriculturists of Saxony so late as 1740 ; but so rapidly did its culture increase, that less than thirty years after the above date, a small detachment of the French army, while in that country, having its supplies wholly cut off; the soldiers subsisted for eight or ten days entirely on potatoes obtained from the fields; nor was this manner of living considered among them as by ally means a hardship.

'The Swiss discovered the value of this cultivation about the same period in which it was introduced

* Traité de la Nature de la Culture et de l'Utilité des Pommes de Terre, par Un Ami des Hommes, 1771. 
into Sweden, and in a few years they not only grew potatoes among their mountains in abundance, but had likewise learnt the art of drying them, grinding them into flour, and making them into bread. A traveller in 1730 relates that the milier of Untersen had scarcely anything to grind but potatoes; and in 1734 a peasant was so well aware of the profit arising from this culture, that he bought a small field situated near the Swiss mountains, and in only two years after paid the purchase-money by the produce of his potato crops*.

It is said by another writer $t$, about the same period $(1770)$, that during the twenty-five or thirty years preceding, the culture of this root in some parts of Switzerland had so much increased, that it constituted the food of two-thirds of the people. In the present day it still forms a principal article of food among the peasantry of that country.

It likewise makes a very prominent figure in the husbandry of Poland, where it is cultivated to an extraordinary extent. In 1827 as much as $4,288,185$ korzecs + of potatoes were produced in that country, while $4,439,399$ korzecs of rye were reaped, $3,183,023$ of oats, 4,506,062 of barley, and 751,076 of wheat $\$$.

The cultivation of the potato has been of late years introduced into some parts of India with every prospect of success. In Bengal, especially, it has been attended with the most satisfactory results. Bishop Heber, in his interesting Journal, notices in several places the progress of this culture, the crops becoming by degrees more and more extended. These roots were at first very unpopular, but they have gradually gained favour, and are now spoker

* Traité de la Nature, \&c.

+ Dictionnaire de Bomare, Art. Pommes de Terre.

† One korzec is nearly equal to two hundred weight.

Foreign Quarterly Reriew, No. xip. p. $5 \% 1$. 
of as being the best gift which the natives ever received from their European masters. They are, we are told, held in much esteem, "particularly by the Mussulmans, who find them very useful as absorbents in their greasy messes*." The following observations are gathered from the same volumes. In the neighbourhood of Patna many descriptions of European vegetables are brought to market in abundance; they are, however, reared for the consumption of the European inhabitants alone, the natives rejecting all but the potato, which, though known only since the last few years, may perhaps soon take its rank with rice and plantains, as a substantive article of food with the frugal Hindu. It is already argely cultivated in that district, but can never become an exclusive crop, inasmuch as those humid stiff soils which are peculiarly favourable to the growth of rice, are wholly unsuited to the potato, the cultivation of which must therefore be confined to those sandy and drier soils, which are inimical to the culture of the rice plant. In such situations this vegetable of English production may be raised with unmixed utility, while the resource of so important a supplementary crop may, in seasons of the failure of the rice liarvest, avert the evils of famine, and diminish, in one strong point of view, the resemblance between the Indian and Irish peasantry-their reliance on a single article of food. The almost infinite division and subdivision of their farms is in India, as in Ireland, a fertile source of poverty and wretcheduess.

The observations of another intelligent writer $\dagger$ on the same subject likewise tend to show the advantages which may result from this cultivation in Hindostan. He remarks that a dry season is preju-

* Heber's Juurney, vol.i. p. 13.

+ Tenuant's Indian Researches. 
dicial to the rice crop, while it is favourable, or rather not so hurtful, to that of the potato, and "therefore nature points out the one crop as a substitute when the other fails." It is certainly a fortunate circumstance that the superstition by which the Hindu is enslaved does not shut up every avenue to innovation and improvement. No religious prejudice forbids the culture of this vegetable, and therefore the natives evince a readiness to adopt it in all situations where it can be as easily obtained as other food*. The soil of Bengal, and the long continuance of dry weather, may, perhaps, be obstacles sufficient to prevent this root from becoming the principal nourishment of the lower orders; but it is supposed that if it could be raised cheaper than rice, the potato would be generally preferred by Hindus. At present it is almost universally served up at European tables in Bengal in the same manner as in England; and though the crop is less abundant, and the roots are smaller in size, they are scarcely inferior in quality to those of this country.

Wherever the Englishman seeks a home, he always strives to naturalize this root, which was so long struggling into notice in his own country. Now amid all the luxuriant and delicions vegetation of tropical climes, he still retains his preference for that simple vegetable, which he considers almost a necessary of life. At Ceylon all his attempts to cultivate this plant have been nearly vain,

* The Southern Africans in this respect prove themselves more oostinately adverse to innovation than the hindu. "The Matchappees, though very fond of potatoes, have never been prevailed upon to plaut any, because they resemble nothing which has been handed down to them from their forefathers, to whose manners and customs they seem as strongly attached as the Hindu or the Mussulman."-Campbell's Travels in South Africa, rol.i. p. 101 . 
as it will not thrive in that island at any place except at Candy, a town almost seventy miles in the interior, and the only spot in the country where European vegetables come to any degree of perfection. $A$ basket of these roots is sent every morning thence for the supply of the governor's table, as all the indigenous vegetables are considered an inferior substitute for this necessary auxiliary to the Englishman's more substantial fare*.

It would be superfluous to give any but a slight description of a plant so well known, as annually forming new subterranean tubers, and rising with weak, slender, and branching stems, from two to three feet in height. The leaves are composed of leaflets of unequal size, the flowers are white or of a purple tinge, producing large berries, which are green at first, but which change nearly to black when at maturity, and contain numerous small white seeds. The supposed root consists of many tubers connected to the base of the stems by cords or fibres, and having minute bianchy rootlets which issue from different parts of each tuber, and which serve to convey nourishment to the plant. The several points whence these are produced are usually called the eyes of the potato, and each of them contains the germ of a future plant.

The uplands and the lighter soils are found to be much better adapted than rich and strong lands to the cultivation of the potato. This root has one great advantage over all grain and leguminous crops, in being perfectly secure against the late rains, which often completely destroy the hopes of the farmer. Rains which have no bad effects upon the potato, injure the bloom upon the cerealia, or canse them and the legumes to run so much to straw as

* Heber's Journey, vol. iii. 
nut only to be less productive of seed, but actually to lodge and rot. The quality of the roots is no loubt a little deteriorated by excess of moisture, but when they are sufficiently matured, rain has little or no injurious influence over them.

This plant seems alone to have been wanted to make the agriculture of the British Isles complete. Upon the western side, and among the mountains, a grain crop is always precarious, and seldom or never good. Scanty and bad as it is, its culture is also expensive, as, after it has been reaped, it cannot be left in the field to dry, but must be taken wet into barns constructed of wicker-work, for the purpose of obtaining a current of air, and there suspended upon ropes. Such a process is not merely tedious and costly, but absolutely incompatible with the culture of any considerable quantity of grain.

A new soil produces better potatoes than worked land in the highest condition; and ground which is light and spongy, provided that it has the advantage of plenty of moisture, which does not stagnate, is better than the strongest lands. The reasons are ubvious-the tubers will form with the greater ease according as the resistance is less which the ground offers to their expansion, while so large a quantity of regetable matter elaborated in so brief a space demands no little supply of humidity. Now the little patches among mountains are composed of the very best soil for this purpose, being generally a mixture of sand and vegetable matter. Such a soil is readily penetrated throughout by every shower, and yet the water does not stagnate; as a mountainous country near the sea is, in high latitudes, always one in which there are frequent showers, the watering of these mountain patches is precisely that which is most beneficial, and therefore it would be difficult to imagine a soil and climate better fitted 
for the growth or for producing excellence in the quality of these tuberous roots.

When cultivated in tenacious argillaceous soils, if the summer be dry, the swelling of the tubers is prevented by the mechanical pressure of the earth; and on the other hand, such soils, if kept constantly in a. state of moisture, produce immature tubers, which are sodden, waxy, and otherwise of bad quality. But in ground which to all appearance is little else than loose sand, if there be humidity enough, potatoes will grow and be of excellent quality, and, even should there be any failure in the sufficiency of moisture, the quality of roots yielded by the first planting will be good, but they will be small, and too hard for propagating. In the mountain districts of Scotland the frequent rains in all seasons are of so constant recurrence, that a whole week of dry weather is considered worthy of record. This circumstance, so unfavourable to the maturity of other crops, operating in union with the peculiar nature of the soil, causes the situation to be well adapted to this cultivation: while there are still other advantages on the west coast of the Scottish Highlands, and which apply in a great measure to Ireland. In the first place there is very little frostnever any except in high and comparatively inland places-until the potatoes are come to their proper growth. Again, spade husbandry is best adapted for potatoes, and it is also the best for those places, where the acclivities are generally too abrupt, and the spots of land really worth culture too small to admit of the use of the plough with any advantage. Persons who are acquainted with only flat countries, where there is little inequality of soil in a field, and no absolute sterility in a parish, but that which is consequent on neglect, can form but an imperfect idea of the variations witnessed in a little portion of 
mountain land. In a section of thirty yards there may be ten yards of useless gravel in which moisture can find no resting-place till it be fathoms deep in the ground, tell where there is not above three inches of soil on the bare rock, and ten of soil of the very best quality. The first and second portions would not of course produce a crop of any description, and yet in the use of the plough it would be necessary to pass over them, or to lose about the same time in turning; so that the expense of ploughing such a piece of land would be triple that of ploughing the same extent of a champaign country. On the other hand, whell the spade is employed, the culture of the fertile spots is not more expensive than if they were continuous, and situated on the flattest surface in the island; while the nature of the soil renders the labour of turning it and taking up the crop comparatively easy.

Thus the potato has this great and peculiar advantage over all other substantive esculent vegetables, that it can be not only cultivated in places where no others can be profitably grown, but that it can be cultivated there at small expense; while it is less subject to disease, and more secure against degenerating in those situations than on richer lands. Consequently, in a soil so diversified as that of Britain, alud where the communication between any two places is so easy, an almost unlimited supply of potatnes may be grown without any diminution of the breadth of profitable crop of the cerealia, the legumes, or indeed of any other useful plant; while this crop is recommended as causing an amelioration rather than an exhaustion of the soil.

The most usual and profitable manner of propagating this vegetable is by putting into the ground the tubers, either whole or divided into as many parts or sets as they contain eyes. 'The quality of soil best 
adapted for this culture has already been sufticiently indicated. The sets are planted in lines from twenty to -wenty-four inches apart, either in drills or by the dibble, at intervals of fiom twelve to fifteen inches. The proper season for planting the main crop is froin the middle to the end of March, and a peck of seed potatoes is usually required to plant a bed of twelve feet by thirty-two. In field culture eighteen bushels are planted in one acre. The young plants are kept free from weeds, and when they are about half a toot or a foot high, some earth is drawn around the lower part of the stem; little or no farther care is required till the taking up of the crop. The plants are suffered to remain until the roots attain to their full growth. This state is indicated by the stalks begimning to decay, which usually takes place at the commencement or latter end of October, when the roots should be dug up for the winter store. Some careful cultivators pinch off the blossoms as they appear on the plant: the good effects of this practice have been very often proved, it being supposed that the weight of the tubers of each plant is increased an ounce in consequence, or considerably above a ton per acre*. The cause of this result has been thus explained;-the fluid or sap gives sustenance alike to the tuber and blossom, and therefore, if a portion be diverted from the formation of the blossom, it ivill be exerted for the enlargement of the root.

This plant may be propagated also from cuttings or layers of the green shoots, and from seeds. The first is not at all advantageous for any culture, except in some instances, when it is required to multiply as quickly as possible a rare sort.

The tubers obtained from seeds are at first very few and very small, and therefore seed "cultivation is by no means adviseable to "the grower" of po.

* Hort. Trans. vol. i. 
tatoes; but it is of great service to " the breeder," who seeks to improve its quality. No vegretable is more yielding to the hand of the cultivator than this plant. Raising it from seed enables him to obtain varieties without end, and attention to the qualities of those between which the crossings take place, admits of obtaining any particular quality that may be wanted.

On the other hand, by cultivation from the tubers a good variety may be extended and preserved after it has been once obtained; as the plant from the tuber is not a new plant, like that which is procured by the operations of flowering and seeding, but an identical part of the old one. Though the planting tubers will not lead to any new variety, it may have effects every way as advantageous; for no plant profits more by changes from one district to another.

Besides improvement in quality which a judicious change produces, it likewise often prevents the most destructive disease to which the potato is liable. That disease is known by the technical name of the curl or the curl-top, a name by no means inexpressive of the appearance of the plant, when under its influence. The top leaves begin to shrink just about the time that the tubers should form, the young shoots cease to expand, and the whole plant assumes very much the appearance of the tip of a cherry twig, when the under leaves are assailed by aphides. From the moment in which this disease appears, all farther growth in the plant ceases, and though it may linger in a yellow and sickly state until autumn, the produce, if any, is little, and that little is of a bad quality. If, as soon as the disease shows itself, the tuber which lias been planted be taken up, it will be found much firmer and less exhausted than those of the plants of the same age that are in a healthy state. This at the same time points out the cause of the disease, and suggests 
its remedy. The old tuber has been too compact for yielding, to the vegetative powers of the plant.

'The curl first made its appearance in this country in the year 1764. in Lencashire, where potatoes had been first introduced into British field culture, and had been propagated without any change of seed. From Lancashire this disease spread over all the potato districts of Britain, and as the cause and cure were equally unknown, there was a general ap. prehension that the plant would be exterminated. Premiums were offered by different agricultural societies to those who should point out a remedy for a disease so destructive; in consequence of which many speculations and theories were raised, which, however, led to very little practical utility

The discovery of at least a temporary preventive, and therefore of the probable cause, was made, as is believed, more from accident than design, in the neighbourliood of Edinburgh. Some of the growers in that situation were in the habit of procuring seed potatoes from the cold moorland districts, and fields planted with these were free from the curl. Upon inquiry it was found that in those bleak and humid situations, the potato crop was so late that the frost came on and blackened the leaves, while they and the stems were still green, and the tubers of course not ripe. The change of climate was therefore not the sole cause of prevention, if indeed it was the cause at all, for when the full ripened potatoes were planted in the moors, the curl appeared in them, in situations where there was none in the native potatoes.

It was thus found that the curl could be prevented by using tubers that were not quite ripe.

A writer in the Gardener's Magazine for May 1827, thus ingeniously accounts for this fact:-" The potato tuber is a perfect organized system, in which the circulation regularly proceeds, and if suffered 
to ripen will then tend to decay; but if separated before ripe from the stem or stalk which furnishes it with blood or fruit sap, descending from the leaves, the circulation of the blood-sap is suddenly arrested. The ripe potato, having performed all its operations, becomes more inert; but the circulation of the sap in the unripe tuber having been stopped, it starts more readily, and with greater vigour, when planted; the one appears to die, worn out with age, the other seems accidentally to have fallen asleep, and when awakened, possesses an unspent vigour and energy."-p. 317.

That over-ripeness is the principal cause of the disease, has been found by experience to be so much the case, that out of the same potato it is possible to make some sets that will, and others that will not, produce the curl. The portion of the tuber that is nearest to the cord by which it is fastened to the plant, ripens first, as any one may observe, especially in an elongated potato, where the root end is often so mealy as to fall to powder, when the top or thick end is soft and waxy. If such a potato be taken when only the small end is ripe enough to boil mealy, the eyes upon another of the same parcel that are upon the waxy part, will al, produce sound plants, while curl may appear in those which are taken from the mealy end. The soil and mode of culture may have likewise some effect in producing this evil. Experience has shown that high culture and stimulating manure tend more to produce curl than poorer treatment, - that this disease is less frequent in new lands than in those which have been long in culture, - and that it seldom appears in cold and upland places.

The economy of this article of food, as compared with wheat, is seldom questioned, although doubts have been raised even as to its comparative cheap- 
ness with wheaten bread. The following statement, from Mr. Jacob's Corn Tracts, contains, as it appears to us, all the facts that can be depended upon for forming an opinion on this question:-

"If an acre of land, with the same degree of labour bestowed upon it, and the same portion of manure applied to it, yields 300 bushels of potatoes, it may yield 24 bushels of wheat. The food produced by the former, at $38 \mathrm{lbs}$. to the bushel, will then be 11,400lbs. in weight; the food from the latter, at $60 \mathrm{lbs}$. to the bushel, will be $1,400 \mathrm{lbs}$, or the weight of the wheat will be one-eighth that of the potatoes. It is difficult to ascertain the quantity of nutrition in a given quantity of either wheat or potatoes. The chemical experiments of Sir Humphrey Davy show that wheat contains about three times the quantity of mucilage or starch, and of gluten or albumen, of what is contained in a like weight of potatoes but that potatoes contain also about from three to four per cent. of their weight of saccharine matter, in which wheat is deficient, though it abounds in barley. The difficulty of estimating the nutritive power of the two substances is not wholly removed by this appeal to chemistry, because we are still ignorant of the effect which the combination of the saccharine matter with the inucilage and gluten may produce when used as aliment. A small addition of the former to the two satter may communicate to the whole mass a degree of nutritive power very far exceeding its own separate proportion of weight. Some inquiries have been made as to the actual quantity of potatoes consumed per head in families in Ireland, in Prussia, and in Saxony; but the answers varied to such a degree, as to be little satisfactory. It does not appear to me to be very far from the fact, if we estimate the proportion of the nutritive power of wheat to that of potatoes, as about seven is to two; or that $2 \mathrm{lbs}$ of 
wheat afford as much subsistence as 7 lbs. of potatoes, though it may be doubtful if it affords so much nourishment. We have seen before, that the mean weight of the two kinds of food, from the same extent of land, is nearly as one to eight; and now assume that the consumption of an individual is yearly one quarter, or 480 lbs. of wheat, or an equivalent quantity of potatoes, being $1680 \mathrm{lbs}$, then one acre of wheat will produce sustenance for three persons, or one acre of potatoes will afford it to six and fivesixths *."

The productiveness and other circumstances attendant on the culture of this root certainly point it out as one of the cheapest articles of substantive food that a population can use; and therefore we may conclude that in those countries where the labouring classes are forced to subsist on this nourishment, they are in a state of indigence in which the healthy industry of a fertile land should not be placed.

Potatoes may be made to yield a spirit of a very pure quality. It is supposed that they are a cheaper material than barley fiom which to extract alcohol. But attempts in this country profitably to distil from potatoes have always failed. At present, however, in a distillery at Guernsey a spirit is made from them with success.

In the eastern part of Prussia, as stated by Mr. Jacob in his Reports, potatoes are applied to many useful purposes. They are cultivated to a great extent, and by converting them into starch and treacle that land is made to yield a profit which might otherwise have produced a loss. Sugar did not answer so well; "but the treacle," says Mr. Jacob, "appeared to me as sweet as any from the tropics, the only perceptible difference between them was that it had less consistence."

$$
\text { * acob's 'Tracts on the Corn-Trade, p. } 169 .
$$




\section{Chapter VII.}

OTHER VEGETABLE SUBSTANCES USED FOR SUBSTANTIVE FOOD.

IT may be useful and interesting to take a rapid view of the food which the vegetable kingdom offers to large bodies of manlind for cultivation, in addition to those most important productions, the corn-plants and the potato, which we have fully noticed.

\section{Casseva.-Jatropha Manihot.}

THIs plant is known also as the edible-rooted physicnut, and in Brazil it bears the name of Mandioc. It springs from a tough, branched, woody root, the slender collateral fibres of which swell into those farinaceous masses for which alone the plant is cultivated.

The height to which the cassava attains varies from four to six feet; it rises by a slender, woody, knotted stall, furnished with alternate palmated leaves, which are smooth, and increase in breadth till within an inch and a half from the top, when they diminish to an acute point. The middle lobes are six inches long, and two inches broad in the broadest part; the two next are an inch shorter, and the outer lobes are only three inches long.

South America is held to be the native region of this plant, which formerly afforded the greatest part of their sustenance to the entire Indian population of that vast region. In the Mexican states, cassava is more used on the western than on the eastern const. 


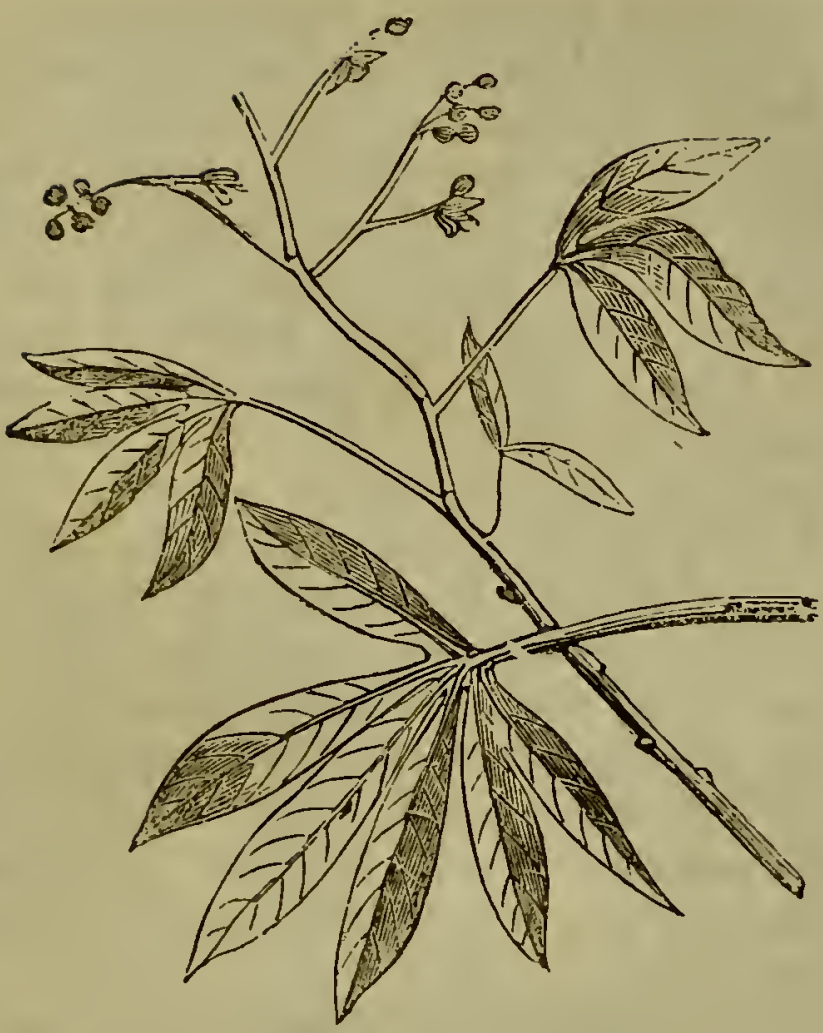

Casse. a-Jatropha Manihut.

When the climate is favourable, the plant is of a hardy nature and of easy culture. It however requires the land to be of good quality, and the same spot cannot well be employed to yield two crops of it in succession. It reeds a dry situation for its most successful cultivation, and when spots of a different nature are applied to the purpose, precautions must be taken, by raising hillocks whereon to set the cuttings, against the effects of excessive moisture, which would rot the plants: some moisture is, notwithstanding this, needed by the plant at its earliest stages.

There are nine different species of Jatropha enumerated by bolanists, only two of which are cultivated for human food. These two are, 
The Jatropha Manihot_or bitter cassava ; and

The Jatropha Janipha-or sweet cassava.

The first of these varieties, when in its natural state, is highly poisonous; while the other, although equally agreeable and wholly innocuous, is yet not cultivated to anything like an equal extent. The two roots are very similar in appearance, their only perceptible cifference being a tough, ligneous fibre or cord running through the heart of the sweet cassava root, which the bitter variety is wholly without. Bread is made of both kinds, which is palatable and wholesome; and although its taste may be thought somewhat harsh by persons accustomed to soft fermented bread made from wheaten flour, cassava bread is not without its admirers, and is in such high repute with those who have been accustomed to its use, as to be frequently procured at some expense and trouble by Creole families who have transferred their residence to Europe.

The tubers are spindle-shaped, much resembling. parsnips in appearance: they are generally about fourteen or fifteen inches long, and four or five inches thick at the middle. When first dug out of the ground they are washed clean; the rind, which is of a dark colour is then peeled off, and the root is ground or grated. In Brazil, where the preparation of mandioc is carried on to a larger extent than in any other place, many persons are employed together in peeling the roots, which are then applied to and pressed against the face of a wheel, which is made to revolve with great velocity, and in this manner they are ground, a trough being placed beneath the wheel to receive the pulp. The next process is that of expressing the poisonous juice, which is effected by placing the pulp in bags, and subjecting it to the action of a press. The only farther operation required to fit it for consumption is that of baking, 
which is then performed on a hot iron hearth. The pulp being placed on this, forms itself into a very thin cake, similar in form to a pancake, and fifteen inches or more in diameter. During the period occupied in this baking, the calie is kept constantly in motion to prevent its being partially burnt, and as soon as it is crisp is removed from the fire: when sufficiently cool it is then quite fit for use. If kept in a dry situation, these cakes will remain grood for a very long period.

To whatever cause the poisonous quality of the juice of bitter cassara may be owing, it is so highly volatile as to be entirely dissipated by exposure to heat. Even a comparatively low temperature suffices for correcting its deleterious nature; for when the root has been cut into small pieces and exposed during. some hours to the direct rays of the sun, cattle may be fed on it with perfect safety. If the recently extracted juice be drunk by cattle or poultry, these will speedily become much swollen and die in convulsions; but if this same liquid is boiled with meat and seasoned, it forms a favourite soup, called by the Brazilians casserepo, and which is found to be wholesome and nutritious. Dr. Pinckard mentions having partaken of this soup in Demerara*.

Stedman acquaints us that the Indians of Guiana, among whom cassava forms the chief bread, first grind the root on a rough stone, and then, for the purpose of separating the juice, prepare a curious kind of press out of reeds, which being disposed in the form of a long tube and secured at bottom, the ground pulp is introduced, and the press being suspended to a tree, a heavy stone or $\log$ of wood is fixed to the lottom, the weight of which draws the tube gradually together, by which means the juice is sqecezed through the interstices. Occasionally the * Notes on the West Indies, rol, ii, p. 257. 
juice is collected into a receptacie, and is thell used for the poisoning of arrows. 'The baking process of these inhabitants of the woods is similar to that described above, with this only difference, that, being without.iron plates, their cooking is performed upon heated stones*.

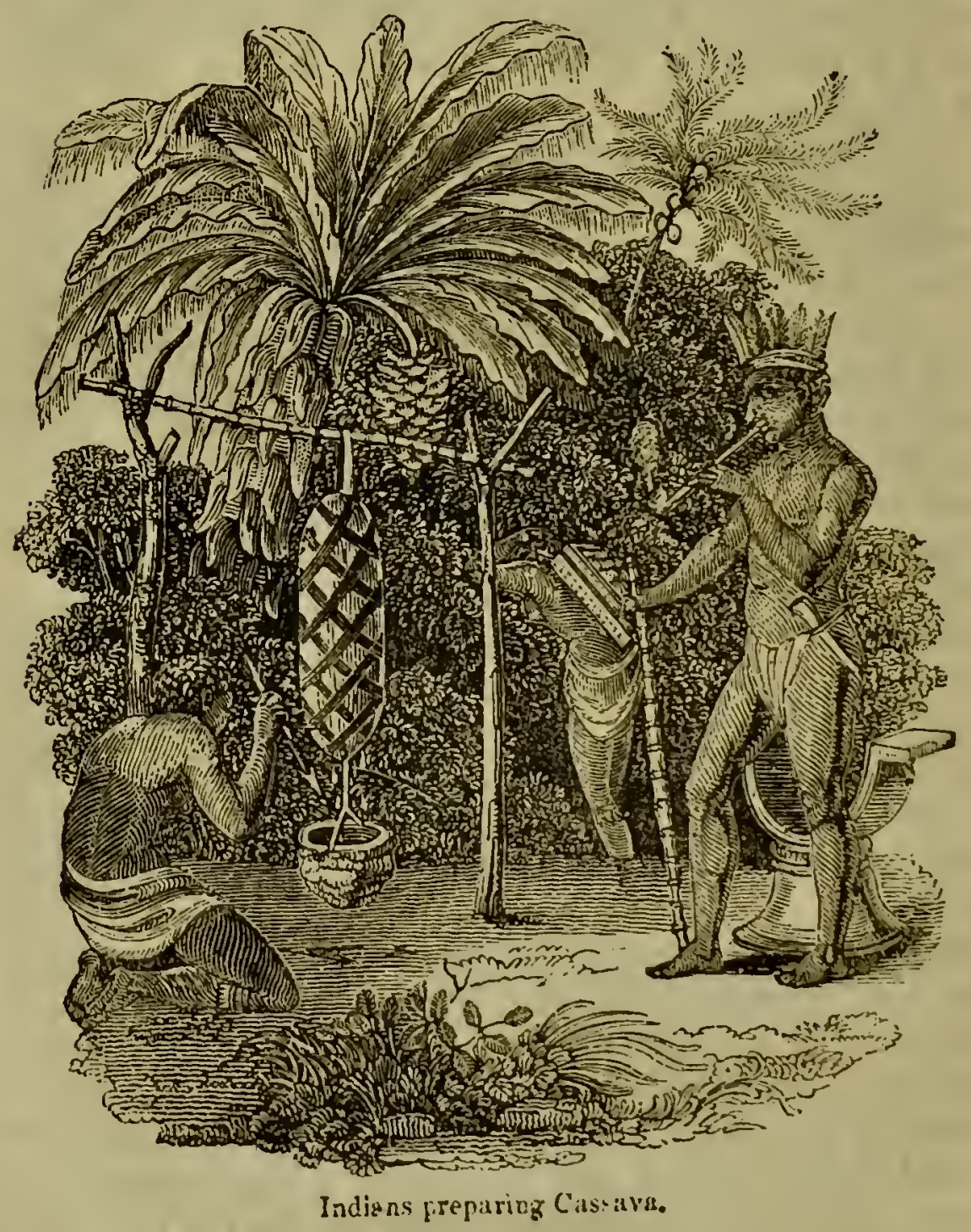

The roois of awect cassava are eater by the in. dians after roasting them in hot ashes, and withous

* Narrative of an Expedition to Surinam, vol. i. p. 105. 
submitting them to the previous processes of grinding and expressing the juice.

Both plants are propagated by cuttings, which very quickly take root, and in about eight months from the time of their being planted, the tubers will generally be in a fit state to be collected; they may however be left in the ground for many months longer withont sustaining any injury.

The juice of mandioc is sometimes fermented with the addition of molasses, and converted into an intoxicating liquor in great favour with the Indians and negroes. The former of these possessed a knowledge of the means of preparing inebriating fluids when first they were visited by Europeans, who in this instance are therefore free from the reproach which in too many cases attaches to them of introducing the practice of drunkenness anong those whom they were bound to have enlightened by communicating knowledgre, rather than to have brutalized by imparting vices.

Tapioca, which is capable of being made into excellent puddings, and which is a very wholesome food for children, and for persons whose digeestive powers are feeble, is a kind of starch prepared from the farina of cassava roots. A considerable quantity of this preparation is exported annually from Brazil to Europe.

A new species of phaseolus was accidentally discovered some time since in the island of St. Domingo. A gentleman, who was collecting plants in that island for the King of France, taking shetter in a cave, observed near it, upon some trees, a climbing plant, bearing clusters of diy pods. 'Tliese seeds he gathered and sowed. The plants grew quickly and luxuriantly, and produced many roots, closely resembling that of cassava, and these, upon heing treated in the manner already describerl, yiekled very good cassava breacl. In consequence of this 
discovery, the plant, which was found growing com. monly in the woods of St. Domingo, was for some time after used in this manner: no part of the plant, with the exception of the tuberous root was found to be edible.

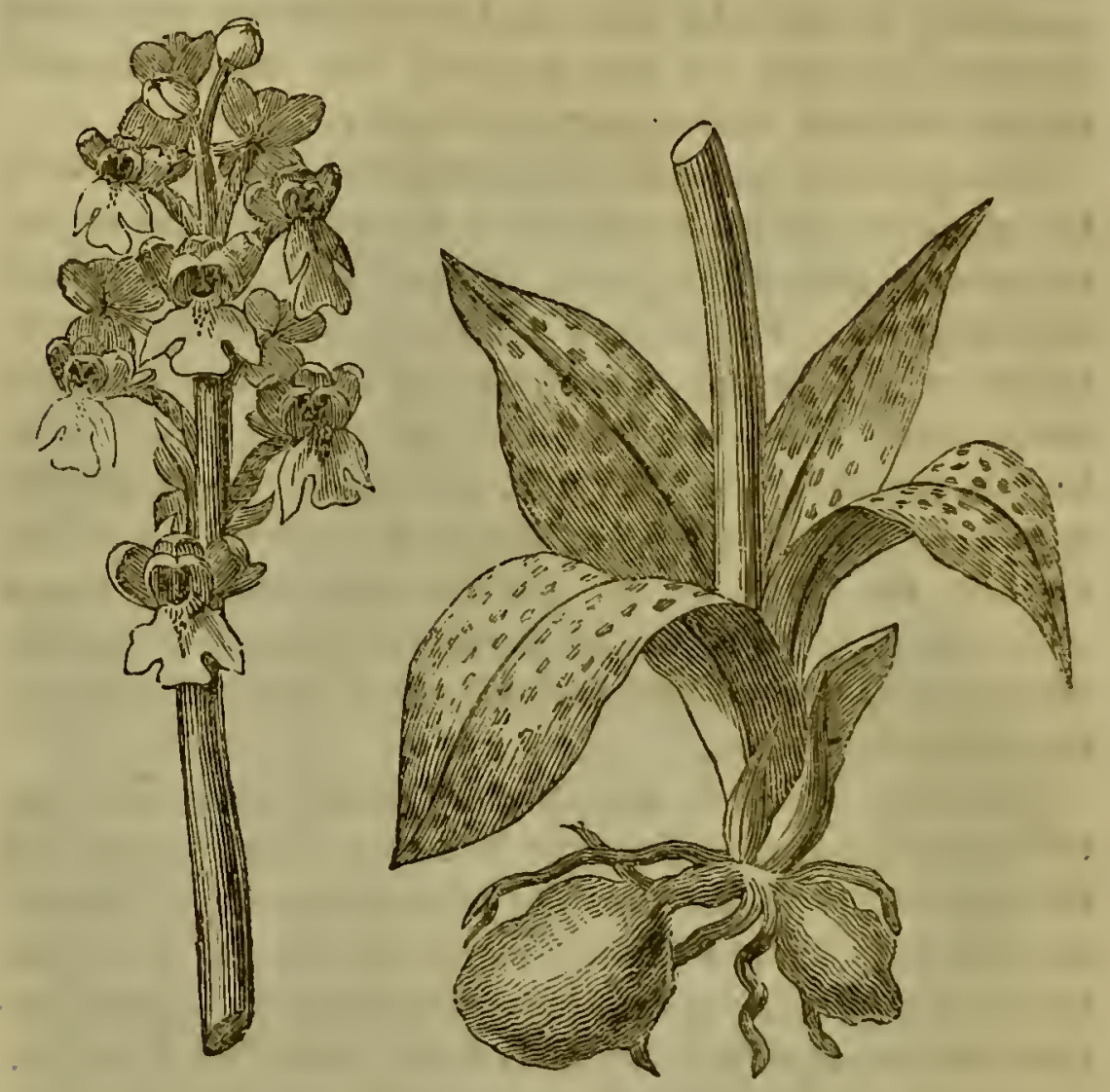

Silep-Orchis mascula.

SALEP-Orchis mascula.-This plant is assidu ously cultivated in the East, for the sake of its root, which forms a considerable part of the diet of the inhabitants of Turkey, Syria, and Persin. Botanists have enumerated many species of this genus or plants, which are fleshy rooted, and from several of which salep may be prepared. That which is generally preferred, however, is the one above named. the orchis mescula, or male orchis, and it is from 
the root of this that the starchy substance brought from the Levant is supposed to be prepared.

This article of commerce comes to us in pieces of an oval form, very hard, approaching to transparency, and of a yellowish white colour. Although this substance has been for so long a time imported from a distant market, the plant from which it is prepared is furnished spontaneously, and in great abundance, in many parts of our own country. The Turkey roots are, however, much finer than ours; which may account for the greater esteem in which they are held.

The plant consists of a root composed of two fleshy lobes, crowned with oblong, broad, spotted leaves, and having upright stalks growing to the height of twelve inches, furnished with one or two narrow leaves, and terminated by a long spike of reddish purple flower's, which exhale a very slight agreeable odour; these commonly appear in the months of May, June, and July. The soil best adapted to its growth is that which is dry and not very fertile. It is worthy of remark that in rich lands, and those which have been highly manured, the orchideæ do not come to maturity; where the experiment has been tried, the roots of the few plants that did appear proved black, and were half rotted in the ground. The stem is sent up by the lobe of a former year, and the new lobe, which is therefore easily distinguishable from the old one, is formed in the course of the summer as the tubers of potatoes. The root is known to be fully matured when the leaves and stalk begin to decay; the plants may then be dug up, and the new lobes-from which alone salep i.s made-separated from the others.

Many methods have been proposed for preparing salep. In the performance of the one among those niethods which appear to be the simplest and best, 
the new root is first washed in warm water, when the fine brown skin with which it is covered may easily he rubbed away, by means of a coarse cloth or a brush. The roots being thus cleaned and peeled, are to be arranged on a tin plate, and then placed within an oven, heated to the same degree as is necessary for the baking of bread; here they are to remain from seven to ten minutes, in which time they will exchange their opaque and milky whiteness for a semi-transparent horn-like appearance, and a yellowish colour, retaining their original bulk. Being then withdrawn from the oven, they are exposed during some days to dry and harden in the air ; or by the employment of a very gentle heat they may be brought to the same state in the course of a few hours : all that is then required to adapt the salep for food, is to boil it in water to the required consistency.

It is said that salep contains a greater quantity of nutriment in the same bulk than any other vegetable body; and for this reason it has been proposed that it should be made to form a part of the provisions of every ship that undertakes a distant voyage. So high a nutritive power has been assigned to salep, that, it is asserted, if one ounce of the powdered root, mixed with an equal weight of the stiff animal jelly or glue, known as portable soup, be boiled in two quarts of water, it will suffice for the daily nourishment of an able-bodied man.

A small quantity of salep added to milk has been found to retard the commencement of the acetous fermentation in that fluid; and there is reason to believe that if it were used in a moderate proportion, it wouid prove a very useful and economical addition to wheaten flower, in the preparation of bread. Dr. Percival, in lis 'Mcdical and Experimental Essays,' mentions the results of some experiments 
of this kind. "I directed," says he, "one ounce of the powder to be dissolved in a quart of water. and the mucilage to be mixed with a sufficient quantity of flour, salt, and yeast. The flour amounted to two pounds, the yeast to two ounces, and the salt to eighty grains. The loaf when baked was remarkably well fermented, and weighed three pounds two ounces. Half a pound of flour and an ounce of salep were mixed together, and the water added according to the usual method of preparing bread. The loaf when baked weighed thirteen ounces and a half, but it should be remarlied that the quantity of flour used in this trial was not sufficient to conceal the peculiar taste of the salep."

It is to be presumed that the last mentioned circumstance did not occur where the proportion of wheat flour was greater, and the result is certainly such as should at least encourage the prosecution of farther experiments. This vegetable preparation is held to be exceedingly wholesome, and was formerly in considerable favour with medical practitioners.

Indian Arrow-root-Maranta arundinacea.Arrow-root, when prepared for use, bear's a considerable resemblance to the substance last described, consisting, equally with that, of little else than mucilaginous matter. It forms, therefore, a pleasant and useful aliment for children and invalids.

The plant from which it is prepared is a native of South America. It is an herbaceous perennial, and is propagated by parting the roots. It rises to the height of two or three feet, has broad pointed leaves, and is crowned by a spike of small white flowers. It is much cultivated both for domestic use and for exportation in our West India islands, and in some parts of Hindostan.

There are several species of maranta, only two of which-the arundinasea, or starch plant, and the 


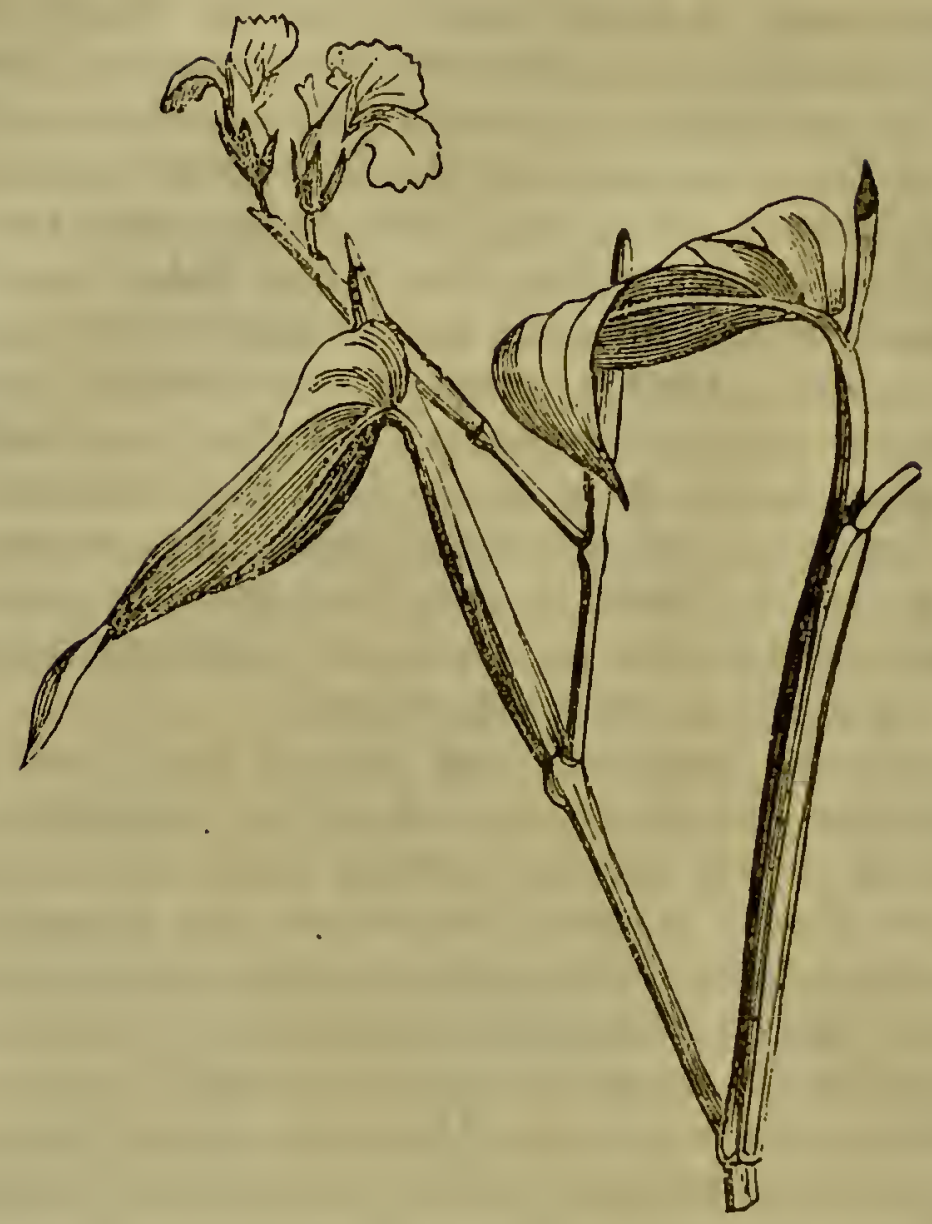

Indian Arrow-root-Maraxta arundinaceli

M. ramosissima of India-are thus cultivated. The name by which it is commonly known it owes to the use which was formerly made of another plant which was once confounded with it, but is now distinguished by the name of Alpinia galanga. The Indians employed that root for extracting the virus communicated by their poisoned arrows.

The starchy matter, for the obtaining of which the plant is cultivated, is prepared by the following process:- When the roots are a year old they are dug up, and having first been well washed in clear water, are eithel grated or beaten to a pulp, 
in large wooden mortars. This pulpy substance is next thrown into a large proportion of clean water, and after the whole has been agitated for some time the fibrous parts are collected in the hand, squeezed, and rejected. The milky liquor which remains is a mixture of the starch with water, and this, after being strained through a hair sieve to separate such fibrous particles as have escaped before, is left for some time to settle, when the water is drained off. The white pasty mass remaining at the bottom is thein again washed in a further portion of water, and allowed to subside as before; and this process is sometimes repeated a third time, and oftener even by persons who wish to be exceedingly nice in preparing the powder. When this is collsidered to be sufficiently cleansed, it is dried on clean white cloths in the sun, and is then fit for consumption; it will keep for a very considerable length of time.

Other plants have been proposed as substitutes for the exotic above described. Among these the arum maculatum, or common wake-robin, has been mentioned. This plant grows wild in woods and on shady banks in many parts of Great Britain.

In its natural state the arum maculatum is exceedingly acrid, so that if a small piece of the leaf be chewed, it produces a painful stinging sensation in the mouth, and by applying the juice of the raw tuber to the skin, this will be considerably blistered. The noxious quality here menttioned, like to that inherent in the cussava root, is, however, extremely volatile, and if the root be either roasted or boiled, and afterwards dried and pounded, it affords a starchy substance which is perfectly inlsipid, and may be used for the same purposes as the powder of the true arrow. root. 


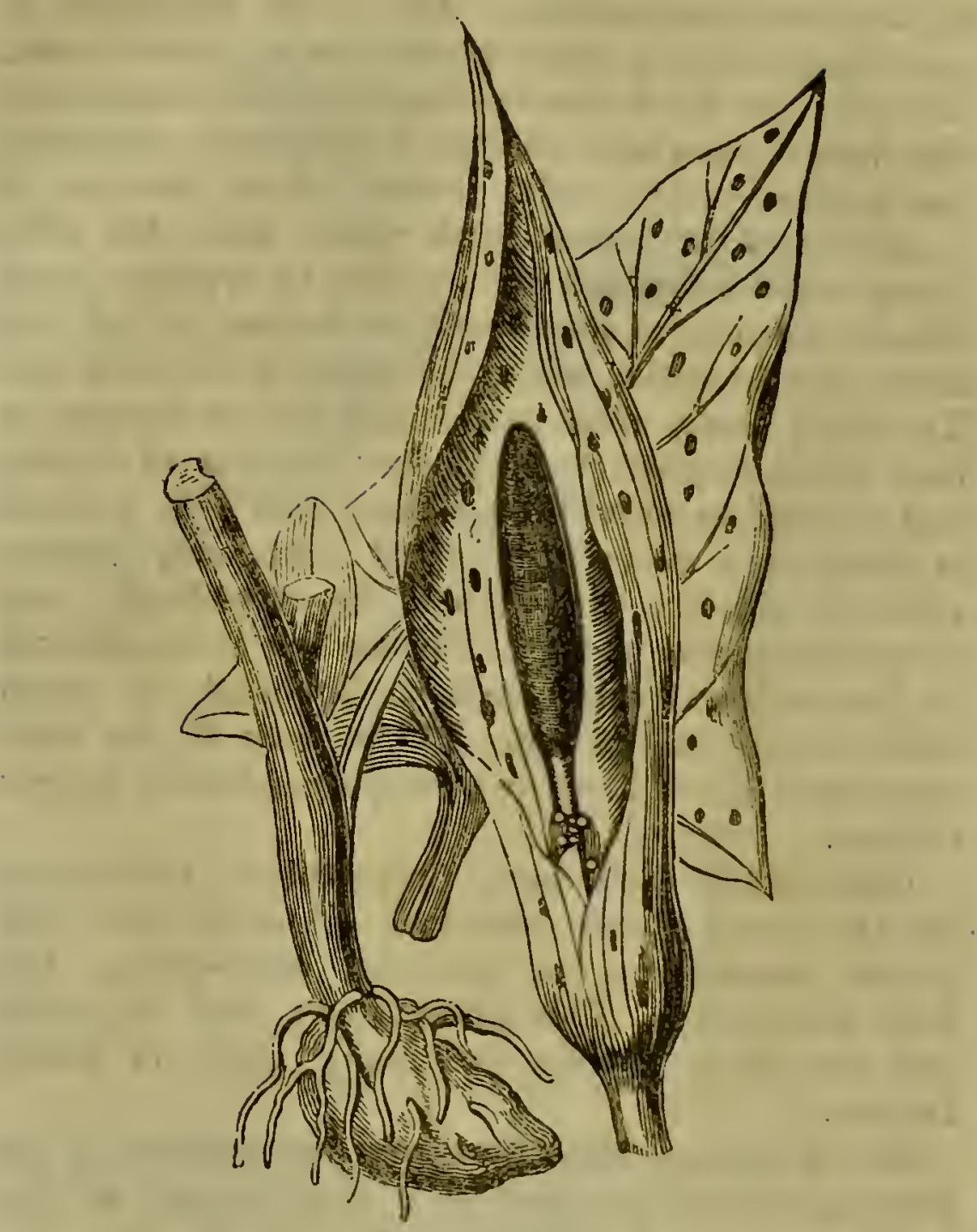

Wake-Robin-Arum maculatum.

Many roots, some the peculiar growth of America, as well as the potato and mandioc, yield substantive food to the inhabitants of both the northern and southern divisions. Among these the Spanish, or Sweet Potato-Convolvulus balata-is eommonly cultivated for its root in the tropical climates, both of 
the eastern and western hemispheres. It was known in this country before the common potato, which, as we have before observed, received its name from the similarity which it bears to the batata.

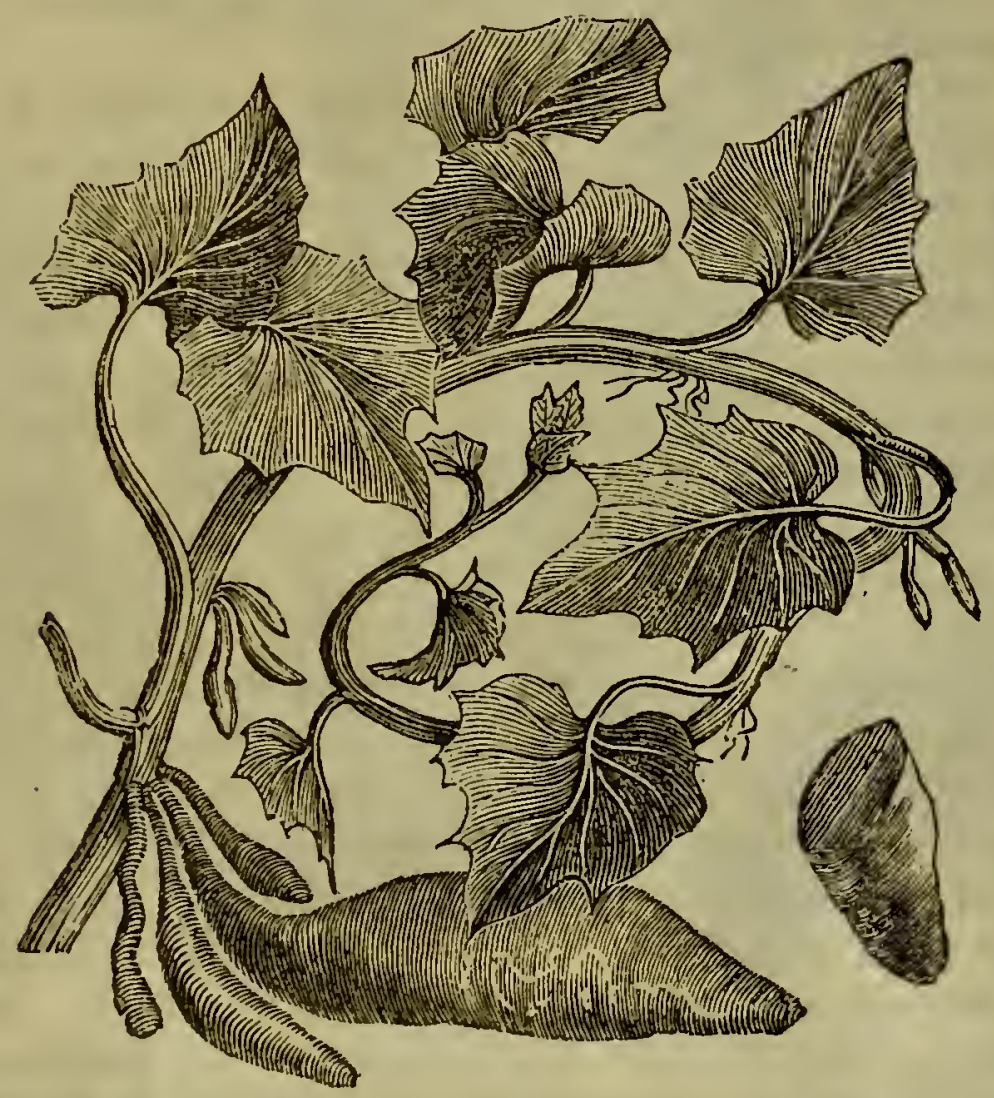

Sweet Potato-Cunvolvulus batata.

This plant was introduced into England by Sir Francis Drake and Sir John Hawkins, in the middle of the fifteenth century. Attempts were made to naturalize it in this country, but it was found too tender to thrive in the open air through an English winter. Gerarde cultivated it in his garden in 1597 , where it flourished during the warm season; but as soon as it was assailed by the cold weather, it drooper, and perished in the ground. The roots were at that time imported into England in considerable quantities 
from Spain and the Canaries; and were used as a confection rather than as a nourishing vegetable. A more abundant supply of fruit of home growth has caused the batata gradually to decline in favour, and for many years it has ceased to be an article of importation into this country.

This plant is an herbaceous perennial, which sends out many trailing stalks, extending six or eight feet every way; these are round, and of a palegreen colour; at each joint roots are put forth, which, in a genial climate, grow to be very large tubers, so that from a single plant forty or fifty large roots are produced. The leaves are angular, and stand on long petioles. The flowers are purple. Several varieties of this plant are to be found in the different countries where it is cultivated, and which differ from each other in size, shape, and the flavour of the roots. The batata is propagated by laying down the young shoots in the spring; indeed, in its native climate it multiplies itself almost spontaneously; for if the branches of routs that have been pulled up are suffered to remain on the ground and a shower of rain falls soon after they have been broken off, their vegetation will recommence. The roots are sweet, nourishing, and though rather insipid, of no unpleasant flavour. In warm climates the batata is of very abundant growth, and easy of propagation; and therefore it is matter of surprise that, in Brazil, the mandioc should be cultivated in preference as food for the negroes, the batata being raised more as a luxury for the planter's table.

In the national garden at Paris this plant is raised in a hot-bed, whence it is transplanted at the latter end of the spring into the open ground, and treated like the common potato. In favourable seasons a tolerable crop is produced; and hopes are entertained that in the course of some years the batata will be so 
far acclimatized as to be the object of successful field sulture in the south of France.

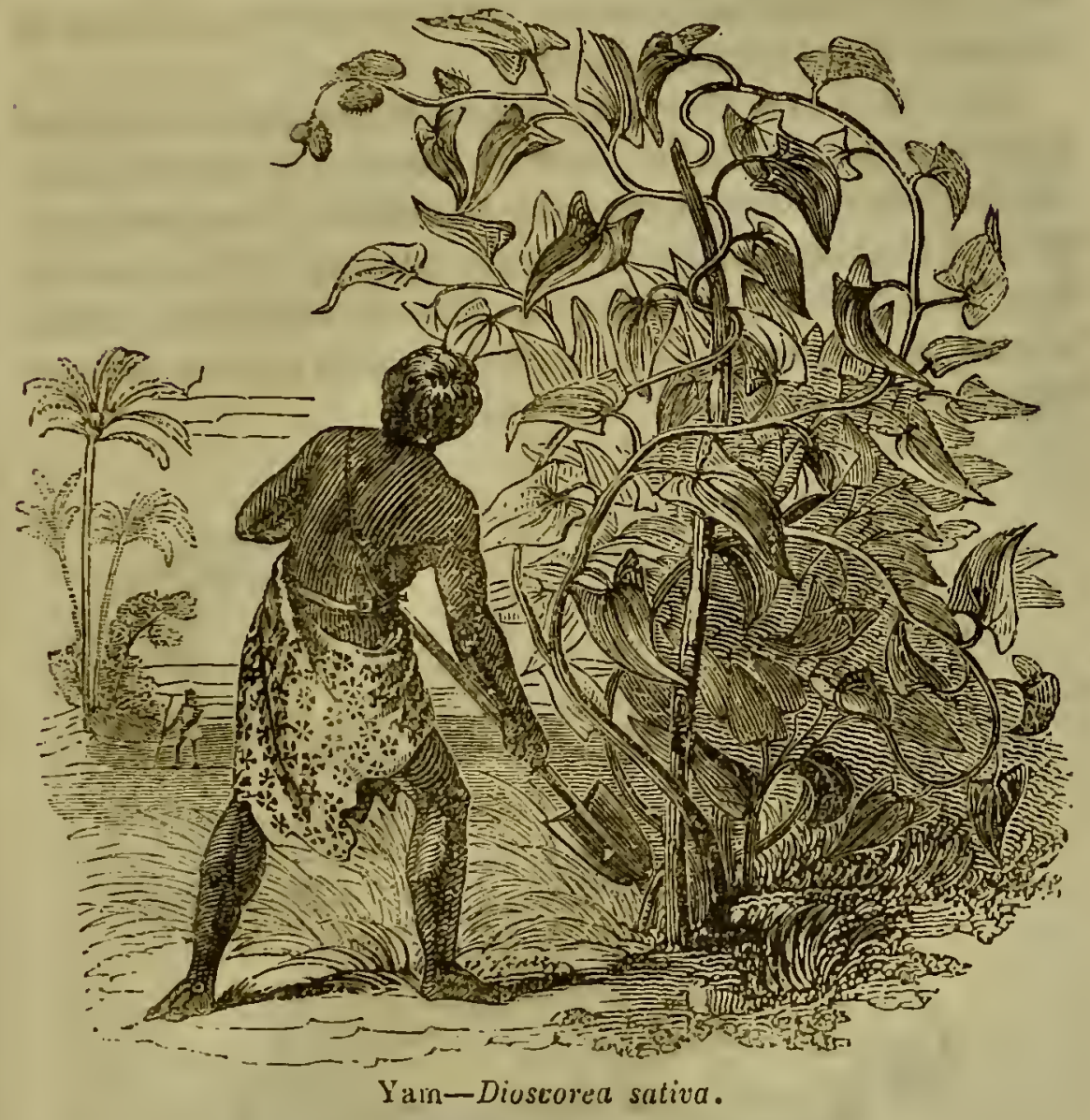

The YAM-Dioscorea sativa-is a native of the East; and is supposed to have been transplanted thence to the West Indies, as it has never been found growing wild in any part of America; while in the island of Ceylon, and on the coast of Malabar, it flourishes in the woods with spontaneous and luxuriant growth. It is very extensively cultivated in Africa, Asia, and America, for its root, which is nutritious and of good flavour, and is used either roasted or boiled as a substitute for bread. This root is farinaceous, and resembles the potate, but is of a rloser texture 
Some yams were first brought into this country from the West Indies in 1733 ; and they are now nccasionally imported, more, however, as ari article of curiosity than of commerce.

'The yam is a climbing plant, with tender stalks of from eighteen to twenty feet in length; it has smooth, sharp-pointed leaves, on long footstallis, from the base of which arise spikes of small flowers. The root is flat, and palmated about a foot in brearth, white within, and externally of a dirk-brown colour. almost approacking to black.

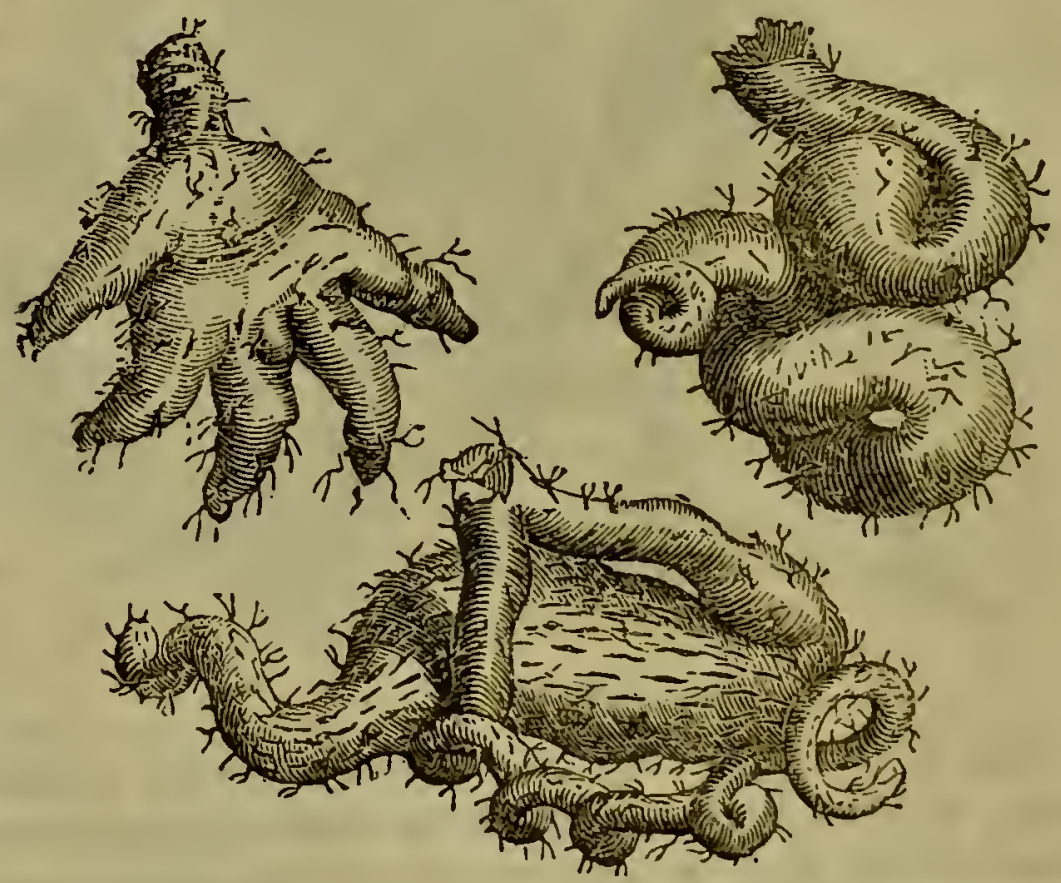

Different surts of Sam Roots.

The Winged YaM-dioscorea alata-is another species very generally cultivated; its roots attain to a larger size, being frequently about three feet long, and weighing about thirty pounds. Both these kinds are cultivated like the common potato. They are usually planted in August, and are fit for use in the November and December following. Brown* directs

* History of Jimaica. 
that the roots for planting should be cut so as to leare a small portion of skin to each piece; "for by that alone," he affirms, "they germinate, the roots having no apparent buds or eyes, but casting out their weakly stems from every part of the surface alike."

When dug out of the earth, the roots are placed in the sun to dry, and are then put into sand or casks, where, if guarded from moisture, they may be preserved a considerable length of time without being in any way injured in their quality.

ArracaCha.-This plant is cultivated in some parts of South America for its root, which is farinaceous, and easy of digestion. The main ruots branch into four or five parts, which attain to the size of cows' horns. Sanguine hopes were entertained by English horticulturists that this root might in the course of time become nearly as important to Europe as the potato, and that it may, like that, be acclimatized in England. It grows on the plains of Bogota, on an elevation of 8700 feet above the level of the sea. The temperature of these lofty plains is found not greatly to vary from that of the south-west of England. The inean temperature of Santa $\mathrm{Fe}$ de Bogota is fifty-eight degrees; the mean temperature of the warmest month sixty-two degrees; of the coldest month fifty-seven degrees. If any spot in the south of England or Ireland can be found of a similar temperature, it is probable that the arracacha will survive throughout the year in the open air. The mean temperature of Plymouth is about fifty-three degrees; mean of hottest month sixty-three degrees ; mean of coldest month forty-two degrees. It is, therefore, supposed that this climate may be favourable to the growth of the arracacha. In 1821 plants were sent to the Horticultural Society, but they unfortunately died. Since that time, however, the in troduction of this plant has been effected; and it is 
thriving in the garden of Dr. Hamilton of Plymouth, who writes, in July 1828, "My arracacha plant is flourishing beyond my most sanguine expectations in the open air; indeed, it grows much more luxuriantly in the open air than in the house*."

To complete a general picture of the substantive vegetable food of the world, it would be necessary that we should notice the fruits of the date-palm, the banana. and the bread-fruit tree; but these having been described at length in a preceding volume, it will be only requisite here to refer to these accounts $\dagger$.

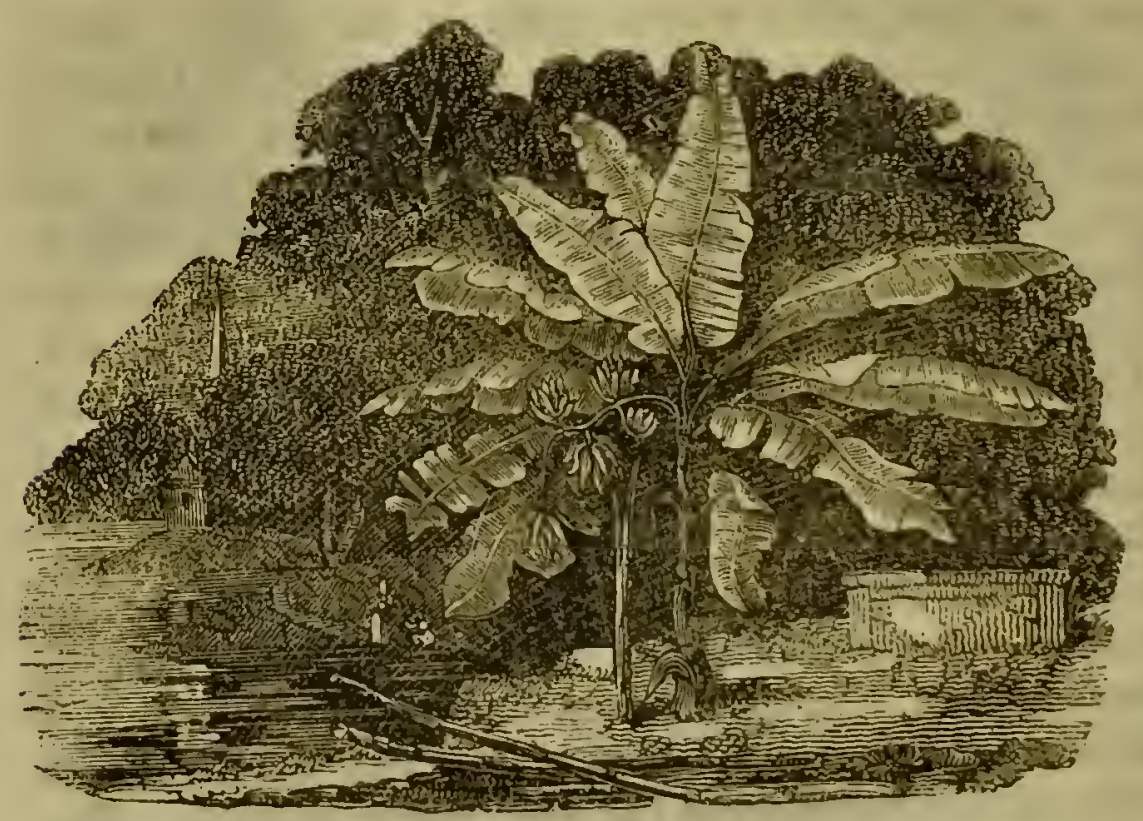

The Banana.

The banana and the bread-fruit are examples of extraordinary vegetable fruitfulness, with very little assistance from the care of man. The banana is not known in an uncultivated state; and those who prin-

* Gard. Mag, rol. iv., p. 40?.

† See 'Vegetable Substances-Trees and Fruits,' pp. 3:18. 363 , and 411 . 
eipally depend upon the plant for subsistence propagate it by suckers. But here the labour of cultivation almost ends; and $M$. Humboldt has calculated that thirty-three pounds of wheat and ninetynine pounds of potatoes require the same space as that in which four thousand pounds of bananas will grow. But the industry of the European surrounds him with a much greater amount of blessings than the almost spontaneous bounty of Nature to the Indian who lives upon his patch of bananas. The same reasoning applies to the bread-fruit; for when the produce of two or three of those trees will suffice for a man's yearly supply, he is not likely to call forth the faculties of his mind which wait upon a constant course of assiduous labour. Those bodies of mankind are in the happiest state who are placed by climate between the extremes of natural fruitfulness and sterility. Where Nature offers spontaneous food to large tribes, as in a few situations in tropical countries, their condition is nearly as wretched, taken under all its circumstances, as that of those poor inhabitants of polar regions, to whom almost everything appears to be denied by the "All-giver," but who really obtain comforts by their persevering labour, which the idle native of the finest soil almost always wants.

ONE of the substances of spontaneous growth, which is largely used as an article of food, is

SAgo-Sagus farinifera, and other species.

The substance known in commerce under the name of sago is a farinaceous pithy matter, extracted from the trunk of a tree.

This tree is a native of the south-east of Asia, and of the islands of the Indian Ocean, where it grows spontancously, and is perfected without any 
culture. This circumstance occurring with regard to a substance highly nutritive, in a climate which dis poses the human frame to inaction, occasions the adoption of sago in many places as the general food of the population, to the neglect of other plants, the cultivation of which would call for some amount of exertion.

The sago, or, as it is called in the Molucca Islands, the libley tree, is of peculiar growth. The trunk, which is formed of the bases of the leaves, grows at first very slowly, and is covered with thorns; so sooll, however, as the stem is once formed, the growth of the tree proceeds with very great rapidity, so that it speedily attains its full height of thirty feet, with a girth of five or six feet, losing in this stage its thorny accompaniments. Like the cocoa-nut tree, the sago has no distinct bark that can be peeled off, but the trunk consists of a long, hard, ligneous tube, about two inches thick, the internal area of which is filled with a kind of farinaceous pith, intermixed with numerous longitudinal fibres. The maturity of the tree is known by the transpiration of a kind of whitish dust through the pores of the leaves, and when this appears the trunk is felled near to the ground.

The best account of this tree, and of the morle of preparing its pith for use as human food, is to be seen in Forrest's account of the Molucca Islands: it is to the following effect.

"The tree being felled, is cut into lengths of five or six feet. A part of the hard wood is then sliced off, and the worlinan, coming to the pith, cuts across the longitudinal fibres and the pith together, leaving a part at each end uncut, so that when it is excivated, there remains a trough, into which the pulp is again put, mixed with water, and beaten with a piece of wood. Then the fibres, separated firom the pulp, 
float at top, and the flour subsides. After being cleared in this manner by several waters, the pulp is put into cylindrical baskets made of the leaves of the tree; and if it is to be kept some time, those baskets are generalk y sunk in fresh water to keep it moist. One tree will produce from two to four hundred weight of flour.

"We seldom or never see sago in Europe but in a granulated state. To bring it into this state from the flour, it must be first moistened and passed through a sieve into an iron pot (very shallow) held over a fire, which enables it to assume a globular form. Thus all our grained sago is half baked and will keep long. The pulp or powder of which this is made will also keep long if preserved from the air, but if exposed, it presently turns sour*."

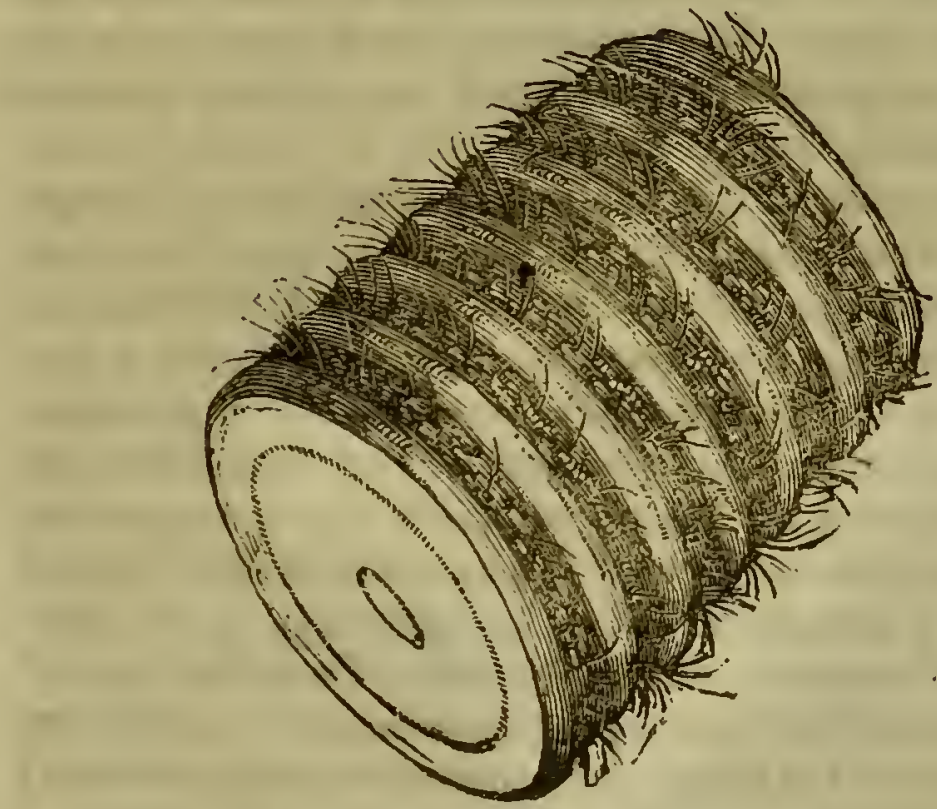

Stem of the Sago Tree, showing the puth from which the sago is extratcted.

We learn also from the same authority, that loaves

* Forrest's Voyage to the Moluccas, p. 39, sccond edition. Q3 
of brend are sometimes made in the Molucca Islands of the pith of the sago, and that these loaves are balied in small ovens, "the floors of which are divided by means of partitions into cells about the size of an octavo volume."

The leaf of the sago is used in the same quarter for covering houses, and in that climate will not need to be renewed oftener than once in seven years.

When the sago tree is cut down, its regetative power still remains in the root, which again puts forth its leaves and forms the trunk, and this proceeds again through its different stages until it is again subjected to the axe, and made to yield its alimentary contents for the service of man.

Sago is also produced from many varieties of palms, but the tree here described is that which fur. uishes the best. The produce of the Cycas circinalis, so often erroneously mentioned as yielding the sago of commerce, is very inferior.

If the native of the Molucca Islands has his sagobread without the labour of cultivating the plant which produces it, the Indian of the Cordilleras of Sonth America has his supply of milk from a tree, growing at a vast height amidst arid mountains. where no cattle can pasture. The Cow-Tree has been described by Humboldt with his characteristic spirit and accuracy ; and it was much earlier noticel by Laet, a Dutch traveller, as growing in the province of Cumana. " On the side of a thirsty rock," says Humboldt, "grows a tree whose leaves are dry and husky. Its large roots penetrate with difficulty through the stony soil. During many months of the year not a shower waters its foliage ; the branches appear withered and dead; but when its trunk is pierced, a sweet and nourishing milk flows from the wound. It is at the rising of the sun that this re- 
getable aliment is most plentiful. The natives and the black slaves then gather together from all parts with large wooden vessels to catch the milk, which as it flows becomes yellow, and thickens on the surface. Some make their abundant meal at the foot of the tree which supplies it; others carry their full vessels home to their children *."

In tropical conntries the force of vegetation is so great, and the wants of society so few, that magniticent trees are destroyed for the sake of a small portion of food, such as a few square feet of an English garden would produce.

The CABBAGE-PALM-Areca oleracea-is a most gigantic tree; its stem, which, near to its base, is about seven feet in circumference, ascends straight and tapering to a vast height. It is of a brown colour, hard, ligneous, divided into short joints, and pithy within like elder. Several feet from the summit, the tree assumes a fluted form, and a green colour; which change is occasioned by the husky tegument that forms the petioles, which thence diverge far in a horizontal direction, like the crown of a pineapple. 'These are decorated with numerous leaflets, some of which are about three feet long, and an inch und a half broad, tapering into a sharp point; the leaflets gradually decrease in size as they approach the extremities of the branches. 'This regular, lofty group of foliage, impelled by the most gentle gale, and constantly waving in feathery elegance, is an object of beaut $y$ which cannot be irnagined by an irhabitant of temperate climes, unused to the magnificent vegetation of a tropical sun. The seed is inclosed in a brown spatha or sheath, which arises from the centre of the branches, and, hanging downwards, consists of small oval nuts, not unlike a bunch of * 'Voyage aux Regions Equinoxiales;' tom. y p. 2z64. 
dried grapes, but much longer in proportion to tlıeir circumference.

Within the leaves which surround the top of the trunk, the cabbage lies concealed. It is white, about two or three feet long, as thick as a man's arm, and perfectly cylindrical. This substance is composed of longitudinal flakes like ribands, but so compact as to form a crisp, solid body. When eaten raw it resembles the almond in flavour, but is more tender and delicious. It is usually cut into pieces, boiled, and served as an auxiliary vegetable with meat.

'To obtain this small portion, borne on the pinnacle of the tree, and hidden from the eye of man, the axe is applied to the stately trunk, and this majestic lord of the mountain-top is laid low, to furnish a small quantity of vegetable matter, which is "eaten like cauliflower," and which receives its distinctive name from our lowly cabbage. Surely this rivals the tales handed down to us of Roman epicurism!

In the cavity made in the trunk by the removal of the cabbage, a kind of black beetle deposits its spawn, from which grubs, which are called the palmtree worms, are produced, and these, strange to say, are eaten as a great delicacy. Stedman gives the following account of this choice luxury of Guiana. "Another negro also brought me a regale of groegroe, or cabbage-tree worms, as they are called in Surinam. This reptile grows to the size and thickness of a man's thumb, and is extremely fat. However disgusting to appearance, these worms are a delicious treat to many people, and they are regularly sold at Paramaribo. The manner of dressing them is by frying them in a pan with a very little butter and salt, or spitting thein on a wooden skewer. In taste they partake of all the spices of India, as inace, cinnamon, cloves, nutmegs, \&c. Several species of 
these worms are produced in all the palm-trees, when beginning to rot, but some are larger than others. 'They are all of a pale yellow colour, with black herds"."

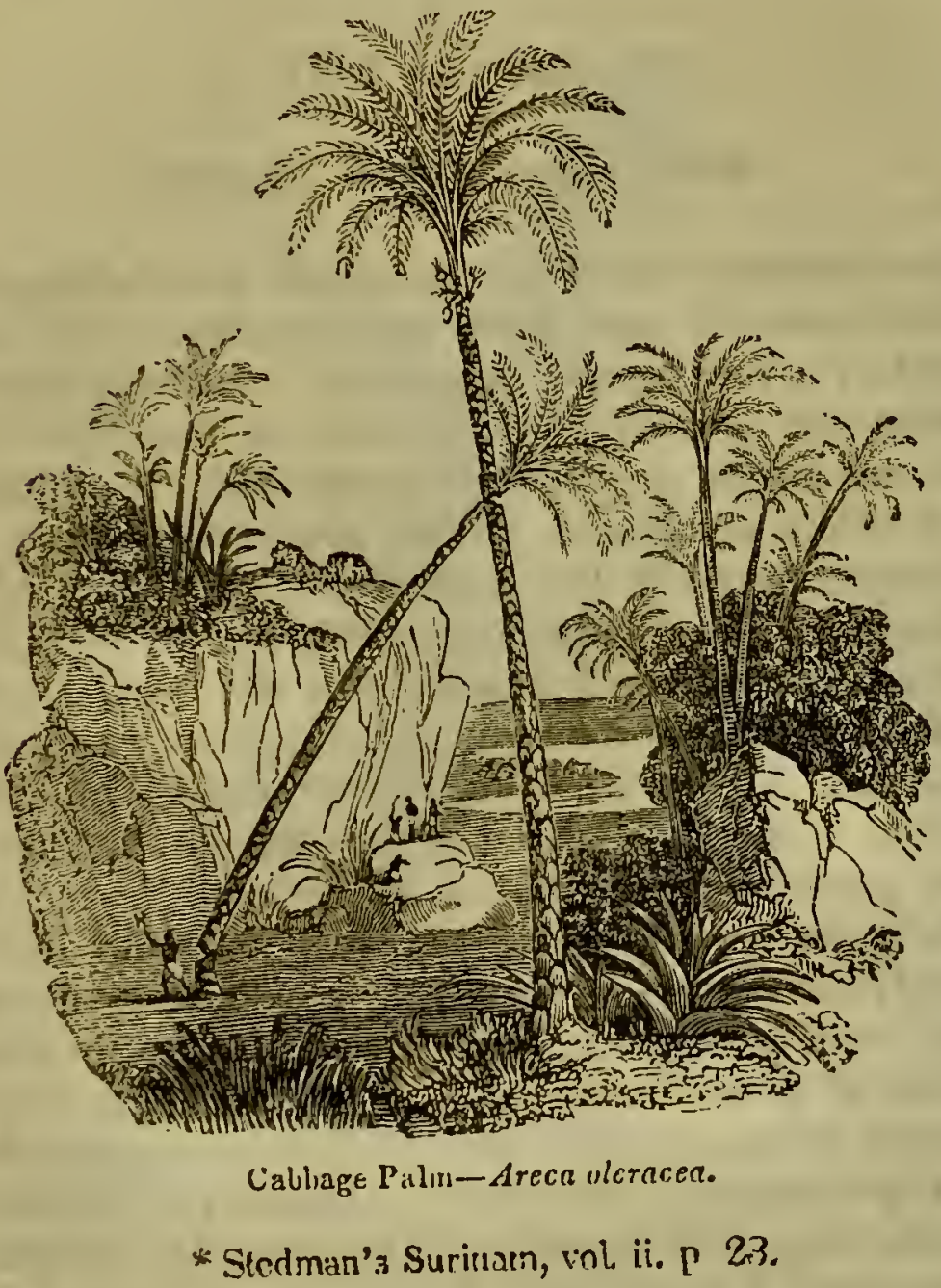




\section{Chapter Vili.}

\section{WILD PIAN'TS ISED AS FOOD.}

THE habitual use of wild plants as food belongs to a state in which man lives either anidst a very luxuriant or a very scanty vegetation. In both cases, in which the spontaneous produce of the earth contributes in any great degree to the support of families and tribes, civilization is very slightly advanced. In Europe, even in the countries least favoured by nature, and least improved by cultivation, wild plants are seldoin resorted to, except in times of scarcity; and these visitations are becoming fewer and fewer wherever the arts of life, whose perfection chiefly results from the division of labour, are understood and practised. It will be desirable to notice very briefly the expedients which men resort to for the supply of their daily wants, in places where agriculture and gardening, whether from the injurious effects of an inclement climate, or particular circumstances of situation, or, what is more depressing, from bad government, are very far below the perfection which they are capable of attaining in countries possessing a moderately favourable soil called into fertility by free institutions.

Covch-grass, one of the greatest pests with which the farmer has to contend,-whose growth is so spreading and rapid, and whose vitality under the extremest drought is equally remarkable, contains a portion of nutritious matter in its roots. In the earlier periods of British history, when, from insuffi- 
cient modes of husbandry, arising out of insecurity of property, dearths were by no means of uncommon sccurrence, the roots of this weed were devoured as one of the substitutes for bread.

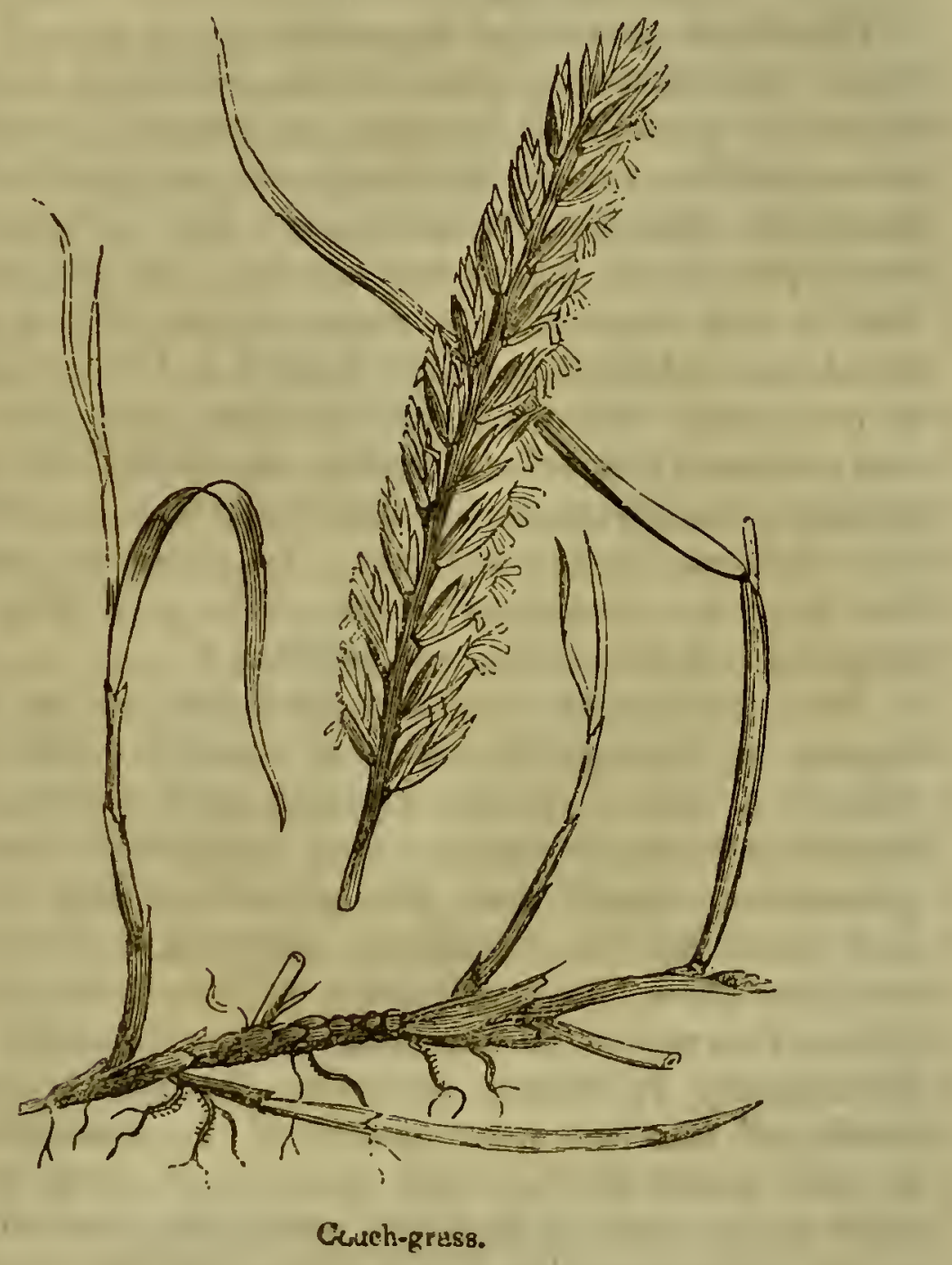

In Africa, in those constantly recurring seasons of scarcity produced by the want of rain, the people apply themselves to gathering seeds borne by grassplants that have grown without moisture, of which they make a wreiched bread. " These people," says 
Bruce, " appear perfect skeletons, and no wouder. as they live upon such fare*." Denham describes a grass, whose seeds are eaten by the natives, that would appear the most forbidding of all vegetables capable of producing even the most scanty food. "The whole surface of the country," he says, " had been covered with a grass which produced a calyx so full of prickles as to annoy us almost to misery. these prickles were of the finest and most penetrating sharpness that can be imagined; they attached to every part of our dress; and sc small were the points that it was impossible to extract them without their breaking and leaving a part behind. If we walked, at every step we were obliged to clear thein from our feet;-mats, blankets, trowsers, were filled with these irritating annoyances, so that there was no getting rid of them by day or night. In short, no part of the body was free from them. The seed from this grass is called kaschia, and is eaten $\uparrow . "$

Wild pulse have furnished food even to the inhabitants of England in times of scarcity. The SEAPEA is a native of this country, and differs from the other esculent peas in being a perennial, the root penetrating deeply into the ground among stones and sands by the sea-shores. During a famine in the year 1555 , the application of the seeds of this plant as an article of food was most extensively and efficaciously practised; according to Turner, thousands of families were preserved in consequence. It was found at that time growing in large quanitities on the coast of Suffoll ; and in the superstitious spirit of the age this seasonable relief was ascribed to the interposition of a saint: the holy man must, however, have been but an indifferent judge of regetables, as the sea-pea is small, hard, and indigestible,

* Travels, vol. is. p. 511.

† Denham's Travels in Africii; p. 5 r. 
and probably not more nutritious than the tare, ux titan many of the vegetables with which the wonds and way-sides abound.

Whenever we picture to ourselves a single man or tribes of men living in a condition where cultivation is not practised, we fancy that they derive their principal support from wild roots. And this fancy is true, to some extent; although most of the edible roots which grow spontaneously are of little value. Many are acrid and some poisonous. Necessity, however, con pels men to resort to this food under particular circumstances. Linnæus thus describes a. very prevalent food of Norwegian Lapland.

"Missen-bread is made of the Water-Dragon (Calla palustris). The roots of this plant are taken up in spring, before the leaves come forth, and, after being extremely well washed, are dried either in the sun or in the house. The fibrous parts are then taken away, and the remainder dried in an oven. Afterwards it is bruised in a hollow vessel or tub, made of fir-wood, about three feet deep; as is also practised occasionally with the fir-bark. The dried roots are chopped in this vessel with a kind of spade, like cabbage for making sour kale (sour-crout), till they become as small as peas or oatmeal, when they acquire a pleasant sweetish smell; after which they are ground. The meal is boiled slowly in water, being continually kept stirring, till it grows as thick as flummery. In this state it is left standing in the pot for three or four days and nights. Some persons let it remain for twenty-four hours: but the longer the better, for if used immediately it is bitter and acrid; both which qualities go off by keeping. It is mixed for use either with the meal made of fir-bark, or with some other kind of flour, not being usually to be had in sufficient quantity by itself : for the plant is in many places very scarce, though here (Tordjür- 
fen) in such abundance that cart-loads of it are conlected at a time. This kind of flummery, being mixed with flour, as I have just mentioned, is baked into bread, which proves as tough as rye-bread, but is perfectly sweet and white *"

In Lapland, when the crops are i1ıjured by severe frost, the missen-bread is a seasonable aid; and happy is the peasant that has a store, to prevent his resorting to the coarser food made of the bark of the spruce-fir.

A species of Silver-Weed-Potentilla Anserina -commonly growing in some parts of Scotland, is held in much esteem by the inhabitants of the islands of Tiras and Col, where the roots are in times of scarcity made a substitute for bread, and have been known to form the chief subsistence of the inhabitants for several consecutive months. They are found most abundant in poor and exhausted soils, thus affording a most seasonable supply when, through the failure of other crops, there is a dearth of the ordinary provisions. These roots are similar to parsnips in flavour; and are frequently eaten in Scotland, either roasted or boiled $\dagger$.

In a cultivated state the CARROT is a nutritious vegetable. The root of a wild species is small, stringy, and hard, of a pale colour and a strong Havour, but without succulence or nourishment. It is indigenous to Britain, where it grows about hedges and way-sides; and, from its flowering head when the seeds are ripening, is in some places popularly known by the name of "the bird's-nest." The Pansnip, again, which belongs to the same family of plants as the carrot (Umbelliferce), is a native of Britain, but its root is harsh and of an unpleasant flavour. Other plants of the same family, growing wild in this country, may on emergency be

- Lianesus'ri Tour, p. 351. + I.ightfoot's Fl. Scot. 
eeten ; but they all offer a very slight addition to the food of man, and show in a marked manner the difference in the useful powers of a cultivated and an uncultivated soil.

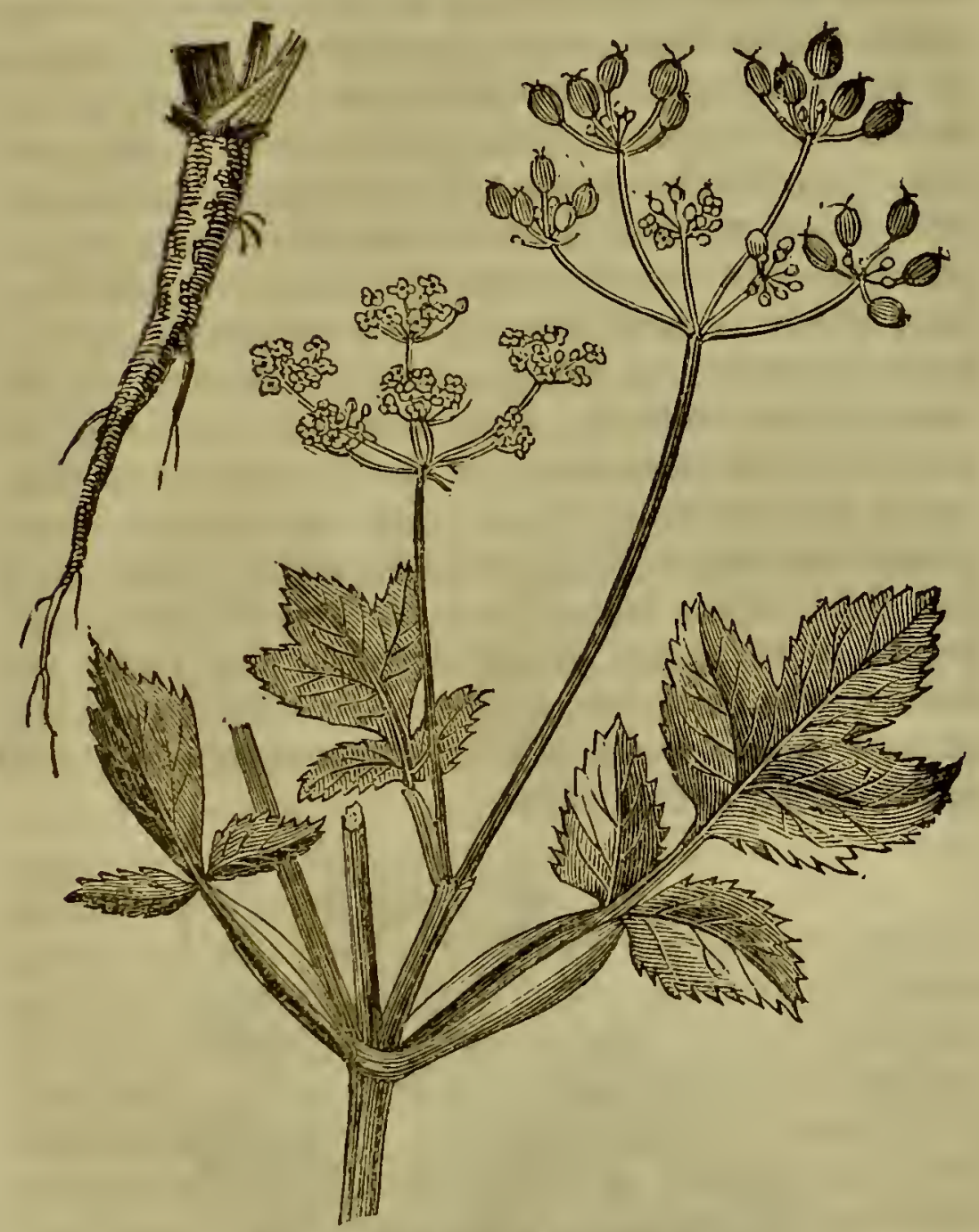

Flower and Root of the Wild Parsnip.

White-BEET is found wild on the salt, marsiny shores of Holland, and on some parts of those of England; but the root is hard, bitter, and worthless.

SALSIFY, in the same manner, which was once much used here as an esculent, and is still com. 
monly found grcwing wild. possesses no useful properties without cultivation.

ICELAND . Moss, or Lichen islandicus, is used as an edible substance by the Icelanders, who rarely obt:in corn-bread, and whose limited stock of substitutes obliges them to have recourse to every species of vegetable production which is permitted by their inclement climate to spring forth. The plant is collected by the inhabiinnts of this northern region, and, after being washed, is either cut into pieces, or it is dried by the fire or in the sun, and then put into a bag, which is well beaten; it is ultimately worked into a powder by being trampled on, and in this state is used as food. 'This lichen is found growing on the mountains, both in the lowlands and highlinds of Scotland. It consists of upright leaves nearly two inches high, soft and pliant when moist, but rigid when dry. They are smooth and shiny, inclining to a red colour towards the roots, and laving the exterior surface sprinkled with very minute black warts. The margins are set with small, short, stiff spinules.

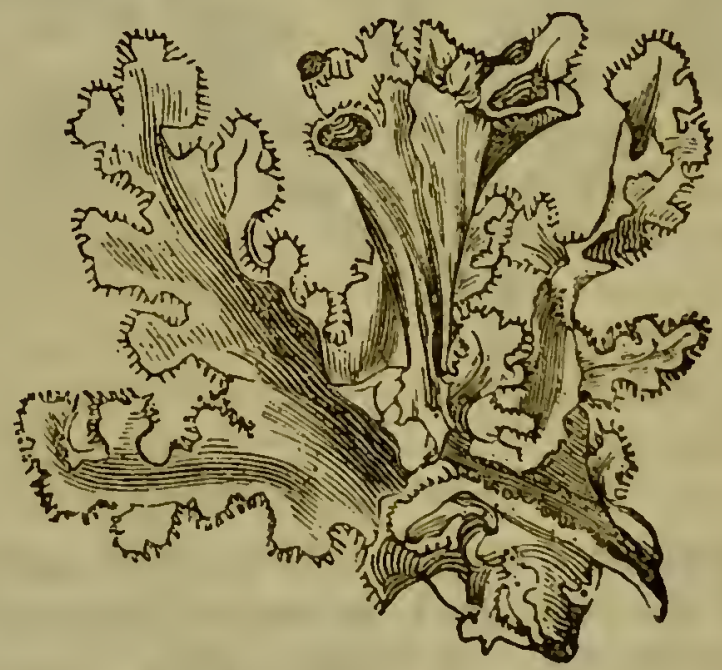

Iceland Noss- ichen Islandicus.

The fisnily of plants known by botanists as Cri- 
ciferce, grow spontaneously in every field. The Wild CabBage, or Brassica campestris, has been found in many countries; -in France, by Bouchet and De Candolle; in Modern Greece, by Sibthorp: and it may be the same that is mentioned by Dioscorides. It grows naturally on the sea-shore near Dover. The leaves of this plant are used early in the spring as an edible; and it is said that they are superior in flavour to those of the cultivated sorts; but as it is found chiefly in situations near the sea, where there is salt in the soil or in the atmosphere, the leaves acquire a saline, bitter taste; this is, however, removed after they have been boiled in two waters. As the wild plants advance towards maturity, the purple, of which there is merely a trace in the young leaves, disperses, and the plants become harsh, bitter, and unfit for use. An accumulation of a larger portion of alkaline matter may be inferred from this fact, consequent on the well-known effect of alkali changing blue to green. A correspondent of a valuable horticultural work describes the young tops of the wild cabbage of Dover as a most delicate vegetable; but he complains that the plant is held in low estimation by the inhabitants of the place* Doubtless they would find it cheaper to cultivate cabbages than to gather them on cliffs. Various spinaceous plants also grow wild in this country; but they will not repay the labour of gathering. Nothing is so common as Sornel, but no one here thinks the plant worth collecting. On the contrary, the Laplanders prepare these leaves, and preserve them for winter store. For this purpose they are boiled in a very small quantity of water, and stirred till reduced to a pulp. This is then mixed with milk, and put in barrels, which are kept in holes dug in the ground, and lined either with bricks or birch-

* Lroudon's Gardener's Magazine, February 1832.

E. 3 
bark, to protect them from rats and mice. This preparation of sorrel was found by Linnæus to posBess a very agreeable acid taste, quite different from the flavour of the fresh plant. The Laplanders, in their paucity of esculent vegetables, gladly avail them selves of those plants which other nations are in the habit of rejecting as weeds, and in some cases indeed avoid as poisonous. Linnæus informs us, on authority to which he gave credence, that the Yellow WOLf'S-BANE-Aconitum lycoctonum-is collected in large quantities in some parts of Lapland, and boiled for the use of the table. Noxious qualities are ascribed to this plant, and to most of the species belonging to the same genus, which have, ever since the time of Theophrastus, been reckoned deadly poisons both to man and beast. 'The deleterious effects, however, may, as in the case of cassava, he probably dissipated by the action of heat.

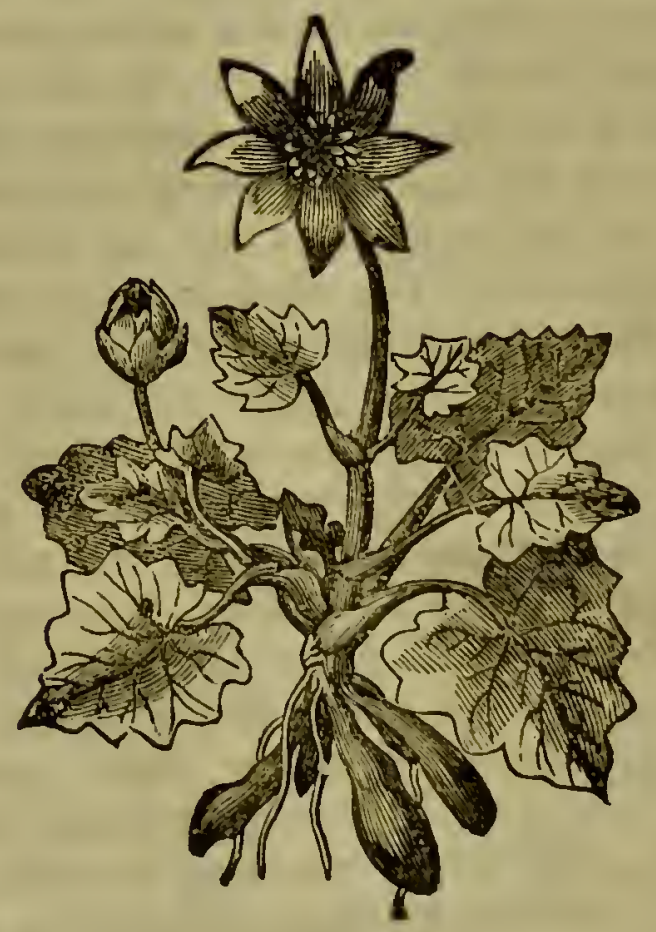

Pilewort-Ficuria ranunculvides.:

The young leaves of PI.EworT-Ranunculus fica- 
ria-are boiled and used as an edible by the Swedish peasantry. 'The earth round the roots of this plant is sometimes washed away by the rain, leaving the small tubers exposed to view. This, in superstitions times, gave rise to the belief that it rained wheat, to the grains of which these tubercles bear some resemblance.

Asparagus is a native both of South and of North Britain, growing, though not very commonly, in stony or gravelly situations near the sea. It is sometimes found on the coasts of Dorsetshire and Somersetshire, and less frequently in Seaton Links, near Edinburgh. 'The steppes, or dry sandy flats, in Poland and the South of Russia, which are par tially saline, and probably at some period of their history have been washed by the sea, produce it much more abundantly; and in some places the ground is covered with it, to the exclusion of almost all other vegetation. When growing thus spontaneously, however, it is a diminutive plant, and is browsed as grass by horses and oxen*. None, indeed, but a practised eye, examining into the minute parts of its structure, could detect it to be the same species which is reared by artificial culture.

'The inhabitants on the coast of Barbary eat the young shoots of another species of asparagus $t$, which one would have supposed was sufficiently unfitted by nature for the support of man. 'This is the thorny asparagus, or asparagus horridus, beset with sharp spines of three or four inches in length. It is said to be indigenous to Spain, as well as to the opposite coast of the Mediterranean.

SEA-CALE is found growing wild on the sandy downs near the sea, of Sweden, Denmark, England, and partially of Scotland. From time immemorial the country people in the west of England have been

* Loudon's Encye. of Gard. † Desfontaines, vol. i. 
in the habit of searching for and gathering the tender shoots which show themselves in the spring through the sand and gravel, and which, thus naturally blanched, are, when boiled, a delicate vegetable. It is also stated that the radical leaves, which have some resemblance to those of the smooth broad-leaved colewort, were likewise eaten like greens by the inhabitants of those places in which the plant grew wild.

Wild plants to be employed as salads and seasonings, when they are used as such in rude states of society, can scarcely be said to form a necessary article of food.. They are approaches to the luxuries and artificial wants of a civilized condition. In every state, however, man is desirous to impart some relish to his food. A refined people do so habitually-a barbarous people when accident places the cool or stimulating vegetable within their reach.

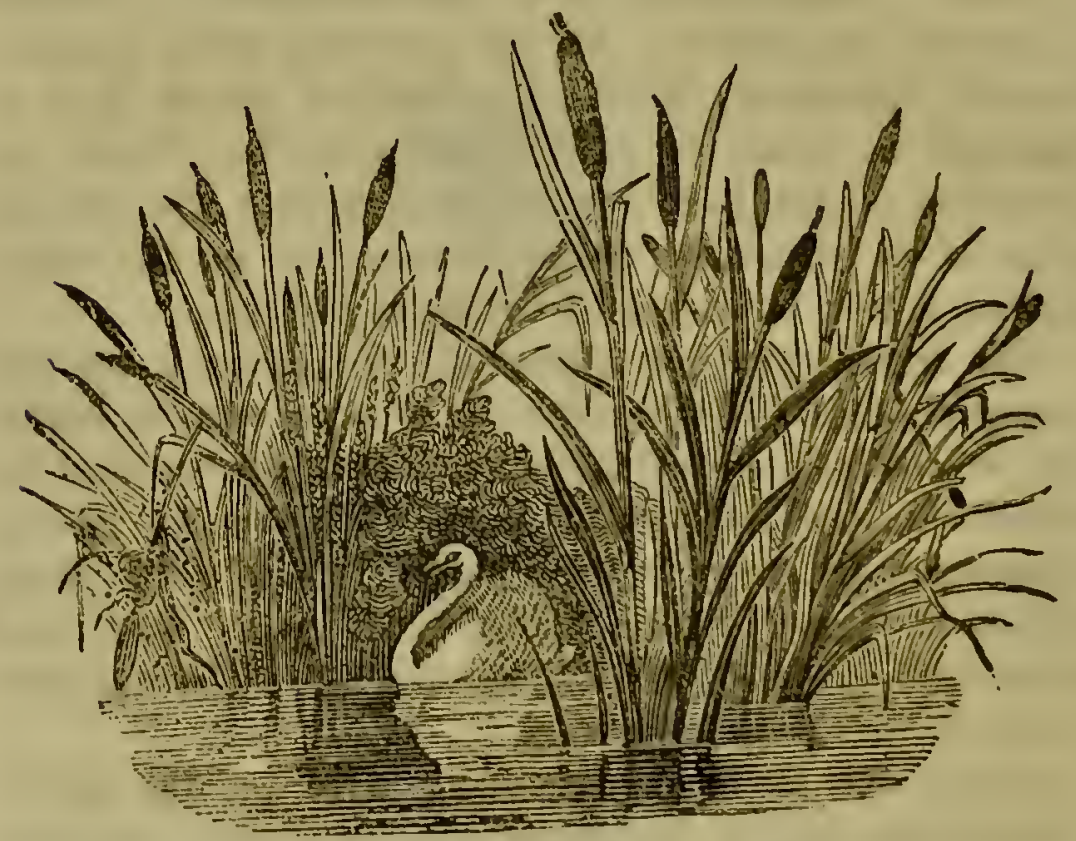

Grent Cat's.Tail-Typhu palustris.

'The Great CA'T's-TaIr, is a perennial reed, grow ing in marshy places. It is a native of Britain, but is 
not in this country used as an esculent. We learn from travellers, however, that some nations apply is to this purpose. In the shallows of the Don this plant flourishes luxuriantly. "We found the inhabitants of Axay," says Dr. Clarke, " and afterwards those of 'Tcherkask, devouring the typha palustris raw, with as much avidity as if this article of diet had been connected with some religious observances. The stalks appeared in all the streets, and in every house, bound into little fascines about three feet in length, as our gardeners bind asparagus; these bundles were hawked about or sold in the shops. The season for eating this vegetable had just commenced. The Cossacks, peeling off the outer cuticle, select, near the root of the plant, a tender white part of the stem, which, for ubout the length of eighteen inches, affords a crisp, cooling, and very pleasant article of food. We ate of it heartily, and became as fond of it as were the Cossacks, with whom, young or old, rich or poor, it is a most favourite repast. The taste is somewhat insipid, but in hot climates this cool and pleasant vegetabie would be highly esteemed. The Cossack officers, however, who had been in other countries, said that it is only fit for food when it grows in the marshes of the Don *." This plant is found native in all parts of the world, in ponds, ditches, and marshy places, and by the sides of brooks and rivers. It flourishes alike in the northern regions of Sweden and under the fervid sun of tho West Indies; it is likewise an inhabitant of Ne'd Zealand.

The Wild-Letruce is indigenous to Englard, and grows abundantly in many parts : yet it is doub:ful whether it ever furnished food to the ancient Britons. The Romans were well acquainted with thy * Travels in Russia, vol. i. p. 349. 
cultivation of this plant, and the name, Lactuca, is ised by Pliny. It would have been contrary to the usual practice of mankind, if the inhabitants of this country had cultivated a plant for themselves out of a wild one, when the very plant so cultivated had been previously well known to the people who introduced civilization, and its attendant arts, among them. The improvement of plants by culture is not the work of man in his rude and savage state, even where the climate is more genial than that of Britain, and the plant more promising than the wild lettuce. The navigators of the South Sea obtained among its islands many specimens of their productiveness; but though some of these plants were beautiful, they were wild, and none could be found that had been improved by culture. The visitors, however, bestowed on the natives many plants of this latter description. Upon the same principle, it is much more natural to conclude that the Romans introduced into the less civilized places which they overran the vegetables previously cultivated in Rome, than that these were the result of native skill in the conquered countries.

CELERY is a native of Britain, and in its wild state is known by the name of smallage. It grows on the sides of ditches and in the neighbourhood of the sea. In all its external characters it bears a marked resemblance to the garden or esculent celery, which is supposed to have been produced from it by the ameliorating effects of cultivation, subduing its rank and acrid taste into an aromatic and pungent flavour. Arisander, which was formerly much cultivated in this country, is also a native plant. It is still found wild on the sea-coast at Dunglass, on the borders of Berwickshire. The Rampion, whose. leaves anu roots were also used for salad, in like manner grows wild in some parts of England. 


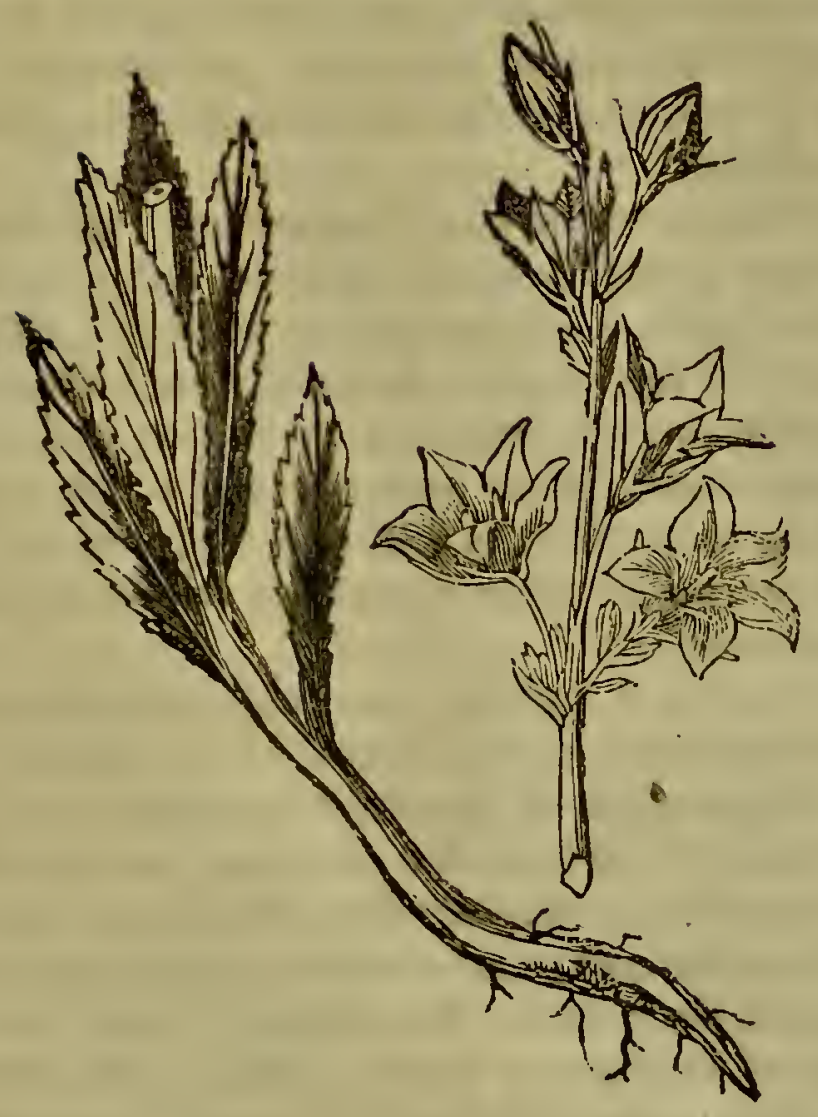

Rampion-Campanula rapunculus.

'These native plants were probably little used without cultivation at any time. But the Laplander is constrained to have recourse to many plants which the inhabitant of more temperate climes rejects as unworthy of notice. Among these is the Cow-THIS'TLE (Sonchus alpinus), which grows spontaneously in Northumberland. It is known in Lapland by the name of Terja, and grows among trees at the sides of mountains, and flowers at the end of July. The stem, which is milky, is peeled and eaten raw by the Laplanders. The taste is extremely bitter, but the people of the country have become so accustomed to this quality, that they are not aware of it, although some of them acknowledged to Linnæus 
that the cow-thistle did appear very bitter to them when they first learned to eat it. As soon as it begins to bloom, the stalk becomes woody, and is no longer edible.

The Water-Cress - Nasturtium officinale which was probably used freely by our simple ancestors, is still a luxury of the crowded city In most parts of the country it is still found abundantly in a state of nature, growing in ditches and brooks, preferring clcar water, and especially the water of springs, to that which is foul and stagnant. For an obvious reason we must somewhat minutely describe the water-cress.

This plant is a trailing perennial, putting out rootlets at the joints of the stems. The leaves, which have a slight tinge of purple, are pinnate and rather heart-shaped. When the current in which they grow is rapid, the rootlets from the young shoots do not easily take root, and then a considerable portion of the plant rises above the surface of the water and the form of the leaves alters. This is the case with many plants; when the leaf is near the ground it is broad, but when elevated it becomes longer and narrower. In water-cresses, this change in the form of the leaves is sometimes followed by unpleasant consequences, since it then causes them to be similar in shape with the joint-flowering waterparsnip (sium nodiflorum), a plant which very generally grows mixed with the cresses, and has poisonous qualities. The leaves of the cress are however more smooth and shining, and are entire st their edges, while those of the parsnip are serrated. When the flowering stems are up, the plants free easily distinguished. The water-parsnip bears its flowers in umbels close upon the joints of the stem, while the flowers of the cress are cruciform and rise into a spike. The four petals in the flower of the 
water-cress, and five in the parsuip, are also an obvious distinction. If they are in seed the parsnip has capsules, the water-cress pods.

The water-cress lias become an object of cultivation; and the demand of the metropolis and of other large towns for this favourite vegetable will, probably, render the natural products of our brooks less and less in request. Few wild plants are the same under cultivation; but even when their qualities are not changed by the care of man, the cultivated sort soon supersedes the uncultivated. The cost of rearing them at will is less than that of searching for them under the difficulties which attend all spontaneous produce.

In a pretty valley called Springhead, situated in Kent, at a short distance from Gravesend, watercresses are grown on a very extensive scale. The plants, neatly trimmed, growing in regular rows, and appearing under a limpid stream of purest water, give the idea of careful cultivation; and present themselves under a more pleasing form to be plucked for the table, than when found the inhabitants of ditches. For the purpose of this culture a clayey soil is selected, in which shallow beds scarcely a foot deep are made, having a slight inclination from one end to the other, and into which a sinall stream of water is introduced. At the bottom of these beds the cress is planted in rows, at about half a foot apart. Dams of six inches high are made at intervals across each bed, their number and frequency being regulated by the length of the bed and its degree of inclination, in such sort, that when these dams are full, the water may rise at least three inches over all the plants of each compartment. 'I'he water will thus circulate throughout, and the plants, if not allowed to flower, will furnish an abundant succession of young tops throughout the spring. 
summer, and autumn. "A stream of water" no larger than what will fill a pipe of one inch bore will, if not absorbed by the soil, suffice to irrigate in this way an eighth of an acre."

SAMPHIRE-Crithomum maritimum-is almost the only wild plant, with the exception of water-cress and laver, which is gathered for the supply of the demands of luxury. Samphire, as is well known, grows on the rocky cliffs of our southern shores; and even in the time of Shakspeare it was a profitable occupation to gather it.

\section{"How fearful}

Arid dizzy 'tis to cast one's eyes so low!

'The crows and choughs that wing the midway air

Show scarce so gross as beetles: half way down

Hangs one that gathers samphire; dreadful trade!

Methiriks he seems no bigger than his head*."

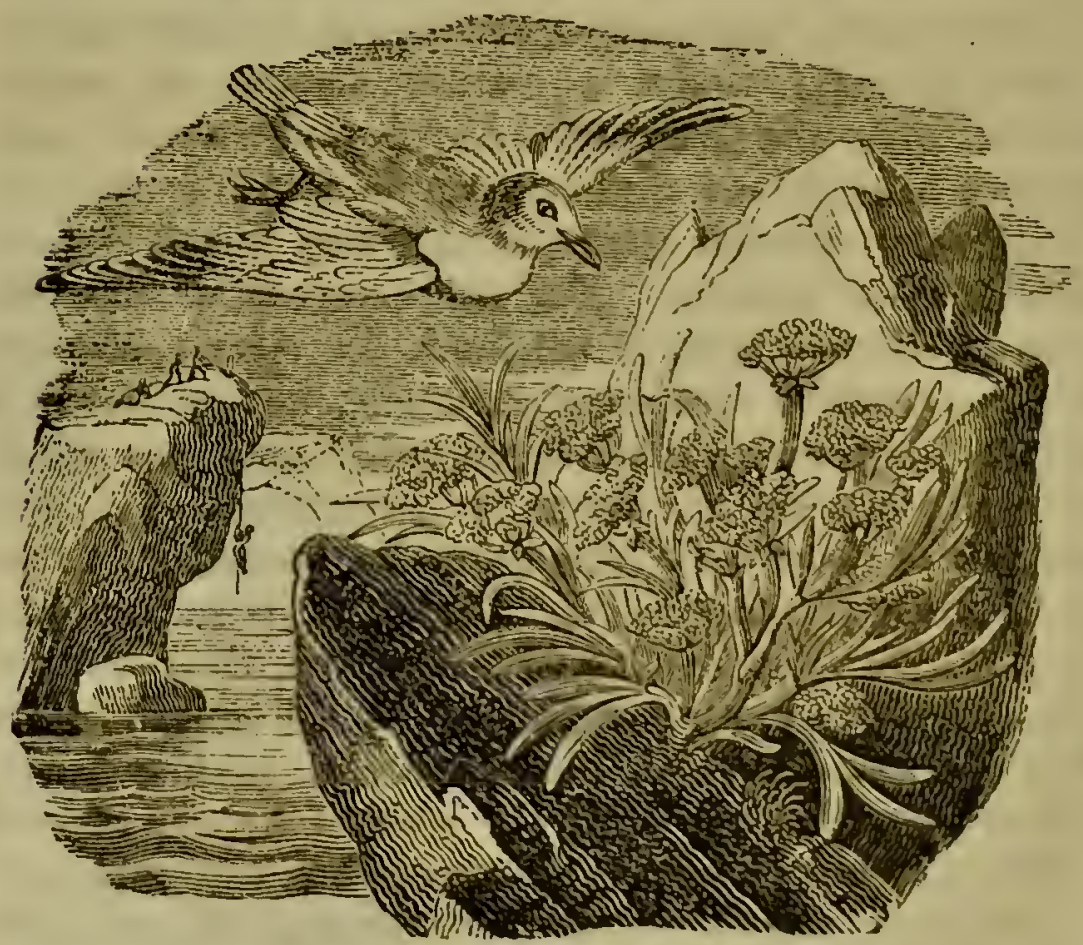

Samphire-Crithomum maritimum.

King Lear, Act iv. Scen 5. 
A few pungent vegetables, and the aromatics of our fields, probably seasoned the homely dishes of our forefuthers, before garden cultivation was understood. or commerce brought the spices of the East, at a cheap rate, to our doors. The mint and thyme and marjoram of the downs gave zest to the barley-broth of the poor cottager; - and the mustard and horse-radish seasoned his salted meat. Several wild species of cress also answered the same purpose ; amongst which was Dittander, a species found chiefly in salt marshes and near the sea. The leaves of this plant are remarkably hot and acrid, and when pepper "was so dear that to promise a saint yearly a pound of it was considered as a liberal bequest," these leaves were no bad substitute for giving pungency to food. They were frequently used by the peasants'for this purpose, whence the plant has obtained the name of "pcor man's pepper."

The Fungr are the most abundant of spontaneous esculent vegetables; but they may be more conveaiently noticed in another portion of this volume. 


\section{Cihapter IX.}

ON VEGETABLE GARDENING.

IN the rudest states of society men depend for supplies of food upon the spontaneous products of uncultivated wilds. An acre of vegetation will not then suffice for a single meal. It is a great step in advance when shepherd tribes convert the pastures, which grow without any human care, into milk and meat. When agriculture is established, civilization has advanced some distance on its journey. But gardening is a much later stage; commerce precedes it. There are few native plants, at least in the more northern parts of Europe, as we have seen, that can be rendered wholesome and agreeable by cultivation. The inhabitants have received them from distant soils. When a nation has commercial intercourse with the uttermost ends of the earth, it soon makes all the valuable products of other places its own-soon, in comparison with the length of time it takes to build up a flourishing, because active and intelligent community. The Dutch were great gardeners, but they were previously great merchants. The Dutch, too, in the height of their prosperity, enjoyed free institu. tions. Gardening may, to a certain extent, prevail in despotic countries. There may be splendid retreats of luxury - bowers and fountains and conservatories-for the great; but the cottages have no pretty patches of rich soil, in which the owner has raised the vegetables of almost every clime. This power of the most humble to partalie of the same class of enjoyments with the most exalted in station, is the best indication 
of a prosperous and happy people. It has been well observed, by a popular writer on gardening, who has perhaps done more than any other individual of our own times for the advancement of horticultural objects, that Louis XIV., who set the fashion of ornamental gardening, not only in France, but in Europe, " never, in all probability, added a foot of ground to the garden of a single cottager, or placed an additional cabbage or potato on his table *."

When a country is depopulated by despotism or civil war, each producing insecurity of property, gardening makes little progress; but when comforts become diffused by profitable industry, and a middleclass is created, the advantages of horticulture are very generally spread. Harrison has a passage in his ' Description of England,' which is particularly illustrative of this principle:- " Such herbes, fruits, and roots also, as grow yeerlie out of the ground of seed, have been verie plentiful in this land in the time of the First Edward and after his daies; but in processe of time they grew also to be neglected, so that from Henrie the Fourth, till the latter end of Henrie the Seventh, and beginning of Henrie the Eighth, there was little or no use of them in England, but they remained either unknowne, or supposed as food more nieet for hogs and savage beasts to feed upon than mankind: whereas in my time their use is not onelie resumed among the poore commons, I meane of melons, pompions, gourds, cucumbers, radishes, skirrets, parsneps, carrets, cabbages, navews, turnips, and all kinds of salad herbs; but also fed upon daintie dishes at the tables of delicate merchants, gentlemen, and the nobilitie, who make their provision yearlie for new seeds out of strange countries, from whence they have them aboundantlie."

* Loudon s Encyclopædia of Garcienlug, p. $\_\geq 2$. 
Gardening and agriculture are in some degree allied in their progress and their results. Vegretables that have been first introduced as luxuries irito our gardens have in time become the staple productions of our fields. A remarkable instance of this is presented in the history of our turnip-husbandry :- " Until the beginning of the eighteenth century, this valuable root was cultivated among us only in gardens or other small spots, for culinary purposes; but Lord Townshend, attending King George the First in one of his excursions to Germany, in the quality of secretary of state, observed the turnip cultivated in open and extensive fields, as fodder for cattle, and spreading fertility over lands naturally barren; and on his return to England, he brought over with him some of the seed, and strongly recommended the practice which he had witnessed to the adoption of his own tenants (in Norfolk), who occupied a soil similar to that : Hanover. The experiment succeeded; the cultivation of field-turnips gradually spread over the whole county; and in the course of time it has made its way into every other district of England. The reputation of the county as an agricultural district dates from the vast improvements of heaths, wastes, sheepwalks, and warrens, by inclosure and manuring-the fruit of the zealous exertions of Lord Townshend and a few neighbouring land-owners-which were, ere long, happily imitated by others. Since these improvements were effected, rents have risen in that county from one or two shillings to fifteen or twenty shillings per acre; a country of sheep-walks and rabbit-warrens has been rendered highly productive; and, by dint of management, what was thus gained has been preserved and improved even to the present moment. Some of the finest corn-crops in the world are new grown on lands which, before the introduction of the turaip husbandry, produced a very scanty supply 
of grass for a few lean and half-starved rabbits. Mr. Colquhoun, in his ' Statistical Researches,' estimated the value of the turnip-crop annually grown in this country at fourteen nillions; but when we further recollect that it enables the agriculturist to reclaim and cultivate land which, without its aid, would remain in a hopeless state of natural barrenness; that it leaves the land so clean and in such fine condition, as almost to insure a good crop of barley and a kind plant of clover, and that this clover is found a most excellent preparative for wheat, it will appear that the subsequent advantages derived from a crop of turnips must infinitely exceed its estimated value as fodder for cattle. If we were, therefore, asked to point out the individual who, in modern times, has proved the greatest benefactor to the community, we should not hesitate to fix upon the ingenious nobleman, whom the wits and courtiers of his own day were pleased to laugh at as ' Turnip 'lownshend.' In something less than one hundred years, the agricultural practice which he introduced from Hanover lias spread itself throughout this country, and now yields an annual return which, probably, exceeds the interest of our national debt *."

What Lord Townshend did for the agriculture of this country, the active research of professional gardeners does at the present day for our horticulture. The earth is minutely surveyed for the discovery of any new vegetable product, and experiments are made upon every mode of cultivation that may impart a new value, either of excellence or cheapness, to those which we already possess. It must be obvious that in gardening, as in every other art, excellence can never be attained, unless the study is systematically and professionally pursued ; and it will only be pursued extensively where society is ready to pay for the pursuit. In a country where the comforts of life are * Quart. Rev., No. 72, pp. 395-6. 
very generally distributed, there will the gardener be most encouraged. In the infancy of societies, where there is little wealth, the gardener's art does not exist as a separate occupation. Each family, if there is any knowledge of gardening, provides for its own wants. There is reason for believing that, in the middle ages, the little garden cultivation was principally committed to the females of the family. The men were fighting. This plan might be the best under the circumstances of the case; but it is obvious that the art would not greatly thrive where there was little profitable industry of any kind. The growth of trade and manufactures established gardens for the public supply. When, through the observation of travellers and the labours of commercial adventurers, the indigenous productions of different regions were assembled together in one country, and the mutual wants of mankind had caused them to dwell together in thickly peopled cities, the minute spots once attached to individual dwellings, and which sufficed for the constant supply to their inmates of a few vegetables, would disappear from the towns. More extensive spaces would be allotted in the neighbourhood, which could be made to contain all the varicties of soil necessary for the successful rearing of dissimilar productions; while the knowledge and the time required for that extended cultivation would no longer be within the compass of members of families. From the very necessity of the case, professional gardeners would be called into occupation.

T'here is perhaps no country to be found, wherein the arts of civilized life have made any considerable progress, to which the foregoing remarks do not in some degree apply; although certainly the amount of skill which has been displayed upon the subject of gardening varies considerably among different communitics. A slight slietch, all that our limits vill 
sdmit, of the state of vegetable gardening as it existed in ancier.t times, and as it is still practised in various countries, may not prove wholly without interest. Our principal inaterials for this sketch are derived from the history of gardeuing in Loudon's Encyclopædia, the perusal of which will abundantly compensate those who are desirous for more minute information upon this interesting subject

The accounts we have received of the gardens of antiquity are for the most part considered fabulous, and present no information upon the particular branch which we are now considering. The hanging gardens of Babylon have been represented as romantic in point of situation, and magnificent not only for their extent, but also for the natural difficulties which were surmounted in their construction. The useful had, however, but little part in their design; and of the less aspiring spots, which were made to minister to the wants of the people of that city by the production of esculent vegetables, it hus not been thought necessary to say one word.

We have abundant reason for believing that the Jews, during their existence as an independent nation, were accustomed to cultivate fruits in abundance, but no mention can be found of the particular herbs and plants which they without doubt produced for their daily consumption.

Our knowledge of the mode of gardening practised in the Chinese empire has been obtained at periods of recent date; yet, from what we know of the inveterate pertinacity wherewith its inhabitants adhere to the customs of their ancestors, we are warranted in believing that the practice of this art has been without any material alteration for many centuries. The learned Jesuits Du Halde and Le Comte, who resided as missionarte in China, speak in commenda- 
tion of the manner in which the cultivation of enlinary vegetables is managed in that country, where indeed the practice of horticulture appears to have reached to considerable perfection, although the scientific principles upon which it should be founded are wholly unknown.

It is said that the lower orders of people in some parts of China draw a chief part of their nourishment from the produce of their gardens, and that they are in possession of some garden esculents which are peculiar to themselves. We are indebted to China for several valuable additions to our flowergardens, and among the rest for various species of the Camellia, Poonia, and Rose ; and it is reasonable to suppose that the same care would have been taken for the transmission of seeds of new descriptions of esculents had any such presented themselves.

In an empire comprehending so great a variety of climate, the natural productions must doubtless be extremely varied, and the Chinese are said to be in the enjoyment of most of the fruits and vegetables that are reared throughout Europe. There is little that is worthy of remark in what lias been stated with regard to the methods employed for the cultivation of their vegetable gardens. Recent travellers have endeavoured to throw an air of discredit upon the relations of the learned men whose accounts have been already noticed. It is indeed not impossible that these Reverend Fathers may have endeavoured to draw a little upon the credulity of their readers; but, on the other hand, it must be considered, that while our own intelligent countrymen who have been admitted within the borders of the Celestial Empire have had their opportunities for observation limited to the time employed in the performance of a rapid jouraey, durng; which they were always watched by a 
governinent escort, their precursors remained for a considerable time in the country, and could consequently examine things at their leisure and i: comparative freedom.

From the earliest times the Persian's have been great gardeners; but historians and travellers have only thought deserving of their notice gardens which have been constructed for the pleasure of monarchs, or as proofs of their wealth and power.

That the Greeks also took pleasure in horticultural pursuits we have the direct testimony of Theophrastus and Aristophanes. Flowers were always in great request among them. At convivial meetings, at public festivals, and in religious ceremonies, the presence of these was always required. To so great an extent was this use of flowers carried, that artists were established in Athens whose sole occupation it was to compose wreaths and crowns with flowers of different species, each of which was understood tu convey some particular mythological idea.

The Romans, amid all their conquests, never forgot to forward the useful arts of life, but carried with them into other countries such as they already pos sessed, while they showed themselves to be willing learners of others which they found established and which were new to themselves. It is fortunate for the interests of humanity that the benefits which they thus became the means of disseminating were in their nature such as would soften and repair the miseries occasioned by the sword; and that these benefits have remained to bless the countries which their armies overran.

It may be supposed that an art which was capable of ministering so greatly to their parsonal gratification as that of vegetable gardening would not be neglected by the Romans. Columella has given a very considerable tist of culinary plants which they pos- 
sessed, and some of these must have been both excellent and plentiful, since he speaks of them as being esteemed both by slaves and kings.

The more luxurious among the Romans were accustomed to force vegetables, and the Emperor Tiberius is said to have been so fond of cucumbers that he secured by that means a supply for his table. throughout the year.

The kitchen-gardens of the modern Italians contain nearly every vegetable that we possess; but their methods of cultivation are not such as to afford them in that degree of perfection in which we are accustomed to elljoy them, and to which the climate would seem qualified to bring them. The gardens of the peasants throughout the Italian states are but very scantily supplied, gourds and Indian corn comprising nearly all which they are made to contain. It is only in the gardens attached to religious houses that horticulture is pursued with any skill. In the labours of these the friars themselves are accustomed to assist, while in other situations in that country the office of a gardener is commonly filled by one who has had little or no instruction to fit him for the employment.

Gardens are found universally throughout the Netherlands, so that, to use the words of Sir W. Temple, "gardening has been the common favourite of public and private men;-a pleasure of the great . est, and a care of the meanest, and indeed an employment and a possession for which no man there is too high nor too low." There is not a cottage to be seen which has not a garden attached to it; and althoingh this is sometimes exceedingly small, the high degree of culture which is bestowed upon it renders the spot available for the comfort of the cottager's family. Towards this desirable object every particle of matter capable of ameliorating the soil is carefully collected 
and applied. From these circumstances, it may be readily supposed that the Dutch are possessed of every fruit and esculent vegetable that their climate is capable of maturing.

In France, although gardens are not nearly so universal as in Holland, they are still very generally met with, their characteristic quality being that of neatness. This statement refers, however, more correctly to the northern than to the southern division of the kingdom, where the cottagers' gardens resemble much those of the Italian peasants, as well in their careless mode of culture as in the paucity of their contents. Nothing can be objected against the system pursued by the market gardeners who supply the French metropolis, and by whose skill and industry many vegetables are brought to a very luxuriant growth.

In the north of Europe gardening is in general a favourite pursuit, and the cottages of the peasants are for the most part provided with a spot of ground sufficient in extent to answer the demands of their inmates. This is not so much the case, however, in the Prussian dominions. Cabbages and potatoes form the greater part of the produce there obtained by the cottagers. The gardens of the higher classes are very differently managed, so as to produce vegetables in great variety and abundance.

The art of gardening in Russia, in common with many other useful pursuits, owes its origin to Peter the Great. Previous to the reign of this monarch, there was scarcely such a thing known throughout the empire as a garden, and the only culinary vegetables grown in the country were a few species of stunted kale. Even now the use of gardens in that country is confined to the great and wealthy of the land, and their choice of culinary vegetables is but small. A considerable improvement in this respect is, however, 
visible of late years, during which time many additions have been made to their kitchen-gardens by different travellers.

Potatoes are now cultivated to some extent in Russia, but they are of recent introduction, and it was for some time difficult to induce the peasantry either to cultivate or to eat them, for the simple reason that they came recommended by their lords, who were not unnaturally perhaps suspected of some selfish or sinister motive in that recommendation. Horticulture has attained to a high degree of perfection in Russia under the auspices of its princes and nobles, and it is a curious fact that more pine-apples are grown in the immediate vicinity of St. Petersburg than in all the other countries of continental Europe.

In Poland, gardening was practised earlier than in Russia, considerable progress having been made in the art at the end of the seventeenth century during the reign of Stanislaus Augustus. There is a very remarkable garden at Warsaw, known by the name of Lazenki. 'This was formed, and the palace to which it was attached was built, by the last king of Poland. Among other. curious and some very magnificent objects in these gardens, are numerous pedestals ranged in various situations, and upon these, instead of sculptured statues, living human figures of both sexes were placed on festal occasions. These persons were dressed in classical costume and were taught to assume and maintain certain attitudes in keeping with the characters they were intended to represent.

It is to Spain that the rest of Europe is indebted for the introduction of many plants from Mexico, Chili, and Peru. Seeds were brought from these regions, in the reign of Ferdinand the Sixth, for the royal garden of Madrid, whence their produce has beell distributed. Spain is very rich in cultivated fruits, so that some species are made to form articles of external commerce; 
but the same pre-eminence in garden cultivation does not now appear which was claimed for her by Columella in the time of the Roman republic, and which was probably as well deserved during the dominion of the Moors. The oldest and most extensive gardens now to be found in Spain are of Moonish origin, and have once been appendages to the palaces of their Arabian kings.

The Chinampas, or floating gardens of Mexico, arz justly considered objects of the greatest curiosity. 'The invention of these gardens is said to have ariseti out of the extraordinary situation in which the Aztecs were placed on the conquest of their country by the Tepanecan nation, when they were confined in great numbers to the small islands on the lake, and were driven to exercise all manner of ingenuity in order to provide a sufficiency of food for their sustenance. Humboldt conjectures that the first idea of these floating gardens may have been suggested by nature herself, seeing that, "on the marshy banks of the lakes of Xochimilco and Chalco the agitated waters, in the time of the great floods, carry away pieces of earth covered with herbs and bound together with roots. The first Chinampas were mostly fragments of ground artificially joined together and cultivated." Following up this suggestion, it would not be difficult, by means of wicker-work formed with marine plants and a substratum of bushes combined with tenacious earth or clay', to construct similar gardens of adequate dimensions. Upon these was placed fine black mould sufficiently deep for the sustenance of the plants which it was desired to raise. The form usually given to these Chinampas was quadrangular, and their size varied from one liundred and fifty to three hundred feet in length, with a breadth of from twenty to seventy feet.

At first the use of these floating gardens was confined to the growth of 'naize and other objects of 
absolute necessity; but in the progress of tine, and when the Mexicans had shaken off the yoke which rendered this restricted appropriation necessary, the owners of the Chinampas applied themselves to the production of vegetable luxuries, and grew fruits and flowers and odoriferous plants, which were used for the embellishment of their teinples and the recreation of their nobles. Daily at sun-rise, according to the Abbé Clavigero, were seen to arrive at the city of Mexico innumerable boats loaded with various kinds of flowers and herbs, the produce of these floating islands. The garden is sometimes seen to contain the cottage of the Indian who is employed to guard a contiguous group of gardens; and on each one there is commonly erected a small liut under which the cultivator can shelter himself from storms or from the intense heat of the sun. If it is wished to place the garden in a different place, this is easily effected by means of long poles, or by rowers placed in a boat to which the garden is fastened. In the driest seasons the Chinampas are always productive, and it is not difficult to renew the powers of the soil by means of mud taken from the bottom of the lake, and which is highly fertilizing. One of the most agreeable recreations afforded to the citizens of Mexico is that of proceeding in small boats in the tvening among these gardens, the vegetation upon which is always in a state of luxuriance.

Floating gardens are maintained also on some of the rivers and canals in China, where an excessive population produces the same effect as that just mentioned as having resulted from the oppression exercised upon the Aztecs by their Tepanecan conquerors; and the inhabitants are obliged to nave recourse to every expedient for increasing the means of subsistence.

Of those emigrants who under ordinary circumstances take up their permanent resioience in distant colonies, a large proportion is drawn from the agri- 
cultural classes. It is natural that these people should provide for their future comfort by conveying with them seeds of various plants, to the cultivation and use of which they have been accustomed in their native land. Accordingly we find, that in almost all places which have been colonized from Europe, the intro duction of such vegetables lias been attempted, and in this respect the condition of colonies frequently presents a fair evidence of the progress of horticulture in the parent state.

The Dutch, who found at the Cape of Good Hope " no other fruits than the chesnut, a nut like the wild almond and the wild plum, and no culinary plants but a sort of vetch *," have rendered that colony, as regards its vegetable productions, one of the most interesting spots with which we are acquainted. Here are to be seen fruits and flowers, beautiful shrubs, and the most magnificent trees, all collected together from every climate and quarter of the globe, and al! flourishing in the greatest perfection.

Our colonists in New South Wales have naturalized in that delightful climate nearly all the culinary vegetables which are to be found in this country, and in the market at Sydney some of these are to be seen in a state of greater perfection than can be given to them in this climate. The fruits of the South of Europe are likewise successfully cultivated, and pineapples, together with many other productions of the tropics, are raised with as little trouble as attends the rearing of cucumbers and melons in this country.

There are good reasons for believing that during the time of their ascendancy in Britain the Romans introduced various vegetable productions, together with the practice of their mode of gardening. This a.t never, however, attained to any degree of perfection in this country until the latter end of the seventeenth cen-

* Loudon's Encjclnpæedia of Gardening, p. 108 
tury, and it is probable that the greatest impetus which it ever received was given by the establishment of the Horticultural Society in 1805. By the exertions of this association, full advantage has been gained from the researches of travellers, and powerful incentives offered for the experiments of ingenious and scientific men.

At present, with the exception perhaps of Holland, there is no country where the use of gardens is so general as in our own. The humblest cottage is frequently seen to be surrounded by a small spot, whence may be drawn a wholesome and agreeable variety for the frugal board of the inhabitants; and even in towns, where the power of vegetation is scarcely able to withstand the effects of the confined and noxious atmosphere, a few yards of soil are often appropriated to the same purpose.

"The laborious journeyman mechanic," says Mr. Loudon, "whose residence in large cities is often in the air rather than on the earth, decorates his garret window with a garden of pots. The debtor deprived of personal liberty, and the pauper in the work-house, divested of all property in external things, and without any fixed object on which to place their affections, sometimes resort to this symbol of territorial appropriution and enjoyment. So natural it is for all to fancy they have an inherent right in the soil, and so necessary to happiness to exercise the affections by having some object on which to place them *"

It is unnecessary in this place to enlarge upon the actual state of vegetable gardening in Great Britain. How greatly advanced that state really is, will be made evident from the perusal of the following pages, which serve to record, among other things, the skill and industry of our countrymen in drawing together and naturalizing upon our soil so many productions of such distant regions for our innocent gratification.

- Loudon's Encyclopxdia of Gardening, p. 95. 


\section{Chapter X. \\ LEGUMINOUS PLANTS.}

The Legumes, or Pulse, are, perhaps, next to the Cerealia and the Potato, the most important of esculent vegetables. They are numerous, most universally diffused, and many which are not applicable for human food can still be advantageously used as nourishment for domestic animals.

The whole of the edible legumes, with the exception of some of the species which grow on trees, have their flowers papilionaceous, or resembling butterflies in shape. The seeds are contained in an oblong legumen, or pod, consisting of two valves, on the upper suture of which they are placed alternately on each side. These seeds, in germinating, have no power of pushing forth more than one stem, as in the case of the cerealia, so that the pea does not tiller, but the buds on the stem produce fertile branches.

Carbonic acid gas is always generated when plants, particularly leguminous plants, are in the greatest vigour of vegetation. The quantity of this gas which is then given out, and more especially during the period of flowering, is very considerable, and being heavier than atmospheric air, it is carried along the surface of the earth into pits and cavities, in the same manner as a flood of water would be carried, unly that its effects are the sole indications of its presence.

It is said that miners, in ferite districts where le. gumes are: exiensively cultivated, are but too we.l 
aware of the production of this mephitic gas, of the noxious effects of which they are sometimes made fatally sensible. Under particular states of the weather, which are known to the overseers from experience and observation, the men do not then go to work until a fire-grate has been let down in one of the ventilation pits, as deep as the rooms or galleries in which the operations are to be carried on. If the fire in the grate will not burn, of course their labours are suspended, until, by the play of the atmospheric current between pits at different elevations, the superabundant carbonic acid gas is removed.

The principal legumes cultivated in Britain are the pea, the bean, and the kidney-bean; which, according to the analyses that have been made, contain quantities of nutritive matter, diminishing in the order in which they have been enumerated, and all of them much less than any of the cerealia.

Peas contain fifty-seven and a half per cent. of nutritive matter, a proportion of which is saccharine. Beans have very nearly as much nutriment, but it is not entirely composed of the same principles. No saccharine matter ready formed is found in this vegetable, which is considered a coarse though nutritive esculent. Kidney-beans do not contain more than nine per cent. of nutritive matter.

The PeA-Pisum-is a climbing plant, furnished with tendrils at the terminations of the compound leaves; and none of the species, not even the dwarf kind, can sustain their stems in an upright position, without either interlacing with each other, or clinging to some extraneous support.

The varieties of this genus are very many. Botanists enumerate several species, which they regard as being distinct. The chief of these are the common or cultivated pea (pisum sativim),- -the sea-pea (pisum maritimum), -the Cape-Hol'n pea (pisum Ameri- 
canum), -and the yellow flowering pea (pisum ochrus). The first is the only a ne which is deemed eligible for cultivation in Britain. The sea-pea is a native of England, which we have noticed in Chapter VIII.

'The Pisum Americanum is a biennial plant which was found growing at Cape Horn by some of the people attached to Lord Anson's expedition. This fresh pulse was a most welcome addition to the ordinary sea provisions, and under such circumstances it appeared to be of more excelling flavour than the common pea. It was accordingly brought home and propagated, but was soon found not to equal even the worst sort of those which were already in cultivation, and it is now only preserved in botanical collections. The flowers are blue, each peduncle sustaining four or five flowers, the pods taper, and the seeds are very small.

The yellow flowering pea is found in a wild state in the corn-fields of Sicily, and some parts of Italy, but is here merely preserved in botanic gardens for the sake of variety. The peduncles have but one flower each, and the pods and seeds are larger than those of the sea-pea. 'They are sometimes eaten, but they are coarse and of little value

The native country of the common pea is not known, it having been a cultivated vegetable before the commencement of botanical history. It is probable, however, that it was introduced into Britain from the warmer parts of Europe, and may have been brought to these from Egypt and Syria. It is known in India, China, and Cochin China; but it is not very plentiful in those places, and there is no evidence of its being a native plant. It is more abundant in the Japan Isles, the climate and soil of which agree better with its habits; and therefore there is reason to conclude that it is not a native of very 
dry and burning regions; neither is it the ffspring of very frigid climes, since it is soon affected by cold, severe weather, and the leaves become blackened by the autumnal frosts.

Historical evidence would make it appear that both the pea and the bean must not only have been introduced, but extensively cultivated in some parts of Scotland, as well as in England, at a very early period. It is on record, that when the English forces were besieging a castle in Lothian, in the year 1299 , their supply of provisions was exhausted, and their only resource, was in the peas and beans of the surrounding fields. 'This circumstance would lead to a belief that the pea was then one of the staple articles of produce for human food.

'The more delicate kinds, however, ds not appear to have been cultivated in England until a much later period, since Fuller informs us that peas, in the time of Queen Elizabeth, were brought from Holland, and were "fit dainties for ladies, they came so far, and cost so dear." In the reign of Henry VIII., too, the pea would appear to be somewhat of a rarity, as in the Privy Purse Expenses of that king is an entry, "paied to a man in rewarde for bringing pescodds to the King's grace, iiijs. viiid." From a song, however, called 'London Lyckpeny,' made in the time of Henry VI., peassods appear to have been commonly sold in London:

"Then unto London I dyde me hye, Of all the land it bearyeth the pryse;

'Gode pescude,' one began to cry."

At Windsor there is a street called 'Peascod,' mentioned by that name in old documents.

The use of the pea as an esculent, both in its green and its dried state, is too familiar to need description. This plant is annually cultivated to a great extent in Britain ; perhaps, since the more general introduction 
of the potato, a diminution of pease culture may have taken place in the poorer districts; but peas are always in constant requisition in this country; they are consumed in immense quantities as sea-provisions; they are likewise largely supplied to hospitals, infirmaries, and work-houses, and are in familiar use in every private family.

The principal varieties of the common pea are the white or yellow, and the grey. Soil and culture have probably produced all the varieties under the two sorts ; different as they now are, both in their colours and their qualities, and even in the number of flowers and pods growing from each peduncle.

Among grey peas, where much attention has not been paid to the purity of the seed, it is not unusual to find several shades of colour from a deep purple almost approaching to a black, to a very pale or nearly white hue. In even the same parcel, some seeds are grey, some mottled, and others purple.

The white and yellow peas are distinguished as garden peas and field peas. 'The former being the choice sorts, are raised by more careful and expensive culture for the purpose of being eaten green; the latter, inferior chiefly on account of the manner of their being raised, are allowerl to come to maturity.

The sub-varieties of the common pea are neverending. These have obtained their names, some from imaginary qualities, some from the peculiar mode of culture, others from the persons who first produced them, and some from more fanciful distinetions. Of those no less than twenty-two are enumerated as being objects of garden culture, differing in the colour of the flowers, height of the haulm or stakk, time of coming to maturity, produce of legumes, or size and flavour of the seeds. The varieties are in different degrees tender or hardy ; if, then, a due regard be paid to the choice of soil and siluation, and 
the time of sowing most favourable to the respective kinds, the success of the crop may, in a great measure, be commanded.

The varieties of the garden peas may, therefore, be divided into early and late. The former are distinguished as being more slender in the plant, and less abundant in the crop, but they are more hardy, and call better withstand the cold weather; while some kinds admit better of being forced, and thus can be produced at the earliest approach of summer, as the grand vegetable luxury of the season. The late sorts are more vigorous, and more productive both in the number of the pods, and the size of the grain ; and as they come to maturity by the natural heat of the season, and in a free change and circulation of the air, they are more rich and saccharine. 'Thus it happens, as is the case with many other articles of human food, that green peas are really of the best quality when they are so cheap that they may be purchased by the people generally.

The pea goes through all the stages of its vegetation in a very brief period. More than one instance is on record of a crop being obtained from seed matured the same season. Some Spanish dwarf peas were sown in February, and the crop was reaped the first week in July; some of the pods were left to mature their seed, which when sufficiently ripe were again committed to the earth on the same piece of ground, and a second crop was reaped on the 27th of September *.

To obtam the very earliest crops, the seeds are sown in a dry soil, about the end of October; in favourable situations and seasons they stand through the winter, and if the spring be a forward one they may be ready for gathering about the end of May. They are a precarious crop, however, and do not pay

* Fleming's British Farmer's Migazine, Nov. 1826 
the cultivator, unless they are produced so early as to command a very high price. In consequence of the uncertainty of the winter, in places where the demand is such as to bear the expense, the earliest peas are brought forward in hot-beds.

Of peas sown in'the field there are several varieties. The dark sorts are generally the longest in coming to maturity, and they have the rankest flavour. In favourable places, if they are sown in autumn, and cleared the instant they are ripe, they may be followed by turnips the same year; but if the sowing is delayed till after Christmas, the ground will not be free in time for any crop save winter wheat. A crop of peas is considered to improve the soil, especially for turnips. But it is not on the whole very profitable, unless upon very rich loams, in which situation they are often sown with beans, and the produce used as food tor stock. 'The bean-stalks, from their greater strength, prevent. the peas from lodging.

THE BEAN-Vicia faba-has been cultivated in Britain from very remote antiquity, having been in all probability introduced into this country by the Romans. It is said to have originated in Egypt ; perhaps because the Greeks, from whom we have the earliest accounts of it, received it from that country as a cultivated vegetable. Some travcllers affirm that the bean is found growing wild in Persia, near the shores of the Caspian ; but that part of A sia has been subjected to so many fluctuations, to so many alternations of culture and destruction, that it is not easy to decide whether any plants which may be discovered vegetating spontaneously be really indigenous, or only the remains of a former cultivation. In many parts of Britain, where all other memorials of former habitations and culture have been swept away, certain plants are found growing which a traveller passing hastily over the country w'ould very naturally describe 
as indigenous, since of their introduction the present mhabitants of the vicinity could most probably give him no account, but which from history and the na ture of the plants themselves are known to be exotics introduced at a specific time.

Beans are cultivated over many countries, as far to the eastward as China and Japan, and they are very generally used as an esculent in many parts of Africa; from its northern coast some of the more valuable varieties were transplanted by the Moors into Spain, and by the Portuguese into their own country.

'This plant is grown abundantly in Barbary, where it is usually full-podded at the latter end of February, and continues in bearing during the whole of spring. When stewed with oil and garlic, beans form, according to Shaw, the principal food of persons of all classes.

The bean in its green state is weil known as a culinary vegetable; when mature and dried it is never used as human food in this country, but is then considered good, though coarse nourishment for labouring horses. Campbell, in his Political Survey, published 1774, mentions that "Beals are exported for the food of the negroes in our plantations, and are employed in feeding liorses at home; so that altogether they are in daily use, and most certainly turn to a very considerable amount*." Provisions for this unhappy race of human beings are in the present day somewhat better selected, and horse-beans do not an! longer form an article of export to the colonies.

All the cultivated beans are annuals, having upright fibrous stems rising from two to four feet high. The flowers are usuall-r white, with a black spot in

* King stated the annual consumption of beans at that period to be four millions, and of peas seven millious of bushels. Campbell, indeed, considered this estimate to be excessive, but if it at all apploximates to the truth, it snows that these legumes were then cultivated to a very great extent. 
the middle of the wing'; these are succeeded by long thick legumes, woolly within, and enclosing large flat seeds. These flowers are very fragrant, and the rich perfume of a bean-field, when the plants are in full blossom, is as familiar as it is delighthtul to all lovers of simple rural pleasures. The popular division of the several varieties is, like that of peas, into field beans and garden beans; the same variety is, however, often cultivated in both situations. The large variety called the "Windsor Bean" is said to have been first cultivated in that neighbourhood by some of the Dutch gardeners who came over at the Revolution. There is a field near Eton still called "the Dutchman's garden."

Beans are propagated by seed sown in rows from two to three feet asunder, either by the dibble or by drilling; the early kinds in October, and from December to January inclusive. The main crop is sown in March and April, and the several varieties are continued in monthly succession until July. For late crops the seeds, previously to being used, are soaked for several hours in soft water. Some cultivators cut off the tops of the plants when in bloom, which operation is supposed to promote an earlier and more abundant production of well-filled legumes. While a very late crop may be obtained by cutting down the plants, as soon as they are in flower, to within a few inches of the base. New stalks spring from the roots, and yield pods at an advanced period of the year.

The bean, though a coarser plant than the pea, is much more liable both to disease and to the depredations of insects. When the plants become sickly from an unfavourable soil or season, small fungi are apt to form withinside the epidermis, such as the nestling spheria (spharia nidula), upon the roots, and the bean blight (uredo $f a b a$ ) upon the stems and leaves. 'Though these are most probably the consequence of a diseased state of the plants, they so destroy the epi 
dermis as to render recovery impossible, and the crop is greatly injured or altogether destroyed. The black aphis also often commits terrible havoc; it generally appears first in the young leaves of the top, and therefore may be removed by a little timely care without injuring the plants, but if once it is allowed time to establish itself, it is very difficult of eradication.

The Kidney Bean-(Phaseolus). - Two species are cultivated in England, beth natives of warm countries, and though they grow and pod well in Britain during the warm months, they will neither bear the frosts of early spring, nor those of late autumn. The dwart kidney-bean (Phaseolus vulgaris), a native of India, but erroneously called the French bean, is mentioned as being in common cultivation in England in the year 1597. The species called the runner (Phaseolus multifforus) was introduced from South America in the year 1633. It is supposed that the scarlet variety, which grows so tall and is so prolific, was first cultivated about that time by Tradescant, the celebrated gardener at Lambetl. It was then, we are told, in so great repute for its flowers, that they formed the leading ornament in the nosegays of the ladies; and it seems to have kept its place only as an ornamental plant for nearly a hundred years, as its legumes were seldom used as an edible substance until brought into notice by Miller of Chelsea in the eighteenth century.

The general characteristics of the two species are the same. The leaves are ternate, attached to long petioles; and the flowers, differing in colour according to the variety, grow on racemes or short lateral branches coming out from one common peduncle. These are succeeded by oblong pods containing smooth shining seeds of a kidney shape.

'The stems are more or less voluble in all, but those of the divarf kind are of very low growth, and require 
no support. The stalks of the runners ascend eight or ten feet, and, therefore, either tall sticks are provided around which they may wind, or they are planted near a building or fence from which slender cords are suspended, and the flexile stems as they rise clasp and entwine themselves with these. "It deserves notice, that in their voluble habit of growth the tendrils turn to the right or in a direction contrary to the apparent diurnal course of the sun : this aberration from the common habit of plants has been accounted for by supposing that the native climate of the scarlet runner will be found to lie south of the equator, and that the plant, although removed to the northern hemisphere, is still obedient to the course originally assigned to it, turning in a direction which in its native climate would be towards the sun *."

Both species are terider plants, and seldom thrive if hey are sown very early in the season; but in favourable weather they are prolific bearers, especially the scarlet runner, which for a long continuance yields a plentiful crop from one sowing.

In England, only the immature pod is used as a legume. The ripe seeds known by the name of haricots are prepared in various ways as a favourite edible in France; where the dwarf white kidney-bean is extensively cultivated as a field crop, to furnish a supply of their seeds, which are in so constant demand. The seeds of the Dutch runners, which are larger than these, and of a superior quality, are made into a kind of soup, which is held in much esteem in Holland. The leaves likewise of the kidney-bean afford when boiled a culinary vegetable which the Nubians consider an excellent esculent.

Some varieties of the kidney-bean are found in cultivation throughout almost every civilized country of the western as well as the eastern hemisphere. 'The

- Loud. Encyc. of Gardening, p. 694. 
small black beans called fricollis, which are in genera, demand all over Mexico, are no doubt a kind of kidneybean. Recent travellers in that country relate that immense fields of these are under cultivation for the supply of the large cities, where they form a part of every meal, and are not only in great favour with the inhabitants, but are considered excellent even by straingers.

Among the productions of Bornou, Major Denham enumerates four kinds of beans, which are raised in great quantities, called mussaqua, marya, lleeny, and kimmay, all known by the general name of gafooly. These are eaten by the slaves and the poorer people. A paste compounded from beans and fish was the only eatable the Major and his companions could find in the towns near the river*.

The Lentru-Ervum-is a small climbing plant, with weak stalks, about a foot and a half high. The leaves are winged, and each is terminated by a tendril. The flowers, of a pale purple colour, are succeeded by short flat pods containing two or three flat round seeds. Another sort, distinguished as the French lentil, is of much larger growth than the former, and altogether more worthy of cultivation. These plants are rarely raised in England, and then only as food for cattle. In most parts of the Continent they are cultivated for the use of man, and the seeds are made into soups, or become an ingredient in other culinary preparations. They are readily softened by, and mix with, water, forming with it a pottage of a chocolate colour. In Catliolic countries, where the formulary of the church enjoins a number of meagre days, such plants as the lidney-bean and the lentil are more cultivated than they are in countries where the religion of the people does not prescribe the same observances. In Englant there are no fasts scattered

* Denham's Tracels, vol. ii. p. 143. 
through the year on which the people are expected to subsist upon pulse with the addition of vegetable oils. The use of haricots and lentils is therefore but little known in this country.

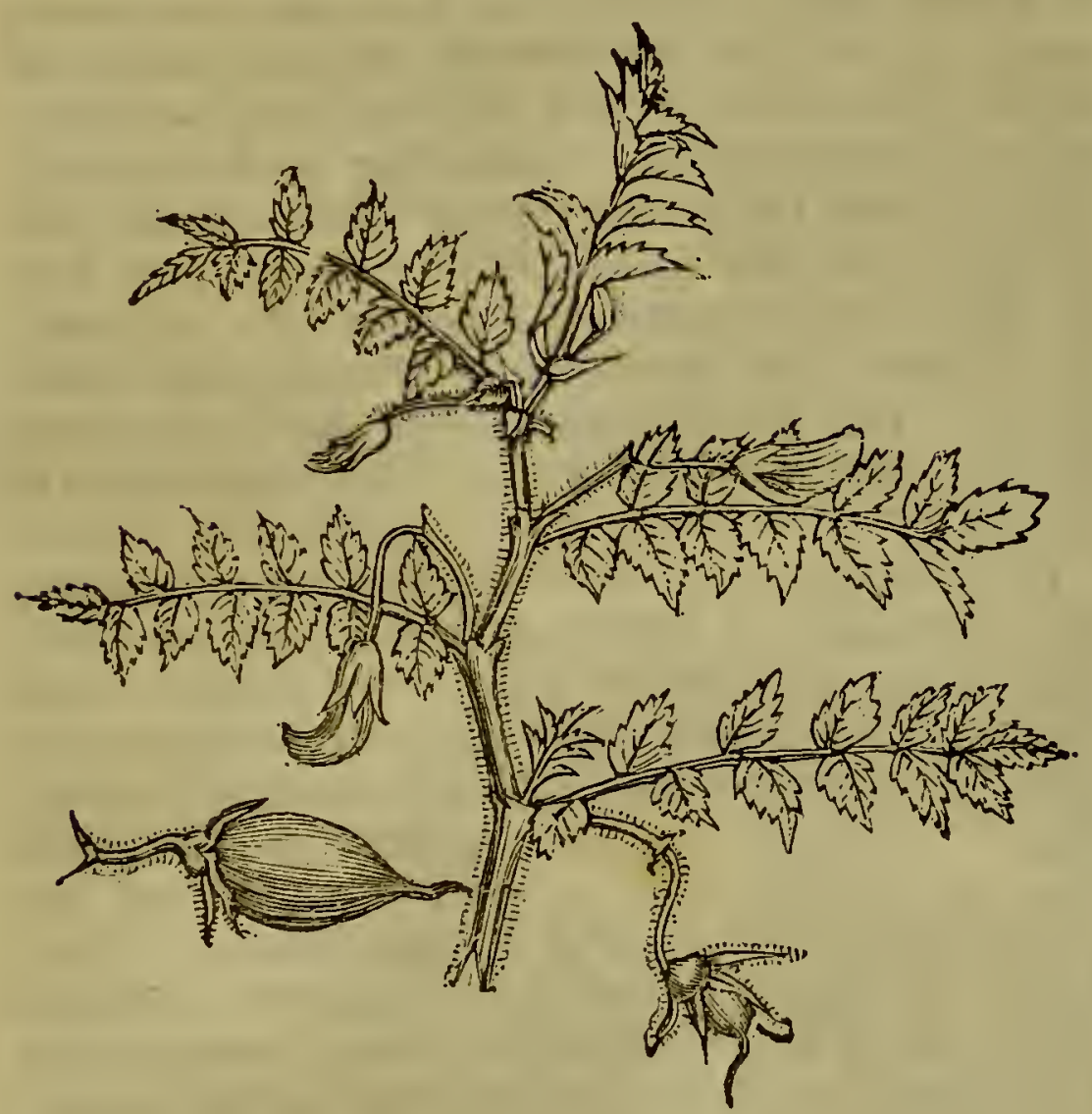

Chick Pea-Cicer arietinum.

The CHICK Pea-Cicer arietinum-is another small legume which is occasionally cultivated in the south of Europe, especially in Spain, where it is used as a dyeing ingredient as well as an article of food. It is known there, and on the opposite coast of the $\mathrm{Me}$ diterranean, by the name of garavance or garvanzos. These seeds do not, like most other pulse, become of a soft and pulpy consistence by boiling, and therefore they never coustitute a dish by themselves, but are 
strewed singly as a garnish over certain savoury viands, and form part of the olla, a dish composed of bacoll, cabbage, pumpkin, and garvanzos, with which a Spanish dinner almost invariably commences. 'The chick-pea, when parched, has been much esteemed among many nations from the earliest periods of history, and in that state it still continues. an article of great consumption. According to Bellonius*, this pea was the parched pulse which formed the common provision of the Hebrews when they took the field; and Cassianus $†$ supposes it to have been the torrified seed mentioned by Plautus and Aristophanes. The frictum cicer seems also to have constituted a part of the usual food of the lower orders at Rome +.

In those warm and arid countries where travellers are constrained to carry their scanty provisions with them across vast desert tracts, they gladly supply themselves with small dried substances which require much mastication, and thus stimulate the salivary glands. Under these circumstances parched chickpeas, or leblebby, are in great demand, and arc as common in the shops as biscuits in those of England. In Grand Cairo and Damascus there are many persons who make it their sole business to fry peas, for the supply of those who traverse the desert.

The seeds of the kerkedan, a small shrub found growing wild and sometimes cultivated in the north of Nubia, are made into a lind of bread, and form the principal food of the Kerrarish Arabs; and a decoction of the roasted grains is used as a substitute for coffec. Another shrub, called symlia, indigenous to the same country, produces legumes resembling

* Calm. Dict. Bibl., lib ii. cap. 53.

+ Cassian. Cullat. 8.

f. Plautus Bacch. act iv. 5, 7. Hor Serm, lib. 2, sat.3, 1. 182, de Arte 1'oet. 1.219. 
peas, and containing round rose-coloured seeds which afford excellent nourishment for camels, and are, when green, employed as human food. These likewise " the Arabs collect and dry, and by hard boiling obtain from them an oil which they use instead of butter to grease their hair and bodies*".

Various descriptions of pulse are cultivated in the East, but these are seldom of a large growth. The culture of smaller legumes as human food, similarly with that of the millets and other small-seeded grains, is adapted oniy to that state of society in which the money-price of labour is low, and yet where the climate and other concurring circumstances are obstacles to the cultivation of the more valuable kinds of regetables. Moisture and heat, as well as a soil comparatively rich, are required for the production of rice; and the cerealia grown in more temperate climates cannot be raised unless there be either a sufficiency of manure, which cannot be procured with. out an abundant stock of domesticated animals, or a natural richness of soil, which is incompatible with dry land in a warm climate.

In the elevated parts of India which lie out of the direction of the periodical rains, a scanty irrigation can at best be obtained, and that only by sinking deep wells or by constructing tanks and reservoirs at a great expense; where these imperfect means are not within reach, the ground is scarcely ever moistened, as probably a shower of rain does not fall during six months. Under these circumstances the cultivation of pulse is resorted to as a matter of necessity, and the smaller and the more hardy these are, the inore certain is the prospect of their yielding a crop. In sultry climates there is often a portion of humidity which plays in the atmosphere, and which will form dew lipon the leaves of a plant, when the evaporative * Burckhardt's Nubia, p. 46. 
power of the naked and baked earth is so great that not a condensed drop will settle upon it, or a trace of moisture be found. From this cause dew may be seen early in the morning spangling the verdant lawn when there is no humidity whatever upon the gravel walk; and upon a burnt-up heath, any plant which may have preserved its greenness, will attract moisture, when the withered grass continues perfectly dry. The pulses which are sown in the rainless parts of India not only preserve themselves, but often aid in preserving millet and other small grain with which they are mixed. When the Hindu, in his simple husbandry, sows several kinds of seed on the same land, he does not therefore give a proof of his ignorance of the art. There is in it a little of the schooling of experience-the practical knowledge of the climate with which he has to deal. He sows his small grain in order that he may have a good crop if the season should send him rain; and he at the same time sows pulse in order that he may not only reap pulse in the event of a drought, but that he may even then perhaps obtain with it a little accompanying grain. 
Úhapter XI.

SUCCULENT ROOTS.

The vegetables which belong to the class of esculents to be hereafter described are mostly auxiliary substances, which are not in themselves sufficiently nutritive to form the whole food of human beings in a state of health and activity; but which require the addition of something more substantial, even by those who eat merely to satisfy the wants of nature, rather than to stimulate an artificial appetite.

The substances which have been already treated of may be considered as stores of matter laid up by nature for the growth of vegetables. The auxiliary substances are mostly vegetables in a growing or active state.

The Turnip-Brassica rapa. A species of turnip is to be occasionally found growing in a wild state in snme parts of Britain; but the root of this plant is of 110 value, and experiments have proved that cultivation cannot, under an English sliy at least, convert this wild variety into that of which the root is used as an edible substance.

The turnip was well known to the Romans, and all that can be gathered on this subject from the writings of the ancients renders it probable that it occupied nearly the same place in Roman culture as it does in British husbandry in the present day. Columella* recommended that the growth of turnips should be

* De Re Rustica, lib. ii. cap. In 
abundant, because those which were not required for liuman food could be given with much advantage to cattle; and both Pliny and he concur in their testimony, that this produce was esteemed next to corn in utility and value. The best grew in the country of the Sabines, and were worth at Rome a sestertius or two-pence each*.

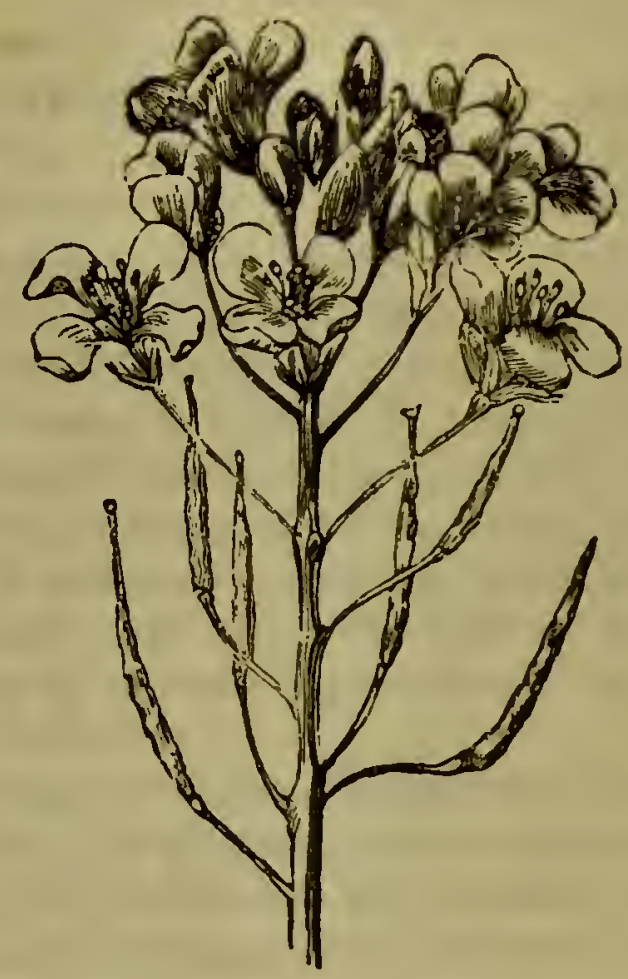

Flowers and Pods of the Turnip.

It is averred that the Roman method of cultivation must have been superior to that of the moderns, since Pliny relates that some single roots weighed as muck: as forty pounds, a weight far surpassing any which has been obtained by the most skilful modern agriculturists. Indeed, the large size of the Roman turnip is supposed by some authors to furnish a collateral proof of the colder temperature of Italy in ancient than

* Hist. Nat. lib. 18, c. 13, lib. 19, c. 5. 
In modern times. Speculations, however, raised upon what might perhaps have been an exagrgerated statement of the Roman naturalist must be purely hypothetical. It is certainly found by experience that a warm climate is not so favourable to the growth of the turnip as cold moist regions. Though receiving equally careful culture, it does not attain to the same size in the south as in the north of England and in Scotland, while it thrives best in the west of the latter country, and in those parts of Ireland where the climate is the most humid. Though the colder parts of the temperate regions are found most favourable for this cultivation, the countries of still higher latitudes are not congenial to the growth of the turnip. 'Those arctic climes where the summer, though brief, is dry and warm, are decided!y adverse to its successful cultivation.

It is very probable that the garden culture of the turnip was introduced by the Romans into this country, and that, like some of the fruit-trees which they had transplanted here, though neglected, it was never altogether lost ; and, if appearing to be so for a time, was restored by the monks, those constant guardians and fosterers of horticulture.

There is no doubt that this root was in cultivation in the sixteenth century. Whether revived by native industry, or introduced at that period by the Flemings, is a question differently answered by different writers; nor does the inquiry possess much interest. Turnips were partially grown for many years in this country, before they came into extensive notice. Horticultural pursuits were at that time so-little understood and practised here, that even the most successful issue which attended the cultivation of the turnip in Norfolk, a county peculiarly adapted to its growth, failed for a time to be followed by its more extended adoption; and a considerable period elapsed before it travelled out of Norfolk into Suffolk, and thence into Essex. 
Towards the latter end of the sixteenth century it is mentioned by more than one writer. Cogan, in lis "Haven of Health," published in 1597, says, that " although many men love to eat turnips, yet do swine abhor them." Gerarde, who published in the same year, and who had rather more rational views on the subject of plants, leads us to conclude that more than one variety was cultivated in the environs of London at that time. "The small turnip," says he, "grown by a village near London, called Hackney, in a sandie ground, and brought to the Crosse in Cheapside by the women of that village to be solde, are the best that I ever tasted." Gerarde is silent concerning the field culture of turnips; neither is this mentioned by Parkinson, who wrote in 1629 . - It is not until the close of the severteenth century that we can find any account of this root being thus cultivated in any part of the country.

'The turnip, in some of its varieties, is of very universal culture throughout Europe. In Sweden it is a very favourite vegetable. We also learn from the interesting journal of $\mathrm{L}$ innæus, that even so far north as Lapmark the colonists sow annually a considerable quantity of turnip-seed, which frequently succeeds very well and produces a plentiful crop. The native Laplanders are so fond of this root that they are often induced to part with a whole cheese in exchange for one single turnip, "than which nothing," our author adds, "can be more foolish"."

In Russia, turnips are used as fruit and eaten with avidity by all classes. In the houses of the nobility, the raw turnip cut in slices is handed about on a silver salver, with brandy, as a provocative to the more substantial meal. "The first nobleman of the empire," says Dr. Clarke, "when dismissed by his sovereign from attendance upon his person, may be

$$
\text { * vul. i. ... } 274 \text {. }
$$


found throughout the day with his neck bare, his beard lengthened, his body wrapped in a sheep's-skin, eating raw turnips, and drinking quass *"

It is said that the root of the turnip cultivated in the plains of Germany seldom exceeds half a pound in weight; and that in France and countries still farther to the south they are yet more diminutive. These are, however, no doubt a particular species naturally of a small growth, and it must not thence be inferred that hot countries are wholly inimical to this production. At Benares, in Hindostan, a latitude of about $26^{\circ}$, turnips, radishes, asparagus, cauliflowers, and other garden vegetables are raised in considerable plenty by the natives, and exposed to sale in the bazaars, principally for European purchasers $\dagger$, to whom these plants of home association are welcome even among the rich display of tropical productions, and even though they cannot be obtained in their native excellence, being comparatively tasteless when raised under the fervid sun of India.

'The turnip is a biennial plant ; the appearance of its large radical leaves is familiar to every body. In the second season after sowing, a flowering stem shoots up, which bears flowers having the four petals arranged in the form of a cross, and therefore called cruciform. The varieties both under garden and field culture are very numerous; while these again differ with soil and climate, and manner of cultivation. When destined for human food, of course the quality more than the size is considered; but in raising them as an economic aliment for cattle the greatest possible quantity of nourishment which can be produced in a given space is the object most to be desired. Various solts, differing in size, shape, and colour, but all assuming, in a greater or less degree, the globular or

* Clarke's Travels in Russia, vol. i. p. 46

+ Tennant's Indian Recreations 
spheroidal form, are the objects of either garden or field culture. Of these there are ten varieties in common cultivation, distinguished by colour, size, time of coming to maturity, productiveness, or flavour. Among this number, the Maltese golden turnip is a very fine variety, of one uniform orange tinge. It is perfectly spherical, and the crown and tap-root are both so very small, that if dexterously removed the exact parts of the root whence they were divided are not easily discernible. When quite fresh, and just before it has acquired its full consistence, it makes its appearance in the northern parts of the country with the dessert, and it is considered to be superior both in form and flavour to many fruits. The Swedish turnip is another variety of a much larger growth, and of a more hardy nature than any of the other kinds under cultivation; this is very seldom raised among garden vegetables, as it is too strong and harsh to be acceptable for human food. It has, however, the advantage of surviving through seasons when even the hardiest of the others would be destroyed. This turnip is largely cultivated in fields and employed as food for cattle.

The root of the French turnip, or naveu, differs from the other varieties, having more the appearance, in shape and size, of the carrot. It is of a very fine flavour, and in hign repute on the Continent. When used, the outer rind is not peeled off as in the common turnip, but merely scraped, since the peculiar taste chiefly resides in that part. In France, as well as in Germany, few great dinners are set on the table without this vegetable appearing under some form, either enriching the gravies and stews, or prepared as a viand by itself *. The naveu was more cultivated in this country a century ago than it is at present, being now but rarely found in our gardens.

* Hort, Trans. 
In Barbary a small parsnip-like turnip with fibrous roots, called in that country el bashoure, is held in mucl esteem for its agreeable pungency*.

A light gravelly soil, broken fine by tillage, is most favourable to the production of turnips of the best quality; but they will succeed in almost any land. Any poor, lighit, sandy ground suits the naveu, which has the great advantage of never requiring any manure in its cultivation.

Turnips may be obtained in this country in succession almost throughout the year by sowing seed every month in spring and summer. 'This is distributed broad-cast, or sometimes sown in drills in the proportion of about half an ounce of seed to one hundred square feet. As soon as the plants are sufficiently advanced, having rough leaves of about an inch broad, they are hoed and thinned to six or eight inches apart from each other. In the early stages of their growth turnips are rather a delicate crop. When they first put forth their tender and succulent seed-leaves, they are liable to be preyed upon by a peculiar species of beetle called thence the turnip fly; this is extremely destructive, and various preventives against the evil have been suggested. Several preparations of the seeds previously to sowing have by turns been recommended, such as steeping them in sulphur-water or sprinkling them with soot at the time of sowing; these, however, have not been considered efficacious, and even when they have apparently been successful, perhaps it has been under circumstances in which the plants would have equally escaped without any precautionary measure. No insect can very well deposit its eggs in the seed of the turnip before it is in the ground, at least there is no known species which perforates the pods for that purpose. The sulphur or soot, or any other

* Shaw's Travels. 
application, is of course thrown off with the tunic or outer coat, and does not in any way protect the cotyledon or side lobes of the seed, which come up in the form of leaves, and in which the eggs of the fly are then deposited. By some cultivators these leaves are powdered with quick-lime as suon as they show themselves above ground; a plan which appears the most rational for preventing the mischief. One of the easiest remedies against it, however, is recommended by Neill, to sow thick, and thus ensure a sufficiency of plants both for the fly and the crop. As soon as the rough leaves are a little developed the danger from the insect depredator ceases.

Turnips, if carefully cultivated, attain to a very great size in this country, though appearing insignificant when compared with the gigantic root of the Roman naturalist. Tull* speaks of some weighing as much as nineteen pounds, and of often meeting with others of sixteen pounds. In Surrey, a Swedish turnip, the seed of which had been sown in July, was dug up in October, 18:2S, which weighed twenty-one pounds, and was one yard in circumference t. But these are far surpassed by one which was pulled up in 1758 at 'Tudenham, in Norfolk, and which weighed twenty-nine pounds + . In No. 360 of the Philosophical 'Transactions, we find a curious calculation made by Dr. Desaguliers, on the rapid increase of a turnip root. One ounce of turnip-seed was found by him to contain between fourteen and fifteen thousand single seeds; therefore, one seed would weigh one-fourteen or one fifteen-thousandth part of an ounce; and assuming its growth to be always uniform, a turnipsced may increase fifteen times its own weight in a minute! By an actual experiment made on moss or

* Tull's Horse-Hoeing Hushandry.

+ Gard. Mag. \$ Camphell's I'ol. Suriey, vol. ii. 
peat ground, turnips have been found to increase by growth 15,990 times the weight of their seeds each day they stood upon it. It is not, however, only the size and weight of the root which renders this crop so productive; the number contained in a given space, with reference to their size, is very great. Some writers speak rather marvellously on this subject, but it is generally thought a good crop to obtain a turnip from each square foot of ground. Mill considers an average crop to be 11,664 roots per acre, which at six pounds each will be 69,984 pounds.

The uses of the turnip as a culinary vegetable are too familiarly known to require that they should be here enumerated. Though in very extensive favour among the moderns, the different modes of preparing it appear poor and insipid compared with those efforts of gastronomic skill by which the ancients made it assume so many inviting forms. It is related that "the king of Bithynia, in some expedition against the Scythians, in the winter, and at a great distance from the sea, had a violent longing for a small fish cilled aphy-a pilchard, a herring, or an anchovy. $\mathrm{H}$ is cook cut a turnip to the perfect imitation of its shape ; then, fried in oil, salted, and well powdered with the grains of a dozen black poppies, his majesty's taste was so exquisitely deceived, that he praised the root to his guest as an excellent fish. 'This transmutation of vegetables into meat or fish is a province of the culinary art which we appear to have lost; yet these are cibi innocintes (harmless food) compared with the things thenselves*."

Our more immediate ancestors appear to have applied the turnip to more extensive uses as an esculent than is done in the present day. It is recorded + , that in the years 1629 and 1630 , when there was a deartb

* Curiosities of Literature, vol. v. p. 88.

† Phil. Trans. Nos. 90 and 205 
in England, very good, white, lasting, and wholesome bread was made of boiled turnips, deprived of their moisture by pressure, and then kneaded with an equal quantity of wheaten flour, the whole forming what was called turnip-bread. The scarcity of corn in 1693 obliged the poor people of Essex again to have recourse to this species of food. This bread could not, it is said, be distinguished by the eye from a wheaten loaf; neither did the smell much betray it, especially when cold

The earliest spring-produced leaves of the turnip are sometimes boiled or stewed, and appear on the table under the name of turnip-tops. The Romans likewise applied these tender leaves to the same purpose.

Turnips, in all their varieties, do not contain so much nourishment as either carrots or parsnips. Sir Humphrey Davy's analysis gives only forty-two parts of nutritive matter in one thousand parts of the common turnip, and sixty-four parts in one thousand parts of the Swedish root; but as the turnips cultivated in the environs of London are not considered of so good a quality as those farther north, it is probable that this estimate may be somewhat below the average proportion.

The Carrot-Daucus carota. It was a subject of much interest among the botanists of the sixteenth and seventcenth centuries to ascertain what plants of the ancients could be identified with those at present lnown. Accordingly we find in the works of those writers many curious and learned disquisitions in support of their respective opinions. A mong the plants which have given rise to so much laborious, and perhaps unprofitable research, the carrot makes a prominent figure. 'This discussion would have little interest in the present day; the result, however, shows that the carrot was cerlainly known and used by the ancients as an edible root. A plant under the name 
of staphylinos is minutely described by Dioscorides*, and this description applies in every respect to that of the carrot. Though growing wild, the plant is noticed by the Greek physician as being likewise reared in gardens on account of its esculent root. It is difficult to trace the progress of the carrot since that period, but it appears to have been always an object of cultivation among various nations.

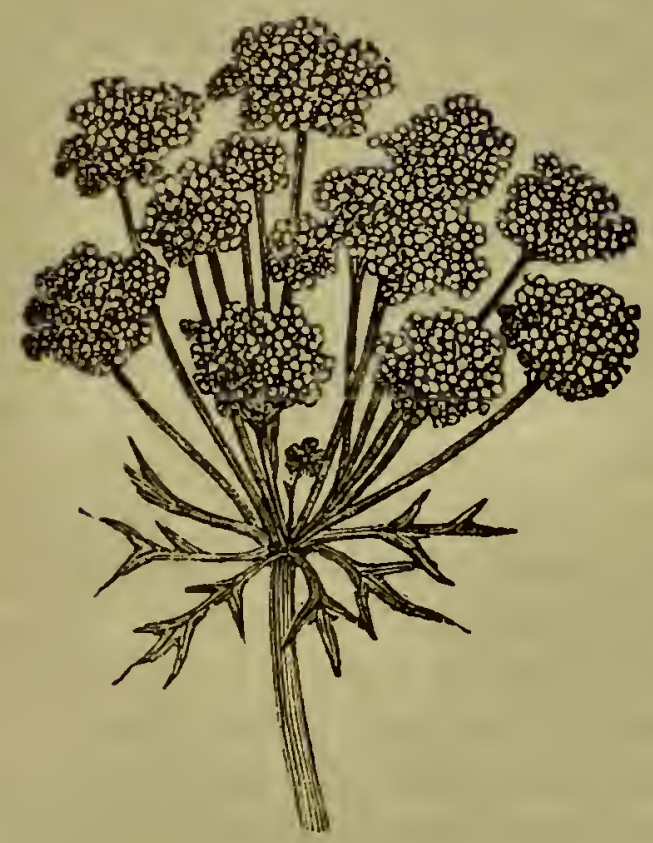

Uinbel of the Carrot.

Miller, and other horticulturists, have made various attempts to change by culture the wild carrot into the esculent one-these attempts have, howerer, always proved unsuccessful-it is therefore probable that the two plants are not identical, or that the cultivated one was first fostered into its present value under a warmer temperature than that of Britain. Whatever may be its origin, it was not, however, inmediately transplanted into this country from a milder climate than our own.

* Lib. iii. cạ. 59. 
We are in lebted for its introduction to the Flemings, who, in the reign of Queen Elizabeth, sought refuge in England from the insupportable tyranny of their Spanish master Philip the Second. Finding the soil about $\mathrm{S} \varepsilon$ ndwich in Kent very favourable for the culture of the carrot, the emigrants soon engaged in its production on that spot. The English, whose knowledge of horticulture was at that time extremely circumscribed, were in this case well pleased to add another edible vegetable to the scanty list which were then under general cultivation. The carrot, therefore, unlike the turnip, grew quickly into esteem, and being made an object of careful culture, was very shortly naturalized throughout the island. We are told by Parkinson, the celebrated botanist to James the First, that in his time the ladies adorned their headdresses with carrot-leaves, the light feathery verdure of which caused them to be no contemptible substitute for the plumage of birds. Although the taste of the fair sex in the present day has discarded this simple and perishable ornament, the leaves of the carrot are even now sometimes used as house decorations. If in the winter a section be cut from the end or thick part of the root, and this be placed in a shallow vessel containing water, young and delicate leaves are developed, forming a " radiated tuft," the graceful and verdant appearance of which make it a pleasing ornament for the mantel-piece in that season when any semblance of vegetation is a welcome relief to the eye.

The carrot is a biennial plant, attaining to the height of two feet; its white flowers grow in umbels, that is, having the common peduncle divided into rays springing from one point, each ray or pedicle being terminated by a floret; they appear in June and July, and are succeeded by rough hairy grains.

Of cultivated carrots there are many varieties. which have in all probability been produced by climatr 
atd culture. The kinds which are commonly grown aredistinguished into two, the long and the hor'n carrot. The first is again subdivided into others which differ in size as well as in colour. The red or large field carrot attains to a considerable growth; it is chiefly cultivated in fields as food for cattle, and in farmers' gardens as a material for colouring butter. The orange carrot, though not so productive, is generally the main crop in garden culture-the flavour of this is more delicate, and therefore it is in higher estimation as a culinary vegetable. There are, likewise, white, yellow, and purple varieties-these are not, however, in comnion cultivation. The horn-carrot has a shorter and smaler root than the long varieties; it is, therefore, a good crop for a shallow soil, and in such a situation is preferable to the larger kind; it has likewise the advantage of coming to maturity in a shorter period than the long, and is consequently found well adapted for the early and late crops.

When a carrot is cut transversely it is found to consist of two parts of different colour and texture. These are the bark and the wood ; the bark is of the darkest colour, and of the most pulpy consistence, and it is also the sweetest to the taste; the heart or wood, especially when the root has attained its full size, is more fibrous or stringy, and, if it be separated, it is bristled over with hard points or fibres that extend to the rootlets outside. Almost the whole crown of the root, or the part which sends up the leaves, is connected with the wood, and only the epidermis of the leaves and stem with the external portion of the root.

The skin or bark is found to be more nutritious than the central part, and consequently the value of the carrot as an esculent will depend on the relative proportion of these two parts of the root. 'The object of the skilful cultivator is, ilerefore, to obtain the root with the smallest possible proportionate quantity of 
wood. In endeavouring to secure this result much must of course depend upon the nature of the planis from which the seeds are obtained; but arlastation of soil is likewise a very important consideration.

The carrot is most successfully cultivated in a light mcllow soil mixed with sand: the ground should be well dug to some depth, and made extremely friable and porous, that the roots may meet with no obstruction in running down, which would cause them to grow forked and to shoot out lateral branches. 'This accident will happen, especially when the ground has been too highly manured previously to the seed being sown. It may perhaps be taken as a general rule that strong soils are not well adapted for any plants which form esculent roots deep under the surface, as the mechanical resistance which is thereby opposed to the swelling of the bulb forces much of the strength of the plant up into leaves; and in the carrot especially, that part of the root which is the most valuable is diminished in the greatest proportion.

'The best mode of cultivating these roots has been made by many agriculturists a subject of inquiry. So early as the year 1765 , this branch of husbandry engaged the attention of the Society for the Encouragement of Arts, \&c.; and, in consequence, an account of the culture of carrots and the uses to which they may be applied was published by Robert Billing, a farmer of Norfolk, in whose work much useful matter on the subject is contained.

The seeds of carrots are surrounded by numerous forked hairs, by which they adhere to each other so tenaciously, that there is some difficulty in causing their separation ; this is performed either by rubbing them through the hands or by passing them through a fine chatf-sieve; but the best and most effectual method, as recommended by an intelligent cultivator *

F Communications to the Agricultural Suciety, vol, ii. 
is to mix them with fine sand in the proportion of one bushel to every four or five pounds of seeds - this mixture is then laid in heaps, being occasionally watered and turned during two or three weeks previous to sowing. The above preliminary process not only occasions the more equal diffusion of the seeds, but likewise promotes their quicker germination; besides this, when they are sown alone their extreme levity causes great inconvenience, and prevents this operation from being successfully performed except in the calmest weather. The ground being duly manured, and reduced to the required degree of fineness, the seed mixed with the sand is sown about the middle of March or beginning of A pril : the seeds thus prepared germinate and send up young plants before the appearance of the annual weeds, which are always abumdant in a soil so worked and manured. In about five or six weeks the plants are in a fit state for hoeing, and that operation two or three times repeated, according to the increase of the weeds, is all the after-culture which is requisite.

From this manner of sowing, more than eight hundred bushels per acre of carrots of very large growth have been obtained. According to Mr. Arthur Young, the produce of these roots on indifferent land is about two hundred bushels, and on a more congenial soil six hundred and forty bushels per acre. The garden culture of carrots is somewhat different. In that case they are sown in a succession of crops from the latter end of February to the beginning of August, and the plants when hoed are thimned at regular distances, of from five to eight inches apart, the particular interval being regulated by the size of the variety under cultivation, and by the period of their growth at which they are to be drawn.

In order to preserve carrots for winter use, they are dugr up in the beginning of November, and placed in 
a dry place in sand, by which means they may be kept without spoiling until March or April of the ensuing year.

To obtain carrot-seed, some roots which have been taken up in November are replanted in February about, two feet apart, and with the crown or head a few inches below the surface. Leaves and flower-stalks will spring up from these, and seeds will be produced which ripen in autumn. A considerable quantity of carrot-seed is raised at Weathersfield in Essex, but this is insufficient for a home supply, and it is said much is imported from Holland into this country*. It would appear that the production of carrot-seed may occasionally be made a source of considerable profit to the cultivator. We find it recorded that in the latter half of the last century a farmer in Essex obtained from an acre of land sown with carrots ten cwt. of seed, which he sold in London for $\mathfrak{E} 10$ per cwt†. This is a very rare case. If it were general the price would soon be reduced.

The size of carrots differs, of course, very much according to soil, culture, and variety. Sorre have been known to measure two feet in length and from twelve to fourteen inches in circumference at the thickest part. In the autumn of 1826 several were taken up in the neighbourhood of Lancaster having an average weight of four pounds each; these were fine firm roots, and in every respect good for the table.

Besides their use as human food, carrots are in some places grown largely for the consumption of stock, especially for horses. It is affirmed that cattle which have once tasted these, usually prefer them so much to turnips as with difficulty to be made to return to the latter. 'The milk of cows fed on carrots never acquires any unpleasant flavour, while at the

* Loudon's Encyc. of Gardening.

+ Campbell's Political Survey. 
same time the quantity produced is increased. Calves thrive admirably, and bullocks are quickly fattened on this food. Calrots are equally beneficial as nourishment for sheep, and are devoured with avidity by swine. In the short space of ten days a lean hog was fattened by these roots, having consumed during that period 196 pounds. Its fat proved very fine. white, and firm, and did not waste in the dressing. Horses receiving no other sustenance perform their work as usual without any diminution of their sleekness. The efficacy of these roots in preserving and restoring the wind of horses had, it is said, beem partially known in Suffolk, where carrots were administered as a secret specific for the complaint, long previously to their being commonly applied as food for horses. These roots may also with advantage be given to poultry. In severe winters they have been found of great utility in the preservation of deer; and they have been strongly recommended as wholesome and cheap nourishment for dogs. Although, perhaps, the virtues and nutritive qualities of the carrot may be somewhat overrated by writers who have evidently a strong bias in its favour, it is more than probable that carrots are a more wholesome food than either cabbages or turnips, as they are so strongly antiseptic (opposed to putrefaction) as to be occasionally used, on account of this property, in certain surgical applications. Various opinions exist among agriculturists as to the relative advantages arising from the culture of the carrot or the turnip as food for cattle. The latter root may perhaps be more productive, and succeed better in a variety of soils, but the positive amount of nourishment it contains would seem to be much less than that of the carrot. 'This assertion is advanced on the testimony of Mr. Billing, who obtained from twenty and a half acres of land, varying in soil and degree of preparation, five hundred and ten loads of carrots. Experience led 
him to conclude that these were equal in use and effect to one thousand loads of turnips, and to three hundred loads of hay. At Parlington in Yorkshire, the stock of a farm, consisting of twenty workinghorses, four bullocks, and six milch cows, were fed from the end of September to the begiming of May on the carrots produced from three acres of land. The animals, during the whoie of that period, lived on these roots with the addition of only a very small quantity of hay, and thirty hogs were fattened on the refuse left by the cattle.

The greater part of the alimentary portion of the carrot consists, according to. Sir Humphrey Davy's analysis, of saccharine matter, which may in a considerable degree account for its antiseptic qualities. The quantity of nutritive matter is nearly ten per cent. in the whole weight of carrot, being 98 parts in 1000 , and of these, three are starch or mucilagge, and the remaining ninety-five saccharine matter. The quantity of ready formed saccharine matter in carrots is much greater than in any of the cerealia, being $2 \frac{1}{2}$ per cent. more than in barley, and about six times more than the quantity contained in potatoes. It is presumed, therefore, that carrots are much better adapted than the latter for the distiilery. Dr. Hunter, in the 'Georgical Essays,' details experiments made to prepare from carrots a beverage resembling beer, and subsequently a spirituous liquor; the former proved unsuccessful; but the result of the latter was, according to the Doctor's opinion, very encouraging. "From a gross calculation," he concludes, "I am induced to think that a good acre of carrots manufactured in this manner will leave a profit of furry pounds, after deducting the landlord's rent, the cost if cultivation, distillation, and other incidental expenses. In this calculation $I$ presume that the spirit is worth six shillings per gatlon, and not excised" This is 
perhaps rather an exaggerated statement: it has, however, been found by other experiments that eighteen tons, the produce of one acre, will yield one hundred gallons of proof spirit, a larger product than that obtained from an acre of barley *; while the refuse supplies a greater quantity of food for hogs.

Attempts have likewise been made to prepare sugar from carrots, but without success; a thick syrupy matter which refuses to crystallize can alone be $\mathrm{ob}$ tained.

The Parsnip-Pastinaca sativa-is, like the carrot, a biennial, and is also a native of Britain. It belongs to the same tribe of plants (Umbelliferce) as the carrot, and resembles it in its general characteristics. The leaves are, however, larger, the parts not being so delicately formed, and the whole plant is more strong and hardy. The flowers are yellow, while those of the carrot are white with a tinge of purple in the middle.

One variety only of the parsnip is cultivated in England, though that runs into many sub-varieties, according to the soil upon which it is grown. In other countries the varieties are more numerous. In France, as well as in Guernsey and Jersey, where the soil is peculiarly adapted to this cultivation, three varieties are distinguished by the names of Coquaine, Lisbonaise, and Siam. 'The first runs very long, to the depth of three and even four feet in the ground, and attaining to from three to four inches in diameter; while its leaves grow proportionally high, and pro-

* The arerage product assigned to twelve stone or one hundred and sixty-eight lbs. of malt, is about six gallons and three-quarters, imperial measure, of spirit twenty-four per cent. over proof; thus giving about two gallons as the product of a bushel. According to this calculation, an acre of barley should produce sixty gallons of spirit of the strength above-mentioned, which is equal to seventy-four gallons of proof spirit, imperial measure, or eighty. nine galluns of the old wine-measure. 
ceer from the whole crown of the root. The Lisboncise is shorter, but considerably thicker. and of an equally good quality; the leaves of this variety are mall and short, and proceed only from the centre of the crown. The Siam has not so large a root, and is of a slightly yellow tinge; it is more tender, and of a richer flavour than the other varieties.

A light, deep soil, free from stones, is requisite for the favourable growth of the parsnip. 'The seed is usually sown at the latter end of February or March, in the proportion of nearly three and a half pounds of seed to one rood of land. It is sown broad-cast, and raked into the ground. The only after-culture required is to keep the plants free from weeds, and to thin them to about a foot distance from each other. The roots come to maturity at the latter end of October; this state is indicated by the decay of the leaf; they are then fit for use. Parsnips are not so susceptible to injury from frost as carrots, and they may therefore remain throughout the winter in the ground without being in any way deteriorated.

A few roots should, however, be preserved in sand for use during those months when the ground is too hard to allow of their being dug up. The seed is obtained in the same manner as that of the carrot.

When the parsnip is grown upon poor land it loses much of the rank taste, which it acquires if cultivated in richer soils, and though not nearly so abundant, is far more sweet and agreeable. 'Thus produced, when slowly roasted in the ashes of peat or turf, it becomes nearly as farinaceous as the best potatoes, and in some of the poorer districts of the country is used with the same additions as an article of substantive food. "In the north of Scotland," Neill cbserves, "parsnips are often beat up with potatues and a little butter" of this excellent mess the children of the peasantry are very fond, and they do 
not fail to thrive upon it." From the same authority we learn that in the north of Ireland an agreeable beverage is prepared from the roots brewed with hops. In some places a species of wine is also made from them, and a very pure spirit is obtained when parsnips are distilled after a similar preparatory process to that used with the carrot. In Catholic countries the parsnip is more abundantly employed for human food than in Britain. It was, however, formerly held in much greater estimation here than it is at present. This root is wholesome as well as hardy, but, as the soil which is most favourable to its production as human food is also best adapted for the growtl of the potato, which is both more productive and more nutritious than the parsnip, the culture of this plant as a culinary esculent has declined; and the use of it with salt fislı in Lent may perhaps be regarded more as the relic of an old custom than as a choice arising from any partiality for the peculiar flavour of the parsnip in combination with this particular kind of viand.

The nutritious matter in parsnips is found by analysis to be ninety-nine parts in a thousand, of which nine parts are mucilage, and the remaining ninety are saccharine matter.

The Skirret-Sium Sisarum-differs from the roots already mentioned, in being a perennial. This plant is not a native of England, or of any part of Europe. It is indigenous to China, but was introduced into this part of the world some centuries back, being known in British horticulture so early as about the middle of the sixteenth century. It was formerly much more prized than it is at present. Worlidge, a writer in the latter end of the seventeenth century, described it as the " sweetest, whitest, and most wholesome of roots." The skirret is one of those plants which are now neglected, because we are become acquainted with others more pleasant to the taste, anp 
more profitable in their culture. Its peculiar sweetness, so delightful to the palates of our less refined fore-fathers, to us appears nauseous lusciousness; and that root which the Emperor Tiberius esteemed so much as to cause it to be brought from the banks of the Rhine for the use of his table, is little relished in the present day. Beckmann ingeniously accounts for this change of taste in the use of vegetable productions. "In the oldest times mankind were so fond of sweet things, that the gondness and agreeable taste of every kind of food was determined according to the degree of its sweetness; and such is the manner of judging, even at present, throughout all the East, in Africa, and in America. This is the case also among us with the greater part of the lower classes, who are not able to follow the mode of richer tables. In the northern countries this taste is almost every where prevalent. 'Thus the Swedes spoil, by the addition of sugar, costly Rhenish wines, sauer-liraut, and other articles, the agreeable tartness of which is gratifying to other nations. In proportion to their population and luxury, the Swedes seem to use more st:zar than the Germans, and the Germans more than the English or French; and one might almost suspect that a taste for sweet things was in the inverse ratio of culture. At any rate, one can thus explain why many regetable productions which some centuries ago were reckoned among the-most agreeable dishes appear to us to be nauseously sweet *".

For some time after the cultivation of skirrets had become neglected in the gardens of the rich, they still continued to be an object of culture among the poor in a few remote parts of the country. But evell in those situations they have now very generally given way to the potato, and are seldom grown, and even then rather from the love of variety than for any

* History of Inventions, vol. iv. p. 358 . 
particular merit which they may possess. The skirret is thus occasionally cultivated in the north of Scotland, under the name of crummach.

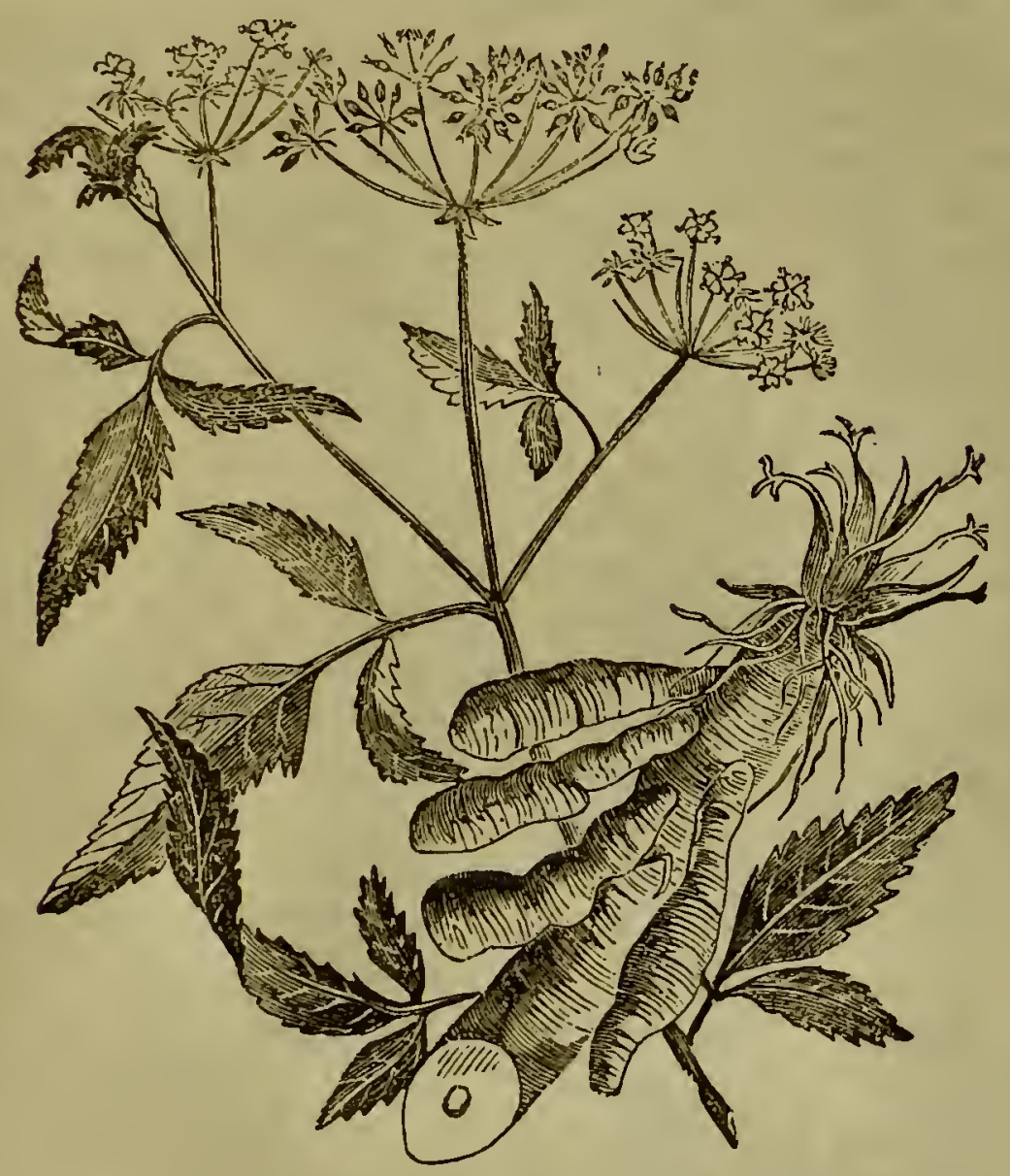

Flowers and Roots of the Skirret.

This plant is small conipared with the carrot and parsnip. It has pinnated leaves, consisting of two or three pair of long dentated leaflets, and terminated by an odd one. 'The flower-stalk rises to the height of about two feet, breaking out at top into branches, each terminating in an umbel of small white flowers. 'The root consists of a cluster of fleshy fibres, which are connected together at the crown or head, and in the course of a few years augment to a considerabls 
bunch. Each separate tuber is about the thickness of the little finger. They grow very uneven, and are covered with a whitish rough bark, while a hard core or pith runs through the centre.

This plant is propagated either by seeds or by offsets from the parent root; the first method is considered the most preferable for obtaining good and tender roots.

The skirret abounds in saccliarine matter. Mr. Margraaf extracted from half a pound of this root one ounce and a half of pure sugar.

The Beft-Betu-was known as an esculent root in the time of Pliny, who has given an accurate description of it in his work. The period when this plant was first introduced into Britain as a garden vegetable is not ascertained. It was cultivated at Lambeth by Tradescant the younger in 1656 ; but there is no reason for supposing that he was the first cultivator; on the contrary, it is more than probable that the beet was brought into this country by the Romans and that it has continued since that period to be an object of partial cultivation.

The cultivated beets, in all their varieties, are plants of the same duration, and nearly of the same habits, as turnips. They are sown in the early part of the summer, bulb towards the close of the season, and, if allowed to stand, send up their flowering stems, and ripen their seeds in the following year.

The variety which has its root red throughout its whole substance is most used in England for culinary purposes. 'This plant is said to be a native of the warmer countries of Europe; but it is sufficiently hardy to bear the climate of most parts of Britain. The root is in the form of a carrot, but thicker in proportion to its length, those of a foot long often being three or four inches in diameter. It is very juicy, and, when wounded, bleeds freely a limpid fluid of a beautiful purple colour. The leaves are large, long, 
and succulent, and generally have a red or purple tinge. When eaten warm, beet-root, has rather a mawkish flavour; it is, therefore, usuafly eaten cold, cut in slices, after having been previously boiled, and with the addition of vinegar is by some persons found agreeable to the palate. Its culture, as an esculent, has not, however, increased of late years, and it is not generally a favourite vegetable for the table ; although, according to Sir H. Davy's analysis, it contains much more nutritive matter than any other root excepting the potato, the total quantity being one hundred and forty-eight parts in a thousand, or nearly fifteen per cent. Nearly twelve per cent. of the whole weight of the beet is saccharine matter, which is a much greater proportion than is contained in any other Europenn esculent. The quantity contained in the red and the white beet is nearly the same; the proportion of mucilage in each is likewise almost equal, the red having rather the advantage, while it has nearly three times as much gluten as the white. From this account of its composition it would appear that the red beet is the most nourishing of all the edible roots, the potato alone excepted.

In a country like Britain, where with the bulk of the people vegetables are esteemed for their agreeable fiavour, rather than for their inutritive qualities, the superiority of the beet, in the latter respect, is disregarded, and those roots which are considered more savoury obtain the preference.

From one variety of this root, which has a red skin, but is internally white, sugar is extensively prepared in France. We shall notice this manufacture in a subsequent chapter.

'The white beet' is seldom, if ever, used as human food, but is largely cultivated for the nourishment of domestic animals, and is preferred for this purpose-to the turnip or carrot, especially in the vicinity of popu- 
lous towns. The field-turnip is esculent when young: the carrot is so in all stages of its growtli; and, therefore, when glown amirl a thick population, they form a great temptation to petty depredators, by whom the farmer finds this provender for his cattle much diminished. The field-beet, however, affords no allurement to the hungry plunderer, as starvation itself could scarcely induce him to make a meal of this harsh, coarse root, previously to its being subjected to culinary preparation, and even then it would prove a most umpalatable repast. When cows are fed with the beet, it is said that they yield a greater quantity of milk in consequence; and this food does not impart any of that rank flavour which is communicated by turnips.

There are several varieties of the field-beet; some with the stem, branches, and veins of the leaves red; others with leaves wholly red; and some, again, with the epiclermis of the root in different shades of red, brown, and yellow. 'Those coloured varieties are considered more hardy than the white, and one, having a reddish skin, the mangold or mangol vurlzel of the Germans, is said to produce the largest roots, and the most weighty crop in a given space of land. In Guernsey crops have been raised of one hundred tons per acre *.

Some varieties of white beet are cultivated in the gardens for their leaves alone; these are larger than the leaves of the red beet, and are more thick and succulent; they are boiled as spinach, and put into soups. One lind, called the great white or sweet beet, is esteemed for the footstalks and midribs of the leaves, which are stewed and eaten under the name of Swiss chard, or poirée aux carotes.

The Jerusalem Artichore-Helianthus tube. rosus -is a native of Brazil; and was first introduced

- Gard. Mag., vol. iv. 
in 1167 into this country, where it was much esteemed before potatoes were brouglit into general adoption. It is of the same genus, and has the same appearance as the common sunflower, except that it attains to a greater height, often being ten or twelve feet high. Its name is derived from the similarity of flavour observable between these roots and the bottom of the artichoke. Its distinctive epithet is said to be a corruption of the Italian word for sunflower, girasole, from girare to turn, and sol the sun; and bears no reference, as many have imagined, to the city of Jerusalem

The period of its flowering is autumn; but though the roots bear unhurt our severest winters, the plant rarely blooms in this country, and, even then, its seeds never come to maturity. The root is composed of many tubers growing in a cluster, and so prolific is this plant, that there are often from thirty to fifty of these tubers attached to one stem. No care is required in its culture. If, when digging up the roots, the smallest piece of a tuber be left, a plant will spring from it, thus propagating itself almost in the :nanner of a weed; so that after it has once found entrance in a garden, there is no little difficulty in extirpating it thence. This plant, however, repays cultivation, and much better roots are obtained from regular setting than from its spontaneous growth. Cuttings of the tubers are planted in the same manner as potatoes in any of the spring months; the crop can be used in September, and taken up in November for winter supply. This root seems to meet with undue neglect in our gardens; for it is an excellent winter vegetable, which may be grown abundantly at very little cost; it is wholesome, nutritious, and savoury; and, either hoiled or stewed, affords a very agreeable variety for the table. These tubers resemble 
potatoes in being of one homogeneous suhstance; and are likewise eaten in their matured state.

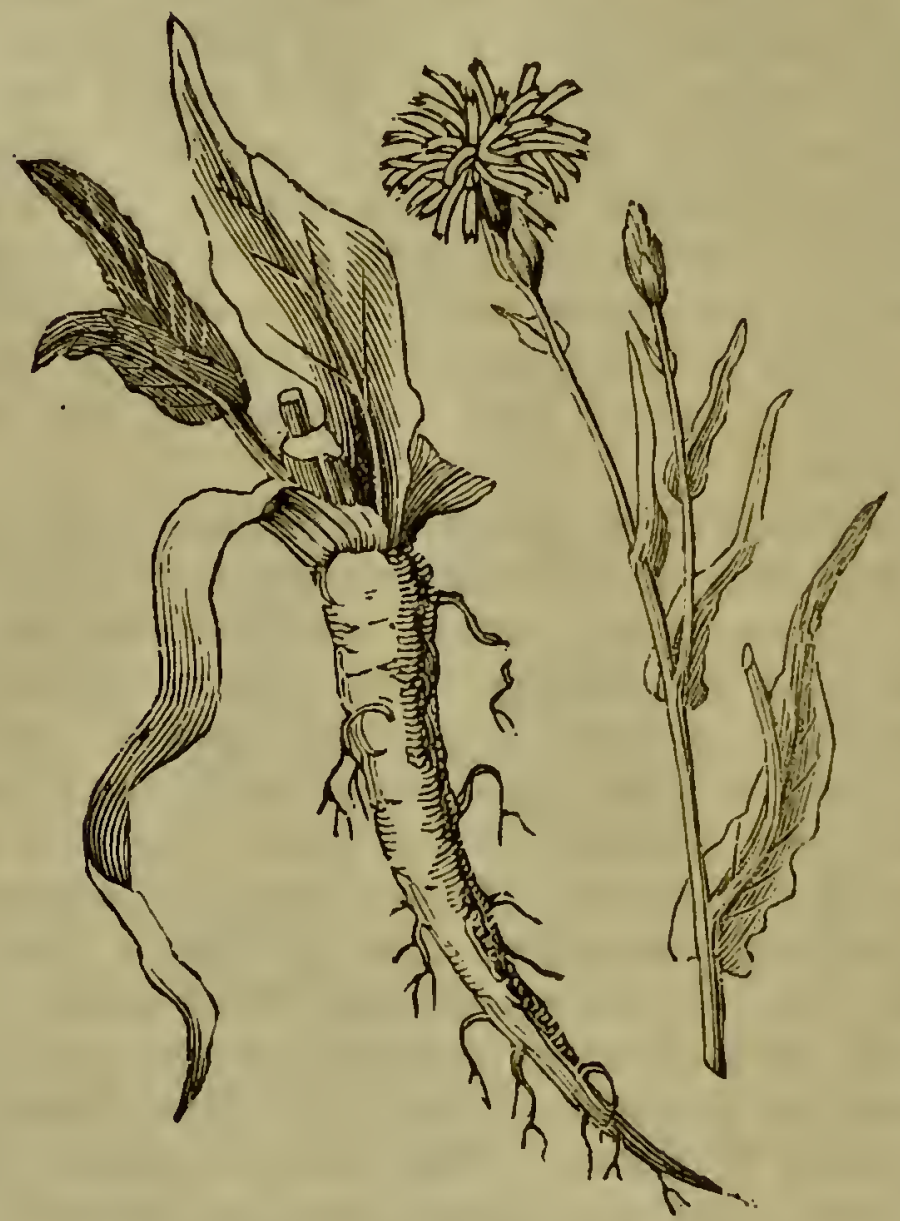

Flower and Root of Scorzonera.

SuORzonera - Scorzonera hispanica - is indigenous to Spain: it was introduced into this country some years after the skirret, and, like it, was formerly more cultivated than it is at present. Its root has not, however, the peculiar sweetness of the latter, but is extremely delicate, and when properly prepared makes so pleasant an addition to the list of culinary vegetables, that it appears to be unjustly excluded from our gardens. It has shared the fate of those 
vegetables which, according to Beckmann, have been banished by fashion; "for this tyrant which rules with universal sway commands the taste, as well as the smell, to consider as intolerable, articles to which our ancestors had a peculiar attachment."

Scorzonera was first known on account of its supposed medicinal properties, but was afterwards cultivated as food in consequence of its agreeable flavour. It was applied to this first purpose in the middle of the sixteenth century in Spain, where it was esteemed as an antidote to the poison of a snake, called there scurzo. A Moor, it is said, who had learnt in Africa that this plant possessed so valuable a property, availed himself of the knowledge in effecting many cures with the juices of the leaves and roots upon peasants who had while mowing been bitten by these venomous reptiles; but he carefully concealed the plant, that he might retain to himself all the honour and the profit attendant on the discovery. He was, however, clandestinely followed to the mountains, where he was observed to collect this plant, to which the name of scurzonera or scorzonera was then given, from the name of the snake, the venom of which it was believed to render innocuous. The knowledge was quickly disseminated. Petrus Cannizer transmitted the plant, together with a drawing of it, to John Oderick Melchion, physician to the queen of Bohemia ; and he, in his turn, lost no time in sending it to Matthioli, who had not any previous knowledge of the plant*. Soon after this Nicholas Monardes published a tract, in which the particular virtue of these roots was panegyrized. It is probable that in Spain their adaptation as an edible substance was likewise firsi discovered; and thence, about the beginning of the seventeenth century, it was introduced into France. The author of 'Le Jardinier François,' who was a

* Matthioli Epistol. Medicinal. 
practical as well as theoretical gardener, assigns to his own exertions its first cultivation in the French gardens*.

Scorzonera is at present much more used on the Continent than in this country; its medicinal virtues are now, however, but little regarded.

This plant is a hardy perennial, with a stem from two to three feet long, and having yellow flowers, which continue to bloom from June to August. The lower leaves, which are linear and pointed, are about eight or nine inches in length. The root is thin and spindleshaped, covered with a dark brown skin, but white within, and containing a milky juice.

Though the plants are perennial, producing offsets from the crown of the root, it is better to propagate from seeds in the same manner in which carrots are cultivated, since the offsets degenerate from year to year, both in size and quality. The roots, like those of parsnips, remain uninjured in the ground throughout the winter, and till. they begin to put out fresh leaves in the spring. The whole plant is somewhat bittcr. To divest the roots of that quality, they are scraped, and then steeped in water previously to their being made to undergo any culinary process.

* "The first cdition of his book, which greatly contributed to improve gardening !n France; was printed iu 1616." -Becknis:u. 


\section{Chapter XII.}

BRASSICA - SPINACEOUS PLANTS - ASPARAGINUUS

PLANTS.

BRASSICA.

Soxt varieties of the cabbage have been cultivated from the very earliest times of which we have any record. But the migrations and changes of the best sorts have not been traced : neither is it at all probable that the varieties which the ancients enjoyed have descended to us unaltered. This particular genus of plants is pesuliarly liable "to sport or run into varieties and monstrosities." They belong to the numerous family Cruciferce. The cruciferous esculents form a much longer list than those bearing umbels; they are applied to a greater number of purposes, and afford an addition to food in a greater number of forms, ages, and parts of the plant. The roots, the leaves, the stems, the buds, are eaten raw, or dressed in various ways; and the seed of many species are valuable on account of the oil which they afford. None of the family are directly poisonous. In their recent state they either contain a portion of nitrogen ready formed, or have the power of detaching it from the atmosphere when they begin to undergo decomposition. This quality exists more, or at least displays itself sooner, in the leaves than in the roots; and to it is owing the very unpleasant odour of the water in which cabbages have been boiled. The Crucifera being round as weeds in almost every field, constant changes aro produced, even in those plants under cultivation 
by crosses with the pollen of wild plants; while soil, culture, and climate, exert a powerful influence over the diflerent species, altogether causing varieties and sub-varieties, of which it would be a hopeless task to attempt the enumeration.

It is probable that some species of the brassica was first introduced into this country by the Romans, since kale is mentioned among the oldest English records. It is well known that brassica was in very common cultivation at Rome, where, according to Columella, it was a favourite edible with freemen, and in sufficient plenty to be an article of food for slaves. The ancient Germans likewise cultivated this plant from very remote times; whetler they, too, were indebted to their Roman conquerors for its introduction it is impossible to decide. The Saxon name for February is sprout-kale*, and that is the season when the sprouts from the old stalks begin to be fit for use ; the Saxons must therefore, of course, have been familiar with the culture of cabbage or kale, as it is not at all probable that they invented the name after their settlement in this country.

The variety of brassica which was first cultivated in England cannot be ascertained, since our ancestors had no distinctive name for the different kinds. Many improvements have been made in the cultivation of this vegetable, and many new varieties introduced by different individuals at comparatively recent dates.

The close-hearted variety, which is now more peculiarly called cabbage, was for many years importer into England from Holland. Sir Anthony Ashley first introduced its cultivation into this country, and made the English independent of their neiglibours for a supply. 'This planter of cabbages likewise rendered his name known by other deeds, less creditable to his character. It is related that he had a command at Cales (Cadiz),

* White's History of Selborne. 
where he got much by rapine, especially from a lady who intrusted her jewels to his honour; whence the jest on him, that he got more by Cales than by cale and cabbage. There is said to be a cabbage at his feet sculptured on his monument at Wimborne St. Giles, in Dorsetshire*. Although Sir Anthony Ashley introduced the cabbage, it does not appear to have become generally cultivated, for we continued to in port the vegetable for many years. Ben Jonson, who wrote more than half a century afterwards, says " $\mathrm{He}$ hath news, from the Low Countries, in cabbag'es."

It is recorded that cabbages were first introduced into the north of Scotland by the soldiers of Cromwell †. A country embroiled in internal hostilities might be supposed not to be in a very favourable state for the more extended cultivation of plants, the passions of the contending parties being too keenly roused to pay attention to improvementis in those arts the progress of which more peculiarly belungs to a period of peace. But in the present case the fact is opposed to this conclusion; we learn that "Cromwell was a great promoter of agriculture and the useful branches of gardening, and that his soldiers introduced all the best improvements wherever they went+."

The colonies of German fishermen from Cuxhaven and the adjacent places, which peopled the coasts of the central parts of the east of scotland, are, howcver, supposed by some writers to have brought with thein their national love of brassica, and to have introduced some species of those plants at a period much anterior to that of the Commonwealth, to this part of Scotland, which is more peculiarly " the land of kale." "There the cabbage and the open colewort are in equal favour, giving the name of kale to a soup of which they form the principal ingredients, the outside

* Gough's British Topography, vol. i., p. 133.

$\dagger$ Edin. Encyc., Art. Horticulture. $\ddagger$ Loud. Encyc. Sard., p. 87 
leaves and the stalks of the plants falling to the share of the cattle. The father of Burns was from Kincardineshire; and the poet alludes to the customs of that county in his humorous comparison of Kilmarnock to a cow.

"Now auld Kilmarnock cock thy tail An' toss thy horus fu' cantie:

Nae mair thou'lt route o'er moor and dale, Because thy fare is scanty;

For lapfu's large o' gospel kail Shall fill thy crit in plenty;

Ari' runts o' grace the feck and wale, No gi'en by way o' dainty,-

But ilka day."

The lapfu's allude to the outside leaves, and the runts to the portion of the stalk and centre from which the parts fit for culinary purposes have been removed; the latter especially were given as a dainty to the favourite milch-cows.

Many allusions in the old Scotch songs point to the fact of the country about Aberdeen abounding with this vegetable. In recommending the good fare of the country, the poet says,

"There's cauld kail in Aberdeen,

An' oastocks * in Stra'bogie."

'The "kale brose o' auld Scotland" is celebrated to the same tune as the "roast beef of old England;" and though, with many of the ancient peculiarities of the people, it has fallen much into disuse, it is still considered a national dish.

All those liinds of cultivated brassica, the leaves and flowers of which are eaten, belong to the species oleracea. This resolves itself into many varieties and endless sub-varieties, which, however, may be reduced

- Cabbage stems having the fibrous part peeled off, and the remainder softened by boiling. Before the introduction of the t..rnip into general use in Scotland, this medullary substance of the stalks of the brassica was very commonly eaten by the peasantry. 
to three classes, having their distinctive characters sufficiently marked for all practical purposes.

1st class.-C $\mathrm{C}_{\mathrm{ABBAGES}}$, in which the leares gather into what is called a head, and are blanched by their own compression. The green colour is always much more completely destroyed by this blanching than the red; and the smaller the tendency which the expanded leaves have to blue or purple, the more sweet and crisp will the head become.

Cabbages are propagated by seed, which is sown at the three seasons, spring, summer, and autumn, to obtain a supply in succession. The soil for the seedbeds should be light, and not very rich.

The plants, from seed sown in autumn, are finally transplanted in spring. Most generally the seedlings are pricked out from the seed-beds as soon as they have one or two leaves of an inch or two broad, into beds of good earth : thence they are transplanted into a rich soil, which sloould be well manured.

$2 d$ class.-KaLe or Conewort. - In these the leaves are expanded and coloured, with the exception of a small portion in the centre, which encloses the rudiments of the flowering stem. The plain-leaved colewort is now seldom found in English cultivation. Borecole, or curly-leaved colewort, Brassica oleracea, var. ó sabellica, very generally, however, finds a place in our gardens. The green borecole, or Scotch kale, and the purple or brown borecole, are the most hardy of the race, and are therefore best adapted for cold situations and late seasons. The plants, when vegetating in a rich soil, grow vigorously, and attain to large dimensions; but, in common with most of the genus, moderate sized plants are best for culinary purposes, the very large being harsh, and those which are so small as to be stunted are bitter. 


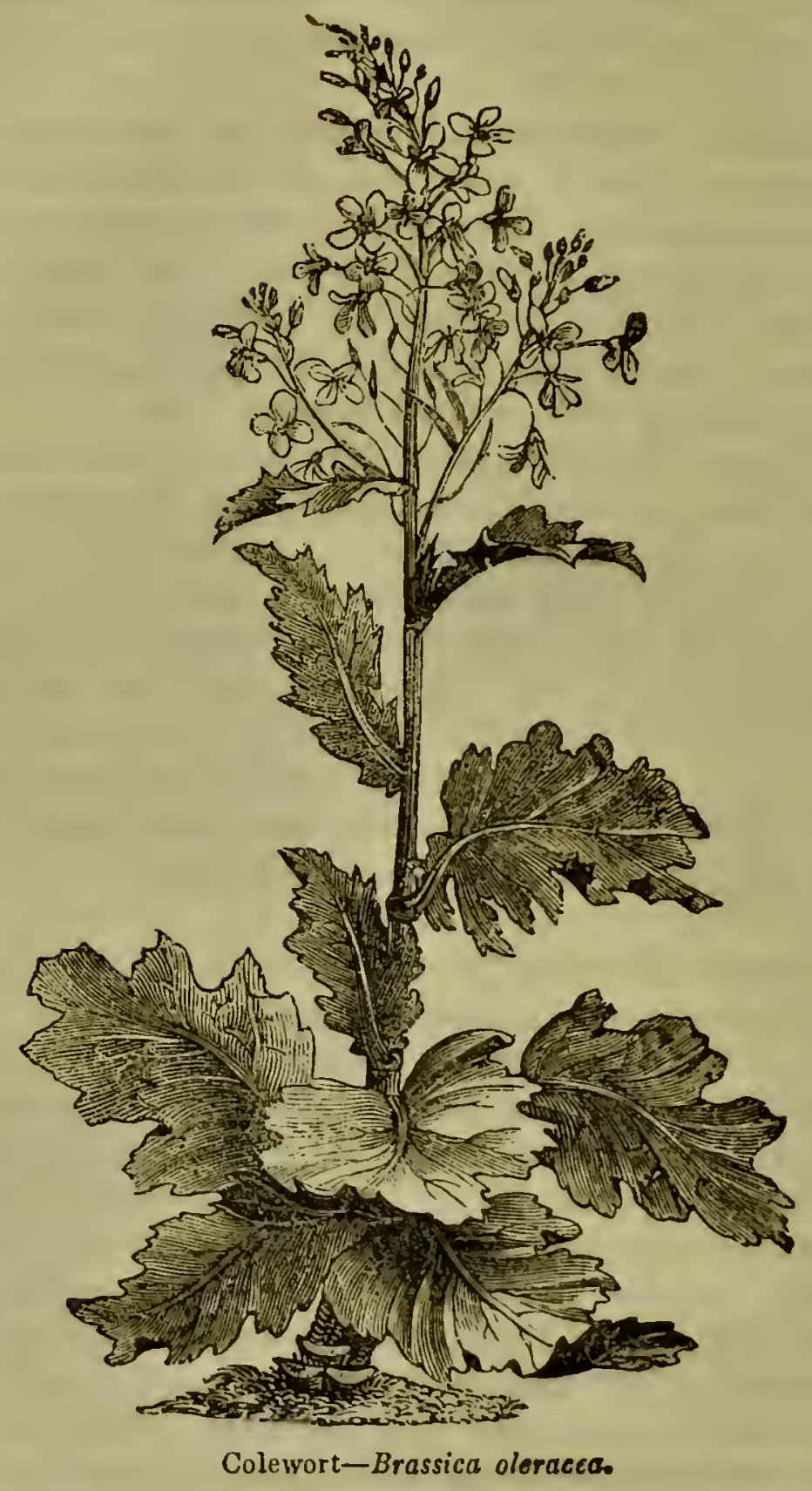

Sauerkraut, " that excellent preparation" of the Germans, and of which they are so immoderately fond, Is merely fermented cabbage. 'To prepare this, closeneaded white cabbages are cut in shreds, and placed 
in a four-inch layer in a cask; this is strewed with salt, unground pepper, and a small quantity of salad oil : a man with clean wooden shoes then gets into the cask, and treads the whole together till it is well mixed and compact. Another layer is then added, which is again trod down, and so on until the cask is entirely filled. The whole is then subjected to heavy pressure, and allowed to ferment ; when the fermentation has subsided, the barrels in which it is prepared are closed up, and it is preserved for use. The preparing of sauerkraut is considered of so much importance as to form a separate profession, which is principally engrossed by the 'Tyrolese. The operation of shredding the cabbage is now performed by a machine, which the men carry on their backs from house to house; this means for the abridgement of labour has not been invented more than ten or twelve years. Every German family stores up, according to its size, one or more large casks of this vegetable preparation. October and November are the busy months for the work, and huge white pyramids of rabbage are seen crowding the markets; while in every court and yard into which an accidental peep is obtained, all is bustle and activity in the concocting of this national food, and the baskets piled with shredded cabbage resemble " mountains of green-tinged froth or syllabub."

Sauerkraut has been found of sovereign efficacy as a preservative from scurvy during long voyages; it was for many years used in our navy for this purpose, until displaced by lemon-juice, which is equally a specific, while it is not so bulky an article for store.

The larger and grosser kinds of cabbage are used as food for cattle. But this nutriment has a great tendency to impart a disugreeable flavour to the milk of cows fed on it, and even to the flesh of other cattle. This unpleasant effect may, we are told, be prevented by removing the withered leaves; but rab. 
bage is more disposed to fermentation and putrefaction than almost any other vegetable. When cultivated as food for stock, it is of course a matter of importance with agriculturists to produce the greatest weight in a given space. The average crop, as stated by Mr. Arthur Young, is thirty-six tons per acre, when the plants are grown on a dry soil, which is very similar to that quoted from other and more modern writers; but on a sandy soil only eighteen tons have been obtained. Some cabbages are occasionally produced of an astonishing size and weight. A cabbage-seed accidentally sown among onions came up in the onion bed, and without any care being taken of it grew to very large dimensions, and weighed, when taken up, twenty-five pounds. A cabbage was also produced in Devonshire, two or three years back, which, when growing, occupied a space of fifteen feet of ground, measured five feet in circumference, and weighed sixty pounds*.

A variety of brassica under the name of cow-cabbage (Brassica oleracea, var. arborescens) has been recently introduced into this country from La Vendée by the Comte de Puysage. The proximity of this department to the ancient province of Anjou, and the description of the plant, leave no doubt of its identity with the Anjou cabbage, a very large variety described by Mill $\dagger$. In 1527 thirty-six seeds + were divided annong six agriculturists, for the purpose of raising this useful vegretaile in England. The perfect success resulting from some of these seeds, which have produced plants of a luxuriant growth, is already known ; and horticulture is now so much more disseminated and understood in this country, that there is every reason to hope that the cow-cabbage will at lengtt.

* Gard. Mag. vol. iii. p. 351.

+ Mill's Husbandry, vol. iii.

† Gard. Mag. vols, iii. and v. 
become naturalized in England. It is said that sixty plants afford provender sufficient for one cow during three or four years, without fresh planting. A square of sixty feet will contain two hundred and fifty-six plants, four feet apart from each other, sixteen plants more than four cows require for a year's provender without the aid of other food. 'This plant is now successfully cultivated in Jersey, whence seeds have been sent to a nurseryman in London.

$3 d$ Class. - This division consists of cauliflowers and brocoli, which have the flowering stem short and succulent, the rudiments of the flowers forming into a curd-like head, which is not higher than the leaves, and becomes a mass of matter before the corolla or any other part of the flower is developed. This is the part of the plant used in this state as an esculent, but at the commencement of the developement of the flowers it becomes bitter, and is no longer considered edible.

The Cauliflower-Brassica oleracca, var. $\epsilon$ botrytis -is the most delicate variety of the brassica genus. It was first brought into England from the island of Cyprus, where it is said to attain to high perfection, although it is not supposed to be indigenous to that country. The exact period of the introduction of this plant into English horticulture is not known; but it was certainly cultivated in this country at the beginning of the seventeenth century, although as a rarity which could only be produced at the tables of the most opulent. In the year 1619 , two cauliflowers cost three shillings, the price of wheat being at that time 35s. $4 d$. per quarter*. It was not however until the latter end of the same century that this vegetable was brought to any degree of perfection ; at least it was not raised * Eiden's 'History of the Poor,' vol. i. p. 152. 
in sufficient abundance to appear in our English markets until that period. The importation then of Dutch gardeners and Dutch gardening gave an impulse to English horticulture, which had been in rather a languishing state during the intestine troubles to which the revolution of 1688 put a termination. But although the Dutch gardening no doubt produced an improvement in the cultivation of the cauliflower, as well as in vegetables generally, this plant became more naturalized in England than in Holland, or any of the adjacent countries of the Continent. Up to the period of the French revolution, cauliflowers were reguiarly exported from England into Holland, some parts of Germany, and even France; and while the seed of very many cultivated plants is in this country preferred, when it is of Dutch rather than of English produce, cauliflower seed obtained from England is the most esteemed in Holland, and indeed throughout the Continent. The superiority of the English cauliflower is to be attributed soiely to culture, and to culture carried on in the vicinity of London, not by experimentalists or amateurs, but by those who rear the plants for sale in the way of ordinary business. This vegetable is now cultivated very generally throughout the island; but since the portion of the plant which is used as food is not nearly as large as that of the cabbage, occupying an equal space while it requires a richer soil and a warmer situation, it evidently can never become so cheap an esculent. Its delicate flavour is, however, in general mucl preferred to that of the cabbage, and it takes a ligher rank in the list of culinary vegetables. Dr. Johnson, whose most trivial and perhaps sometimes absurd remarlis have been considered worthy of record, used to say "Of all flower's I like the cauliflower the best."

This plant, like the common cabbage, is first raised in a sced-bed of light eartl, and finally transplanted 
Into soil which can scarcely be either naturaliy or artificially too rich. The seed is generally sown at the latter end of the months of February, May, and August, for three succeeding crops. The plants raised from seed sown in the latter month stand through the winter, during which season and the first part of spring they are usually protected under hand-glasses. In the neighbourhood of London it is not uncommon to see whole acres overspread with such glasses fostering an early supply of this vegetable for the inhabitants of the metropolis, and conveying to the mind of the beholder a forcible idea of the riches and luxury of this vast city.

The head of the cauliflower is not nearly so liable to putrescency, after being cut, as its leaves, which in this respect are similar to those of the cabbage. For a considerable time after the leaves have become flaccid and in a state of decay, the head remains unchanged, and with care may be preserved without putrefaction for sorne months. By merely drawing up the plants entire, and hanging them in a cellar, they will continue in a sound state for a considerable time. The method most successfully adopted in Scotland, is to place the plants in layers ín a pit, with their heads inclining downwards. The pit is then covered up closely with earth, beaten down, and smoothed in a sloping direction, so as to exclude both the rain and the atmosphere.

Brocoli is usually considered as merely a subvariety of cauliflower, and that this is the case is rendered very probable from the great tendency of the plant to run into new varieties, which are constantly making their appearance, and as rapidly vanishing and giving place to others. It is a matter of common observation, that the more any plant has been changed by culture, the more readily does it admit of other changes. 
But a few years back, only two sorts of brocoli were recognised-the red and the purple, both of which originally came to us from Italy. 'Thirteen varieties are now enumerated as raised in the English garden, and each in turn is recommended to the notice of the cultivator by some characteristic quality. In the culture of no vegetable has so marked and rapid an improvement taken place as in that of brocoli; horticulturists have recently succeeded in producing a hardy white variety, which has a handsomer appearance than either the green or the purple, while it is more delicate in flavour. White as well as purple are now obtained throughout the winter, some attaining to the size and equalling the cauliflower in appearance, though not in taste. The earliest spring crop follows without an interval the late winter crop, and no cessation need take place in the supply of brocoli, although, perhaps, it is not commonly raised during a month or two in the mildle of the summer, when many other vegetables are produced in abundance.

Brocoli succeeds best in a fresh loamy soil; the seed-beds slould be of rich mould, on which the sceds are thinly scattered, and covered with mats or litter till the plants appear.

\section{SPINACEOUS PJANTS}

TuE leaves of these plants are most generally of a softer texture and more insipid flavour than those of the brassica tribe. As their excellence consists in the succulence of the leaves, a rich soil is required for their cultivation. 'They generally belong to the family Chenopodec*, having very small flowers of a greenish tinge, formed into heads of various shapes, as at ball, a bunch, or a spilic.

$$
\text { * De Candolle. }
$$



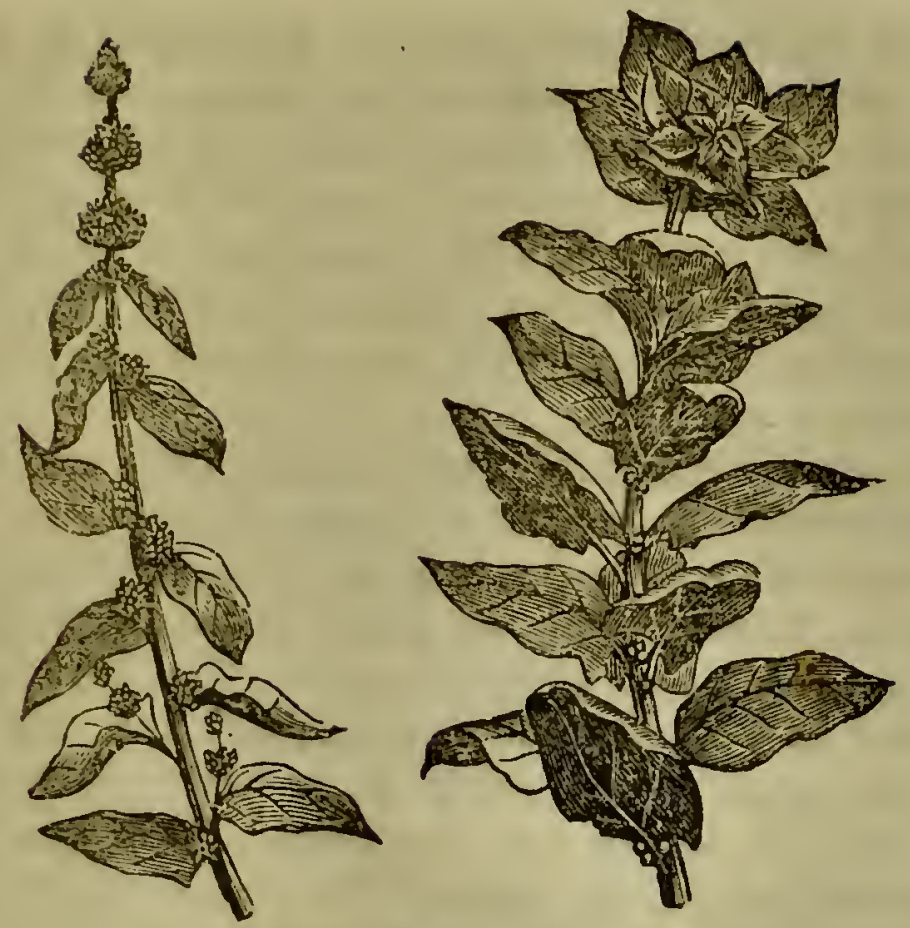

Spinach-Spinacia oleracea.

SPINaCH-Spinacia olcracea.-The native country of the common spinach, and the time of its introduction into Britain, are not precisely known.

The west of Asia is assigned as its native country, but on what grounds are not very clearly shown, except that the earliest noiice we find of it is in the works of the Arabian physicians, who of course only treat of its supposed medicinal properties, which might probably have originally led to its adoption as an edible vegetable. Spain is supposed to have been the first European country into which it was introduced, for many of the old botanists call it olus hispanicum; while some writers, among whom is Ruellius, distinguish it as atriplex hispaniensis, and the latter adds that the Moors call it hispanach or Spanish plant. According to Beckmann, the first notice of its being used as an edible substance in Europe occurs in the year 1351, in a list of the 2 A 3 
different vegetables consumed by the monks on fastdays: at that time it was written spinargium or spinachium. This plant found a place among culinary vegetables at rather an early period in Engrland, for Turner, who wrote in 1568, mentions it as being at that time in common cultivation, and prepared for the table precisely in the same manner as it is at present.

Spinach is an annual plant, having large and succulent leaves : the flowering stems, which are hollow and branched, rise to the height of two or three feet. 'The male flowers grow on different plants to those of the female, which yield the seerl. The former are produced in long terminal spikes, and the latter in close branches at the joints of the stem, or in the axillæ of the leaves and branches. This plant is remarkable as being one of the plants which are dicecious, that is, having the different parts of fructification upon separate plants. Some trees which are cultivated for their fruit, such as the date-palms, have the same peculiarity.

Two varieties of spinach are cultivated. The leaves of the one are arrow-shaped and rough, and of the other round and smooth. July and August are the months in which the seeds of both kinds would naturally come to maturity; but as they slightly differ in their qualities it is found more advantageous to sow them at different seasons. The round-leaved grows the fastest, is the largest and most sncculent, and therefore is sown for succession crops in spring and summer; the other, being much more hardy, is preferred for winter supply. 'The former is usually sown in January, from which time nutil the end of July frequent sowings are made for a regular succession. from the beginning of A pril to continue throughout the summer. The roughleaved is usually sown in August for a winter crop- 
The seed is sown broad-cast, and in subsequent culture the plants are thinned first to three inches apart, and as they increase in size that distance is doubled.

From the circumstance of the male and female flowers errowing on different plants, when they are left to bring their seed to maturity care is taken that a due proportion of each is suffered to remain. As soon as the seed capsules are set, the male plants are pulled up, this allowing a freer space for the female plants wherein to perfect their seeds.

Wild Sprnach, or English Mercury, or Good King Harri-Chenopodium bonus Henricus. This plant, which has obtained so many names, grows wild on a loamy soil, and may be found on waysides and among ruins in many parts of England. The stalks rise to the height of a foot and a half; they are upright, thick, and striated, and covered with a whitish powder, which is likewise found on the nnder side of the leaves. These are arrowshaped, and rather large :ur the size of the plant. 'The flowers, of a yellowish green colour, grow upon close spikes; they appear in June and $J$ uly, and in August the seeds come to maturity This plant is a peremial, and may be propagated by seeds or by offsets from the root. When young, both the stem and the leaves are succulent, the former being used as an asparagus, and the latter as a spinach.

Lincolnshire is the part of England where it is most in request, and where it is cultivated and preferred to the common spinach. It is, however, more nearly in a state of nature than the latter plant, and therefore cannot accommodate itself to differences of soil and situation.

The superior docility of a plant which has been long under cultivation, and which has travelled or borne changes of soi! and climate in a growing state, 
is very apparent to those who attempt to rear wild plants in situations where they are not indigenous. This fact is so important a feature in the natural history of plants, that it is not perhaps sufficiently pointed out or explained in books treating on these subjects. It is a very natural result, which on con sideration should not excite surprise, that a wild plant, which has been from time immemorial produced on the same spot, and has there accommodated itself solely to the circumstances of that spot, should refuse to grow in any other situation where the circumstances are not preciscly similar. It is upon this principle that the mountain berry will not flourish upon the champaign country, and that the sweetest flowers of the woodlands refuse their odour to the parterre. In like manner, "Good King Harry," which makes a very estimable spinach or asparagus in its native country, might make but a very sorry one if remored to a place where it is not indigenous.

New Zealand Spinach-Tetragonia expansa,so called, because it was found growing wild on the shores of New Zealand when Captain Cook first touched at that island. Although the natives made no use of this plant as an esculent, the naturalists who accompanied the expedition were induced to recommend it as a regetable which might be safely eaten, since its appearance and general characteristics were so similar to the chenopodium. On trial, it was found to be both agreeable and wholesome. Sir Joseph Banks brought it into culture in England in 1772 , and it has subsequently been found to be a much more hardy and valuable plant than was at first supposed. It was at first treated as a greenhouse plant; but now grows freely in the open garden, and indeed seems already to have naturalized itself in the south-west of England. A writer, from 
Exmouth, observes, in the Gardener's Magazine for February, 1829, "The New Zealand spinach is quite a weed with us, as, wherever it has once grown, plants rise spontaneously, even when the seeds have been wheeled out with the dung in the winter, and again brought in as manure in the spring. I have now a full supply of it in my old pirk bed." This spinach has an advantage over the common sort under cultivation, in producing an abundance of large and succulent leaves during the hot weather, when the latter plant runs almost immediately to seed, and produces little or nothing. It is likewise milder in flavour, and of so rapid growth, that a bed with about twenty plants is sufficient for the daily supply of a large family.

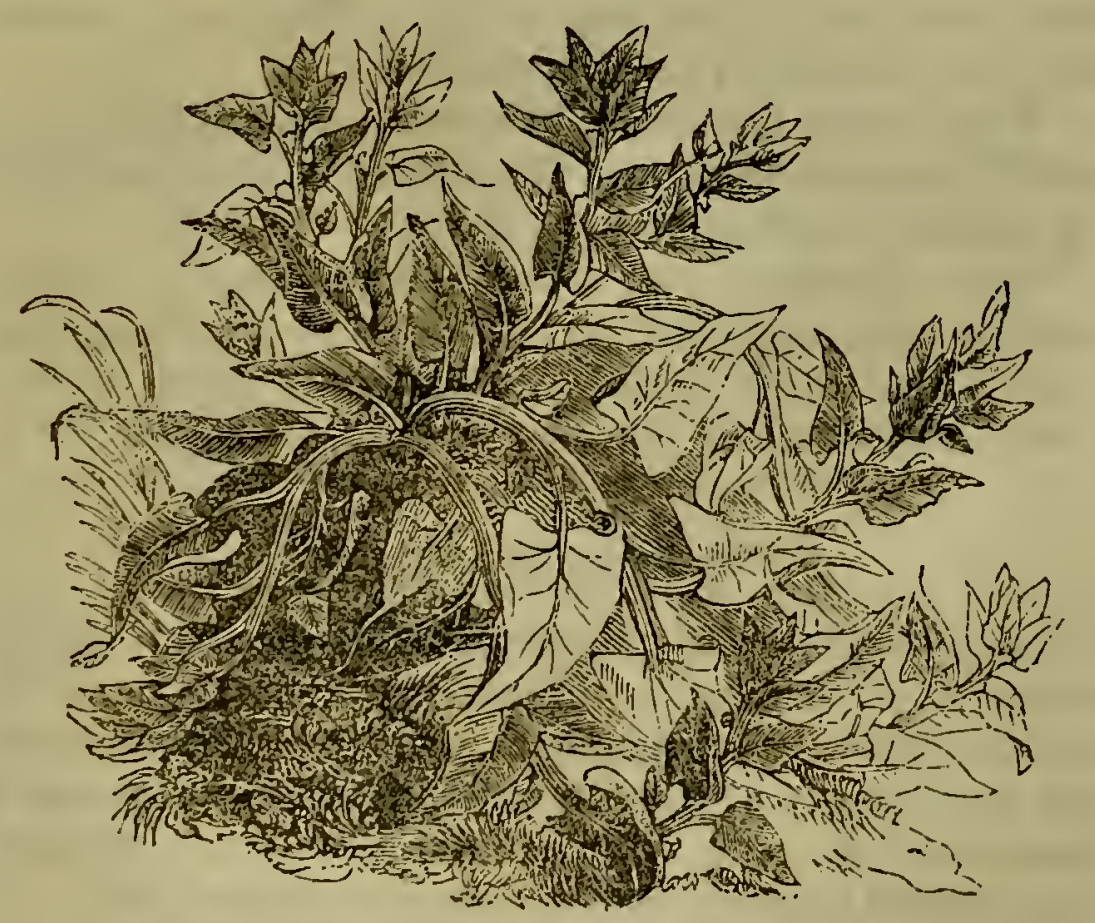

New Zenlınd Spinich-Tetragonia cxpansa.

Though by some called a biennial, this spinach is an annual in our climate. The stem has numerous 
thick and strong branches, somewhat procumbent for the greater part of their length, but raised at the points. The leaves are fleshy and succulent, three or four inches long, of a dark green on the under part, but of a paler colour on the surface, on which the mid-ribs and nerves are strongly marked. They are triangular, or rather of an elongated heartshape, having the angles at the base rounded, and the apex sharp and extended. The flowers are small, and of a yellowish green colour ; they appear in August and September. The whole plant is thickly studded with minute aqueous tubercles; a peculiarity likewise to be found in some species of atriplex and chenopodium.

In six weeks after sowing, rome of the leaves of the plants are fit for gatheririg. These are pinched off, and not torn from the branches.

This plant has been likewise found growing on the Tonga islands; and 'Thunberg discovered it of spontaneous growth in Japan*.

New Zealand spinach is remarkable as being almost the only native of the isles of Australasia which has been found worthy of a place in the kitchen-gardens of Europe.

\section{ASPARAGINOUS PLANTS.}

THE ancients were accustomed to class all young sprouts of vegetables under the general name of asparagus. In agreement with this arrangement, all those pulpy shoots, stems, buds, and bottoms of compound flowers, which undergo culinary preparation before they hecome auxiliary articles of food, will be here designated as asparaginous plants.

The nature of this class of vegetables causes them to be always of more expensive cultivation than other

* Hort. Trans. vol.iv. 
plants, the leaves or roots of which are used as esculents. For it is only a comparatively small portion of the whole plant which is here appropriated; and that too, most generally, when in a young and undeveloped state. Asparaginous plants must, therefore, always belong to luxurious, rather than to economic management.

Asparagus-Asparagus oficinalis-stands foremost in this iist, as having been of most ancient cultivation, and as being most esteemed in every age. It was held in much favour by the Grecians, and is handed down to us by its present name in the writings of Dioscorides. The Romans must have been particularly skilful in its cultivation, since, according to Pliny, three shoots of that grown in Ravenna weighed a pound, which is considerably more than the weight of the largest English asparagus.

Asparagus has a perennial root and annual stalks. The root is fleshy and succulent, composed of round knobs, which are united together into a kind of tuber. This is seated deep in the ground, and is not liable to be much affected by the winter frosts. From this root, which contains turions or eyes somewhat analogous to those on the tuber of the potato, the stems rise up in the early part of the spring, and are cut for use when only a few inches above the ground. There are few subjects in vegetable anatomy which display more beauty in their structure, than may be disclosed in a transverse section of a head of asparagus. The shoot of an asparagus grows only from the extremity, and works or vegetates from the centre, and not from the surface as in trees. Thus it pushes up through the soil en masse, if it may be so expressed. 'The branches, which lie so thick together, safe and well protected under their scaly leaves, soon begin to be developed, and are drawn out until the whole plant, with its numerous thread-like leaves, assumes 
very much the character of a larch tree, having its miniature parts more light and elegant, and the colour of a more lively greell. The flowers, which wave in graceful panicles, are of a yellow hue and of a fragrant smell. They are followed by round berries of a briglit orange-red.

The head of the young shoot of asparagus is edible just as far as the part which is to flower extends; and thus one who eats a head of asparagus eats in that little space the rudiments of many liundreds of branches and many thousands of leaves.

Asparagus is distirıguished into two varieties, the red and the green: the first is a larger kind, growing fuller and closer; though handsomer in appearance, it is not considered of so good a flavour as the rreen. In consequence of its being more showy, it is, however, held in greatest esteem with narketgardeners. 'This kind has been cultivated with great success in soils consisting of little else than sea sand, dressed anmully with sea-weed; and by attending to this mode of culture it is probable thit asparagns might be reared on many spots on the coast, that will hardly produce any other veretable.

A large quantity of asparagus is raised for the London market. Battersea, Mortlake, and Deptfort, at each of which places the soil is lightat and friable, are the chief localities for' its cultivation. 'The breadth of land in asparagens-ijeds, in the parish of Mortlatie alone, is estimated to be nearly a lundred acres: one of the principal growers having sometimes forty acres under this crop. 'The largest cultivator in Deptford has eighty acres entirely laid out in aspatraggus beds.

Althongh the natural soil of this plant is pour and light, beds tor aspraragils call scaredy he tor highluly manured, since its good yuality depends on the quickiness of its growth, which is idcelerated by 
richness of soil. It is propagated by seed, which is sown broad-cast in spring; and at the same period of the ensuing year the young plants are transplanted to beds prepared for their reception, and where they are allowed to remain three or four years before the tender shoots are cut for use. When these are from two to four inches above the ground, they are cut two or three inches below the surface. In cutting, care is taken to leave to each plantule or stool one or two shoots, to grow up into flower and seed, or otherwise the roots would perish. Under good culture, the same plants will continue to furnish annual crops during twelve or fourteen years. It is estimated by a practical gardener that five square poles of ground, planted with sixteen hundred plants, will yield, during the season, from six to eight score heads daily*.

Asparagus contains little or no nutriment, but it is a mild vegetable, and pleasant to the taste. 'Though this plant is much cultivated in places where the inxuries of horticulture are abundant, its use is little known in situations remote from populous towns; of this the following anecdote will serve as an illustration. About the close of the last century the proprietor of a considerable estate in one of the midland counties of Scotland, who prided himself upon his general knowledge and uniform consistency, had passed the meridian of life without ever having seen asparagrus. When he did at length meet with some at a dinner in a neighbouring town, he selected the white end, and having with some difficulty cut off a piece, he subjected it to rather a laborious process of mastication. A gentle hint was given that he had taken the wrong end; but disliking to confess ignorance in the matter, he assured the company that he always ate asparagus in that fashion, and for the sake

* Auercrombic. 
of consistency he continued to gnaw the hard end as long as he lived.

Asparagus contains a peculiar vegetable principle to which the name of asparagin has been given, and to which, in part in least, the plant owes its qualities.

Sea-Kale-Crambe maritima. In the first volume of the Transactions of the Horticultural Society, it is stated by Maher, that sea-kale was sent from England to the Continent by L'Obel and Turner, before the middle of the sixteenth century. No professional account of it, however, appeared for nearly a century after that period; the earliest notice being that taken of it by Miller, in 1731; and it was not until the year 1767 that it was first brought by Dr. Lettsom into fashionable repute as a garden vegetable. Since that time it has gradually come into very general culture in Britain though, for the same reason as has been assigned in the case of asparagus, it can never become a cheap vegetable.

The cultivation of this plant is but little attended to, and apparently not very well understood on the Continent. In the 'Manuel du Jardinier,' for 1807, a French horticulturist described the chou marin d'Angleterre; but he was not aware of its proper application as an esculent. since he used the broad green leaves instead of the blanched shoots. This of course proved no very tempting preparation, and caused the plant to be condemned as only fit for the coarser tastes of the inliabitants of colder climates.

Sea-kale is a hardy perennial, and when allowed to attain its full growth is a very beautiful plant. It is of a delicate sea-green colour, with a tinge of purple, and is powdered over with a very fine meal or bloom. The radical leaves are large, of a rounded form, waved, and deeply notched at the edges, and 
having very thick foot-staliks and mid-ribs. The flowering head is much branched ; the single flowers are of a beautiful white, and have a rich odour of honey. They are followed by roundish pods, having two cells, one of which generally contains a seed, and the other is abortive. Notwithstanding which, however, the number of flowers upon one plant is so great as always to produce an abundance of seed. The shoots proceed from eyes on the roots, or from buds in the axillæ of the radical leaves; if these leaves are removed, and the flowering stems, as soon as they begin to appear, are cut, the number of the sloots, and the rapidity of their growth, are increased. This is an effect very desirable to be attained, since these shoots when young and tender, and the stalks of the unfolding leaves when blanched either by natural or artificial culture, are the parts used as an edible substance in the manner of asparagus. The peeled mid-rib of the large leaves which have been allowed to expand, after the plants have ceased to send up young shoots, is sometimes applied to the same purpose.

As the roots of sea-kale are perennial, and contain eyes or buds, the plant may be propagated either by sowing the seeds or parting the roots. Either of these methods may be advantageously pursued in the middle of the spring.

A deep light soil is so essential to this culture, that if the earth do not naturally contain sand, as much of this must be mixed with it as will ensure a drainage to the depth of at least two feet and a half. Water stagnating in any part of the soil to which the roots may reach, is found injurious to the plants.

The weil-known nature and peculiarity of the soil and situation in which sea-kale is found point out the mode of its artificial culture much more clearly than 
is the case with plants of which the natural habits and localities are not so well ascertained. This culture, therefore, is similar in its circumstances, except in that of time, to those which attend the growth of the plant when in a state of nature. The soil is made light and porous, and as the young plants advance they are artificially, if not naturally, watered. When the leaves of the first year die down, the beds are covered with a thin layer of very light and sandy mould, and over that with a layer of about six inches of light litter, to protect the plants from frost, and to preserve abont the same temperature which the soil has during winter upon a light sandy beach. In the second season nearly the same treatment is pursued, the object being not to force the upward production, but to make the roots as full of germs and as strong as possible. The earthing up in those two seasons changes the buds in the axillæ of the radical leaves into germs, which will produce shoots in the ensuing year; and, as the process continues, the buds of one season become the stems. of the next.

When the shoots of the third year are coming into action, preparations are made for obtaining the first crop. For this purpose a layer of about an inch thick of fine sand or gravel is laid on the sea-kale bed, that it may have a still nearer resemblance to the sea-beach. If the plants were left to their natural action in that soil, freely exposed to the air and the heat of the sun, they would come into flower in May or June, and the progress of the flowering stems, and the expanding and colouring of the radical leaves, would be so rapid, that the plants would be esculent only when very small, and would in consequence be of little value ; they would not, in fact, differ much from the wild plants which the peasants gather upon the beach, being, perlaps, inferior, if 
tixe temperature were warmer than it is in those situations which are refreshed by the immediate presence of the sea.

'This, therefore, is the point at which the skill of the cultivator changes the season of the plant, not by forcing it forward into productiveness, as is the case with fruits that are forced, but by checking its upward growth, and causing the nourishment which would be thus expended to be directed to the enlargement of the shoots previous to their expansion. To produce this effect, as well as to blanch and prevent them from becoming bitter, the plants are covered with pots, so pressed down into the soil as to preclude the admission of light and the circulation of air, as both are detrimental to the colour and flavour of the produse.

Pursuing this method shoots are produced fit for use generally in April or May, and a succession may be obtained during six weeks. No plant is more easily and cheaply forced than sea-kale, and, therefore, a supply of this vegetable may be usually obtained for the tables of the affluent during midwinter, and throughout those months when fresh vegetables are most difficult to be procured *.

The Artichоке-Cynara scolymus-is a native of some of the warmer parts of the temperate zone, and is supposed to be indigenous to the countries which bound the Mediterranean, as well as to the islands which are situated in that sea.

Like sea-kale, it is naturally a maritime plant, or at least one which thrives best on soils where there is a mixture of saline or alkaline matter. It does not, however, flourish on the same sandy shore with the former plant, its most genial soil being that in which there is a mixture of peat, or other decayed marshy vegetable matter. Nowhere does the artichoke arrive

* Loudon's Encyc. of Gard. p, 731. Abercrombie. 
at greater perfection than in the Orkney Islands, and this successful culture is said to be consequent on the plentiful supply of sea-weed, with which the ground is annually dressed.

Beckmann made very laborious researches to ascertain the positive antiquity of the artichoke. 'These discussions are, however, more curious than interesting. A commentator of Dioscorides, Hermolaus Barbarus, who died in 1494, relates that this regetable was first seen in the Venice garden in 1473 , at which time it was very scarce. A few years previous to that time it was, however, an object of cultivation in other parts of Italy. It was introduced into France at the beginning of the sixteenth century, and not many years afterwards, during the reign of Henry VIII., was first transplanted into our gardens. In the Privy-Purse expenses of this king we find several entries regarding artichokes. 'Thus:-“Paied to a servant of maister Tresorer in rewarde for bringing Archecokks to the king's grace to Yorke place, iiijs. iiijd." - A treatise, written in the reign of Mary, on " the best settynge and keepynge of artichokes," is still preserved in the Harleian library, of which it forms the 645th number. Though in very common culture in this country this plant is not held in as much estimation here as on the Continent.

The artichole has large thick perennial roots and annual stems, rising to three feet or more in height. The leaves are large and pinnatified, or cut in deep, horizontal, convex segments; these are covered with an ash-coloured down. In the midst of them rise the upright stalks, which are surmounted by large, scaly heads, composed of an involucrum, having numerous oval leaves or scales, enclosing the florets, and placed on a broad, fleshy receptacle; this, and the lower part or talus of the scales, are the only edible portions of the plant used in the early stage of their 
growth, before the central leaves of the calyx are separated, or the flowers in any way exposed. A large portion of the centre is occupied by what is. vulgarly called the choke, which consists of the young flowers and seed-down, having the appearance of bristles or prickly filaments, and from which the receptacle, or bottom, must be entirely freed before it can be eaten.

Artichokes are most readily propagated by offsets from the roots of the old plants, from which they may be separated, and planted out anew in March or April, when they have attained a height of about five inches. They will produce a crop the same year, but not an abundant one, commencing in August, and continuing till November; the second year they will be in full bearing, and produce two months earlier. Thus by planting fresh offsets every rear, a succession of artichokes may be obtained from June to November. The old plants, however, will continue productive for many years, provided the ground be annually manured at the winter dressing. But although the heads may be obtained from roots twenty years old, they degenerate in size and abun dance with the age of the plant, and therefore it is advisable often to renew the plantation.

The Cardoon-Cynara cardunculus-is a native of Candia, whence it was not introduced into England until more than a century after the artichoke. Its cultivation has never, however been an object of much attention in Britain, where it is considered of little value. On the Continent this vegetable takes a higher rank, and is much more extensively used.

The stems of the young leaves, rendered mild and crisp by blanching, are the only edible parts of the plant; these are stewed or used as an ingredient in soups and in salads. 
The cardoon very much resembles the artichoke in appearance; but it is of a larger and more regular rrowth.

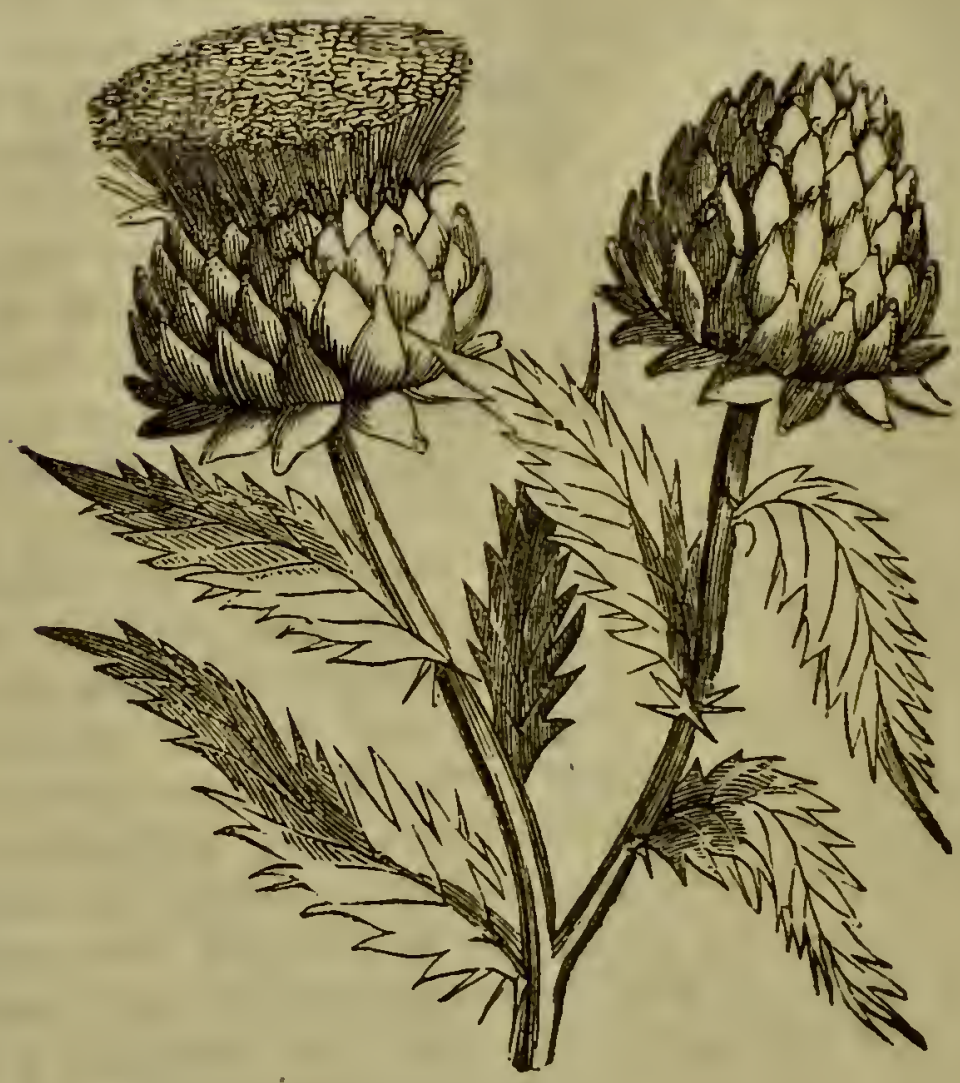

Cardoon-Cermum cordunckius. 


\section{Chapter XIII.}

\section{ALLIACEOUS PLANTS.}

THESE plants consist of bulbous ronts, belunging to the natural order, Asphodelea, so called from the asphodel, which, though not a native of Britain, is cultivated as an ornament to our gardens.

A bulbous essentially differs from a tuberous root in growing from the coronal plate upwards, and is, in reality, not a root but a bud, which defends the embryo or future shoot from external injuries during the winter; and which is always made up of parts which are ultimately to be developed in the atmosphere. Whatever may be their form and structure, or whether they grow in the earth or above the surface, they are, in reality, stalks or leaves, generally the latter.

Bulbs are not very nourishing; yet though most of those under present notice have an odour that is far from agreeable, their pungency and supposed sanative qualities render them general favourites, especially among the humbler classes. The rustic inhabitant of the northern parts of Britain looks upon the onion as his chief vegetable dainty; and on some parts of the Continent, the garlic, which is rather too strong. in flavour for the people of this country, is as much esteemed, being eaten by the poor as almost the sole addition to their black hrearl. and entering inte many of the made dishes of tne nicn.

The ONIon-Allium Cepa.-The use of the onior has been so long known in this country, that whence, and at what period, it was obtained cannot now be 
ascertained. It is not supposed that any variety of it is indigenous, since the large and mild roots which are imported from warmer climates deteriorate both in size ard sk'eetness after having been cultivated a few years in this climate. The onion called the Strasburgh, and the varieties which have been obtained from it in this country, appear to be the most naturalized, as they are the hardiest which are grown. It is, therefore, probable that this plant was first introduced into England from the central parts of continental Europe; although it may have been originally the native of countries farther to the south, and have been rendered hardier and less prone to degenerate riom its gradual change of climate.

The onions of Spain and Portugal, and even those of the south of France, are very superior to the common onion of our gardens, being of a much larger size, and more mild and rucculent. These sorts, however, will not bear the colder climate of this country without degenerating, while their seed seldom comes to maturity in Britain

Though the history of the onion can be but imperfectly traced in Europe, there is no doubt as to its great antiquity in Africa, since there is evidence to show that this bulb was known and much esteemed in Egypt 2000 years before Christ. It still forms a favourite addition to the food of the Egyptians. Hasselquist, in a panegyric on the exquisite flavour of the Egyptian onion, remarks, that it is no wonder the Israeites, after they had quitted their place of bondage, should have regretted the loss of this delieacy; for whoever has tasted of the onions of Egypt must acknowledge that none can be better in any part of the universe. "There," says he, "they are mild and pleasant to the palate; in other countries they are strong and nauseous. 'There they are soft and yielding, but in countries to the north they are lard, 
and their coats so compact, as to render them less easy of digestion." 'The Egyptians divide them into four parts, and eat them roasted together with pieces of meat; which preparation they consider so delicious, that they devoutly wish it may form one of the viands of Paradise. A soup made of these onions was pronounced by the learned traveller to be certainly one of the best dishes of which he ever partook.

This predilection for the savoury bulb extends in Africa beyond the country of the Nile. Major Denham, in his route south from Bornou, observed numerous gardens, but the only vegetable produced in them appeared to be onions.

This plant is a biennial, having long tubulated leaves, a swelling, pithy stalk, thiclier in the middle than at either of the ends, and a large spherical head of flowers, which expand the second summer after sowing. The root is a bulb, tunicated or formed of concentric coats ; this varies in size materially, according to the variety, soil, and mode of cultivation. It seems to be a general law among this species of roots, that the small are more pungent than the large,- that those which have a tinge of red or purple are more pungent than those which are white, - and that those which have the rind or outer membranous tunic upon the bulb thin and transparent are always of milder flavour than those which have it thick. It would be unprofitable as well as uninteresting to attempt an enumeration of the varieties of onions; and, even though it should be made complete at the present time, new varieties are so constantly springing up, that it would not long remain a correct list. Nearly twenty different kinds are recommended as being worthy of garden culture.

A rich mellow ground, on a dry subsoil, is the most favourable to the growth of this plant. It is propagated by seed sown broad-cast in spring; the 
quantity of seed being regulated according to the destination of the onions, whether they are to be drawn young or to remain for bulbing. The plants begin to bulb in $\mathbf{J}$ une, increasing in growth till the middle of August, when the necks shrink and the leaves decay: they are then in a fit state to be drawn, and preserved for the winter store.

A method of improving the size of onions by transplanting them was recommended by Worlidge, so early as the beginning of the seventeenth century, in his 'Systema Horticulturæ;' and this practice has lately been revived with great success by some emi nent horticulturists.

The theory on which it is founded is extremely ingenious. Every plant which lives longer than one year, generates the sap or vegetable blood which will elaborate the leaves and roots of the succeeding spring. In bulbous roots this reserved sap is deposited in the bulb, which, in a great measure, it composes. Now the store which is thus tormed varies considerably in the same species of plant, according to the particular circumstances under which it is raised. 'Thus the onion in the south of Europe accumulates a much greater quantity in a single season, under a greater degree, and longer duration of heat, than is afforded by our colder climates, and therefore it acquires, in a given time, a much larger size. Mr. Knight was induced by these observations to suppose that two short and variable summers in England might, perhaps, be equal in effect to one long and bright season in Portugal; and, accordingly, he attempted a method of culture which has proved his inference to be correct. In pursuance of this plan seeds of the Portugial onion were sown in spring very thickly, on a poor soil, and in a shady situation. Under these circumstances, the bulb in the autumn had attained scarcely beyond the size of at iarge pea. 'The bulbs were then 
taken from the ground and preserved durng the winter ; in the ensuing spring they were again planted at equal distances; from this treatment the plants afforded bulbs very superior to those raised immediately from seed, some exceeding five inches in diameter; and being more matured they may be preserved sound throughout the winter with greater certainty than those which are raised from seed in a single season *. Many other cultivators pursue, with some slight alterations, the same method, and find it perfectly successful.

It is found that in those countries in which the onion comes to the greatest perfection, the practice of transplanting it prevails.

In Portugal it is sown in November and December on a moderate hot-bed, and protected from the frost, in which situation the plants remain till April or May, when they are transplanted to a rich soil $\dagger$.

Onions are considered wholesome under any form ; but they become more succulent and mild after having undergone culinary preparation.

'The Welsh Onion, or Cibouie-Allium Fistulosum-is originally from Siberia. It is a hardy plant, and strong in flavour, approaching more nearly to garlic than onion. 'This species does not form a bulb. 'The cultivation of the ciboule has been known in England since the early part of the seventeenth century; how much earlier there are now no means of knowing. It is much less cultivated in the present day than it was in former times, when broths and pottages, seasoned with the green tops of the onion tube, were more in fashion. It is now only occasionally raised for a spring crop. For this purpose the seed is sown at the end of July or August; in a fortnight the plants usually appear above ground; but in October their leaves wither, and the ground appears quite bare. In the beginning of the ensuing year, how-

* Hort. Trans., vol. iv. † Ibid, vol, iii. 
ever, they become renovated, and in March are fit for drawing to be used as onions. The SCALiEN is another name given to long-necked onions, which produce leaves abundantly, but do not bulb.

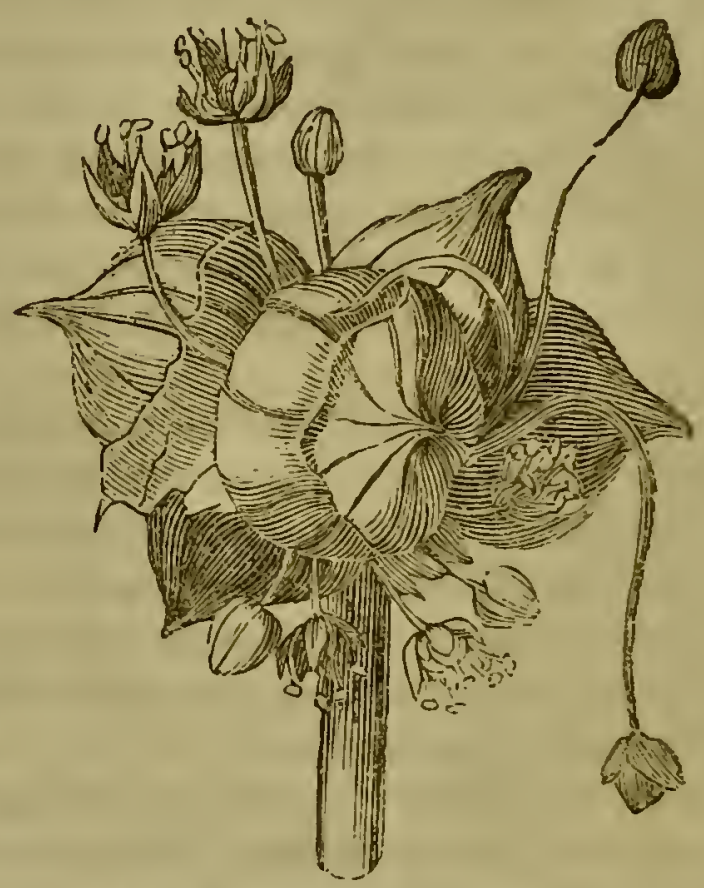

Tree-onion-Allium prolifen um.

The Tree, or Bulb-bearing Onion-Allium Cepa, var.Viviparum-is a singular variety, which has probably been produced by climate. It runs with a strong stem, about two feet in height, on the top of which the flowers are produced in a manner similar to the rest of the species; but instead of being succeeded by capsules containing seeds, the germs swell, and towards the end of the season a crop of bulbs is obtained from the top of the stalk, and which, in a natural state, as soon as they drop off and fall to the ground, begin to put out roots and vegetate. This variety is more an object of curiosity than of use, though we learn that in some parts of Wales these 
bulbs are planted, and produce ground-onions of a considerable size, while the stem supplies a succession of bulbs for the next year's planting*

This variety is said to have been introduced here from Canada; the French call it l'ognon d'Egypte; there is no proof, however, of its being a native of the country which its name would indicate, while the probability is greatly to the contrary. It is not in such a climate, but in cold and wet countries, that seminal plants are changed to viviparous. The same species of grass which has perfect seeds upon warm and dry grounds, bears little plants in the spike when grown upon the cold and humid mountain top; and the corn, which in a dry season remains firm and without any signs of vegretation in the grain, sprouts in the ear, and becoines green and matted in the shock, when the weather is lainy; this effect being produced much more frequently in the northern parts of the country than in the south. It is by no means improbable that in the humid atmosphere of the Hebrides, both grain and pulse would become viviparous, if they were not taken to the barn and dried by artificial means. By analogy drawn from facts it is therefore probable that the tree-onion is not only from Canada, but that it is not indigenous there, being merely the common onion introduced from France by the colonists, and changed to the viviparous form by the climate.

The Ground, or Potato Onion is another curious variety. This multiplies itself in an opposite direction to that of the tree-onion, producing, by the formation of young bulbs on the parent root, an ample crop below the surface. This plant has also been described as being a native of Egypt, or at least as having been brought from that country by the British army in the early part of the present century. It

$$
\text { * Hort. Trans., vol, iii. }
$$


must be admitted that a plant which bears an additional number of bulbs is more likely to be a native of a dry and warm climate than a plant which is viviparous. The time of the introduction of the potatoonion has, however, been erroneously assigned, since it was known and cultivated in the south and west of England some years prior to the Egyptian expedition. If it be a native of Egypt, or of any other warm country, it is, indeed, a hardy one, since it bears the alteration of the seasons, and resists the attacks of insects much better, it is said, than the common onion.

The bulbs are planted in the middle of winter; as the tops appear they are usually earthed up like potatoes, and by the middle of summer the new crop is ready for removing. The size and number of the new bulbs depend very much on the size of those which have been planted, but they always yield a provortionately large produce.

The Chive-Allium Schœnoprasum-is the smatlest, though one of the finest flavoured of the genus. It is a hardy perennial plant, an inhabitant of Siberia, and said to be a native of Britain, though rarely found growing in an uncultivated state. The bulbs are very small, connected in clusters of an elongated form, and the leaves are long, slender, and pointed. The flowering stem, when it is allowed to rise, is slightly curved and seldom attains to more than a few inches in height; the flowers are white, with a purple tinge ; they grow crowded together, and are, even in the most cold and moist situations, followed by capsules and seeds. When cultivated, the plants are, however, seldom allowed to run to seed, as they are not usually drawll to be eaten entire, but have the leares and young tops cut off to be used as a potherb. Chives are very hardy, and require no attention during their growth except to keep them free fiom weeds; they 
are propagated by slips, or by dividing the roots in the spring or autumn.

When the leaves are gathered for use, if they are out close, others will shoot up in succession, and in this manner a bed lasts three or four years; after which period it must be renewed. When fresh cut these leaves are by some persons considered as an improvement to salads and seasonings. Their flavour suffers greatly if they be kept after gathering even for a very short time, and their produce is but small. in proportion to the labour of gathering. On these accounts they are not much cultivated in places where vegetables are supplied in the markets; and they seldom find a place in the garden of the English peasant, who, partly from ignorance, and partly from prejudice, does not live much upon those soups and savoury dishes which, while they are more wholesome and nourishing than the food which he consumes, are also considerably cheaper.

The LEER-Allium porrum-is said to be indigenous to Switzerland, whence it was introduced into this country; but it has been for so many ages under cultivation, that its native place cannot, perhaps, be very accurately traced. According to translator's and commentators, this, as well as the onion and garlic, was included among the Egyptian luxuries after which the Israelites pined. It still makes its constant appearance at the tables of the Egyptians, who eat it chopped small as a savoury accompaniment to meat.

The exact period when the leek was first brought into this country is not known, but it is mentioned by Tusser, in his 'Five Hundred Points of Good Husbandry,' as early as 1562 . There is, however, every reason for believing that it was introduced prior to that time, and had long been the favourite badge of the Welsh principality. Shakspeare makes this to have 
arisen at the time of the battle of Cressy. In the play of Henry V., Fluellin, addressing the King, observes,

"Your grandfather of famous memory, an't please your Ma. jesty, and your great uncle Edward the Plack Prince of Wales, as 1 have read in the chronicles, fought a most prave pattle here in France.

"King Henry. They did, Fluellin.

‘: Fhellin. Your Majesty says very true: if your Majesties is remembered of it, the Welchmen did goot service in a garden where leeks did grow, wearing leeks in their Monmouth caps, which your Majesty knows to this hour is an honourable badge of the service; and I do believe your Majesty takes no scorn to wear the leek upon Saint Tavy's day."-Act 4, Scene 7.

Worlidge gives a good idea of the love of the Welsh for these kinds of odoriferous vegetables. $\mathrm{He}$ says, "I have seen the greater part of a garden there stored with leeks, and part of the renıainder with onions and garlic."

The hardiness and pungency of the leek both tend to recommend it in those countries where few potherbs are grown, and it seems to have great facility in adapting itself to climate. The leek which is cultivated in the colder parts of Scotland, and thence is called the Scotch leek, is more hardy and also more pungent than the broad-leaved variety, chiefly cultivated in England. It was formerly a very favourite ingredient in the "cock-a-leekie" of the Scotch, which is so graphically described in 'The Fortunes of Nigel ;' and of which James the First is reported to have been so fond that he retained his preference for it notwithstanding all the dainties of London cookery.

This spccies requires more boiling than others of tlie same genus, and, unless it be reduced nearly to a pulp, it taints the breath in a very offensive manner. The offensive odour of a vegetable is, however, no evidence of unwholesomeness, provided the odour is natural to it, and not the result of putrefaction *.

* See the account of the Durion; Library of lintertaining Lnowledge, rolume on Timber 'rees and Fruts: 1. 404. 
The bulb of the leek consists of the bottoms of the leaves, which do not form in bulbules or cloves like those of the garlic, neither are they so entire as the tunics of the onion; the stem runs to the height of about three feet; the flowers, which are bell-shaped, appear in May, in large close balls, followed by capsules containing seeds. As the root of the leek is rather the blanched end of the leaves than a bulb, properly so called, the plant is to be considered chiefly as a potherb; though in some places both the root and the greater part of the leaves are eaten by the peasantry as an accompaniment to their bread. Its chief value, however, is as a potherb, which stands the winter well, and is in a forward and succulent state at that part of the season when fresh vegetables are the least abundant. The culture of the leek is similar to that of the onion.

Garlic-Allium sativum-is the species from which the genus takes its name. It is very extensively used in most of the continental states. This plant was first cultivated in England in 1548, and was held in greater repute by our ancestors than is in accordance with modern English taste. It is a native of the countries on the shores of the Miediterranean, and is still to be found growing wild in the island of Sicily, and in the south of France. Though thriving best on a naturally rich and dry soil, garlic is a very hardy plant, and not very particular as to climate. Its leaves are linear, long, and narrow; the root is perennial, composed of twelve or fifteen lesser bulbs, cnclosed in one common membranous tunic, and easily separable from one another; these are called cloves of garlic, and are the only parts used. 'The whole plant, and especially the cloves, has a most acrimonicus taste, and offensive smell; and even in those countries where it is most in fivour it is seldom eaten in substance or even mixed in sub. 
stance in those culinary preparations which it is intended to flavour. The garlic is generally only introduced during the cooking, for a time longer or shorter according to the intenseness of the flavour required, and is then withdrawn. This plant is readily propa gated by the cloves or subdivisions of the bulbs which, if put into the ground in March, produce a crop in July or August.

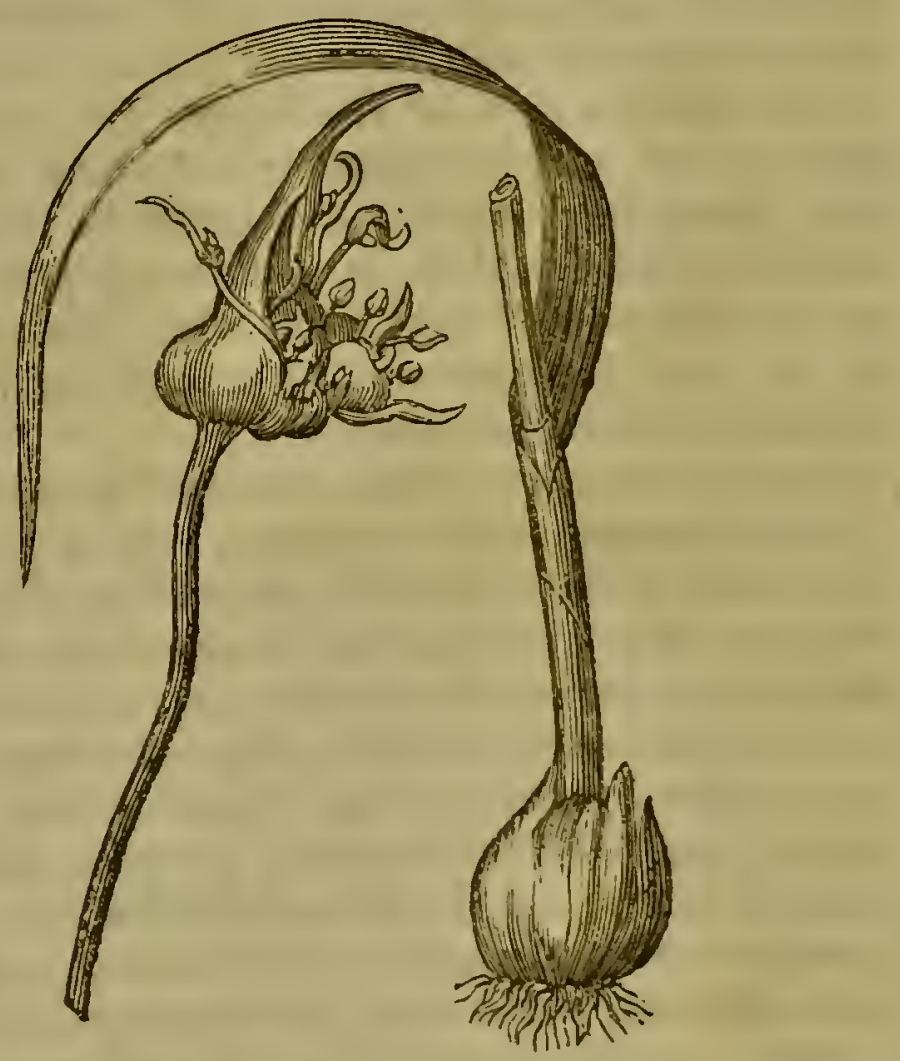

Garlic-Allium satioum.

Several species of garlic are found growing naturally in varions countries. The wild garlic of Kamchatka (allium ursinum) is much prized by the inhabitants, both as a medicine and as an auxiliary article of food. 'The Russians, as well as the natives, gather it in large quantities for winter use. After being steeped in water, it is mixed with cabbage, onions, 
and other ingredients, the whole forming a ragout, which is eaten cold. 'I'his plant is there considered as almost a specific against the scurvy, no sooner lifting its head above the snow than the dreadful disease loses all its horrors; as even in its worst stages a cure is produced by the plentiful use of the wild garlic.

Three species, the sand garlic, the crow garlic, and the leek garlic, are found native in some parts of Britain ; but they are of little or no value, and have never been introduced into culture.

The Shallot-Allium ascalonium-is a native of warmer climates than that of England; it is found growing wild in many parts of Syria, especially near Ascalon, whence it derives its name. 'The time of its introduction into this country is not known; some writers assume that it was brought home by the Crusaders. It is mentioned as a well-known plant by Turner, in his 'Signes of Herbes,' published in 1548. This plant resembles the true garlic in having its roots divided into cloves or smaller roots, and enclosed in a thin membrane. Each of these small roots sends forth two or three fistular awl-shaped leaves, issuing from a sheath; they are nearly similar, but not so large, as those of the onion. 'The shallot does not in all situations produce perfect seeds, or even flowers, and sometimes, indeed, does not send up any foot-stalk. 'The want of seed is, however, fully compensated by the multiplication of the roots. It is sufficiently hardy to bear uninjured the severest winters of England, but it is liable sometimes to be attacked by insects. This evil is found to be surely prevented when the bulbs are planted rather above the surface, instead of being buried in the earth; and this improved mode of culture has a farther advantage of bettering the quality and increasing the quantity of the crop obtaine?.

'The flavour of the shallot is much more pungent 
than that of garlic, but not nearly so rank. It sea. sons soups and made-dishes, and makes a good addition in sauces, salads, and pickles

Rocambole-Allium scorodoprasum-is a native of the northern parts of Europe, and is found in situations which are rather elevated. It has been cultivated in this country, though not very extensively, from a period much anterior to any annals of horticulture; the earliest records on this subject mention it as being a plant in common cultivation. It is a perennial, having narrow flat leaves, with the mark of a keel or ridge on the under sides. The flowerstem rises to the height of about two feet; the globular liead, on its first appearance, is contorted. As the plant advances, however, the head untwists, and the flowers come to maturity; after which the spherical top changes into a cluster of small bulbules, which have a tinge of purple. The cloves of the rocambole, taken either from the root or the top of the flowering stalk, are the parts used; the latter being the largest in size; but those from the roots have the must pungency, especially when the whole of the bulb is buried in the earth.

Rocambole holds an intermediate place between garlic and shallot, and is applied to the same purpose as the latter. 


\section{Chaptei XIV.}

ACETARIOUS PLANTS, \&c.-SEASONING HERBS.

VEGETABLES which are eaten raw, either in their natural state, or blanched, are usually termed acetarious, or salad plants. Though these contain scarcely any nourishment, and are not at all essential accompaniments to a meal, yet they are recommended by so agreeable a coolness, pungency, or flavour, as to render the food with which they are eaten more grateful to the palate; while some are considered a wholesome addition to more substantial aliment.

LetтUсE-Lactuca sativa-has acquired its generie name from the milky juice which it contains. This species comprises many varieties, all of which possess a slightly narcotic principle in their juice, which is, in general, elaborated only in small quanties during the early stages of the plant, but increases greatly as that advances towards flowering. This juice is very bitter, and when it becomes abundant, the plant ceases to be useful.

The absolute quantity and strength of the opiate portion of the juice most probably varies both with the variety of the plant and with the soil on which it is produced. In the strong-scented wild lettuce (Lactuca virosa) the narcotic juice is so abundant, and so acrid in itself, or so mixed with other acrid principles, as almost to bring the plant within the class of vegetable poisons.

The narcotic property of lettuce-juice has been 
long farriliarly known. This quality has not been overlooked even by the poets. Pope says,

Lettuce and cowslip wine Probatum est."

It is only very recently, however, that this juice, inspissated, or the extract of lettuce, has found a place among our pharmaceutic preparations, under the name of Lactucarium. It is supposed to possess, though in an inferior degree, the virtues of opium, without producing the same deleterious effects; and, therefore, it is held that it may be safely administered in cases where the more powerful medicine is not desirable, or even admissible. Brechin, in the county of Forfar, is among the places where the lettuce is cultivated, and its juice collected in considerable quantity for medical purposes. The plants are grown in a dell, composed of rich soil, and opening to the south. In so favourable a situation they thrive very vigorously, sending up thick and juicy flower-stems. As soon as these have attained a considerable size and height, but before the flowers begin to expand, a portion of the top is cut off transversely. This operation is performed when the sun has excited the plants into powerful action. The milky juice quickly exudes from the womnd, while the heat of the sun renders it so immediately viscid, that it does not flow down in a fluid state, but concretes around the part whence it issues, forming a brownish scale, about the size of a sixpence. When it has acquired the proper consistence it is removed, and as the inspissated juice closes up the extremities of the divided vessels, it is necessary to cut off another small piece of the stem; this causes the escape of the juice again, and another scale is formed. The same process is repeated as long as the weather is farourable, or the plant will yield any juice. 
Under so variable an atmosphere as that of Britain, a crop of this lind must be precarious, unless in those places where there is generally a week or two of setuled drought, about the warmest period of the year, and where the cultivator has sufficient local linowledge for enabling him to time the state of his plants accordingly. Mr. Henderson, the Brechin cultivator, an intelligent and experienced horticulturist, states, that in favourable years the lettuce-opium, notwithstanding the trouble of collecting it, is much more profitable than any other crop that comes to maturity, in so short a time, upon the same breadth of land.

Turner mentious the lettuce as being, in 1652, not a rare or recently cultivated plant, but one with which the public generally had been long familiar. In the Privy-Purse expenses of Henry VIII., in 1530, we find that the gardener at York-Place received a reward for bringing "lettuze" and cherries to Hampton Court. Although it cannot now be definitely ascertained when or how this plant was first introduced into Engiand, we are no doubt indebted for some of its varieties to the Greek islands. The Cos lettuce, as its name indicates, is a native of the island of Cos, and was most probably brought thence into this country.

The culture of this plant is so simple, and it requires so little space, that a garden of the most humble dimensions is seldom found without having a small nook appropriated to this cooling and agreeable vegetabile. 'There are many varieties of the lettuce, very nearly twenty being enumerated as objects worthy of grarden culture, and each of them differing somewhat in colour, shape, or some other circumstance attending its growth. These, however, may all be ranged under two distinctive heads, the cos and the cabbage lettuce. The former grows upright, 
and its leaves are of an oblong shape; the latter has rounder leaves folded together, and forming a low, full head, spreading ont close to the ground. When in perfection for gathering, the leaves of both sorts are lapped one over the other in a compact, close order, forming what is usually called the heart, the inner part of which, being thus excluded from light and air, becomes nearly wlite. This natural blanching is often assisted by artificial means, and when the inner leaves begin to close, the outer ones are tied round them with a piece of bast*. The blanching prevents the formation of the bitter or acrid principle, which is very perceptible in all the varieties, if allowed to remain in the ground and complete their growth, when the leaves expand and the flower-stalk begins to ascend.

Lettuce being a hardy and free growing plant, may be obtained early in the season, if sown in a warm border, and protected from the frost during the night. For early use the cabbage is the best, as in that stage it is more delicate in flavour than the other; but when both have arrived at maturity, the $\cos$ is the most succulent.

Endive-Cichorium endivia-is abundantly cultivated, if not found wild, in China and $J$ apan ; and thus the accounts that describe it as a native of those countries, and as having been imported into the West about the early part of the sixteenth century, have probability on their side. Few particulars of the history of this plant are, however, linown.

It is a hardy annual, producing a great stock of leaves from the crown of the root. 'Ihese leaves are large, smooth on the surface, but much divided into lobes, and toothed at the edge. The flowering stem

* The material of Russia matting, made from the inner lark of the lime-tree, and which is a well-known essential in kitchen. gardens. 
rises to the height of about two feet, and the flowers, which are of a pale blue colour, bloom in July and August. Like the lettuce, its leaves are used as an edible before its flowering stem begins to appear. These leaves are very harsh and bitter when exposed to the air; they are therefore blanched, and if this be properly performed, they become crisp and tender, and retain only an agreeable bitterness. Endive may be blanched for use by tying the leaves together, by earthing up the plants, or by covering them with pots. By judicious culture and a succession of sowing, endive may be obtained during autumn, winter, and spring; it is considered a valuable salad at a time when few other vegetables are furnished for the table; and it also serves as an ingredient in some other culinary preparations.

Succory, Chicory, or Wild Endive-Cichorium intybus. There is little doubt that the cichorium, as mentioned by Theophrastus, in use among the Ancients, was the wild endive, since the names by which this plant is known in all the languages of Modern Europe are merely corruptions of the original Greek word; while there are different names in differeut countries for the garden endive.

Succory is a hardy perennial plant, not uncommonly growing about the edges of fields, in those parts of England where the sub-soil is lime. It will bear all the varieties of climate in Europe, being cultivated from Italy to St. Petersburgh. This plant has a strong and fleshy root; the leaves have some resemblance to those of endive, differing only in being narrower, more feathery at the edges, and having the mid-rib beset with hairs. 'The flowering stem rises much higher, sometimes attaining to five feer in height ; the flowers are like those of the garden plant in appearance as well as in time of blooming.

This plant is not much valued or cultivated in 
Britain. On the Continent it is held in greater esteem, and is used as an edible vegetable in a variety of ways.

Both in France and England succory has occasionally been cultivated as food for cattle; it is in a proper state for this purpose just as it is coming into flower.

The root of this plant is used as a substitute for coffee ; and it is sometimes considered superior to the exotic berry. Dr. Howison* is of this opinion; while Dr. Duncan $\dagger$ believes that the plant might be cultivated for this purpose with great national advantages. In many parts of Holland and Germany this prepared root is used in large quantities, either alone or mixed with coffee by those who cannot afford to indulge in the latter luxury in its genuine state. Indeed, it has been very recently introduced into this country as an addition which much improves the flavour of coffee; but where economy is not the consideration, it is not likely to gain much esteem. The succory root, when applied to this purpose, is merely cut in pieces, and sufficiently dried to admit of its being easily ground.

Cress is the general name of a number of plants, mostly, if not all, "bearing cruciform flowers, and possessing, in common with plants of the same family, pungent and aromatic quaiities.

Galiden Criss-Lepidium sativum-is a hardy annual, not found wild in England. Its native country is Persia, and also Cyprus. It has been cultivated here since the middle of the sixteenth century. 'This plant produces a number of small leaves, which are curled in some of the varieties, and plain in others. 'The flowering stem is branched and rises to

* Caled. Hurt. Mem. iv. 132.

$\dagger$ Disc. to Caled. Hort. Soc. 1820. 
the height of about a foot and a half, producing white flowers which blow in $\mathbf{J}$ une or July. It germinates very rapidly, and is most generally used in its earliest growth. In this state it is mixed with the young leaves of mustard, and is the most esteemed of all the small salads or plants which are used in the early leaf.

Its flavour is so warm and pungent as to have procured for it the name of pepper-wort. During the greater part of the year a constant supply may be obtained by sowing a portion every week, and the application of a moderate artificial heat will furnish it throughout the winter.

Mustard-Sinapis alba-is often found growing wild among corn; but it is very generally cultivated, being sown with the garden cress to be eaten in the seed-leaf as a small salad; but when the plants are of a more advanced growth, the leaves become harsh and rank. Its flowers appear in June or July, and these are succeeded by round rough pods. Like cress it most readily germinates, and is, indeed, of still quicker growth. The seeds, strewed on wet flannel, or on cork, floating on water, quickly put forth tender leares, and a salad is thus in a few days produced at the winter fireside.

The Sinapis alba is not generally cultivated for its seeds, which are used as a condiment; the species usually grown for this purpose is the nigra.

BURnet - Poterium sanguisorba-is an upland perennial, found upon dry soils, and attaining to rather more than a foot in heights. Its flowers, forming small greenish heads tinged with purple, appear in July. 'The leaves, when bruised, smell like cucumber. They have a slightly pungent taste; but their chief value consists in their continuing green and fit for use during winter. This plant was formerly much more cultivated than it is at present. 
Garden Rocket-Brassica cruca-was likewise cultivated by our ancestors, who first obtained it from Austria in 1573. It has now entirely fallen into disuse in this country, but is still to be found in gardens on some parts of the Continent.

The list of plants which are occasionally eaten as salads is so numerous, and some of them are so little used, that a farther detail of them wonld possess little interest. In fact any plant of rapid growth, and which has the seed-leaves pungent, without any deleterious property, may be used as small salad.

Celery-Apium graveolens. There are several varieties of the cultivated celery. The upright kinds are distinguished as the red and the white, and by having their stems either hollow or solid. Of these the red variety is of a coarse but more hardy nature than the others, and though not so good in its crude state, is well adapted for stews and soups.

The blanched foot-stallis of the leaves are the part generally used as an esculent. The Italians, however, take the unblanched leaves as an ingredient for soup; and when no other part of the plant can be obtained, the seeds alone will communicate a very agreeable flavour to certain culinary preparations.

'The turnip-rooted celery, or celeriac, is more hardy than the upright varieties. 'The root of this is the only part used. It attains to a very considerable size, especially in Germany, where it is much csteemed, either as forming an ingredient with other viands, or prepared by itself, the outer coat and fibres being always previously detached. 'The boiled root, sliced when cold, and mixed with oil and vinegar, is considered a very choice salad. Celerjac is occa- 
sionally imported from Hamburgh into this country; but it rarely forms an object of cultivation in English gardens.

The most favourable soil for the growth of celery is a rich vegetable moúld. This plant is raised from seed sown in spring; an early crop being sometimes brought forward on a moderate hot-bed. When the plants are from two to four inches high, the seedbed is thinned, and those removed are transplanted, from three to six inches apart from each other, in an intermediate bed. They remain in this situation till they become vigorous plants of from six to twelve inches high ; they are then finally transplanted, and, generally, into trenches. The plants are placed at from five to ten inches apart, and as vegetation goes forward the stems are gradually earthed in; this operation being repeated every fortnight, till at length they are covered to one and even to two feet high, in order that they may be blanched, and thus a considerable portion be made edible. By this management celery is obtained from August till March; and where the soil is favourable, and the cultivation skilful, these plants attain to a very large size. A head of celery, cultivated in the neighbourhood of Manchester, and dug up in the autumn of 1815 , weighed, when washed, nine pounds, inclusive of the roots and leaves, and measured four feet and a half in height. It was of the red sort, very crisp and delicate, and of a good flavour*.

The RADIsH-Raphanus sativus-is usually de scribed as being a native of China; but whether it was introduced thence direct into Britain has not been ascertained. It has long been in cultivation in this country. Bullein, who wrote in 1562, says: "Of radish-rootes there be no simall store growing about the famous city of London: they be more * Loudon's Encyc, of Gard. 
plentifull than profytabie, and more noysome than nowrishinge to manne's nature*." Yet they were used thirty years before at the table of Fenry VIII.

'This plant is of quick growth, shooting up its flower-stem in a few weeks, after which the root becomes stringy and too pungent to be agreeable; it is, therefore, fit to be pulled sooner after sowing than almost any other plants, except those of which the seed-leaves are eaten as salad.

There are many varieties of the radish, which differ from each other in shape, colour, flavour, or in the seasons most suitable for their cultivation. Radishes are distinguished, according to their form, into long or spindle-shaped, and round or turnip-ronted.

Rhubarb-Rheum The petioles of rhubarb have a pleasant acidity; these, when peeled and cut into pieces, form no unworthy substitute for fruit in spring tarts; to furnish a supply for which this plant is now largely cultivated in the vicinity of the metropolis.

Several species of Rhen The root of the true Rhubarb-Rheum palmatumis well known as a medicinal drug, and for that purpose has long been imported from the Levant, though the particular plant, of which it was the root, was not ascertained until $175 \mathrm{~S}$, when it was first introduced and cultivated in this country by Dr. John Hope $†$. It is a native of some parts of Tartary, where the physical characters of the climate are well adapted for the perfecting of its root, the properties of which are very faintly retained in countries where the season of dormant vegetation is humid. This plant is of very handsome appearince. Its beatiful palmate leaves distinguish it from the other species; but as the parts used for culinary purposes, the footstalks of the radical leaves, are much smaller than those of the other linds, it is not in general cultivation.

* 'Book of Simples,' fo. 53.

+ Phil. Trans. vol. lv. 


\section{MISCELlaneOUS VEGETABLE ISCULENTS. MO}

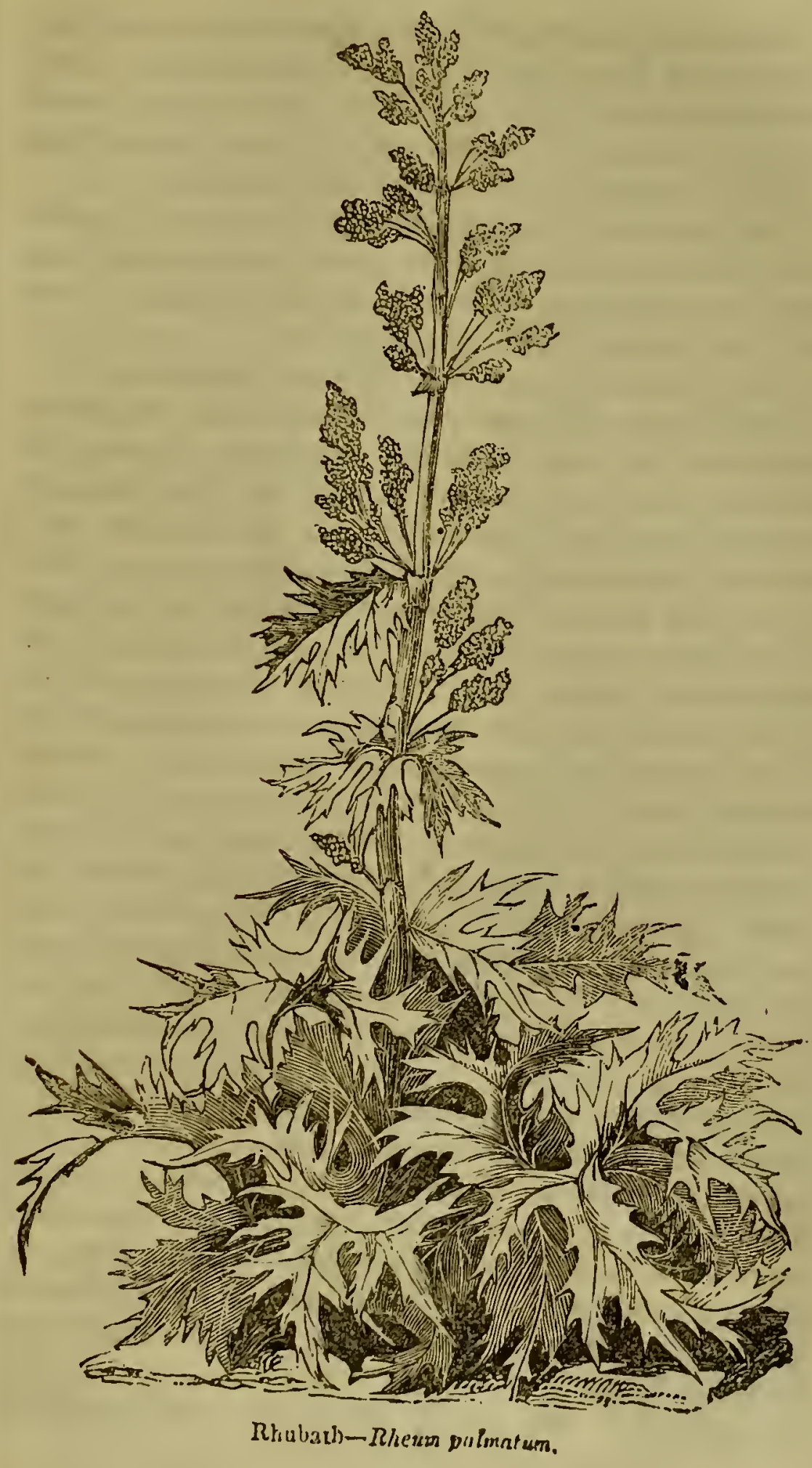


Monk Rhubarb-Rheum rhaponticum-is also a native of Asia, but of what particular part is not known, neither is the time of its introduction ascertained; we find it mentioned by Tusser so early as 1573, as being then cultivated in England.

The leaves of this species are blunt and smooth, with red veins; the footstalks have also a red tinge, they have a groove or furrow on their upper sides. and are rounded at the edges.

The Hybrid Rhubarb-Rheum hybridum-is a native of more northern parts of Asia than the others, and is of more recent introduction into Britain. It was first cultivated in this country by Dr. Fothergill in 1778 , but it did not come into general use as a culinary vegetable till several years after, having been introduced in our kitchen-gardens for this purpose about thirty years back. 'This plant is of a much more lively green than the former species. The leaves are slightly heart-shaped and very large, being, in favourable soils and under good culture, sometimes as much as four feet in length, including the footstalk. In the Gardener's Magazine for February, 1829, we find a notice of a plant of this species, the leaves of which attained to great dimensions. One leaf being cut, with its petiole, was found to weigh four pounds. The circumference of the leaf, not including its foot-stalk, measured twenty-one feet three inches ; its diameter, three feet ten inches; length of leaf, including the petiole, five feet two inches, and length of petiole, one foot four inches. The stalks of the hybrid are much more succulent, as well as larger, than those of the Monk Rhubarb, which, therefore, cause it to be the preferable species for cultivation, although Rhcum undulatum, called by gardeners Buck's Rh., and the Elford Rh., has been found the finest in flavour.

Rhubarb is very easily cultirnted, and though it 
occupies much space, the produce, under proper treat ment, is very considerable. The petioles obtained from it will furnish a greater supply of material for tarts than the fruit of either apple or gooseberry trees occupying an equal breadth of ground. It may, therefore, be considered as a good plant for the cottage garden, more especially as it comes into productive bearing in the earliest spring, a time when fresh fruit cannot be obtained.

New plantations may be raised either by sowing the seeds or parting the roots. The latter is not, however, an eligible mode of culture. As in most cultivated plants, the produce of a sucker is, when it has to make its own root, always inferior in vegetative power to that which is originally from the seed,-and vigorous vegetation is the quality most sought for in rhubarb, - the flowering stems should be removed, except in such plants as may be wanted for seed. If the seeds are sown in spring, the plants will be ready for planting out in autuinn, and will come up strong enough for use the next spring, after which the plantation will last for many year's. The plants of the hybrid kind require from two feet and a half to three feet of space for each, and those of the other species ahout a foot less; but the superior produce of the former, under favourable circumstances, will more than compensate for the greater breadth required.

Angelica-Angelica Archangelica-is occasionally to be found native in cold and moist places of Scotland; but it is more abundant in countries farther to the north, as in Lapland and Iceland. This plant was formerly much more in repute than it is at pre. sent. It may be inferred from its common name of angelica, as well as from another nume, 'The Holy Gliost,' which was scmetimes given to it, that superstitious virtues were imputed to it. 'The chict of 
these virtues was driving away the pestilence, for which general cleanliness has proved to be a better preventive than all the charms which ever were named.

Its stem was formerly blanched and eaten like celery, but the use of this plant in the present day as an English edible is mostly confined to confectionary, for which purpose the young and tender stalks are candied. The roots, seeds, and leaves, are sometimes, though not very commonly in modern practice, used in medical preparations. The whole plant is highly aromatic. In Lapland the inhabitants consider the stalks of angelica as a great delicacy. These are gathered before flowering ; the leaves being stripped off and the peel removed, the remainder is eaten with much relish. This is a favourite plant with the Laplanders, who have given so many names to it, according to the different stages of its growth, as to occasion much confusion to a stranger*

\section{VEGETABLES USED FOR PICKLING.}

MANY of the regetables which have been already described are applied to this purpose,-which use has been noticed under the different heads, as they have presented themselves; those plants which are more particularly and exclusively employed in this manner are but few in number. Cucumbers, loveapples, capsicums, and capers are the only pickling plants which have not already found a place in the present volume. The two first mentioned have already been described in auother division of this series $t^{-}$

* Linnaus's Tour in Lapland.

+ See Volume treating on Timber-Trees and Fruils, pp. 28i and 291. 


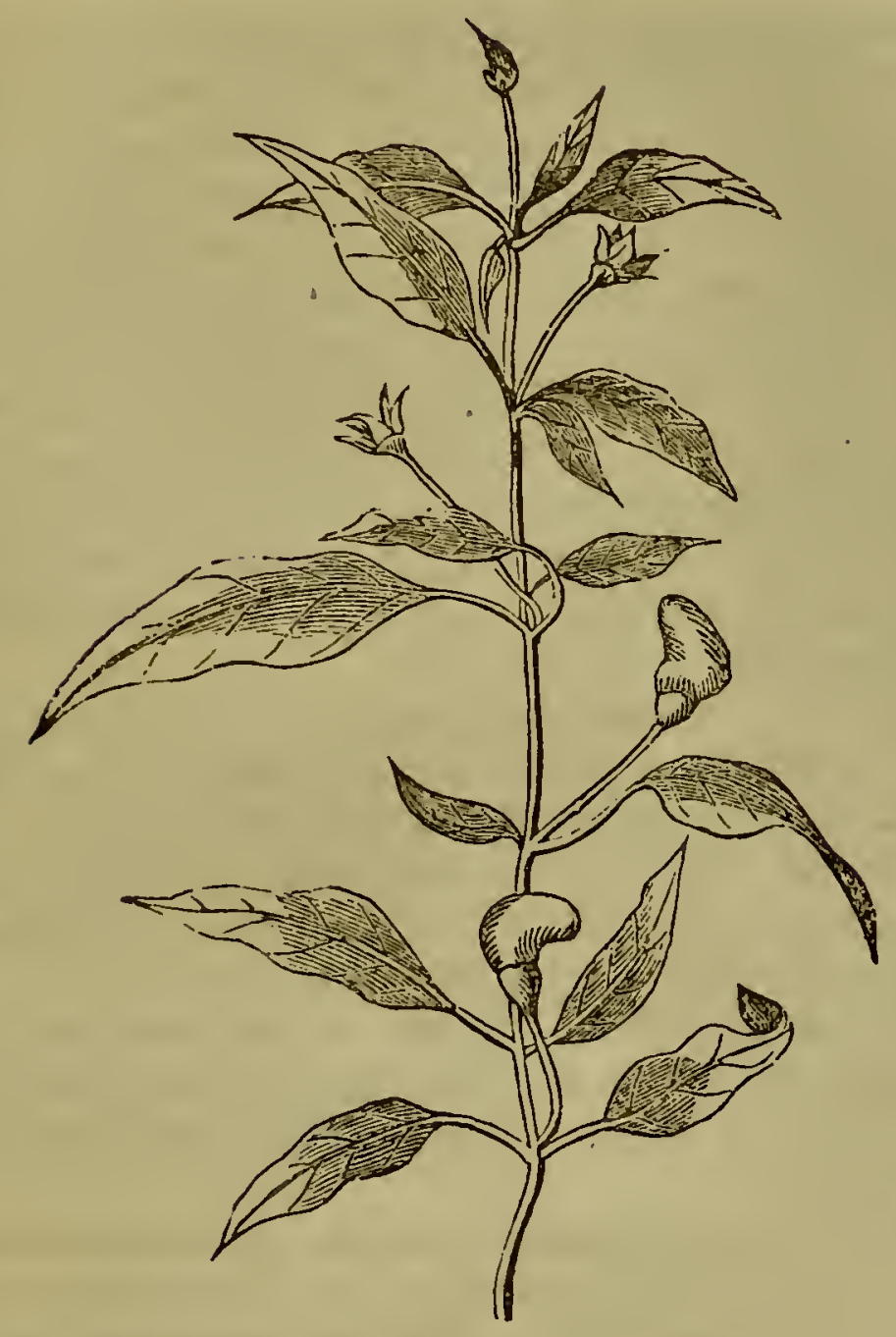

Capsicun.

The Capsicun is a native of tropical regions, but is become so far acclimatized in this country as to be successfully reared, and during summer to endure the open air uninjured.

Three species of capsicum are cultivated in England. The Guinea Peprer-Capsicum annuumwas introduced into England, from India, so early as 1548 , and is mentioned by Gerarde as beingr under cultivation in his time. This plant has a branchy stem, rising about two feet high; the leaves 
are long, narrow, and of a dark green colour. White flowers bloom in June or July, and are succeeded by pods varying in shape and colour; some being long, others short, some round, and others again heart-shaped, while the colour is either red or yellow.

The Cherry Pepper-Capsicum cerasiforme-is a native of the West Indies, and was not cultivated in England until 1759. This species is very similar in appearance to the first, and is only characterised by the different shape of the pods, which take somewhat the form of a cherry; sometimes heart-shaped, bell-shaped, or angular; their colour is the same as the preceding.

Both these species are annuals. The BeLr PE:PER-Capsicum grossum-is a biennial, a native of India; it produces larger pods than either of the others. It may be transplanted with safety in the open garden, on the arrival of summer, requiring a place in the stove during the winter season.

The green pods of all these varieties are used for pickling; those of the last are senerally preferred, being not only larger, but having the skin nore pulpy and tender.

The CAPER-Capparis spinosa-is a native of Italy and Sicily. It was introduced into this country as an exotic so early as 1596. Modern horticulturists are of opinion that with care it might be raised in the open air in England, but this has never yet been accomplished to any useful extent. One instance, indeed, is recorded by Neill, of a caper-tree standing alive in the open air for nearly a century; this was in the garden at Campden-House, Kensington. 'This plant was sheltered from the north, and remained uncovered during winter. It was generally much in. jured by fiost, but the roots being particularly strong and vivacions, it sent out strong shoots and pro. duced flower-buds every year. In France the caper. 
tree has been long naturalized, being cultivated in the vicinity of Paris with no other shelter than a low wall, against which it is trained; in winter, the shoots are laid down, and covered with litter or fern. Near Toulon it is not trained in this manner, but overspreads the ground in the manner of brambles. It is a trailing shrub, and in the southern parts of Europe, where it is found native, grows very abundantly out of the joints of old walls, the fissures of rocks, and amongst ruins. The stem is ligneous, sellding out many lateral branches; the shoots rise two or three feet, and then become procumbent. From under each of the branches proceed two crooked spines; immediately above these the petioles of the kidney-shaped leaves are produced. White flowers, growing on long peduncles, would, if allowed to remain, bloom through the summer; but before they expand, their buds, with the empalements, are plucked and used for pickling. A large quantity of these, which form a well-known pickle, is annually imported into England, from Italy and ports in the Mediterranean。

\section{SEASONING HERBS.}

VEgetables of this description are never used with any reference to their substantive qualities, as articles of food. They are employed merely for their flavour, forming subordinate ingredients in the culinary art, and are respectively applied in various combinations according to the slill or the pleasure of the operator.

Many of this class of plants were formerly much esteemed for their real or imaginary medicinal virtues, and some of them are in the present day considered of sufficient value to be ranked among pharmaceutic sinıples. 
Parsley-Apium petroselinum-was known to the Greeks, and received its distinctive name of $p e-$ troselinum from Dioscorides. It is said to be a native of Sardinia, whence it was brought into Eng land about the middle of the sixteenth century; but the plant is of so ancient culture in this country, that the period of its introduction cannot, perhaps, be accurately assigned, and though supposed not to be indigenous to Britain, it is now completely naturalized in various parts, both of England and Scotland. It is a hardy biennial plant.

The principal varieties are the common plainleaved, the curled-leaved, and the Hamburgh or broad-leaved. The plain-leaved parsley was the first known in this country; but it is not now much cultivated, since the leaves are not so handsome as those of the curled, are of a less brilliant green, and are coarser in flavour. Another reason for banishing it from the gardens is its resemblance to fool's-parsley, or lesser hemlock, Ethusa cynapium, which is a noxious weed of a poisonous nature, infesting gardens and fields. If this intruder were growing among plain parsley, an unobservant person might confound the leaves of the one with the other, although they differ somewhat in shape and colour; the leaves of the poisonous plant being of rather a darker green, and, if bruised, they emit an unpleasant odour, very different to that of parsley. When in flower they are easily distinguished, the athusa having an involucrum of three long, narrow, sharp-ponted leaflets, hanging down under every partial umuel, and vulgarly termed the bcard; while in the garden parsley there is usually only one leaflet at the general umbel, and at the partial umbel the involucrum consists of only a few short folioles, almost as fine as hairs.

Parsley is raised from seed, which is sown in the 
early part of spring, most generally in single drills, round the edges of any of the vegetable beds. 'The plants appear in three or four weeks, and soon the tender leaves are fit to be gathered for use; a succession springing forth and furnishing a supply throughout the whole of the year, till the ensuing May, when the flower-stalks begin to run, bloom, and bear seed in July or August.

Parsley has been supposed to be an effectual cure for the rot in sheep, provided it be given to them in sufficient quantities. Attempts were made some years ago to promote its extensive culture in fields for this purpose, under the auspices of the Society for the Encouragement of Arts, \&c. It is said that this specific was tried in Hampshire with success; and Mortimer ${ }^{*}$ mentions the cultivation of parsley, as a remedy against this destructive disease, being practised in Buckinghamshire. This herb, when used as food for sheep, imparts to their flesh, it is said, a very agreeable flavour $t$.

Hares and rabbits, we are told, will come from a great distance in order to indulge their taste for parsley; and in countries where these animals abound, in no situation does their favourite herb escape from their depredations unless securely fenced.

Purslane-Portulaca oleracea-was introduced from South America into this country in 1652. It was formerly held in more esteem, and was more cultivated, than it is at present.

Fennel - Anethum freniculum - is a plant of very ancient use, and if not native, is at least naturalized in England, where it is sometimes found growing on chalky soils. It is a perennial, rising to the height of five or six feet. The leaves are divided into a variety of fine, long segments, of a

* Mortimer's Husbandry, vol. i.

+ Campbell's Pol. Survey, vol. ii. 
bright green colour. Yellow flowers, growing in umbels, appear in July and August. The whole plant has a strong and disagrecable odour. Its light and delicately formed leaves are occasionally used as a garnish; and, when boiled, enter into the composition of certain fish-sauces.

Horse-RAdish-Cochlearia armoracia-is a native of some marshy situations in Britain, where it may be found of spontaneous growth. It has been long an inmate of our gardens, and is well known with its large oblong leaves, sometimes entire ronnd their edges, and sometimes deeply serrated. White, cruciform flowers, growing in loose panicles, bloom in the beginning of summer. This plant is made the object of careful cultivation among market gardeners, who find that its most congenial soil is a leep sandy loam. It is propagated by offsets, planted in February, and in the autumn of the ensuing year the roots are fit for use.

Min'T-Mentha-is a perennial plant, of which there are many species and varieties. They are all indigenous to Britain, and chiefly delight in low, moist situations. They are all more or less aromatic in the scent, and pungent in the flavour. Many of them yield sharp volatile oils by distillation. With very few exceptions, the whole of this description of plants is perennial, though the leaves in some, and the flowering stem in most, die down in the winter. They are all native plants, and their qualities are pungent and agreeable, not one of them being in the least degree poisonous; thus, whenever their taste is such that they can be used as giving flavour to food, that applicition may always be made with perfect safety. Much of the natural fragrance of the fields is owing to the Labiater, the family to which these sweet herbs belong. 'The various species of thyme impart their grateful odours to the arid 
wastes; the bainy calamint, and others of the same gemus, diffise their aromatic sweets over the cultivated fields; and the mints correct the effluvia arising from stagnant pools in marshy lands.

Spearinnt, or common mint-Mentha viridis,Pepperant-Mentha piperita,--and Penni-rovar. Mrnt-Mentza puleginm, - are the principal species of mint. All are propagated either by paring at the rnot, by offsets, or by cuttings. When designed for distillation, the stalls should not be gathered until they have attained their full growth and are beginning to bloom; they should then be used as soon as cut. The same roots will send forth annual stalks for many years without degenerating.

Tнуме-Thymus. Two species are found natives of Britain, the Thymus serpyllum and Thymus acinas; but that which is cultivated in our gardens, Thymus vulgaris, is a native of Spain, and other parts of Southern Europe. The climate of Spain seems peculiarly genial to the growth of all sweet herbs. A t Marvella, about midivay between Malaga and Gibraltar, De Laborde speaks of "sage, thyme, marjorum, lavender, myrtle, and rosemary, more than six feet high, embalming the air on all sides *." Thyyme was introduced into this country certainly before the mididle of the sixteenth century, but how long previous to that period is not ascertained. 'This herb is well known as a low shrubby evergreen, of a strongly aromatic odour. When of the largest growth it scarcely attains to a foot in height. Its ininute leaves are smooth and oval, and the flowers are smaller than those of the wild thyme. Three varieties are usually cultivated, and distinguished as the broad, the narrow, and the variegated leaved.

Two or three tufts of another species, the Lemol: Thyme-Thymus citriodorus - sometimes find a * De Laborles Spain, vol. iii. 
place in the herb compartment of the kitchen-garden. 'This is a trailing evergreen, of still sinaller growth than the common kind, and is remarkable for its smell, which resembles that of the rind of lemons, whence its distinctive name. Both the species thrive best in a dry soil. They are propagated most generally from seed; but they can likewise be multiplied by slips, or by parting the roots.

This herb is used in many savoury preparations. It was employed by the Romans to give its peculiar aromatic flavour to cheese- a practice pursued likewise with some flowers and seeds of other plants. This manner of preparing cheese was still continued during the middle ages. We collect this from an anecdote told of Charlemagne, who, travelling unattended, arrived at a bishop's palace. It was unfortunately a fast-day, and the only fare which the bishop would set before his royal guest, was bread and some choice cheese; this the king did not appear particularly to relish, picking ont with his knife small specks, which he mistook for unsound parts, but which, in fact, were parsley seeds. The prelate ventured to hint that he was throwing away the best parts of the cheese; when the monarch tasted it, and liked it so much, that he requested the bishop to send him an annual supply of this excellent flavoured curd; and, lest the cheese-merchant might by chance pack cheeses without any admixture of seeds, the king desired that they might always be cut in two, in order to ascertain the fact, and be then fastened together again with a skewer*. The mountaineers, in the canton of Glaris, in Switzerland, prepare a cheese known by the name of Schabzieger, which is readily distinguished by its peculiar marbled appearance and aromatic flavour; these are com-

* Foreign Review, and Continental Miscellany 
municated by the pressed flowers, or the bruised seeds, of the Melilotus officinalis.

SAGE-Salvia officinalis-is a native of the warmer parts of Europe, but it has long been cultivated in Britain. Gerarde notices it as being, in 1597, a well-known herb of the English garden. It is a hardy plant, but, though a perennial, does not last above three or four years without degenerating New plantations are readily made by cuttings of the young shoots taken in the latter end of spring.

This aromatic herb is chiefly used with the more strong and oily kinds of food, as a mixture in stuffings, and an ingredient in sauces. The leaves are sometimes introduced into English cheese.

A species of sage (Salvia pomifer a), of a very peculiar growth, is common to some of the Greek islands. It has firm fleshy tumours, of about threequarters of an inch in thickness, swelling out from the branches of the plant, and supposed to be produced in the same manner as oak-apples, by the puncture of an insect of the Cynips genus. These excrescences are semi-transparent, like jelly. They are called sage-apples, and under that name are always to be met with in the markets, as an article of ordinary sale. 'They are made into a kind of conserve, which is highly esteemed by the Greeks. Dr. Clarke, in the sixth volume of his travels, mentions having been regaled with this delicacy by the English consul, at the island of Syros, and he bears testimony to its excellence. This plant is considerably larger than the common sage of our gardens, and its flavour and smell are much more powerful. It grow's very abundantly in Candia, Syros, and Crete, where it attains to the size of a small shrub.

Clary-Salvia sclarea-is a biennial plant, a native of the south of France, of Switzerland, and of 
Italy. It was first introduced into English cultivation in the year 1562 .

Marjoran-Origanum. The common marjoram, or Origanum vulgare, is a native of Britain; it is a perennial under-shrub, growing among copsewood in calcareous soils. The leaves are small and acute. The flowers are slightly red, and appear in July and August, in smooth clustered spikes. The winter marjoram (Origanum heracleoticum) very much resembles the above species in appearance; but it is of a more aromatic flavour, and is always used in preference. It is indigenous to Greece, whence it was introduced into this country in 1640. A sheltered, dry situation is most favourable to its growth. The seeds of this, and of the two following species, seldom come to maturity in England. Winter marjoram is, therefore, usually propagated by cuttings. Sweet marjoram, Origanum majorana, was an inhabitant of the English garden about seventy years prior to the first cultivation in this country of the above species. It is a biennial, having its flowers growing in close knotted-like heads. As soon as it blossoms, this plant is cut and dried for winter use ; it must be renewed by seed annually, for which purpose the seed is imported from France and Italy into England. Pot marjoram, Origanum onites, was not introduced into English cultivation until the middle of the last century. It is a hardy perennial, with a hairy stem, rising to more than a foot high; it blooms from July to November, and is usually propagated by cuttings.

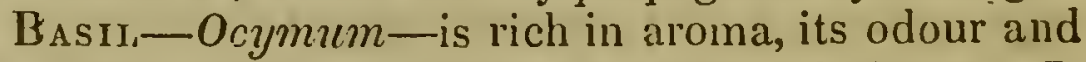
pungency being very similar to those of cloves. It is a favourite herb among French cooks, as giving an additional zest to highly-seasoned dishes. The leaves in small quantities are sometimes mixed in solads, or are made a flavouring ingredient in soups 
BaLm-Melissce officinalis-is a native of the south of France, and was introduced into this country in 1573 . It is a hardy perennial.

Balm was long famed for its merlicinal virtues; and although it has ceased to be invested with its former supposed potent qualities, it still retains a kind of posthumous fame, and "balm" has become the generic name for a soothing healer of wounds, both of the body and the mind. Balm was the plant which the adept Paracelsus selected from which to prepare his elixir vila, his primum ens melissa, whereby he was to renovate man; and, if he did not bestow on him absolute immortality, to produce a very close approximation to that state. Such strange conceits of ill-directed minds have, however, lougr gone by ; and balm, stripped of its fancied virtues, is now only employed as an infusion in preparing a cooling drink, or in giving flavour to a weak factitious wine.

There are other seasoning herbs which were once much esteemed in this country, but are now little used. Among these are, Tarragon, Chervil, Borage, Costmary, and Marigold. The lesves and flowers of these plants were in request for their slight aromatic taste; and they sometimes imparted their flavour to "cool tankards," and sometimes to soups and salads. 'There was a notion that they produced exhilaration of spirits, and some of them were called " comforters of the heart." The delusion has passed away, yielding in too many cases to more violent excitements, and in others to the conviction that the heart must derive its best comfort from a steady performance of our duties.

We cannot conclude this part of our volume without noticing that Saffron (a species of Crocus) 
was once largely cultivated in England to be used in cookery. We find it mentioned in the "Forme of Cury" of the time of Richard II.; and in the Northumberland Household Book. Harrison says, that the produce of an acre was usually worth $£ 20$. Such are the changes of taste, that a plant which was grown in fields to meet a general denand, is now entirely gone out of use. 


\section{C'hapter XV.}

\section{ESCULENT FUNGI.}

TuE fungi are a most singular class of productions, and their place in the kingdom of nature has been made a subject of much discussion among physiologists. Some refer them to the animal, some to the vegetable, and others to the mineral world; while one naturalist* has asserted that the fungi ought to be excluded from all these divisions and considered as intermediate beings. It would be foreign to our subject to give any abstract of the different arguments by which each party has supported his peculiar opinion. In the present day it is tolerably well established, and generally admitted, that the fungi are of vegetable production.

They have the habits of vegetables, but when analysed they yield the same products as animal matter, and in a state of putrefaction give out a similar odour. Ammonia, the phosphoric salts, and albumen, very analogous to that of animals, are found in the fungi. It might be supposed that such substances would be highly nutritious. This, however, is not the fact, as they are among the most indigestible of edibles. Most of them, when grown in aliy situation, and all of them in some situations, are hurtful and even poisonous. They differ from many noxious vegetables in this, that their poison cannot be separated by boiling, or even by distillation, which has been satisfactorily proved by the experiments of Parmentier.

$$
\text { - Necker's Mycitologia. }
$$


In the economy of nature the fungi are the attendants of decomposition. Their seeds are too minute for the eye, or even for the microscope, and therefore may be present every where undetected in the vessels, the fluids, and probably the solids of plants and animals. The instant vitality ceases in these, the seeds of the fungi come into action. Accordingly they are most abundant during autumn, in rank and shady places, and in rainy weather, when decayed plants and insects may be presumed most to abound.

This class of plants is still very imperfectly understoud, and the phenomena attendant on their growth cannot be explained. It has been found, by fatal experience, that some species, which are not poisonous when they grow upon an open and dry champaign, become so when they meet with stagnant water, putrescent plants, and dead insects.

The kinds which are used as esculents in Britain are principally the truffle, the morel, and some species of mushroom ; but in other countries, and especially in Russia, most species are eaten, even those which in Britain are the most poisonous, or at least the most acrid.

What the poison in fungi may be has not yet been accurately ascertained. Some of the boleti, which have the under sides of the caps formed of tubes instead of gills, yield even spontaneously crystals of oxalic acid, and others, as the champignon, are supposed to contain prussic acid. According to the analysis of Braconnot, fungi contain two peculiar substances, fungin and boletic acid. The nutritive part seems to reside in the fungin, and the poison and flavour in the acid, or at least in the juices of which the acid forms a part. Fungin is white, soft, and insipid; when burnt it smells like bread, and by distillation it yields a brown oil, water, ammonia, 
and charcoal. The charcoal contains phosphate of lime, some silica, with traces of phosphate of alumina, carbonate of lime, and sulphuretted hydrogen. Fungin, obtained from whatever species of fungi, has all these characteristics. This composition shows that it combines the nature of vegetable and of animal matter; and when it is allowed to putrify in water, it has first the odour of putrifying vegetable gluten, and then that of a putrid animal substance.

Boletic acid crystallizes in irregular white prisms, does not alter when exposed to the air, is soluble in forty-five times its weight of alcohol, or in one hundred and eighty times its weight of water, at the temperature of sixty-eight degrees. Its taste is like that of cream of tartar.

The propagation and growth of the fungi are among the most curious subjects in the economy of nature. Their seeds or germs, too minute in general to be injured by any mechanical, or dissolved by any common chemical, process, remain in the earth or in the substance of vegetables for an unlimited period of time; and they pass through the digestive organs of animals, or endure the action of heat, without sustaining the smallest injury. This is exemplified in paste made of flour, which produces mould or a species of fungi, as indeed does almost every vegetable and animal substance when it comes to a certain degree of decay, and this developement is only prevented by the action of the more active metallic saits. The fungi themselves, when they decay, are, as well as extraneous substances, subject in their turn to the attacks of other fungi.

iMontagu* mentions a case in which the membrane that separates the lungs of an animal from the rest of the viscera was covered with blue mould even

* Ornithological Dictionary, Att. Ducl., Scaup. 
before death; but the membrane itself was diseased, and the surface dead.

The rapidity with which the germs of the fungi develope themselves is quite as wonderful as the length of time, and the number of dangers, through which they will continue their dormant existence. To spring up "like a mushroom in a night" is a scriptural mode of expressing celerity, which accords wonderfully with observation. "I have often," says Sowerby, "placed specimens (of the phallus cani$n u s$ ) by a window, over night, while in the egrg-form, and they have been fully grown by the morning." He adds, "They have never grown with me in the day-time." From this and other analogous experiments, it is not ton wild a speculation to suppose, that if placed in the requisite circumstances as regards temperature, moisture, and absence of light, the whole earth would speedily be overrun with fungi.

These substances sometimes grow in a singular manner, a remarkable instance of which is furnished in the "fairy rings," which are found chiefly upon dry downs, and which are circles perfectly regular when the surface is uniform, but vanishing when they come to gravel or marsh. On these rings an innumerable array of fungi spring up in the latter end of summer.

When the fungi are in progress the grass withers, and the ring has the appearance of having been trodden by invisible feet: hence its name. The destruction is, however, only temporary ; for by the time that the rest of the grass is withered, that on the "fairy path" becomes green and vigorous, and a new circle is formed, next season, immediately outside. When two rings meet they do not cross each other, but unite and gradually become an oval; but if a circle be interrupted by any small obstacle, such as a tree or a stone, it will unite again on the 
other side. These rings are formed by various species of mushrooms, and also by some of the lycoperdons, or puff-balls; but the cause of the circular formation has not been satisfactorily explained. It would seem that the ground which has produced one crop of fungi is not immediately fit for the production of another, and thus the annual sowing is outwards. It also appears that the decayed matter of the fungi is favourable to the grass by which it is succeeded.

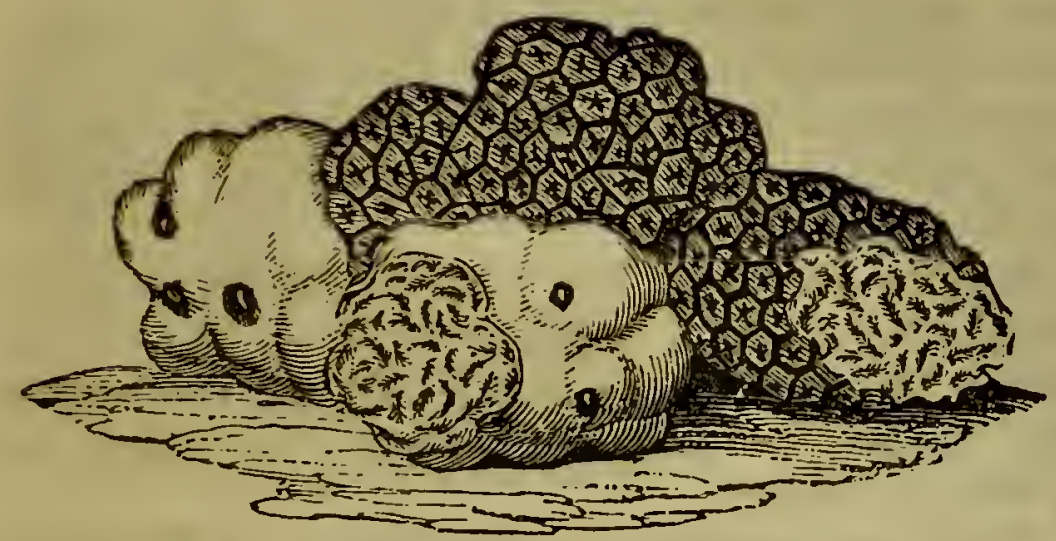

Blacl: and White Truftes.

The Trufrle-Tuber cibarium-is found growing in clusters some inches under the surface of the ground, in a soil which is composed of clay and sand. It is nearly spherical, and without any visible root; of a dark colour, approaching to black, and studded over with pyramidal tubercles. The internal part is firm, and grained with serpentine lines; its colour is white when young, but becomes black from age. Naturalists, who have examined its structure with microscopic attention, affirm that minute oval capsules, each containing from three to four seeds, are embedded in its substance. Truffes are natives of the woods both of Scotland and England; but they are not produced in the same 
abundance, nor do they attain to equal perfection, with those which grow in some parts of the Continent, and especially in Italy. When of more than three or four ounces in weight, they are considered large, for the production of this country; but it is said that, in Italy, some are occasionally found weighing from eight to fourteen pounds.

Since there is no appearance to indicate the particular spot where the truffles lie concealed, man calls the sagacious dog to assist him in his search after these subterraneous delicacies. With much pains this animal has been trained to discover them by the scent : if successful, he barks and scratches the ground-when the gatherer follows and digs up the object of his pursuit.

Truffles are used, like mushrooms, as an ingredient in certain high-seasoned dishes. They are estecmed the best of the fungi, but are confined in their locality, and have not hitherto been distributed by artificial culture.

They are common on the downs of Wiltshire, Hampshire, and Kent.

The Morel-Phallus esculentus-is a spheroid; hollow within, reticulated with irregular sinuses on the surface, and of a yellowish colour, standing on a smooth white stalk, the whole rising to the height of about four inches. 'The substance, when recent, is wax-like and friable. It is used in the same manner as truffles; and, when gathered dry, will keep for several months. The morel is a native of Britain, growing in damp woods and moist pastures, and coming to perfection in May or June. Gleditsch mentions, that in some woods in Germany this fungus har been found in the greatest perfection in those parts where charcoal had been made. Acting upon this hint, the morel gatherers were accustomed 10 make fires in certain spots in the thicket; but 
these were sometimes attended with such serious consequences, that the magistrates felt it necessary to interfere and forbid the practice.

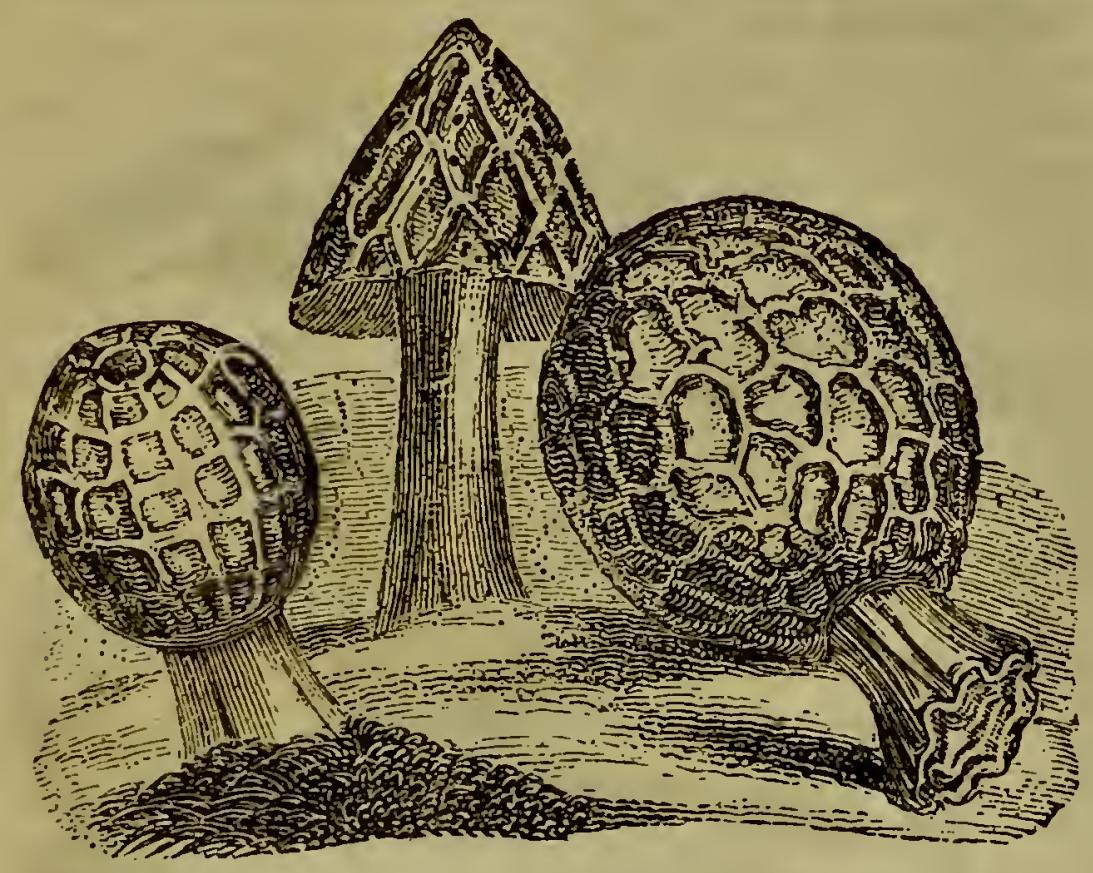

Morelles-Phalli esculenti.

The morel is not, like the mushroom, made an object of culture; but Lightfoot says that he has raised it from seed.

The Field Mushroom-Agaricus campestris-is the only species which is cultivated in this country. The stem of this fungus is short, solid, and white, marked a little below the cap with a prominent ring. the remains of the curtain which covers the gills in their early stage. The cap is at first white, regularly convex, and a little turned in at the edge : as it advances in growth the surface becomes brown, scaly, and flattened. 'The flesh is white, firm, and solid; the gills are loose, reaching to the stem on all sides, but not touching it. When young these are of a pinky red, but change to a liver colcur about the 
same time that the cap alters its form, and the upper surface also changes colour. The latter circum. stances distinguish it, in this stage, from the darkgilled toad-stool, with which it might otherwise be confounded.

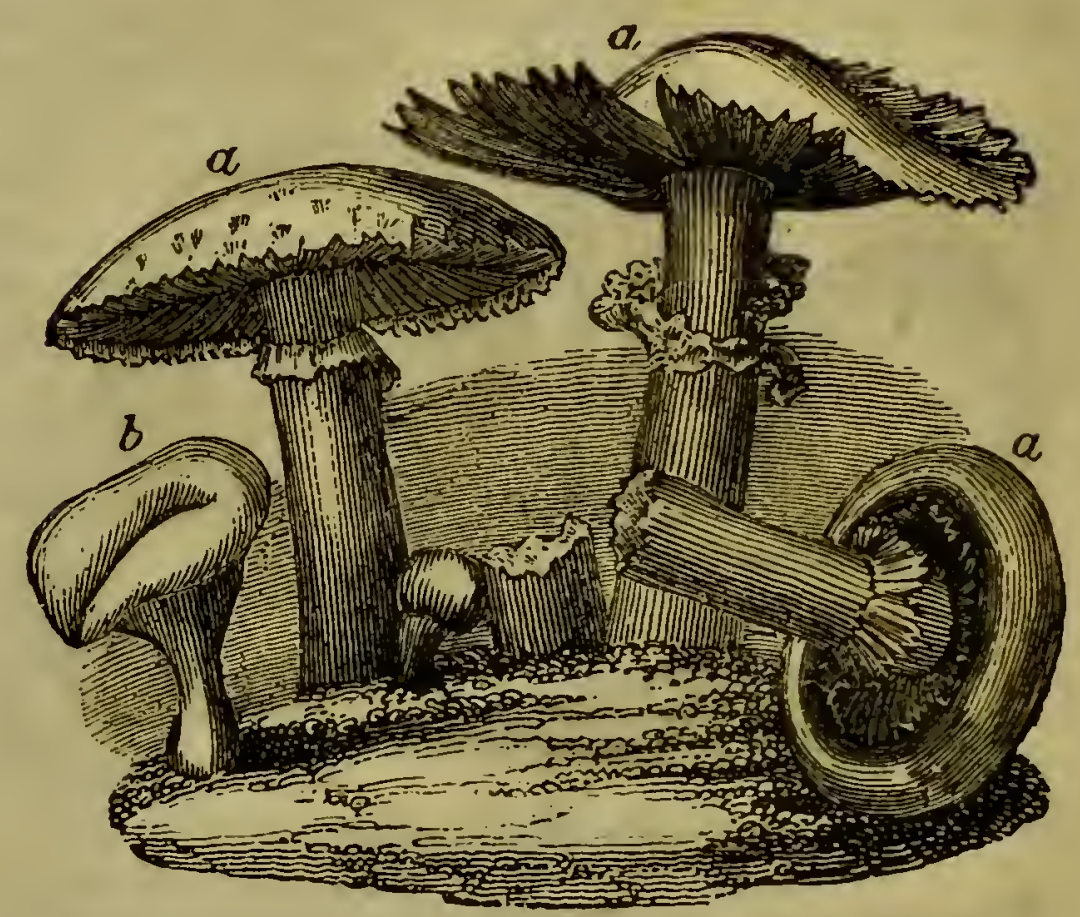

Common Mushrooms. a, a, a, Agaricus campestris. $b$, Agaricus auruntiacus.

Mushrooms of this species vary very much in size, some being not more than two inches in diameter, others as much as eight or nine inches, and a few reaching to much larger dimensions. We are told that, in some parts of the northern counties, one mushroom was gathered which measured thirty-four inches in circumference, and weighed one pound. Another, measuring almost thirty inches in circumference, weighed one pound one ounce*; and a third, thirty-two inches in circumference, and ten

* 'Newcastle Courant,' Sept. 13, 1828 
inches round the stem, weighed as much as one pound eight ounces*.

The mushroom is chiefly used to communicate its peculiar flavour to ragouts, or is served up by itself, prepared with rich gravy. The " button," or fleshy part, is the only portion employed, the stem, gill, and skin being removed. One very general application of mushrooms is, in converting them into the sauce called catsup. For this purpose they are laid for some time in salt, by which means a juice is extracted which is afterwards boiled with spices.

'The places in which mushrooms chiefly grow are dry and rich old pastures, where they are ga thered in the months of August and September. Their powers of vegetation are extremely strong; this is instanced by the following circumstance.

Some men in the Isle of Wight, a few years ago, observed a large stone rising considerably at the interstices, and upon removing the pavement to discover the cause, found it to be occasioned by a mushroom, the vigorous efforts of which, to increase upwards, had forced the stone from its proper station $\dagger$

In some parts of the country mushrooms are to be found in great abundance, and sometimes under circumstances and situations very unexpected. Some cultivators of a patch of potatoes situated in a fiela in Derbyshire, proceeding to dig up their crop found, to their great surprise, that a large quantity of fine mushroems had sprung up among their potatoes, and in a small space of ground they gathered at least five pecks. The ground, previously to planting the potatoes, had been dressed with roadscrapings, and with a small quantity of moss tiken

* 'Manchester Herald,' Sept. 1827.

t (iard. Mag. vol. iv. 
from off an old building*. Indeed, in no case does it appear absolutely necessary to sow the visible seeds of these fungi. They seem to be existent almost everywhere, and all that is wanted is to induce the circumstances proper for their germination.

Four or five years ago, during a few weeks in the autumn, such an abundant supply of " this voluptuous poison" was brought for sale to Preston, that immense quantities were sold at from threepence to fourpence per peck, and the smallest kind, for pickling, at twopence per quart. Cart-loads were purchased for the Mancl.ester markets $\dagger$.

Although of so spontarecus and abundant growth in some situations and seasons, yet, to obtain a regular and unfailing supply, mushrooms are, in most large gardens, raised artificially from the spawn, or seed, in an incipient state of growth ; but wild mushrooms from old pastures are generally considered more delicate in flavour than those obtained by garden culture. Mushroom spawn is a white fibrous substance, running like broken threads in any nidus which is fitted to nourish it; this, scattered on beds dressed with stable manure, and skilfully managed, produces a very plentiful crop of mushrooms. Many methods are pursued and recommended by different cultivators; but it would lead us wholly beyond our province to attempt any description of these.

Besides the cultivated mushroom, about a dozen other species growing in England are described by botanical writers as esculent.

The Champignon - Agaricus pratensis-has a solid stem, like the common mushroom, with the cap of a pale brown at the upper surface, and the gills yellowish. It grows on more moist land than

* Flemıng's Brit. Farm. Mag., November, 1826.

f Preston Pilot; Gard. Mag. 


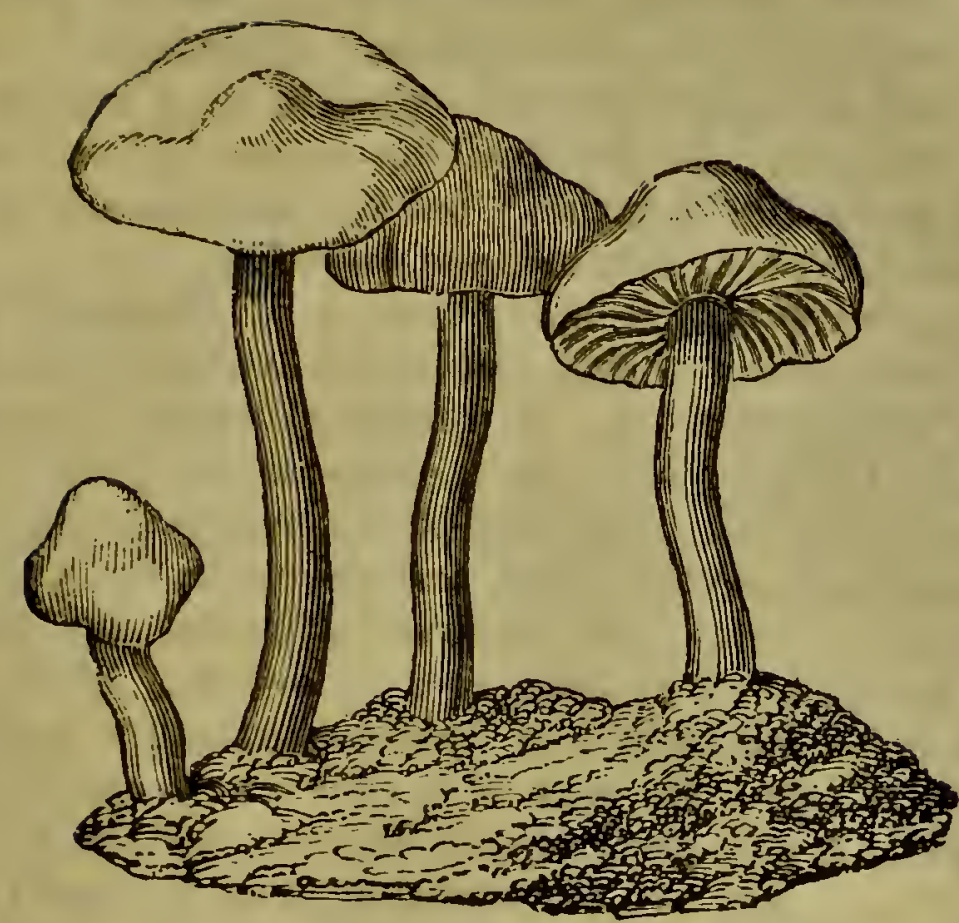

Champignons-Agaricus pratensis.

the common mushroom, and therefore is, in itself, to be looked upon with some suspicion. There is, however, another circumstance which renders the eating of this mushroom unsafe. On the upper surface it very much resembles the most poisonous of all the toad-stools, agaricus virosus, and they both grow in similar situations. The gills of the poisonous fungus are, however, broader, in proportion to the size of the plant, than in the champignon, and they are very dark-coloured, or black. 'The fleshy part of the cap is also thinner, and there is a collar on the stem of the poisonous one, while that of the champignon is naked. Many of the different species of agaricus are, however, so similar to each other, some being wholesome, while others are highly noxious, that persons who are not perfectly familiar with all their respective characteris- 
tics should hesitate before they venture to gather the mushroom for consumption. In judging of the qualities of a mushronm, the smell is not a perfect or safe criterion. If the smell be nauseous, that is a good ground of rejection; but the opposite odour is no decided proof of innoxious qualities.

In other countries many species of fungi are not only considered edible, but are likewise made the objects of cultivation. A species of boletus is raised by the Italians, for which purpose two kinds of stones are used. The one of calcareous formation, containing vegetable fibre, and found in the chalkhills near Nuples; the other an indurated turf, from the volcanic mountains near Florence. Both of these have the quality of imbibing moisture, and if either of them be kept in a cellar and constantly watered, it will produce this fungus; but the water with which they are moistened must occasionally be that in which the boletus has been washed, and in which, of course, its seeds are contained. This proves that, under particular circumstances, some fungi have the power of elaborating their own substance out of moisture and the atmosphere*. At Brescia one species of fungus, Amanita incarnata, is produced from the bruised fragments of the mushroom. The Agaricus, ostreatus, another edible species, is obtained from the husks of the berries of the sweet bay, Laurus nobilis; after the oil has been extracted by boiling, the husks are buried in a trench, and are then submitted to considerable pressure, and covered with a layer of earth about half a foot thick, and the whole is protected from excessive rain. From this trench muslirooms will spring up in October, and afford a supply during that and the two following months, for three successive years. At Genoa mushrooms are produced in a similar

- See Transactions of the Swedish Academy, for 1797. 
marmer, by using the refuse of the olive-oil presses. In the Landes of the south of France, the earth under oak-trees is sometimes kept continually moist by water in which the Boletus edulis has been boiled, whence, it is said, arises an abundant crop of that species, which we are told resembles the cocoanut in taste*.

The Agaricus muscarius is used by the inhabitants of the north-eastern part of A.sia, in the same manner as ardent spirits or wine, to promote intoxication. This species, which is a native of Britain, abounding in the woods of the Highlands of Scotland, is one of the largest and most beautiful of the agaric tribe. It has a large cap, nearly flat, of a brilliant pink or a crimson colour, sometines beset with angular warts, and " is extremely conspicuous, even at a distance, in the shaded recesses of its native woods." It is the favourite drug, moncho-more, of the Russians, Kamchadales, and Korians, who use it to proinote intoxication. "These fungi are collected in the hottest month, and hung up by a string in the air to dry; some dry of themselves on the ground, and are said to be far more narcotic than those artificially preserved. Small deep-coloured specimens, thickly covered with warts, are also said to be more powerful than those which attain to a larger size, and are of a paler colour.

"The usual mode of taking this fungus is to roll it up like a bolus, and swallow it without chewing, which the Kanchadales say would disorder the stomach. It is sometimes eaten fresh in soups and sauces, and then loses much of its intoxicating property. When steeped in the juice of the berries of Vaccinium uliginosum, its effects are the same as those of strong wine. One large, or two small fungi, is a common dose, to produce a pleasant intoxication Ball. Univ. October. 1827. 
for a whole day, particularly if water be drank after it, which augments the narcotic principle. The desired effect comes on one or two hours after taking the fungus. Giddiness and drunkenness result from the fungus in the same manner as from wine or spirits. Cheerful emotions of the mind are first produced, involuntary words and actions follow, and sometimes, at least, an entire loss of consciousness. It renders some persons remarkably active, and proves highly stimulant to muscular exertion; with too large a dose violent spasmodic effects are produced.

"So very exciting to the nervous system in some individuals is this fungus, that the effects are often very ludicrous. If a person under its influence wishes to step over a straw or small stick, he takes a stride or a jump sufficient to clear the trunk of a tree ; a talkative person cannot keep secrets or silcnee, and one fond of music is perpetually singing *."

- Malical izotany, No. 43, p. IEC. 


\section{Chapter XVI.}

Some of the most important circumstances in the history of mankind have arisen out of their desire to possess the luxuries of distant countries. This desire has sometimes appeared to interfere with human happiness, by engendering wars of commercial rivalry;-but upon the whole it has steadily advanced civilization by binding nations together by ties of mutual interest. If we were to follow out this observation, the history of Spices, of Coffee, of Tea, of Sugar, would form a large and instructire volume. But we cannot so treat the subject here, whatever we may do at some future time in accounts of nations such as the Hindoos and the Chinese. We must here content ourseives with a brief sketch of each production, to complete our notice of "Vegetable Substances used tor the food of man."

\section{SPICES}

THE plants which produce the more esteemed of these are all natives of tropical climates; and, with the exception of some of the capsicums, none of them can be fruited in the open air in this country, nor can the choicer sorts he brought to maturity even by artificial heat. These substances are either simply hot and acrid, in which case they get the name of peppers, or they have aromatic flavour in addition; and when they have this, they are called spices,-though, in some cases, the names are applied indiscriminately to the same substance. 
Spices have always been regarded as luxurious acquisitions, while their small comparative bulk, and consequent facility of transport, caused them to be anong the first articles of commerce obtained from remote countries. The inhabitant of more temperate regions has therefore, for ages, been in the enjoyment of most of the delicious aromatics, fostered by a tropical sun.

The higher classes of the Romans used spices in more costly profuseness than the moderns, though the better knowledge of navigation, by producing a direct and frequent intercourse between nations, has now caused them to be sufficiently cheap to place them within the reach of all ranks of society.

Among the ancients, spices of all kinds, as well as frankincense and myrrh, were made to lend their perfume to the wreathed smoke which ascended both from the altars of their gods, and the funereal piles of their nobles. Prodigious quantities of frankincense and spices were thus consumed at the funeral of Sylla; and Nero is said to have lavished more than a whole year's supply in celebrating the obsequies of his wife Poppæa. The country of the Sabeans, situated in Arabia Felix, was celebrated for the abundance of these aromatic plants. "Among this people," says Pliny, " no other kinds of wood but those which sent forth sweet odour were used as fuel, and they cooked their food with the branches of trees yielding frankincense and myrrh*." The very ocean, it was said, was perfumed with the fragrance of their spices and aromatics. Agatharchides, an ancient author, who wrote about two thousand years ago, gave a glowing description of this country. It is probable that his panegyric suggrested to Milton the following simile :-

* Pliny, lib. xii. cap. 18. Tacitas, Ann. lib. xvi. cap. 6. 
"As when to them who sail

Beyond the Cape of Hope, and now are past

Mozambic, off at sea north-east winds blow

Sabean odours from the spicy shore

Of Araby the Blest : with such delay

Well pleased they slack their course, and many a league

Cheered with the grateful smell, old Ocean smiles."

Although the ancient writers all agree that Arabia Felix has thus obtained its name from its odourbreathing plants, it is probable that their accuunts are mostly fabulous, and that being but imperfectly acquainted with the regions beyond, they concluded that the country whence they procured their spicy luxuries must, of necessity, be the country of production. The spices which Queen Sheba presented to Solomon* were not known in Jerusalem, and were probably obtained from Ceylon, or the islands still farther to the east. It is, however, most certain, that, with but one or two exceptions, those of familiar use among the moderns were all originally derived from these latter countries.

Cinnamon-Laurus Cinnamomum-is said to be indigenous only to the island of Ceylon, and even there confined to a small district in the south-western part of that island. 'There are however doubts, whether the inferior sorts, found in other places, known by the name of Cassia, and considered by botanists as a distinct species (Laurus Cassia), be not the very same tree, deteriorated by being produced on a soil and in a climate less adapted for the developement of its finer qualities. Whether it be cinnamon or cassia, the bark of the tree, freed from the external part, forms the spice.

Although, ever since the Dutch first had a settle* Chron. ii. 9. 


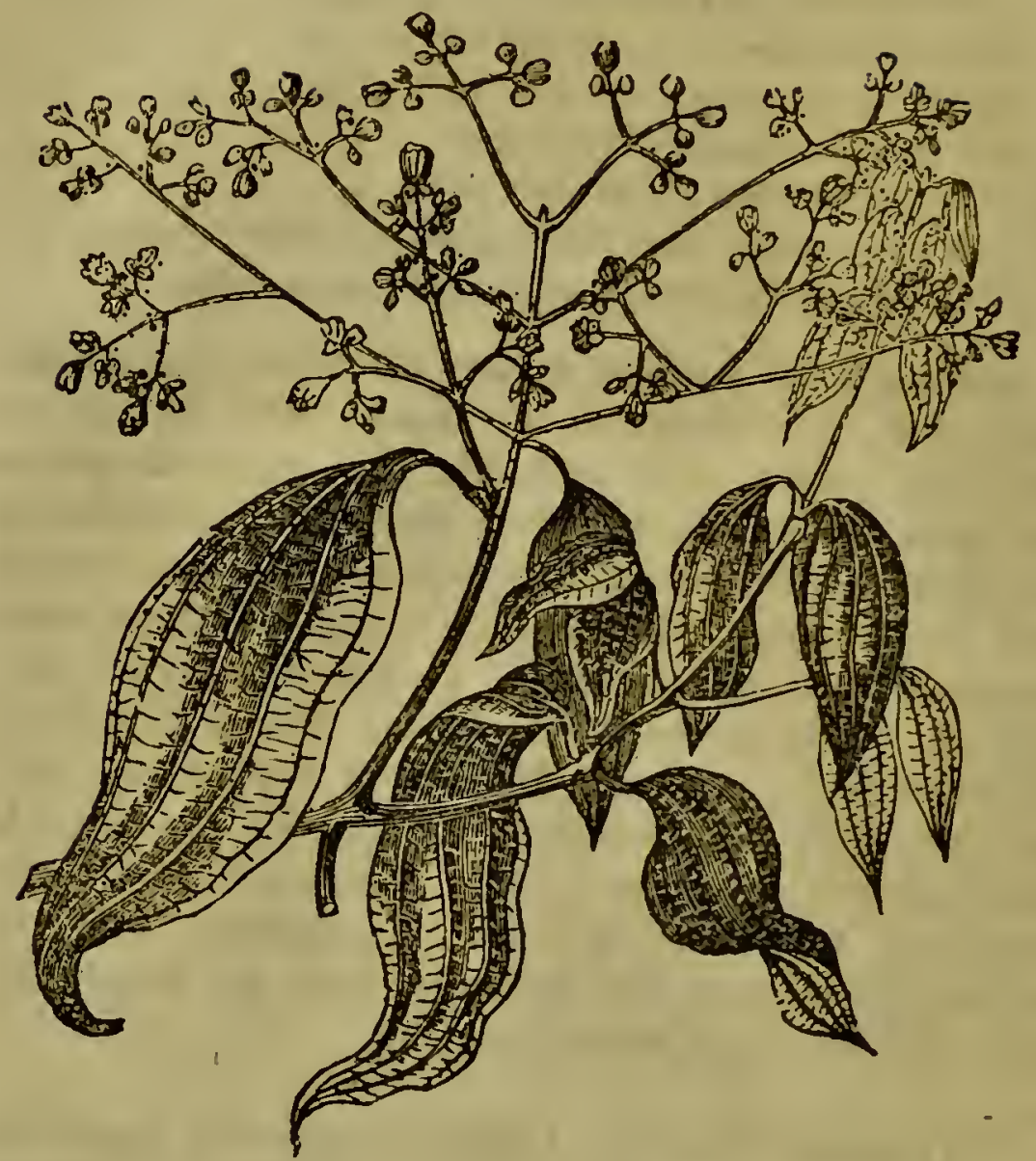

True Cinnamon-Laurus cinnamonum.

ment in Ceylon, cinnamon was nade by them a lucrative article of trade, and one which they strove by every means wholly to monopolize, this tree was not made by thein an object of cultivation in Ceylon until 1766. Before that period cinnamon was collected in the forests and jungles, since an idea prevailed that its excellence depended on its sfontancous growth, and that if once subjected to culture it would no longer be genuine.

When Falk was appointed Governor of Ceylon, he felt the inconvenience of depending for a regular supply on such a resource, the more especially as the 
greater part of the cinnamon-trees lay in the dominions of the King of Candy, who frequently, with or without apparent reason, refused the cinnamon peelers admission into his dominions, and the Dutch were, in consequence, often restricted to less than half their required annual exports.

Governor Falk, in his attempt to remedy this evil, by cultivating the cinnamon-tree in the territory belonging to the Dutch, was discouraged by the prejudices of the natives, and discountenanced by the parsimony of the Supreme Government of Batavia. It was said, " for one hundred and fifty years Ceylon had supplied the requisite quantity of cinnamon, the expense of which was ascertained and limited: why then risk the success of a new plan, attended with extraordinary charges." This public-spirited governor nevertheless persevered in his undertaking, and to his success the English owe the flourishing state in which they found the cinnamon plantations of Ceylon, when they captured that island. This tree is now cultivated in four or five very large gardens, the extent of which may in some measure be imagined by the quantity of cinnamon annually exported thence, amounting to more than $400,000 \mathrm{lbs}$.; and from the number of people who are employed in the cinnamon department, these being from twenty-five to twenty-six thousand persons *.

The trade in this produce had always been a monopoly; during the government of the Dutch this was enforced with an excessive degree of rigour, at which humanity revolts. It is painful to contemplate man, wnen greediness for exclusive gains, the meanest of all motives, incites him to acts of oppression and tyranny. "The selling or giving away the smallest quantity of cinnamon (even were $\mathrm{i}^{*}$ bull

- Frans, of the Royal Asiatic Society, vol. I. 
a single stick), the exporting of it, the peeling of the bark, extracting the oil either from that or the leaves, or the camphor from the roots, except by the servants of government, and by their order, as well as the wilful injuring of a cinnamon-plant, were all made crimes, punishable with death, both on the persons committing them, and upon every servant of government who should connive at it *."

In order to keep up the price of the spices, the Dutch government was formerly accustomed to have these destroyed, when supposed to be accumulated in too large quantities. Sometimes, it was said, this oriental produce was thrown into the sea, and sometimes the work of destruction was accomplished by other means. M. Beaumare relates, that on the 10th June, 1760, he beheld, near the Admiralty at Amsterdam, a blazing pile of these aromatics, which were valued at eight millions of livres, and an equal quantity was to be burnt on the ensuing day. The air was perfumed with this incense, the essential oils, freed from their confinement, distilled over, mixing in one spicy stream, which flowed at the feet of the spectators; but no person was suffered to collect any of this, nor on pain of heavy punishment to rescue the smallest quantity of the spice from the wasting element!

When in its natural state, the cinnamon-tree attains to the height of twenty or thirty feet, sending forth large spreading branches, clothed with thick foliage. The leaf, when first developed, is.partly of a bright red, and partly of a pale yellow; it soon, however, assumes a verdant hue, and when at its full growth is on the upper surface of a dark olive colour, and on the under side of a lighter green; it somewhat resembles that of the Day, but is 'onger

* Bertolacci's Ceylon, p. 241. 
and narrower. The flowers bloom in January; they grow on footstalks, rising from the axillæ of the leaves, and the extremities of the branches, clustering in bunches, which resemble in size and shape those of the lilac, but they are white, with a brownish tinge in the centre; these are followed by one-seeded berries, of the shape of an acorn, but not so large as a common pea. When first gathered their taste resembles that of the juniper-berry. When dry, this fruit becomes merely a thin shell, containing a kernel about the size of an apple-seed. The smell of the flowers, though not powerful, is extremely fragrant. 'The footstalks of the leaves have a strong flavour of cinnamon. 'The fruit, if boiled, yields an oil, which when cold becomes a solid substance like wax, and is formed into candles; these emit an agreeable odour, and in the kingdom of Candy are reserved for the sole use of the court.

The trees which are cultivated are kept as a sort of coppice, and numerous shoots spring apparently from the roots; these are not allowed to rise higher than ten feet. We are told, that "when the trees first put forth their flame-coloured leaves and delicate blossoms, the scenery is exquisitely beautiful." In three years after planting each tree affurds one shoot fit for cutting, at the fifth year from three to five shoots may be taken, but it requires the vigour of eight year's' growth before it yields as many as ten branches of an inch in thickness. From the ages of ten to twelve years is the period of its greatest perfection; but its duration of life is not limited, as the root spreads, and every year sends up new shoots or suckers.

'Trees which grow in rocky situations, and the young slioots. when the leaves are of a reddish colour, yield the best and most pungent aromatic bark. The tree is known to be in the best state 
when the bark separates easily from the wood, and has the inside covered with a mucilaginous juice; but if that be not carefully removed, the flavour 0 the spice is injured. The shoots are cut when from half to three-quarters of an inch in thickness, and in lengths of from two to three feet. Many hands are employed in this work; each man is obliged to furnish a certain quantity of sticks. When this part of his task is fulfilled, he conveys his fragrant load to a shed allotted for the purpose, where the bark is instautly stripped from the wood, and freed from the epidermis, which is scraped off. The fragrance diffused around, during this process, is described as being extremely delightful; but in parts of the plantation remote from this spot, unless the trees be agitated with violence, the peculiar smell of the cinnamon cannot be distinguished*. The wood, deprived of the bark, has no smell, and is used as fuel.

When the bark is perfectly cleansed it is of a pale yellow colour, and about the thickness of parchment. It is then placed on mats, to dry in the sun, when it curls up, and acquires a darker tint. The smaller pieces are then put inside the larger, and the whole close together into the tubular form in which it is sold in the shops. When the rind, or part forming the cinnamon, is first taken from the tree, it is described as consisting of an onter portion which tastes like common bark, and an inner portion, which is very sweet and aromatic. In the course of the drying, the oil of the inner portion, on which the flavour depends, is communicated to the whole; and the quality of the entire bark is understood to depend more upon the relative quantities of those portions of the bark than upon anything else. The cinnamon of Ceylon has the outer

* Cordiner's Ceylon. 
portion much thinner, in proportion to the inner, than the cassia of other countries; and to that its higher pungency is attributed.

Under fuvourable circumstances, the cinnamontree yields a large and a small liarvest every year. The large one is obtained soon after the fruit is ripe; that is, when the tree has again pushed out shoots, and the sap is in vigorous circulation. May and $J$ une are the best months in the year for the great harvest; in November and December the little harvest is obtained. In those plantations which belong to government, however, there is but one harvest, beginning in May, and ending in October.

Though cinnamon has found a place in our Pharmacopœia, the purpose to which it has been applied by the South Americans invests it with medicinal properties which it is not usually supposed to possess. "One thousand bales $(92,000 \mathrm{lbs}$.) are said to be consumed annually by the slaves in the mines of South America. Each receives daily a certain quantity, cut into pieces one inch in length, which he eats as a preservative against the noxious effluvia of the mines*

Oil of cinnamon was formerly obtained at Colombo, from distilling the fragments broken off in packing ; latterly a great proportion has been made from coarse cinnamon unfit for exportation. A very small quantity of oil is contained in the bark ; three hundred pounds of which are required to yield twenty-four ounces of oil $t$, and consequently this is extravagantly dear. When made from the finest cinnamon its specific gravity is greater, but from the coarse sort it is less than that of water.

CASSIA-Laurus cassia-is a native of several parts of the south of Asia, but it is chiefly brought from China as an article of commerce. The bark

$$
\text { * Cordiner's Ceylon. }
$$

t Ibid. 
and buds are known in commerce as cassia lignea and cassia buds; these have the same aroma though in an inferior degree to cimnamon, and it is said that they are in many cases very extensively substituted for the latter. They are both imported into this country to a very large amount.

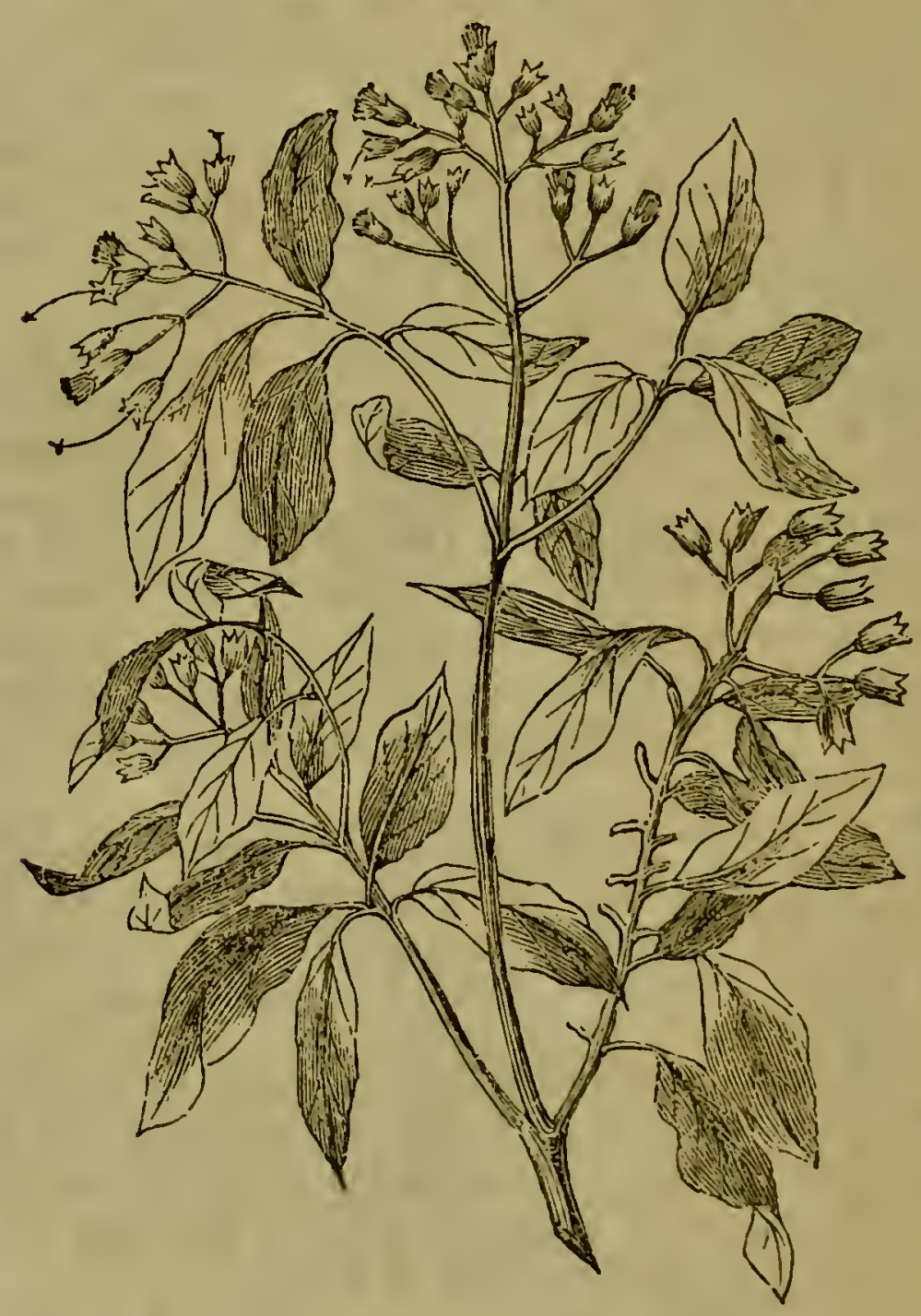

The Clove-Caryophyllata.

The Clove-Caryophyllatus aromaticus-is native of most of the Molucen islands, where it has 
been produced, from the earliest records, so abundantly, that in exchange for their spicy produce, the inhabitants were enabled, before the intrusion of the Europeans into their country, to procure for themselves the productions which they required of almost every other region. Although Europeans have for more than two thousand years known the use of this spice, yet little more than three hundred years back they were ignorant whence it was obtained. The Persians, Arabians, and Egyptians formerly brought cloves and nutmegs to the ports in the Mediterranean, and hither the Venetians and Genoese resorted to buy the spices of India, until the Portuguese, in 1511, discovered the country of their production. This nation did not, however, long enjoy the fruits of its discovery; the Dutch soon drove them from the Moluccas, and for a long time retained a very strict monopoly over the productions of these islands. It is said that they destroyed the clove trees growing on the other islands, and confined their culture wholly to Amboyna. They allotted to the inhabitants four thousand parcels of land, on each of which it was expected that one hundred and twentyfive trees should be cultivated; and in 1720 a law was passed compelling the natives to make up this number: there were in consequence five hundred thousand clove-trees planted in this small island, each of these on an average produced annually more than two pounds of cloves, so that the aggregate produce weighed more than a million of pounds. Subsequently to this period, the policy of the Dutch somewhat relaxed, and the tree has been suffered to grow on other islands, and even to be carried to the West Indies; where, however, it does not appear until very lately to have succeeded. Sir Juseph Banks introduced it into this country about 1797, 
but of course it is raised here only as a mere ornament or curiosity of the hothouse.

The clove is a handsome tree, somewhat like the bay tree in some of its characters, though the leaves more nearly resemble those of the laurel. The flowers of the clove grow in bunches at the very extremity of the branches; when they first appear, which is at the beginning of the rainy season, they are in the form of elongated greenish buds, from the extremity of which the corolla is expanded, which is of a delicate peach-blossom colour. When the corolla begins to fade, the calyx turns yellow, and then red: the calyces, with the embryo seed, are in this stage of their growth beaten from the tree, and after being dried in the sun, are what are known as the cloves of commerce. If the fruit be allowed to remain on the tree after arriving at this period, the calyx gradually swells, the seed enlarges, and the pungent properties of the clove are in great part dissipated. Each berry contains only one seed, which is oval, dark coloured, and of a considerable size. It is a long time before a clove-tree yields any profit to the cultivator ; it rarely producing fruit till eight or nine years after being first planted.

The whole tree is highly aromatic, and the footstalks of the leaves have nearly the same pungency as the calyx of the flowers. "Clove-trees," says Sir T. Raffles, "as an avenue to a residence are perhaps unrivalled-their noble height, the beauty of their form, the luxuriance of their foliage, and above all, the spicy fragrance with which they perfume the air, produce, on driving through a long line of them, a degree of exquisite pleasure only to be enjoyed in the ciear light atmosphere of these latitudes."

Cloves contain a very large proportion of essential oil, larger perhaps than any other plant or parts of a 
plant. This oil is extremely pungent, and is one of the few essential oils which is specifically heavier than water. It is usually procured by distillation, but when the cloves are newly gathered it may be obtained by pressure. A part is often so taken, and the cloves, which are thereby rendered of little value, are fraudulently mixed with sound ones; but the robbed cloves are easily detected by their pale colour, shrivelled appearance, and want of flavour.

The pungent and aromatic virtues of the clove reside in this essential oil, combined with the resinous matter of the spice; but it does not appear that these qualities are absolutely necessary to the growth or fructification of the tree. To give to this its greatest value, it must, however, be cultivated in a situation where they can be elaborated in the greatest quantity. Its profitable growth is therefore limited to a very narrow range of temperature and climate; as the clove loses its flavour if the situation be too moist or too dry, too near the sea, or too much elevated above its level. Though the tree be found in the larger islands of Eastern Asia and in Cochin China, it has there little or no flavour. The Moluccas seem to be the only places where the clove comes to perfection without cultivation.

This tree is so great an absorbent of moisture that no herbage will grow under its branches; while the cloves, when gathered, if placed in a heap near a vessel of water, are found very much to have increased their weight at the end of only a few hours, in consequence of the large portion of water which they lave attracted and imbibed. It is said that both the grower and trader in cloves avail themselves of the knowledge of this fact, and since this spice is always sold by weight, thus give a factitious value to their goods. 


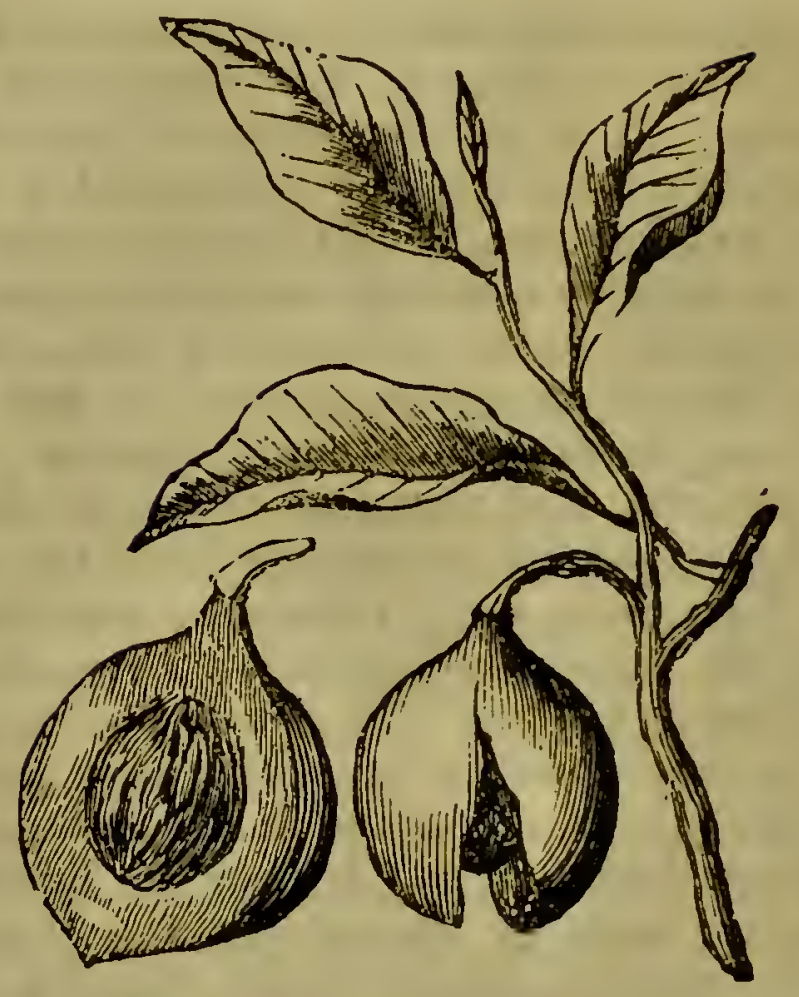

Nutmeg-Myristica moschata.

The Nurmeg-Myristica moschata-is likewise a native of the Moluccas, and after the possession of these islands by the Dutch, was, like the clove, jealously made an object of strict monopoly. Actuated by this narrow-minded policy, the Dutch endeavoured to extirpate the nutmeg-tree from all the islands except Banda; but it is said that the woodpigeon has often been the unintentional means of thwarting this monopolizing spirit by conveying and dropping the fruit beyond these limits; thus disseminated, the plant has been always more widely diffused than the clove. This tree grows in several islands in the Eastern Ocean, in the southern part of both peninsulas of India, and it has been introduced into the Mauritius and some other places. It was for a long time supposed that though the plant 
could be transplanted, the peculiar aroma of the nut, which gives to the tree its commercial value, was weakened, if not entirely lost, when this was removed from its native soil, and that, as a spice-producing tree, it, as well as the clove, was confined to the same narrow locality to which the clove was said to be restricted. In Sumatra, however, it has been successfully cultivated to a large extent. Sir Thomas Raffles gives an account of the plantation at Bencoolen in 1820: "Out of the number of one hundred thousand nutmeg-trees," he writes, "one fourth are in fullbearing, and although their culture may be more expensive, their luxuriance and produce are considered fully equal to those of the Moluccas." An attempt has been made at Trinidad to naturalize there the clove and the nutmeg; and, very recently, samples of these spices produced in that island have been transmitted to England for the inspection and approval of the Society for the Encouragement of Arts, \&c. The opinions of the best judges have been taken with respect to their quality as compared with the Oriental produce, and, in consequence of a most favourable report, the gold medal of the Society has been awarded to the western cultivator of these spices; while sanguine hopes are entertained that the clove and the nutmeg will one day be perfectly acclimatized in the tropical regions of the Western Hemisphere. The nutmeg-tree, as well as the clove, was introduced into this country by Sir Joseph Banks as an ornamental hot-house plant.

Two spices are obtained from the nutmeg-treenutmeg, which is the kernel of the fruit; and mace, which is the membranous tunic or covering immediately investing the thin black shell in which the nutmeg is contained; the whole is enveloped by the external portion of the fruit in the same manner as the stone of a neach is by the pulp. This tree is 
larger than that of the clove; the leaves are more handsome in the outline, and are broader in proportion to the length. They are of a fine green on the upper surface, and grey beneath. When the trees have attained the age of about nine years they begin to bear. They are dicecious, having male or barren flowers upon one tree, and female or fertile upon another. 'The flowers of both are small, white, bell-shaped, and without any calyx; the embryo fruit appearing at the bottom of the female flower, in the form of a little reddish knob. The female flowers grow on slender peduncles, two or three together, but it is rare that more than one flower in each bunch comes to maturity and produces fruit; this resembles in appearance and size a small peach, but it is rather more pointed at both ends. The outer coat is about half an inch thick when ripe, at which time it bursts at the side and discloses the spices. These are-

The Mace, having the appearance of a leafy network of a fine red colour, which seems the brighter by being contrasted with the shining black of the shell that it surrounds. In general, the more brilliant its hue the better is its quality. This is laid to dry in the shade for a short space; but if dried too much, a great part of its flavour is lost by evaporation, while it is also more apt to break in packing On the other hand, if packed too moist, it either ferments or breeds worms. After being dried, it is packed in bags and pressed together very tightly.

The Nutmeg. The shell is larger and harder than that of a filbert, and could not, in the state in which it is gathered, be broken without injuring the nut. On that account the nuts are successively dried in the sun and then by fire-heat, till the kernel shrinks so much as to rattle in the shell, which is then easily 
broken. After this, the nuts are three times soaked in sea-water and lime; they are then laid in a heap. where they heat, and get rid of their superfluous moistire by evaporation. This process is pursued to preserve the substance and flavour of the nut, as well as to destroy its vegetative power. Dry lime is the best package for nutmegs.

There are two varieties, the royal and the green. 'The royal is the largest, and it produces mace longer than the nut; on the nut of the green the mace reaclies only lialf-way down. A good nutmeg should be large, round, and heavy, of a light grey colonr, and finely marbled in the cross section.

Oil of nutmegs is obtained by pressure from the broken kernels; a pound of them generally yields three ounces of oil. According to Neumann's experiments, the oil produced is one third of the weight of nutmeg; it is yellow, of the consistence of tallow, and of a pleasant smell. This is a fixed oil, but a transparent volatile oil may likewise be obtained by distillation, in the proportion of $\frac{1}{32}$ part of the weight of nutmeg used.

There are other spices, natives of the Moluccas, the principal of these are Massoy hark, and a species of cinnamon, or cassia; but these, though much used in Chinese and Japanese cookery, are of inferior consequence, and nearly confined to the commerce of the East.

Ginger-Zingiber officinale-is a native of the south-east of Asia and the adjacent isles. It was naturalized in America very soon after the discovery of that country by the Spaniards; indeed, at so early a period that it is scarcely believed to be an exotic, and is supposed to have been found indigenous in the Western World. Acosta relates that a person named Francisco de Mendoza first transplanted it from the East Indies into New Spain, where its cul. 
tivation was diligently pursued by the Spanish Americans to no small extent, as, from the testimony of the same author, 22,053 cwt. were exported thence to Europe in the year 1547 *.

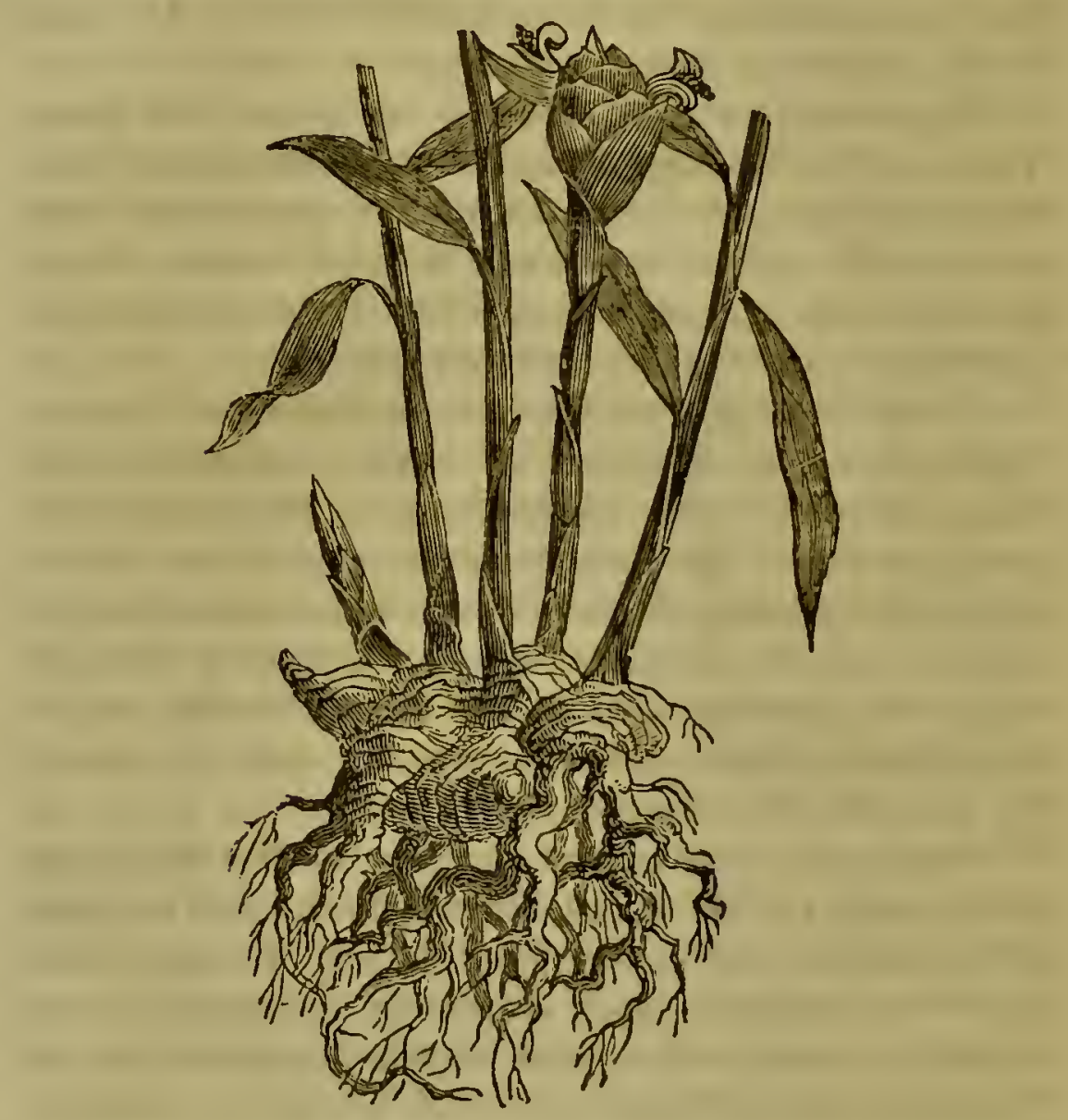

Ginger-Zingiber afficinale.

The plant is now cultivated in great quantities in the West Indies, especially in the island of Jamaica. Ginger is imported into this country under the form of dried roots, and as a preserve. We receive it both from the East and West Indies, but that from the latter

* Edivards's West-Indies, vol. ii. 
is much superior in quality to the former. British plantation ginger pays eleven shillings per cwt., import duty, and all other is not admitted under fiftythree slillings per cwt.; these two causes unite in confining the home consumption of ginger almost entirely to that coming from the West Indies.

'The ginger plant has been cultivated in this country as a stove exotic since abont the year 1600 . It has a perennial root, which creeps and increases under ground in tuberous joints, from each of which arises in the spring a green reed-like stalk of about two feet and a half in height, having narrow and lanceolate leaves. 'The stem is annual; the flowering stalk rises directly from the root, ending in an oblong scaly spike; from each of these scales a single white and blue flower is produced. The ginger of commerce is distinguished into black and white; but the difference of colour depends wholly on the modes of preparation. For both of these kinds the tubers are allowed to be ripe, that is, the roots are taken up after the annual stalks are withered. For the black, they are scalcled in boiling water and then dried in the sun; and for the white, they are scraped clean and dried carefully without being scalded. The best and soundest roots are selected for the latter process, and therefore white ginger is, independent of the manner of preparation, superior to the black, and it always bears a much higher price in the market. When a preserve is to be made of the roots, they are dug up in the sap, the stalks not being then more than five or six inches long. For this purpose the young roots are scalded, then washed in cold water and afterwards carefully peeled. This process lasts for three or four days, during which period the water is frequently changed.

When the cleansing is complete, the tubers are put into jars, and covered with weak syrup of 
sugar. After a day or two the weak syrup is removed, and replaced by a stronger; and the shifting is two or three times repeated, increasing the strength of the syrup each time. The preserve thus formed is one of the finest that is made; and the removed syrups are not lost, but fermented into a pleasant liquor, which gets the name of " cool drink."

The manner of cultivating ginger is extremely simple, requiring little skill or care; it is propagated with as much ease and nearly in the same manner as potatoes are in Great Britain.

Pepper-Piper.-The species of this genus are very numerous - botanists describing about sixtysome of which are to be found in every quarter of the world except Europe. The Piper nigrum produces the black and white pepper of commerce. This pepper-bush is a perennial plant found native upon the slopes of mountains in the southern parts of both the Indian peninsulas, especially on the coast of Malabar. It is likewise cultivated to a great extent in Sumatra, Java, and the adjacent places. Pepper at one time formed the principal export from Java; it was chiefly cultivated in Bantam, and likewise in the dependencies of that province in the southern part of Sumatra; these districts producing the greater part of the supply exclusively furnished by the Dutch to the European market. It is, however, a satisfaction to find that the greedy spirit which would appropriate all to self, may sometimes, in its unjust efforts to secure this end, defeat its own purpose. We learn from Sir T. S. Raffles, that "the system by which it (pepper) was procured, was too oppressive and unprincipled in its nature, and too impolitic in its provisions to admit of long duration. It was calculated to destroy the energies of the country, and with them the source whence the fruits of the monopoly proceeded. In the year 1811, ac- 
cordingly, neither Bantam nor its dependencies furnished the European government with a single pound of this article *."

The system of raising pepper in $\mathbf{J}$ ava is now, however, completely changed; there is no longer a monopoly, and the cultivation of pepper has for the last few years been declared free.

This plant was introduced some time back at Cayenne, by General Bernard, who has with unceasing preseverance attended to its cultivation in that settlement, in the hope of making the French independent of foreign supply for its produce. It is said that he has already formed a plantation of more than thirty thousand pepper-trees on his estate $t$.

The pepper-plant, or pepper-vine as it is sometimes called, is a creeping or climbing plant, with a dark coloured stem, which requires support. When dry it exactly resembles the grape-vine branch, having the same sort of knots or joint:- It is usual to plant a thorny tree by the side of this plant, to which it may cling. In Malabar, the chief pepper country of India, the Jacca tree (Artocarpus integrifolia) is made thus to yield its support, because the same soil is well adapted to the growth of both plants.

The stem of the pepper-plant entwines round its support to a considerable height; the flexile branches then droop downwards, bearing at their extremities, as well as at other parts, spikes of green flowers, which are followed by the pungent berries; these hang in large bunches resembling in shape those of grapes, but the fruit grows distinct on little stalks like currants. Each berry contains a single seed, which is of globular form and brownish colour, but changes to nearly a black when dried-this is the

* History of Java, vol. i. p. 131.

+ La Guiane Française for 5th January, 1825. 
pepper of commerce. The leaves somewhat resenble those of the ivy, but they are larger, and of rather a lighter colour; they partake strongly of the peculiar smell and pungent taste of the berry.

The plant is propagated by shoots, which do not produce fruit the first three years; the fourth year they come into bearing, and yield an increase of produce annually until the eighth year of their growth; they then gradually decline, and rarely bear for more than two or three years longer. When in full vigour, the pepper-plant is very prolific; each bunch usially contains from twenty to thirty berries, and sometimes as much as six or seven pounds of pepper are obtained from one tree. The time of the pepper harvest orr the western coast of Sumatra is usually about September and October, and sometimes another smaller crop is gathered in March and April. The pepper plantations on this island are described as being most carefully cultivated; not a weed is to be seen, every species of litter is removed, and if the season be dry, the plants are watered with unreinitling assiduity.

The black and white sorts of pepper are both the prodnce of the same plant ; the best white peppers are supposed to be the finest berries which drop from the tree, and lying under it become somewhat blanched by exposure to weather-these the poor people pick up and bring to the merchants; they are, however, obtained in very small quantities, and are on that account, as well as for their superior quality sold much dearer than the gathered pepper. The greater part of the white pepper used as a concliment, is, however, the black merely steeped in water and decorticated, by which means the pungency and real value of the pepper are diminished; but in this state it can be more readily reduced to powder, and. 
when thus prepared, it has a fairer and more untor'n appearance.

The pepper is distinguished in Sumatra into three sorts: the Molucca, which is the best; the second, Caytongee; and the worst sort, Negaree, which last is the most abundant; this is a small pepper usually full of dust; it is much lighter than the others, and therefore, unless the buyer be wise enough to purchase his pepper by weight instead of measure, he will assuredly be imposed upon, and have this substituted for the heavy Molucca berry

By distillation a green coloured matter is obtained from pepper; this is partly resinous, and party oily, and to this the pepper owes its pungent quality*.

Several other species of this genus are used besides the piper nigrum. The southern Asiatics wrap up the slices of the areca nut, which they are in the habit of chewing, in the leaves of the beetta codi (piper betle), which is a native of India and China. Some species are likewise found in the West Indies and in South America; they are used there to season food, but are not at present known in commerce.

Cayenne pepper is the pod of a species of capsicum dried and reduced to powder. There are many species of this genus, some of which have been aiready described in a former section. They differ from each other in bearing fruit of various size, shape, and colour; but they all have, in different degrees, the same pungent qualities; the smallest possessing them with the greatest intensity. They are natives of most of the tropical regions, but are most abundant and most used in the Western Hemisphere. In the West Indies, and in some parts of South America, they form, either in substance or in powder, an ingredient to almost every dish.

* Thomson's Chemistry. 


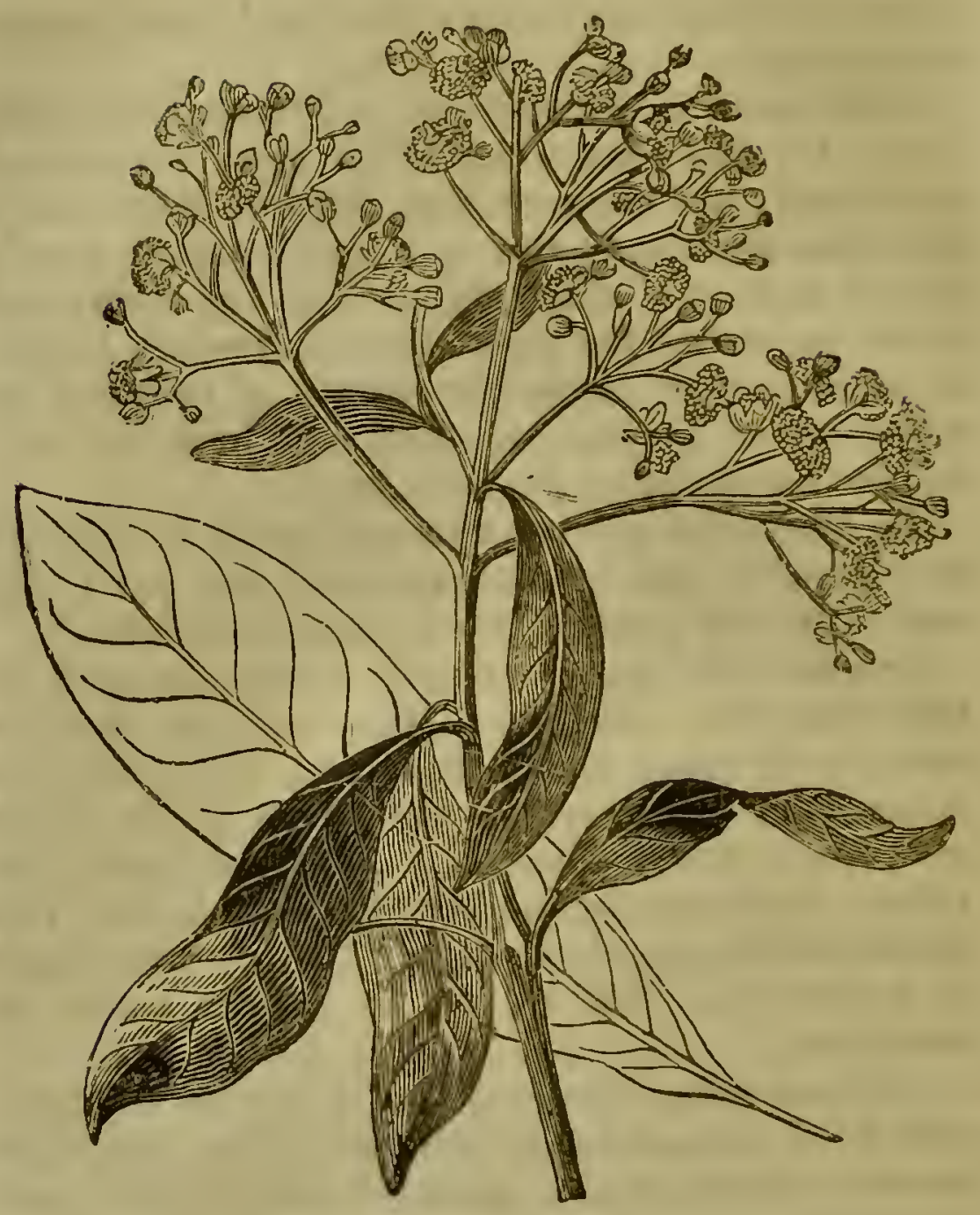

Allspice-Myrtus pimenta.

Pimento, Jamaica Pepper, or Allapice TreeMyrtus pimenta -is an extremely handsome tree; native of South America and the West Indies-especially of the island of Jamaica, whence the berries or pimento of commerce, are exported in large quantities. This tree grows to the height of about thirty feet, with a smooth brown trunk, and shining green leaves, resembling those of the bay; branches, coming out on al' sides, are olothed in the most luxuriant 
foliage. In the months of July and August a profusion of white flowers pleasingly contrast with the dark green leaves-the whole forming an object of vegetable beauty rarely surpassed; while the rich perfume which is exhaled around, and which is wafted by the gentlest breeze, renders an assemblage of these trees one of the most delicious plantations of even a tropical clime. When the leaves are bruised, they emit a fine aromatic odour as powerful as that of the fruit; indeed it is said that they yield by distillation a delicate oil, which is often used in the dispensaries as a substitute for oil of cloves.

The pimento tree grows spontaneously in many parts of Jamaica; it abounds more particularly on the northern side of that island, in elevated spots near the coast. When a new plantation of these is to he formed, no regular planting or sowing takes place; it is usuai to appropriate a piece of land either in the neighbourhood of a plantation already formed, or in a part of the woodlands where these trees are scattered in a native state. The land is then cleared of all wood but these trees, which are left standing, and the felled timber is allowed to remain where it falls to decay and perish. In the course of a year young pimento plants are found springing up on all parts of the land; produced, it is supposed, in consequence of the ripe berries having been scattered there by the birds, while the prostrate trees protect and shade the tender seedlings. A.t the end of two years the land is thoroughly cleared, only those plants being left which promise a vigorous growth; these come to maturity in about seven years from the first formation of the plantation, and usually attain to the height of thirty feet. But though apparently of so easy propagation, it is only in those parts where the tree is of spontaneous production. Ldwards observes, that " this tree is purely i child of 
nature, and seems to mock all the labours of man, in his endeavours to extend or improve its growth: not one attempt in fifty to propagate the young plants, or to raise them from the seeds, in parts of the country where it is not found growing spontaneously, having succeeded." The tree was introduced into this country in the early part of last century, but the fruit does not ripen. It is delicate and difficult to manage, requiring at the same time warmth and a great deal of air.

The flowers scarcely fade and give place to the berries, ere these are fit for gathering; since, if the fruit be suffered to ripen on the tree, it loses its pungency and becomes valueless. While yet green, therefore, the berries are carefully picked by hand; one person on the tree gathers the small branches; and three others, usually women and children, find full employment in picking the berries from these. The produce is then spread on terraced floors, and exposed to the action of the solar heat for about a week; in the course of this time the berries lose their green hue, and become of a reddish brown. When perfectly dry, they are in a fit state for exportation.

In a favourable season the pimento crop is enormous. "A single tree has been known to yield one hundred and fifty pounds of the raw fruit, or one hundred weight of the dried spice; there being commonly a loss in weight of about one-third in curing." This return is not, however, of very usual occurrence, as the produce is variable; a very plentcous harvest seldom occurring above once in five years.

Pin.ento combines the flavour and properties of inany of the oriental spices, hence its popular name. 


\section{COFFEE.}

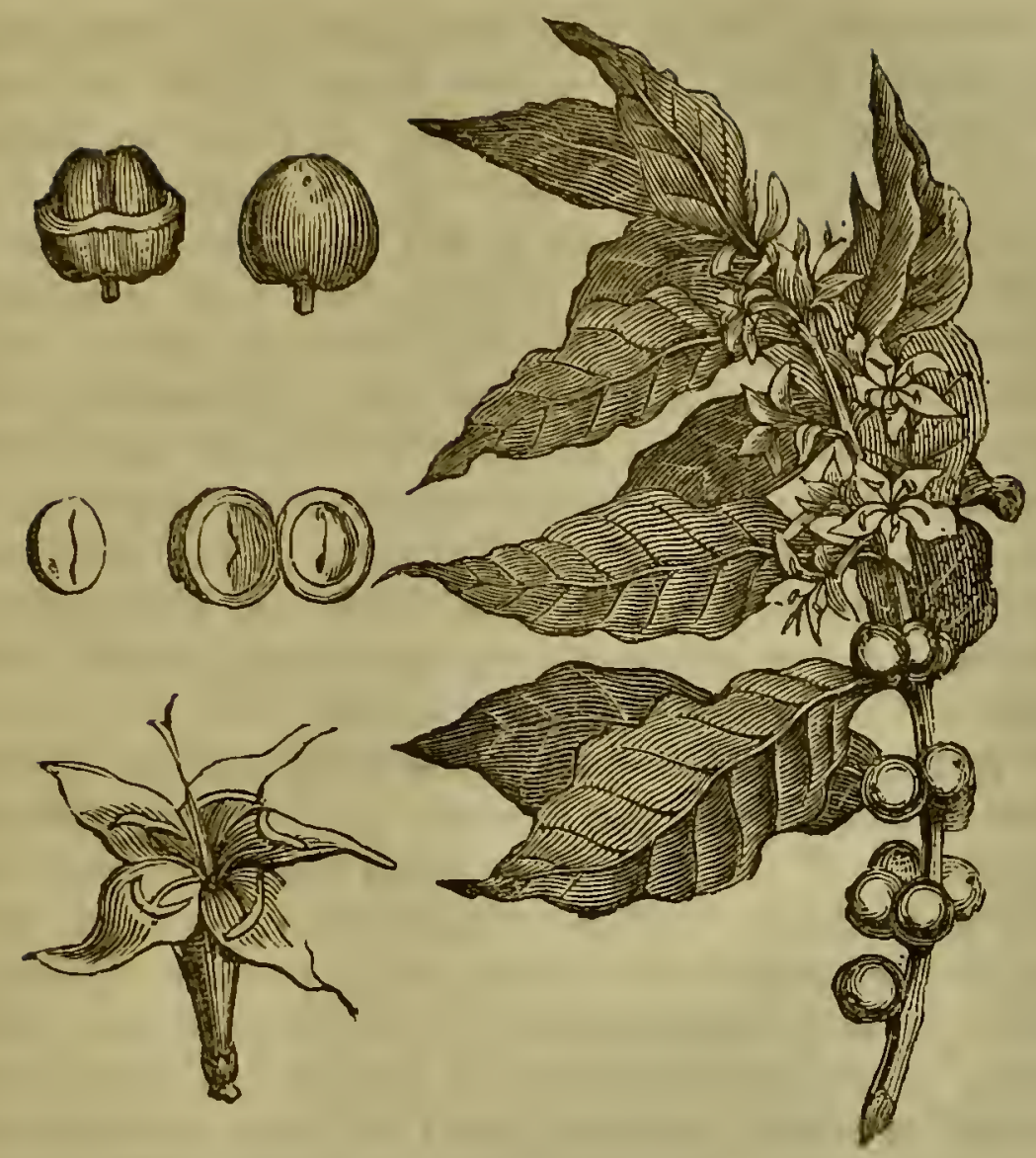

Coffee, with the F.ower and Berry.

\section{Chapter XVII.}

COFFEE-CACAO-TEA-SUGAR.

\section{COFFEE.}

COFFEE is the seed contained in a berry, the prosluce of a moderate-sized tree called the Coffea Erabica, and which has also been named Jasminum Arabicum. This tree grows erect, with a single stem, to the height of from eight to twelve feet, and has long, undivided, slender branches, bendiug 
downwards: these are furnished with evergreen, opposite leaves, not unlike those of the bay-tree. 'The blossoms are white, sitting on short foot-stalks, and resembling the flower of the jasmine. The fruit which succeeds is a red berry, resembling a cherry, and having a pale, insipid, and somewliat glutinous pulp, inclosing two hard oval seeds, each about the size of an ordinary pea. One side of the seed is convex, while the other is flat, and has a little straight furrow inscribed through its longest dimension; while growing, the flat sides of the seeds are towards each other. These seeds are immediately covered by a cartilaginous membrane which has received the name of the parchment.

Botanists have enumerated several varieties of this tree as existing in the Eastern and Western Hemispheres. These varieties result from accidents of soil and climate, and must have been produced subsequently to the naturalizing of the plant in Anerica, since it is pretty certainly shown, that all the coffee trees cultivated there are the progeny of one plant, which so recently as the year 1714 was presented by the magistrates of Amsterdam to Louis XIV., King of France. This plant was placed at Marly under the care of the celebrated Mons. de Jussieu, and it was not until some years after this that plants were conveyed to Surinam, Cayenne, and Martinico. The cultivation must have afterwards spread pretty rapidly through the islands, since in the year 1732 the production of coffee was considered to be of sufficient consequence in Jamaica to call for an act of the legislature in its favour.

The use of coffee as an alimentary infusion was known in Arabia, where the plant is supposed to have been indigenous, long before the period just mentioned. Ali authorities agree in ascribing its introduction to Megalleddin, Mufti of $\mathbf{A d e} \mathbf{n}$, in Arabia 
Felix, who had become acquainted with it in Persia, and had recourse to it medicinally when he returned to his own country. 'The progress which it made was by no means rapid at first, and it was not until the year 1554 that coffee was publicly sold at Constantinople. Its use had, in the meanwhile, been much checked by authority of the Syrian government on the ground of its alleged intoxicating qualities; but more probably hecause of its leading to social and festive meeling's incompatible with the strictness of Mahommedau discipline.

A similar persecution attended the use of coffee soon after its introduction into the capital of Turkey, where the ministers of religion having made it the subject of soleinn complaint that the mosques were deserted while the coffee-honses were crowded, these latter were shut by order of the Mufti, who employed the police of the city to prevent any one from drinking coffee. This prohibition it was found impossible to establish, so that the grovernment, with that instinctive faculty so natural to rulers of converting to their own advantage the desires and prejudices of the people, laid a tax upon the sale of the beveragre, which produced a considerable revenue.

The consumption of coffee is exceedingly great in Turkey, and this fact may be in a great measure accounted for by the strict prohibition which the Moslem religion lays against the use of wine and spirituous liquors. So necessary was coffee at one time considered among the people, that the refusal to supply it in reasonable quantity to a wife, was reckoned among the legal causes for a divorce.

Much uncertainty prevails with respect to the first introduction of coffee into use in the western parts of Europe. 'The Venetians, who traded much with the Levant, were probably the first to adopt its use. A lotter, written in 1615 from Constantinople, by 
Peter de la Valle, a Venetian, acquaints his corre spondent with the writer's intention of bringing home to Italy some coffee, which he speaks of as an article unknown in his own country. Thirty years after this, some gentlemen returning from Constantinople to Marseilles brought with them a supply or this luxury, together with the vessels required for its preparation; but it was not until $167 \mathrm{l}$ that the first house was opened in that city for the sale of the prepared beverage.

Coffee-houses date their origin in London from an earlier period. The first was opened in George Yard, Lombard Street, by one Pasqua, a Greek, who was brought over in 1652 by a Turkey merchant named Edwards.

The first mention of coffee that occurs in our statute books, is found in the act 12 th Car. ii.cap. 24, (Anno 1660,) whereby a duty of fourpence per gallon, to be paid by the maker, was imposed upon all coffee made and sold: three years after this, coffee-houses were directed to be licensed by the inagistrates at quarter-sessions.

Coffee cannot be cultivated to advantage in climates where the temperature at any time descends below 55 degrees of Fahrenheit's scale. The trees flourish most in new soils on a gentle slope, where water will not lodge about the roots. In exposed situations it is necessary to moderate the scorching heat of the sun by planting rows of umbrageous trees at certain intervals throughout the field.

Coffee-trees are usually raised from seed in nursery grounds, and are afterwards planted out at regular distances, which vary according to the nature of the soil. Where this is very dry or gravelly, the trees seldom rise higher than six feet, and may be planted five feet apart; but in rich soils, where they attain the heipht of nine or ten feet, or more, the 
plants should not be so crowded, and intervals of eight or ten feet should be left between them.

It is well known that coffee imported from the West Indies does not equal in its flavour that produced in Arabia and other parts of the East; and it is commonly imagined that this inferiority is principally owing to local causes, and is therefore incapable of being remedied. There is reason for believing, however, that the superior quality of Turkey and East-India coffee is not in any great degree to be referred to the influences of soil and climate, but depends, in part at least, upon the age to which the seeds are kept before they are brought into consumption. Trees planted in a light soil, and in dry and elevated spots, produce smaller berries, which have a better flavour than those grown in rich, flat and moist soils : the weight of produce yielded by the latter is, however, double that obtained from the former; and as the difference in price between the two is by no means adequate to cover this deficiency of weight, the interest of the planter naturally leads him to the production of the largest but least excellent kind. It is confidently asserted that this difference of quality entirely disappears by keeping, and that " the worst coffee produced in America will, in a course of years not exceeding ten or fourteen, be as good, parch and mix as well, and have as high a flavour as the best we have now from Turkey."

The trees begin bearing when they are two years old; in their third year they are in full bearing. The aspect of a coffee plantation during the period of flowering, which does not last longer than one or two days, is very interesting. In one night the blossoms expand themselves so profusely as to present the same appearance which has sometimes been witnessed in England when a casual snow-storm at the close of autumn has loaded the trees while still 
furnished with their full complement of foliage. The seeds are known to be ripe when the berries assume a dark red colour, and if not then gathered will drop from the trees. The planters in Arabia do not pluck the fruit, but place cloths for its reception beneath the trees which they shake, and the ripened berries drop readily. These are afterwards spread upon mats and exposed to the sun's rays until perfectly dry, when the husk is broken with large heavy rollers made either of wood or of stone. The coffee thus cleared of its husk is again dried thoroughly in the sun, that it may not be liable to heat when packed for shipment.

The method employed in the West-Indies differs from this. Negroes are set to gather such of the berries as are sufficiently ripe, and for this purpose are provided each with a canvas bag having an iron ring or hoop at its mouth to keep it always distended, and this bay is slung round the neck so as to leave both hands at liberty. As often as this bag is filled, the contents are transferred to a large basket placed conveniently for the purpose. When the trees are in full-bearing, an industrious man will pick threc bushels in a day. If more are gathered, proper care can hardly be exercised in selecting only', the berries that are ripe. It is the usual calculation' that each bushel of ripe berries will yield ten pounds weight of merchantable coffee.

In curing coffee it is sometimes usual to expose the berries to the sun's rays in layers, five or six inches deep, on a platform. By this means the pulp ferments in a few days, and having thus thrown off a strong acidulous moisture, dries gradually during about three weeks: the husks are afterwards separated from the seeds in a mill. Other planters remove the pulp from the seeds as soon as the berries are gathered. 'The pulping mill used for this pur- 
pose consists of a horizontal fluted roller, turned by a crank and acting against a movable breast-board, so placed as to prevent the passage of whole berries between itself and the roller. The pulp is then separated from the seeds by washing them, and the latter are spread out in the sun to dry them. It is then necessary to remove the membranous skin or parchment, which is effected by means of heavy rollers ruming in a trough wherein the seeds are put. This mill is worked by cattle. The seeds are afterwards winnowed to separate the chaff, and if any among them appear to have escaped the action of the roller, they are again passed through the mill.

The roasting of coffee for use is a process which requires some nicety; if burned, much of the fine aromatic flavour will be destroyed, and a disagreeizble bitter taste substituted. 'The roasting is now usually performed in a cylindrical vessel which is continually turned upon its axis over the fire-place, in order to prevent the too great heating of any one part, and to accomplish the continual shifting of the contents. Coffee should never be kept for any length of time after it has been roasted, and should never be ground until the moment of its infusion, or some portion of its fine flavour will be dissipated.

The quantity of coffee consumed in Europe is very great. Humboldt estimates it at nearly one hundred and twenty millions of pounds, about one fourth of which is consumed in France. Since the time when this estimate was made, a vast increase has been experienced in the use of coffee in England. 'I'his was at first occasioned by the very considerable abatement marle in the rate of duty, and the public taste has since been continually growing more and morc favourable to its consumption. 


\section{CACAO}

The Cacao, or Chocolate-tree, is known to botanists by the name of Theobroma, signifying "food for a god," ard which name was bestowed upon it by Linnæus, to mark his opinion of the excellent qualities of its seeds. Benzoni, who travelled in the sixteenth century, formerl a very different estimate of its merits, and declared that chocolate was a drink " fitter for a pig than for a man.

The Cacao-tree is carefully cultivated in many of the settlements in Spanish Ainerica, and particularly in Mexico, where, we learn from Humboldt, it was extensively reared so long ago as the time of Montezuma ; and whence, indeed, it was transplanted into other dependencies of the Spanish monarchy. The names whereby the plant, and the food prepared from its seeds, are recognized in the present time, are both derived from the Mexican langruage; the former being called by that people, cacava quahuill, and the latter chocolatl. The seeds of the cacao were made use of as money in Mexico, in the time of the Aztec kings, and this use of them is still partially continued, the smaller seeds being employed for the purpose. The lowest denomination of coined money current in Mexicn is of the value of about sixpence; and as there must arise many petty transactions of business to a lower amount, the convenience of these seeds, six of which are reckoned as of the value of one halfpenny, must needs be very great.

'The cacao-tree seldom rises above the height of twenty feet; its leaves are large, oblong, and pointed. The flowers, which are small, and of a pale red colour, spring from the large branches; they are succeeded by oval pointed pods, that contain a white pithy substance, which is sweet, but disagreeable, and 
surrounding numerons seeds: these are the cacao of commerce. These seeds are oval-formed, and about as large as a moderate-sized almond-kernel, but not so slender; they are internally of a very dark brown colour, approaching to black, and are covered with a thin skin or husk, of a light reddish-brown colour. The nuts are very numerous, but vary in this respect some pods continining as many as a hundred, while others do not yield more than twenty, seeds: they are of a very oily nature.

The trees are raised from seed, which is sowr under the shade of the coral-tree, or the banana, and they do not come into bearing until six or seven years old. Their cultivation does not call for any great application of labour; and when the trees are once in a productive state, they require but little attention beyond that necessary for merely collecting the produce.

Cacao is principally used after having been made into cakes, to which the name of chocolate is given. The method anciently employed by the Indians in making these cakes, was simply to roast the seeds in earthen pots, and after clearing them from the husks, which by reason of the heat employed could be easily removed, the naked seeds were bruised between two stones, and made up with the hands into cakes. 'The process at present used by Europeans does not differ greatly from that just described: more care is taken in grinding the seeds after they are roasted, so as to convert them into a paste which is perfecily smooth, and some flavouring ingredients are added, according to the taste of the people who are to consume the chocolate. Cloves and cinnamon are much used for this purpose by the Spaniards; other aromatics, and even perfumes, such as musk and ambergris, have sometimes been added; but the principal flavouring ingredient used with cacao is vanilla, a short notice 
of which is here givell. The intimate mixture of these substances having been effected, the whole is put while yet hot into tin moulds, where it hardens in cooling, and in this form, if preserved from the air, it will keep good for a considerable time. Chocolate is not very much consumed in England; it is in greater esteem in France; it forms the ordinary breakfast in Spain; and in Mexico, according to Humholdt, it is not considered an object of luxury, but rather of prime necessity.

VANILLA - Vanilla aromatica-is a native of Mexico, and of some parts of India. The Spaniards found its fruit in use omong the Aztecs at the time of their first invasion of Mexico. At this day, although a considerable quantity of vanilla pods is collected in that state for the purpose of exportation, the people do not themselves employ them in the manufacture of chocolate-the nnly use to which they have ever been anywhere applied-conceiving them to be possessed of unwholesome properties.

The vanilla is a parasitical plant; its leaves are lanceolate and ribbed, eighteen inches long, and three inches broad. Its flowers are white, intermixed with stripes of red and yellow colours; these are succeeded by long and slender pods, which at first are green, but become yellow as they ripen, and are then collected for use. The cavity of the pod contains, besides its numerous seeds, a substance which is black, oily, and balsamic; when recently gathered this is humid, and its odour is said to induce a kind of temporary intoxication. The pods are harvested during the three latter months of the year, and are carefully dried by exposure to the sun's rays until they are made warm, in which state they are wrapped in woollen cloths, to promote and absorb evaporation. By this process the vanilla acquires a black hue, with 
a somewhat silvery appearance. Five of the pods, thus treated, will usually weigh one ounce.

The vanilla plant is very easily propagated by cuttings; these, each about a foot in length, are planted at the root of the tree about which it is intended to climb. These plants will yield pods in their third year, and each will continue to furnish about fifty annually for thirty or forty years. What is a singular advantage in that climate, no insect will attack this plant.

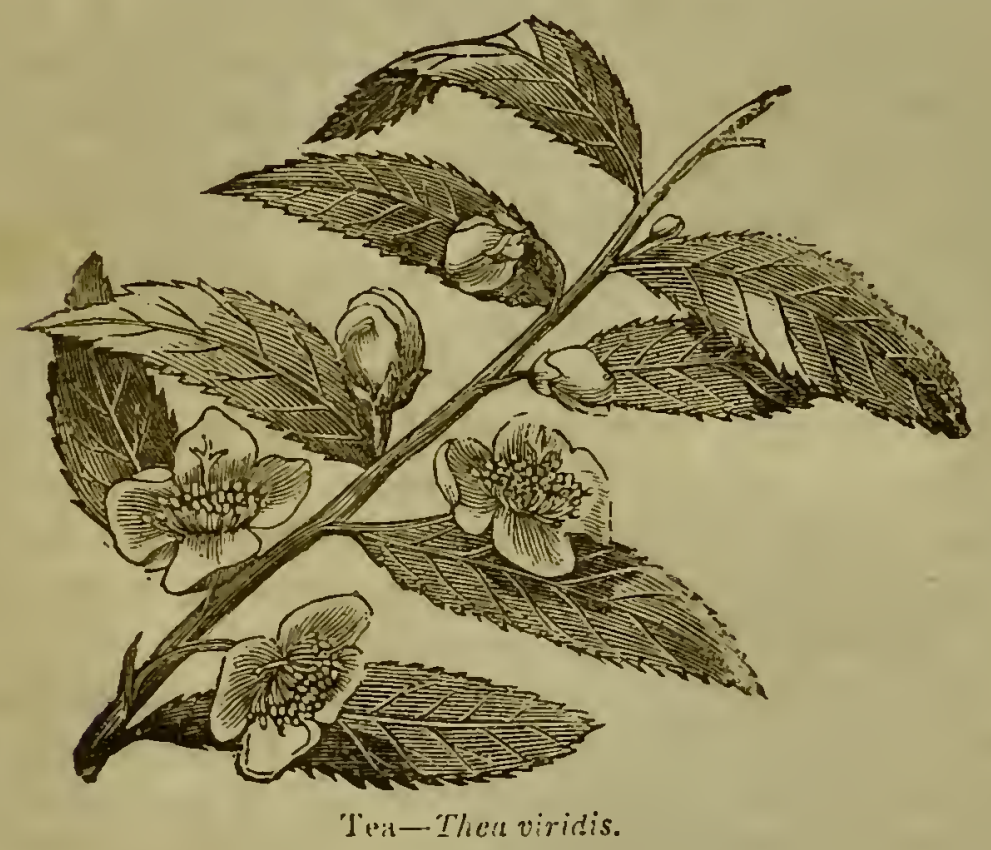

TEA.

THE history of commerce does not, perhaps, present a parallel to the circumstances which have attended the introduction of tea into Great Britain. This leaf was first imported into Europe by the Dutch EastIndia Company, in the early part of the seventeenth century; but it was not until the year 1666 that a small quantity was brought over from Holland to 
this country by the Isords Arlington and Ossory; and yet, from a period earlier than any to which the memories of any of the existing generation can reach, tea has beell one of the principal necessaries of life among all classes of the community. To provide a sufficient supply of this aliment, many thousand tons of the finest mercantile navy in the world are annually em ployed in trading with a people $\mathrm{kv}$ whom all dealings with foreigners are merely tolerated; and from this recently-acquired taste, a very large and easilycollected revenue is obtained by the state.

The tea-plant is indigenous to China or Japan, and probably to both. It has been used among the natives of the former country from time immemorial ; and, from the age of Confucius, has been the constant theme of praise with their poets. It is only in a particular tract oi the Chinese empire that the plant is cultivated; and this tract, which is situated on the eastern side, between the 30th and 33rd degree of north latitude, is distinguished by the natives as "the tea country." The more northern part of China would be too cold; and further south the heat would be too great. There are, however, a few small plantations to be seen near to Canton.

The tree or shrub vrhence the tea of commerce is derived, is the Thea of botanists. 'There is only one species of this plant; and although it has been said by some writers that there are two varieties, differing in the breadth of their leaves, this assertion is as confidently denied by others, who affirm that the differences discernible in the qualities of the dried leaves are owing to the period of their growth at which they are gathered, and to some variations in the methods employed for curing them.

The Chinese give to the piant the name of tcha or tha. It is propagated by them from seeds, which are deposited in rows four or five feet asunder; 
and so uncertain is their vegetation, even in their native climate, that it is found necessary to sow as many as seven or eight seeds in every hole. The ground between each row is always kept free from weeds, and the plants are not allowed to attain at higher growth than admits of the leaves being conveniently gathered. The first crop of leaves is not collected until the third year after sowing; and when the trees are six or seven years old, the produce becomes so inferior that they are removed to make roum for a fresh succession.

The flowers of the tea-tree are white, and somewhat resemble the wild rose of our hedges: these flowers are succeeded by soft green berries or pods, containing each from one to three white seeds. The plant will grow in either low or elevated situations, but always thrives best and furnishes leaves of the finest quality w? sen produced in light stony ground.

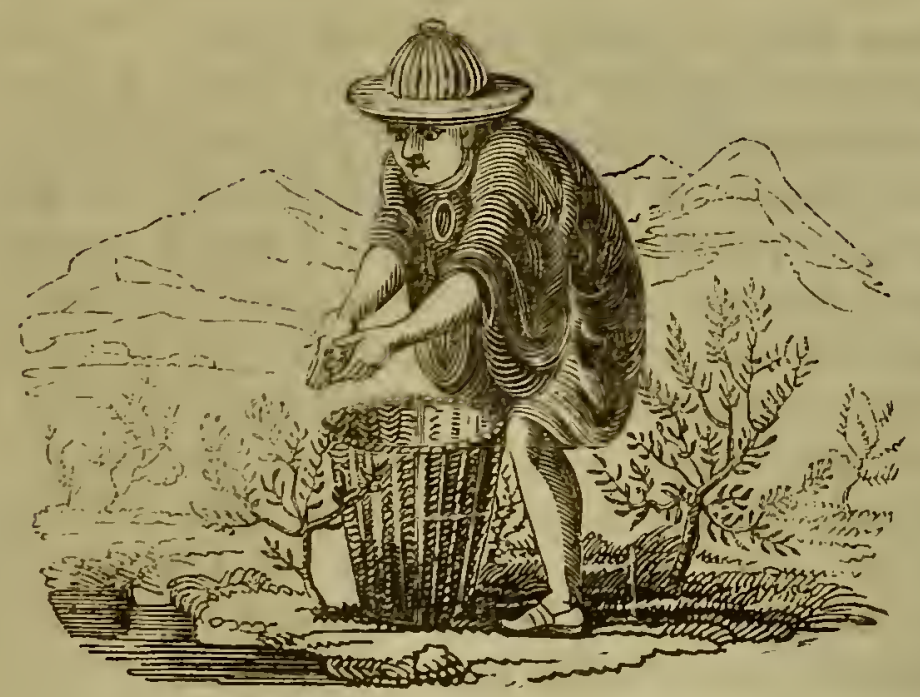

Tea-gathering - from a Chinese drawing.

The leaves are gathered from one to four trmes during the year, according to the age of the tree Most rommonly there are three pericds of gathering 
the first commences about the middle of April; the second at Midsummer; and the last is accomplished during August and September. The leaves that are earliest gatliered are of the most clelicate colour and most aromatic flavour, with the least portion of either fibre or bitterness. Leaves of the second gathering are of a dull green colour, and have less valuable qualities than the former; while those which are last collected are of a dark green, and possess an inferior value. The quality is farther influenced by the age of the wood on which the leaves are horne, and by the degree of exposure to which they have been accustomed; leaves from young wood, and those most exposed, being always the best.

The leaves, as soon as gathered, are put into wide shallow baskets, and placed in the air or wind, or sunshine, during some hours. They are then placed on a flat cast-iron pan, over a stove heated with charcoal, from a half to three quarters of a pound of ieaves being operated on at one time. These leaves are stirred quickly about with a kind of brush, and are then quickly swept off the pan into baskets. The next process is that of rolling, which is effected by carefully rubbing them between men's hands; after which they are again put, in larger quantities, on the pan, and subjected anew to heat, but at this time to a lower degree than at first, and just sufficient to dry them effectually without risk of scorching. This effected, the tea is placed on a table and carefully picked over, every unsightly or imperfectly-dried leaf that is detected being removed from the rest, in order that the sample may present a more even and a better appearance when offered for sale. With some finer sorts of tea a different manipulation is employed; the heated plates are dispensed with, and the leaves are carefully rolled into balls, leaf by lear, with the hands 
The names whereby sume of the principal sorts of tea are known in China, are taken from the places in which they are produced, while others are distinguished according to the periods of their gathering, the manner employed in curing, or other extrinsic circumstances.

Bohea, of which description there are five kinds, takes its name from the mountain of Vou-yee, which is covered with tea plantations. The earliest gatherings, in this district, is called Souchong, the Chinese name for which is Saatyang; and Pekoe, called by the ciltivators back-ho, or pack-ho; Congou, Kongfou, and other commoner kinds of Bohea-tea, are made from the leaves when in a state of greater maturity. Padre-Souchong, or Pao-sut-tcha, is gathered in the province where the best green tea is produced. This kind is esteemed on accounit of some medicinal virtues which it is supposed to possess.

Thcre are three kinds of green tea, of which one called hyson, hayssuen, is composed of leaves very carefully picked, and dried with a less degree of heat than others: it is one-fourth dearer than souchong. The kind of green tea which is most abundant is called Singlo, which is the name of a mountain on which it grows, about one hundred and fifty miles to the southward of Nan-king. Gunpowder tea is made of tender green leaves, which yet have attained a considerable size. This kind is sometimes rolled into balls by hand, and is very highly esteemed; it sells for fifteen per cent. more than hyson. It is a coinmonly received opinion, that the distinctive colour of green tea is imparted to it by sheets of copper, upon which it is dried. For this belief there is not, however, the smallest foundation in fact, since copper is never nsed for the purpose. Repeated experiments have been made to discover, by 
an unerring test, whether the leaves of green tea contain any impregnation of copper, but in no case has any trace of this metal been detected.

The succulent tea-leaves are sometimes twisted into thin rolls or cords, about an inch and a half or two inches long, and several of these are tied together by their ends, with coloured silk threads. This is done with both green and black tea.

The Chinese do not use their tea until it is about a year old, considering that it is too actively narcotic when new. Tea is yet older when it is brought into consumption in England, as, in addition to the length of time occupied in its collection, and transport to this country, the East-India Company are obliged by their charter to have always a supply sufficient for one year's consumption in their London warehouses; and this regulation, which enhances the price to the consumer, is said to have been made by way of guarding, in some measure, against the inconvenience that would attend any interruption to a trade entirely dependent upon the caprice of an arbitrary government.

The people of China partake of tea at all their meals, and frequently at other times of the day. They drink the infusion prepared in the same manner as we employ, but they do not mix with it either sugar or milk. The working classes in that country are obliged to content themselves with a very weak infusion. Mr. Anderson, in his narrative of Lord Macartney's embassy, reliates that the natives in attendance never failed to beg the tea-leaves remaining after the Europeans had breas fasted, and with these, after submitting them again to boiling water, they made a beverage which they acknowledged was better than they could ordinarily' obtain.

'The tea-plant is found in oul conservatories, and in such situations has occasionally put forth blossoms 
in this country. It is not qualified to bear a full exposure to the cold of our winter; and if even this difficulty could be surmounted, there is but little reason for wishing that it should be naturalized among us, as the amount of labour required for its culture, and for the preparation of the leaves, woula, at the lowest rate paid in England, raise the produce to a price out of all proportion greater than we now pay for the tea of China, burthened as it is with the expenses of a lengthened voyage, and with a government duty which doubles the selling price. Attempts have been made to cultivate the plant in Brazil, where no obstacle is offered by the climate; but the comparative dearness of labour in that quarter offers a serious barrier against the successful prosecution of the scheme.

\section{SUGAR.}

Sugar must be considered as one of the most valuable vegetable substances with which civilized man has become acquainted. So varied and extensive are its uses, and so greatly does it minister to the social gratifications of mankind, that we are justified in: ranking it as inferior only in the vegetable economy to the cereal grains described in the first division of the present volume.

Sugar, speaking chemically, is included in, or forms a constituent part of, a very numerous range of plants, being either contained ready formed, or capable of being developed in all that will yield alcohol after fermentation and distillation. Among these vegetable bodies there are several from which, at various times and in different countries, sugar has been drawn as an alimentary substance; but of these it is quite impossible for us here to offer any satis. factory description. We must limit ourselves to a 
very short notice of that one among the sugarproducing plants, which furnishes our own tables with this indispensable article of daily consumption ; and to a few particulars relating to the manufacture of sugar, in France, from the White Beet.

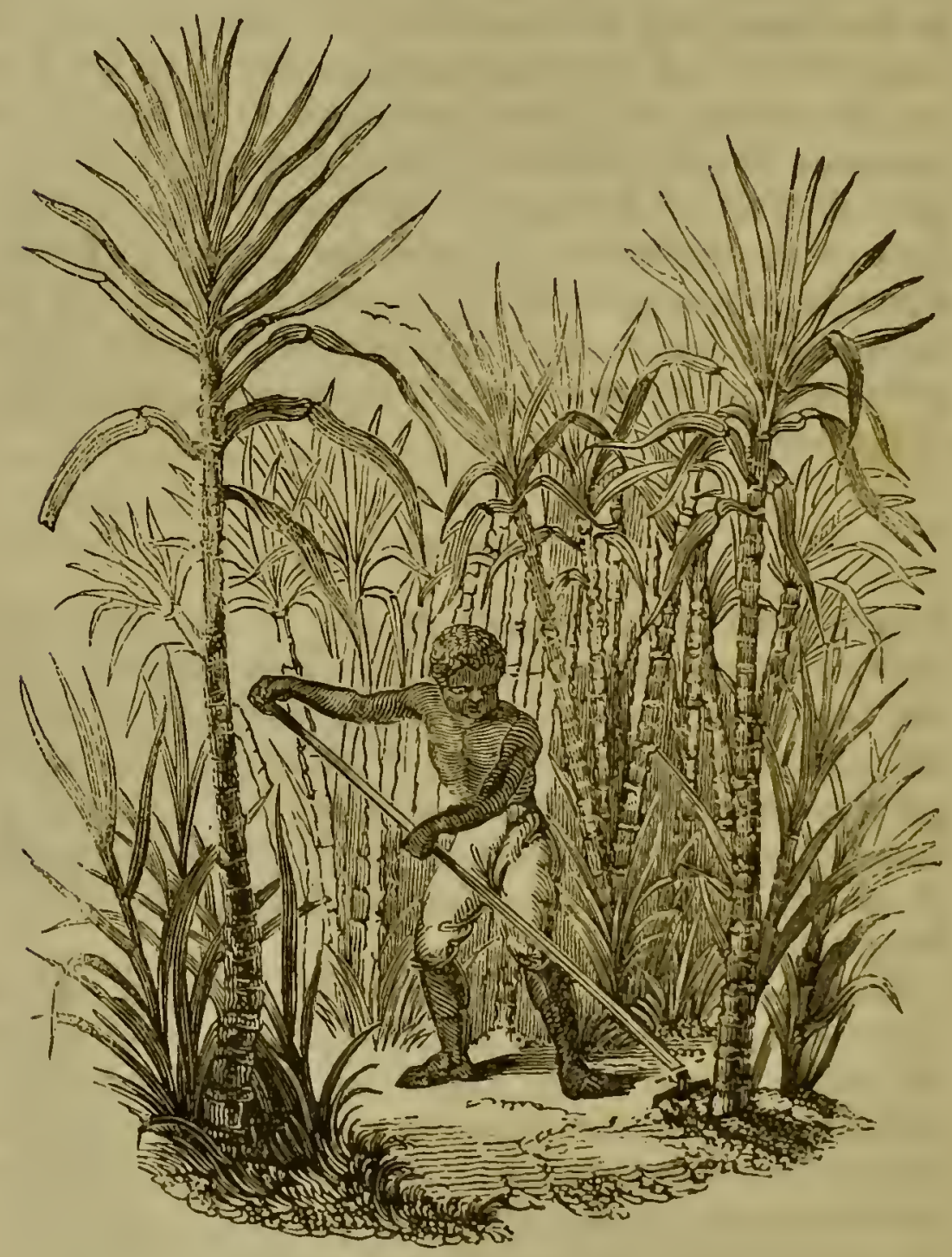

Sugar-canes.

The Sugar-cane-Saccharum ofjicinarum-must be considered as a native of China, since it has been pretty accurately shown that its cultivation was pro. 
secuted in that empire for two thousand years before sugar was even known in Europe, and for a very long period before other eastern nations became acquainted with its use. For some time after this substance, in its crystalline form, had found its way to the westward, through India and Arabia, a singular degree of iguorance prevailed in regard to its nature, and the mode of its production; and there is reason for believing that the Chinese, who have always evinced an unconquerable repugnance to foreign intercourse, purposely threw a veil of mystery over the subject. Persons have not been wanting, even in modern times, who have approved of this anti-social spirit, as being the perfection of political wisdom;but is it not a complete answer to their opinion, that every nation which has cultivated commercial relations has been steadily advancing in civilization, and adding most importantly to the sum of its comforts and conveniences; while the inhabitants of China, although possessed of the greatest natural advantages, arising from variety of soil and climate, and whereby they had so long ago placed themselves in advance of other people, have remained altogether stationary? The case of this extraordinary people forms altogether, and in many ways, a standing enigma in the history of our species, the solving of which could not fail to prove highly instructive and interesting.

A knowledge of the origin of cane sugar was correctly revealed in the middle of the thirteenth century, by the celebrated traveller Marco Polo; though it was partially known much earlier. The plant was soon conveyed to Arabia, Nubia, Egypt, and Ethiopia, where it became extensively cultivated. Early in the fifteenth century the sugar-cane first appeared in Europe. Sicily took the lead in its cultivation ; thence it passed to Spain, Madeira, and 
the Canary Islands; and shortly after the discovery of the INew World by Columbus, this plant was conveyed to Hayti and Brazil, from which latter country it graduallv spread through the islands of the West Indies

The canes have knotty stalks, and at each joint or knot a leaf is produced. The number of joints varies in different specimens, some having as many as eighty, and others not half that number. There ale now several varieties cultivated in the American colonies, which were conveyed to that quarter, about the end of the last century, from the islands of Bourbon, Java, and Otaheite. These are so far superior to the old plant, that its cultivation has nearly ceased. The new varieties are larger in diameter, have a much greater distance between the joints, and come sooner to maturity than the old Brazil cane. This occupies, from the time of its being planted until it is fit for being cut, a period of from twelve to twenty months; while the larger varieties, by which it has been superseded, are fully ripe in ten months.

The sugar-cane varies exceedingly in its growth, depending upon the nature of the soil. In new and moist land it sometimes attains the height of twenty feet; while in ground that is arid and calcareous, its length does not exceed from six to ten feet. It is always propagated from cuttings. When sown in the colonies of America, the seeds have never been known to regetate; and although there must, doubtless, be some conntry where the course of nature could be followed in this respect, we are not acquainted with any place in which the cultivators resort to the sowing of seed, in order to the propagaltion of the plant. The top joints are always taken for planting, because they are less rich in saccharine juice than the lower parts of the cane, while their 
power of vegetation is equally strong. The caneplant is possessed of the power of tillering, in a manner similar to that shown by wheat, although not to an equal extent.

In preparing a field for planting with the cuttings of cane, the ground is marked out in rows three or four feet apart, and in these lines holes are dug from eight to twelve inches deep, and with an interval of two feet between the holes. Where the ground is level, larger spaces are left at certain intervals, for the facility of carting; ; but there are many situations at the sides of steep hills where no cart can be taken, and in such cases these spaces are not required. The ripe canes are then conveyed to the mill in bundles on the backs of mules, or are passed down to the bottom of the hill through wooden spouts.

The hoeing of a cane-field is a most laborious operation when performed, as it must be, under the rays of a tropical sun. Formerly this task was always effected by hand labour, but, of late years, where the nature of the ground will admit of the employment of a plough, that instrument has been substituted, to the mutual advantage of the planter and his labourers. The planting of canes does not require to be renewed annually; in such a case the utmost number of labourers now emplnyed on a sugar plantation would be wholly inadequate to its performance. The most general plan is for a certain portion of the land in cultivation to be planted armually and in succession, the roots and stoles of the canes of the former year being left through the remaining parts of the plantation. From these, fresh canes, which are called rattoons, spring up, and are nearly as large the first year as plant canes. Rattoon canes have a tendency to deteriorate -at least in size-every year they are continued, for 
which reason the progressive renerval of the plants is adopted. 'Ihis plan may, however, be continued with very good effect for several years, provided the roots are furnished every year with a liberal supply of manure, that the ground about them is well loosened, and that all weeds are carefully removed. In this way it is said the same roots have been made to send up canes during twenty years In some few cases, the planters adopt a different course, and never wholly renew any individual field of canes, but content themselves with supplying new cuttings in such particular spots as from time to time appear to be thin.

The mode of cultivation varies in some particulars in different countries. In India, where the price paid for daily labour is exceedingly small, great pains are taken in preparing the ground for the reception of the plants, which are carefully weeded and watered, and freed from insects, at all periods of their growth, when such operations are called for. Unfortunately for the Indian sugar-cnltivator, something more than mere labour is required for the proper manufacture of his produce-an acquaintance with chemical science, and the possession of adequate apparatusin both which particulars he is lamentably deficient. The Indian agriculturist would suffer martyrdom rather than be guilty of the crime of innovation; the discoveries of scientific men are to him as though they never had been made, and in conducting proresses he is contented with apparatus, the total cost of which does not exceed many shillings, where manufacturers of other countries think it necessary to expend many hundred pounds. If their inreterate prejudices conld be overcome, and the Indian sugarplanters were furnished with adequate utensils, there is every reason to believe that the markets of Europe 
could be supplied thence with sugar of a quality quite equal to that of West-India manufacture, and at a considerably lower cost.

The manufacture of sugar is a somewhat complicated process, requiring for its successful performance not only some degree of chemical knowledge, but likewise a considerable amount of practical experience. We must content ourselves here with giving the merest outline of the operations, referring the reader who is curious in such matters to books wherein the whole details are given.

When the canes are fully ripe they are cut close to the stole, and being then divided into convenient lengths, are tied up in bundles, and conveyed to the mill. This always consists of three iron cylinders, sometimes standing perpendicularly in a line with each other, and at other times placed horizontally, and disposed in the form of a triangle, and so adjusted that the canes, on being passed twice between the cylinders of either kind of mill, shall have all their juice expressed. This is collected in a cistern, and must be immediately placed under process by heat to prevent its becoming acid, an effect which has sometimes commenced as early as twenty minutes from the time of its being expressed. A certain quantity of lime in powder, or of lime-water, is added at this time to promote the separation of the feculent matters contained in the juice; and these being as far as possible removed at a heat just sufficient to cause the impurities to collect together on the surface, the cane liquor is then subjected to a very rapid boiling, in order to evaporate the watery particles, and bring the syrup to such a consistency that it will, granulate on cooling. The quantity of sugar obtainable fiom a given measure of cane-juice varies according to the season, the soil, the periorl of the year, and the quality of the canes; but it may be calculated, that 
taking one state of circumstances with another in these respects, every five gallons, imperial measure, of cane-juice, will yield six pounds of crystallized sugar, and will be obtained from about one hundred and ten well-grown canes.

The fuel used for thus concentrating the juice is furnished by the cane itself, which, after the expressing of that juice, is dried for the purpose by exposure to the sun.

When the sugar is sufficiently cooled in shallow trays, it is put into the hogsheads wherein it is shipped to Europe. These casks have their bottoms pierced with holes, and are placed upright over a large cistern into which the molasses-which is the portion of saccharine matter that will not crystallize - drains away, leaving the raw sugar in the state wherein we see it in our grocers' shops: the casks are then filled up, headed down, and shipped.

With the planters in our own colonies, the process of sugar-making mostly ends with the draining away of the molasses in the manner just mentioned; but in the French, Spanish, and Portugueze settlements it is usual to submit this raw sugar to the farther process of claying. For this purpose the sugar, as soon as it is cool, is placed in forms or moulds, similar to those used in the sugar refineries in England, but much larger; and these being placed with their small ends downwards, the top of the sugar is covered with clay moistened to the consistence of thin paste, the water contained in which gradually soaks through the sugar and washes out a farther quantity of molasses, with which it escapes through a hole purposely made at the point of the earthen mould. It is then called clayed-sugar : the loaves when removerl from the forms are fiequently divided into three portions, which, being of different colours and qualities, srising from the greater effect of the water in cleans- 
ing the upper portion, are pulvcrized and packed separately for exportation.

The molasses which have drained from the sugar, together with all the scummings of the coppers, are collected, and, being first fermented, are distilled for the production of rum. The proportionate quantity of this spirit, as compared with the weight of sugar produced, varies considerably with the seasons and management. In favourable years, when the canes are fully ripened, and the quality of the sugar is good, the proportion of molasses and scummings is comparatively small, and the manufacture of rum is consequently lessened: the proportion usually made is reckoned to be from five to six gallons of proof spirit for every hundred-weight of sugar.

\section{BEET-ROOT SUGAR.}

Sugar may be properly reckoned a necessary of life. It is of almost universal use throughout the world. The scattered tribes of North American Indians spend the months of spring in their rude encampinents, manufacturing sugar out of the juice of the maple; - the five-and-twenty million inhabitants of the United Kingdom employ, throughout the year, two hundred thousand tons of shipping to export five hundred million pounds of sugar from their colonies. This enormous supply affords, upon an average, 20lbs. of sugar to each individual of our twenty-five millions of population. Through the natural operation of our commercial power this important article of comfort is placed within the reach of the humblest in the land, although the revenue received by the state from the consumers amounts to $5,000,000 l$. annually. In France, on the contrary, where the government has chosen to force the manuacture of sugar at home, the article is consumed onlv 
by the wealthy in large towns, and is quite beyond the reach of the labouring population, although it is entirely freed from all duty. The history of Beetroot Sugar forms one of the inost instructive chapters in the history of the evils resulting to a nation from what is called " the protection" of particular interests by a government.

The celebrated Prussian chemist Margraff, about the year 1747 , discovered the existence of a certain portion of sugar in the beet. This discovery was communicated to the Scientific Society of Berlin; but no attempt was made to carry the principle of the discovery into practice. Forty years after this, Achard, another Prussian chemist, resumed the experiments which Margraff had commenced. This man was somewhat of a visionary; and he was so enraptured by the prospects which his labours opened to him, that he announced the beet-root as " one of the most bountiful gifts which the Divine munificence has awarded to man upon the earth ;" affirming that not only sugar could be produced from beet-root, but also tobacco, molasses, coffee, rum, arrack, vinegar, and beer. Here, then, was clearly nothing for Europe to do but to apply itself to the cultivation of beet, and leave the West Indies to be covered once more with jungle. The Institute of Paris, however, did not sympathise with the enthusiasm of Achard; for in 1800 a committee of that body, having gone through a series of the most careful experiments, reported that the results were so unsatisfactory that it would be unwise to establish any manufacture of sugar from beet.

Here, probably, the matter would have rested, and Europe would have continued wholly to receive its sugar from countries adapted to the growth of the sugar-cane, lad not the decrees of Bonaparte, in 1809, excluded France from purchasing the produce 
of the West Indies. To a large number of the French, sugar was an article of the first necessity ; and the public dissatisfaction at the Milan decrees was therefore excessive. The Emperor directed his active mind to the best method of obviating the inconvenience which his political schemes had imposed upon his people. Manufactories of syrups from raisins and honey were established; but sugar, or a crystallized saccharine substance, could not be procured. M. Deyeux, a member of the Committee appointed by Napoleon to consider how the wants of the people could be supplied without foreign commerce, once more turned his attention to the beetroot. His experiments were more satisfactory than those of the Committee of 1800 ; probably because the necessity of producing sugar at home was more pressing. An imperial manufa story of sugar was forthwith established at Rambouillet; imperial schools were instituted for instructing pupils in the process; premiums were given for the best samples of sugar; and thus, by 1812, the manufacture of beet-root sugar might be considered prosperously set on foot. The profits of the mannfacturers were so large, that in one year they were reckoned sufficient to cover all the expenses of the original establishment. 'There was no competition. Of course these cnormous profits were paid by the consumer. The French obtained some sugar, but they paid an extravagant price for the luxury. In 1814 Europe was at peace; the ports of France were again open to the produce of the West Indies; and in a moment the foreign sugar swept the beet-root manufacture entirely away. The consumers once more had cheap sugar; and the government had not then made the discorery that it would be a good thing to compei them to eat dear sugar, that the manufacturers of beet-root sugar snight be kept in activity. 
This cheapness was a natural and healthy state of things, which would be sure to provoke the meddling propensities of that class of rulers who can never believe that the interests of trade can take care of themselves. Immediately after the peace, sugar from the French, English, and American colonies was permitted to enter France at the same rate of duty. In a few months, however, it was found that the sugars from the English colonies were driving the sugars of Martinique, Guadaloupe, and Bourbon out of the market. The Colonies must be protected; so a protecting duty of twenty francs the 100 kilogrammes* was imposed upon all sugars of foreign origin. In 1816 the duty on foreign raw sugar was increased to forty-five francs; in 1820 to seventy-five francs, and in 1822 to ninety-five francs, the 100 kilogrammes. The law of 1816 was the first bounty to the beet-root sugar manufacturers, and they accorlingly once more began to be active. But when the duty of 1822 upon foreign sugar amounted to a prohibition, their prosperity was certain. They were enabled to tax the consumer to the amount of the prohibition. The beet-root sugar pays no duty whatever. In 1829 there were 101 manufactories of this sugar in employment, which produced five million kilogrammes in the year, or about one-sixteenth part of the whole consumption of sugar in France. That the people of France are the sufferers by this miserable policy is sufficiently evident, from the fact that their average yearly consumption does not exceed four pounds of sugar per héad: in the United Kingdom it is twenty pounds per head.

Upon the national advantage of that commercial policy which has given rise to the manufacture of beet-root sugar in France, and which may probably

* A kilogramme is equivalent to $2 \mathrm{lbs}, 2 \mathrm{ox} .4 \mathrm{dr}$. $16 \mathrm{gr}$. English avoirdupois. 
extend the system to Germany and Russia, we have much pleasure in extracting the following sensibla observations from a valuable periodical work:-

"The history of this manufacture in France is an illustration, we apprehend, not of the nacural progress of industry and of the arts, but of the effects of a system which counteracts the natural progrcss of both. Whatever may be the ultimate state of this singular manufacture, in consequence of mechanical and chemical improvements yet unknown to us, it is now only supported by a system of commercial and financial policy, which it is for the interest of all countries to see proscribed in Europe. The people of France were the first to be taught by their own pliilosophers those principles of mutual intercourse which form the basis of trade. Nearly a hundred years have elapsed since Quesnay and his followers taught his countrymen, that freedom of intercourse is the soul of commerce. But his countrymen have yet to learn that liberty is as necessary to the health of commerce as to the well-being of the citizen; that trade is but an interchange of things produced, and that if France will not take the productions of other countries, other countries will not and cannot take the productions of France. 'The cultivation of the beet is but one ramitication of that system of repulsion and exclusion which has been adopted in France, to the oppression of her domestic industr $\%$, the ruin of her foreign commerce, and the inaintenance o false principles in the commercial policy of sur rounding countries*."

In the course of this volume we have endeavoured to show, incidentally, and without embarrassing the subject with minute details which belong to another branch of inquiry, that at every successive step which

* Quarterly Journai of Agriculture, Nu. xii. Edinburgh, 1831. 
man makes in the knowledge of right principles of exchange with his fellow men, he multiplies his power of procuring a constant and equal supply of what conduces to the support and comfort of life, at the least expenditure of labour - that is, at the cheapest cost. In the infancy of societies, when there is little exchange, and when that little is conducted upon principles which allow scarcely any freedom of industry, famine invariably indicates the want of that civilization which would produce plenty. The fluctuating production of the seasuns is not counteracted by the natural balance of an open market; the people, without refinement, and therefore without any luxuries, living habitually upon the lowest food, have no stores to fall back upon when they are compelled to retrench their consumption; and, above all, the want of intercourse with other great bodies of mankind confines that consumption to the limited produce of their own district or country. It is a beautiful arrangement of Providence, and one which will probably lead to the ultimate civilization of the entire world, that one countr' $_{j}$ has the means, in its climate, or soil, or other natural sources of riches, of directing the labour of its inhabitants into channels of production which cannot be so profitably followed, if they can be followed at all, by the people of another country. When mankind are more advanced in knowledge than they are now, the territorial division of labour will be held in as great esteem as the personal division of labour. When this happens, France will see that her real interests are to cultivate her vines, and leave to the West Indies to cultivate their sugar-canes. The imperfect exchanges of nations resulting from! proliibitory laws, existing by the force of popular prejudices, produce the same effects, though perhaps not so fatal in degree, as the imperfect exchanges between districts of the same couniry. There are legitimate 
objects for the industry of a country to be employed upon, and there are objects which are not legitimate. Attempts to force the labour of a country into channels for which it is unfitted by nature interfere with the otherwise certain progress of mankind in civilization, which is diffused over ali the earth by peaceful intercourse. 'That it is the policy of a nation to be independent of foreign supplies is false in principle and ruinous in practice. All attempts to enforce this delusive doctrine have no other tendency than to keep the mass of consumers wretched, that a few mistaken persons may thrive by a monopoly, who would even thrive much more themselves if their capital were employed in proper enterprises. Before a country has roads and bridges, the inhabitants of one valley separated from another valley by a mountain or a river, must raise everything for themselves. The roads are made and the bridges are built, and then one raises corn and another cattle, for one valley is fitted for tillage and the other for pasture. As civilization advances, and roads are carried through a country, and rivers are made navigable, the benefits of exchange are not confined to a few districts, but are diffused amongst many. Then, one raises corn, and another manufactures cloth. Foreign commerce then begins to give a new direction to the genera! industry, and the cloth is manufactured for some distant nation, that will exchange commodities that none of these districts can profitably raise for themselves. Is there any limit to this beautiful principle of one district and one country supplying by exchange the wants of another district alld another country? There is no limit, but what is raised by the prejudices, which, in a ruder state of society, shut up a miserable population amidst some apparently impassable barriers, to be starved upon their own produce when they might have had plenty by exchange. A writer in the 
- Quarterly Review nas recently observed with great truth, that "the cost of conveying flour from Quebec to Liverpool or Masıchester, is scarcely more now than that of its land-carriage, a century back, from a distance of fifty miles." The inference from this statement is undeniable. If the manufacturers of Lancashire cannot receive corn from countries that have corn to spare in exchange for cottons, because it is thought, essential chat the sandy and gravelly wastes of England shall be under the plough, the progress of civilization, which is the progress of inan in wealth and comfort, is just as effectually innseded as if the legislators of a century back had ordained that Lancashire should grow its own corn alone, and have no communication with the corngrowing counties of Norfolk and Essex. 'The only semblance of reasoning by which the principla of excluding foreign produce can be maintained, is, that a country may be deprived by war of its foreign supplies. In the fear of war, then, a system is set up which perpetuates war. More wars have been engendered by the commercial system of exclusion than by all the other follies and passions of subjects and rulers. The true way to keep mankind in peace is to let them prove how dependent every nation is upon the other for the profitable employment of its jeople, and for the general comforts of its people, resulting from that profitable employment.

THE END.

London : Pinted by W. Clowes and Soss, Stamford-strect. 


$$
\text { Lla.W }
$$


RECORD OF TREATMENT, EXTRACTION, REPAIR, etc.

Pressmark:

Binding Ref No: 3762

Microfilm No:

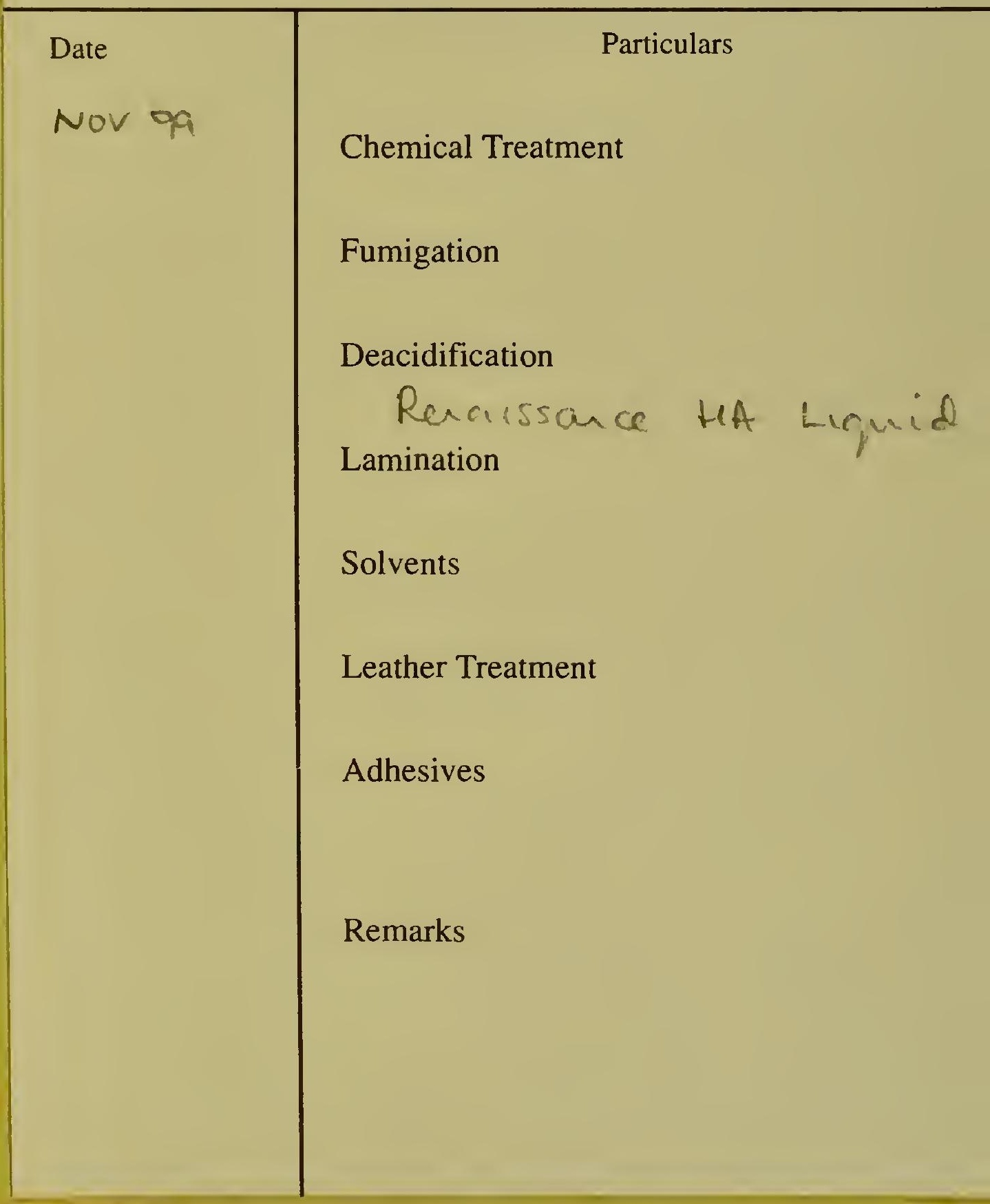


